ANDRE HIDEKI HIGA

UNIVERSIDADE, CIDADE E SAÚDE:

Planejamento institucional sustentável em contexto urbano consolidado 


\section{ANDRE HIDEKI HIGA}

UNIVERSIDADE, CIDADE E SAÚDE:

Planejamento institucional sustentável em contexto urbano consolidado

Dissertação apresentada ao Programa de PósGraduação Ambiente, Saúde e Sustentabilidade, da Faculdade de Saúde Pública, da Universidade de São Paulo, para a obtenção do título de Mestre em Ciências.

Orientadores:

Prof. Dr. Paulo César Xavier Pereira

Prof ${ }^{a}$. Dr ${ }^{a}$. Wanda Maria Risso Günther

\section{VERSÃO REVISADA \\ SÃO PAULO}

2019 
Autorizo a reprodução e divulgação total ou parcial deste trabalho, por qualquer meio convencional ou eletrônico, para fins de estudo e pesquisa, desde que citada a fonte.

Higa, Andre Hideki

UNIVERSIDADE, CIDADE E SAÚDE : Planejamento

institucional sustentável em contexto urbano consolidado /

Andre Hideki Higa; orientador Paulo César Xavier Pereira; coorientadora Wanda Maria Risso Günther. -- São Paulo, 2019. 266 p.

Dissertação (Mestrado) -- Faculdade de Saúde Pública da Universidade de São Paulo, 2019.

1. Saúde ambiental. 2. Planejamento. 3. Metabolismo urbano. 4. Resíduos sólidos. 5. São paulo. I. Pereira, Paulo César Xavier, orient. II. Günther, Wanda Maria Risso, coorient. III. Título. 
HIGA, Andre Hideki, UNIVERSIDADE, CIDADE E SAÚDE, planejamento institucional sustentável em contexto urbano consolidado - Faculdade de Saúde Pública da Universidade de São Paulo, São Paulo, 2019. 
Universidade de São Paulo

\section{ATA DE DEFESA}

Aluno: 6139 - 5914627 - 1 / Página 1 de 1

Ata de defesa de Dissertação do(a) Senhor(a) André Hideki Higa no Programa: Mestrado Profissional Ambiente, Saúde e Sustentabilidade, do(a) Faculdade de Saúde Pública da Universidade de São Paulo.

Aos 26 dias do mês de junho de 2019, no(a) realizou-se a Defesa da Dissertação do(a) Senhor(a) André Hideki Higa, apresentada para a obtenção do título de Mestre intitulada:

"UNIVERSIDADE, CIDADE E SAÚDE: Planejamento institucional sustentável em contexto urbano consolidado"

Após declarada aberta a sessão, o(a) Sr(a) Presidente passa a palavra ao candidato para exposição e a seguir aos examinadores para as devidas arguições que se desenvolvem nos termos regimentais. Em seguida, a Comissão Julgadora proclama o resultado:

$\begin{array}{llll}\text { Nome dos Participantes da Banca } & \text { Função } & \text { Sigla da CPG } & \text { Resultado } \\ \text { Paulo Cesar Xavier Pereira } & \text { Presidente } & \text { FAU - USP } & \text { Não Votante } \\ \text { Roberta Consentino Kronka Mülfarth } & \text { Titular } & \text { FAU - USP } & \text { APPOUADO } \\ \text { Karin Regina de Castro Marins } & \text { Titular } & \text { EP - USP } & \text { Aprovado- } \\ \text { Marcia Rocha Monteiro } & \text { Titular } & \text { UFAL - Externo Apovado } & \text { Apovedo }\end{array}$

Resultado Final: Aprivarbo

Parecer da Comissão Julgadora *

Eu, Carlos Alberto da Silva Santos far tos tS Sartos, lavrei a presente ata, que assino juntamente com os(as) Senhores(as). São Paulo, aos 26 dias do mês de junho de 2019.

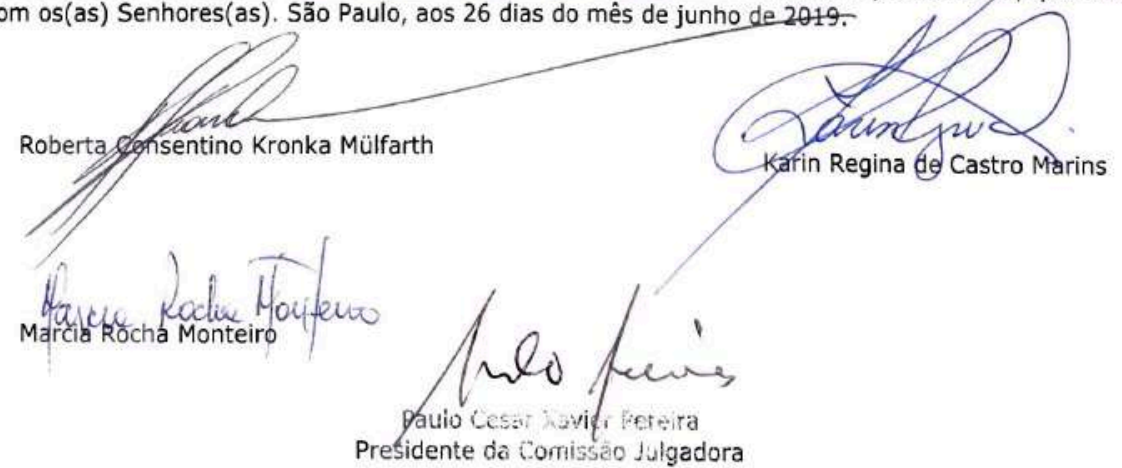

* Obs: Se o candidato for reprovado por algum dos membros, o preenchimento do parecer é obrigatório. 


\section{AGRADECIMENTOS}

Aos meus pais, Eunice e Osvaldo e às minhas irmãs, Lais e Leila pelo apoio de sempre.

Às minhas famílias, que escolhi e que não escolhi obrigado a todos.

Agradeço meus professores, em especial meu orientador, Prof ${ }^{\circ}$. Dr ${ }^{\circ}$. Paulo Cesar Xavier Pereira cujas contribuições me fizeram pensar nos problemas do conhecimento e à minha coorientadora Prof ${ }^{a} D^{a}$ Wanda Maria Risso Günther cujas contribuições me fizeram pensar nos problemas de aplicação.

Aos membros da banca de qualificação, Prof $^{o}$ Dr $^{o}$. Ednilson Viana e a Prof $^{a}{ }^{D} r^{a}$ Roberta Consentino Kronka Mülfarth pelas contribuições à pesquisa.

Aos membros da banca de defesa, Prof ${ }^{a} \operatorname{Dr}^{a}$ Roberta Consentino Kronka Mülfarth, Prof ${ }^{a}$ $D^{a}$. Karin Regina de Castro Marins e Prof ${ }^{a}$ Dr $^{a}$. Márcia Rocha Monteiro por aceitarem o convite e pelas valorosas contribuições a esta Dissertação.

Aos professores e colegas da Faculdade de Saúde Pública e da Faculdade de Arquitetura e Urbanismo da Universidade de São Paulo que me ajudaram a construir o arcabouço teórico e conceitual.

Aos meus amigos, que nas conversas de bar e nos cafés da vida sempre ampliaram meus horizontes criticos e do conhecimento, mas nominalmente, que contribuíram especificamente para esta Dissertação:

À querida Helena Oliveira, pelas análises estatísticas.

Ao querido Rodrigo Nogueira pelos toques das ciências da informação.

Ao querido Henrique Arantes, pelo companheirismo e debates acerca dos gráficos, conceitos e a vida.

À instituição que acolheu minha pesquisa, a Faculdade de Saúde Pública e a que acolheu o meu trabalho, a Universidade Federal de São Paulo.

Aos meus colegas do Departamento de Infraestrutura, da Diretoria do Campus São Paulo e da Pró-reitoria de Planejamento com quem trabalho e dedicamos nossos esforços para uma universidade pública e de qualidade.

E aos colegas da Equipe Técnica de fiscalização e aos profissionais da MPS Arquitetos Associados, pelo árduo trabalho que foi o PDInfra. 


\section{EPÍGRAFE}

"Pensar globalmente, agir localmente" 


\section{RESUMO}

\section{HIGA, A. H. UNIVERSIDADE, CIDADE E SAÚDE: Planejamento}

institucional sustentável em contexto urbano consolidado. 2019. 266 f. Dissertação (Mestrado) - Faculdade de Saúde Pública, Universidade de São Paulo, São Paulo, 2019.

Como a universidade, a cidade e a saúde se relacionam através do planejamento institucional foi investigado tendo como objeto de estudo, o Plano Diretor de Infraestrutura (PDInfra) do Campus São Paulo (CSP) da Universidade Federal de São Paulo (Unifesp). Problema: Como planejar as atividades e infraestrutura da universidade almejando a sustentabilidade? Objetivo: Realizar uma análise interdisciplinar e crítica de quais propostas do planejamento do CSP da Unifesp contribuem efetivamente para o desenvolvimento sustentável, nos aspectos institucionais, urbanísticos e de saúde ambiental, contextualizada com a implantação física no Município de São Paulo. Como objetivos específicos, busca-se identificar os instrumentos de planejamento de universidades adequadas à sustentabilidade e que permitam integração da universidade com a cidade e identificar, por meio do diagnóstico de gerenciamento de resíduos sólidos, componentes do metabolismo urbano que podem contribuir para melhorias no fluxo de materiais e outros processos. Métodos: Analisar o escopo dos planos e instrumentos destes que permitam visualizar possibilidades de integração com a cidade e caracterizar as propostas. Analisar o metabolismo urbano da universidade por meio dos dados do diagnóstico do gerenciamento de resíduos sólidos. Analisar o PDInfra do ponto de vista dos "pontos de alavancagem". Resultados: Panorama dos instrumentos de planejamento das universidades federais selecionadas, permitindo comparação entre metodologias e procedimentos que as universidades adotam no planejamento institucional. Caracterização das propostas e valores desenvolvidos nos planos institucionais que considerem interfaces com a cidade. Com os dados do estudo de caso, formula-se balanço de entradas e saídas, diagrama de fluxo, mapas e indicadores. Também são identificados pontos de intervenção no sistema mais efetivos que o plano diretor pode aplicar esforços. Conclusões: O PDInfra ao incorporar o diagnóstico de gerenciamento de resíduos sólidos no planejamento aliado a um processo participativo, procedimento inédito entre os planos levantados, introduz a promoção da saúde por fatores não médicos às propostas institucionais, contemplando as dimensões ambientais e comportamentais dos determinantes sociais da saúde. O plano diretor é o tipo utilizado para planejamento institucional com maior potencial de direcionar ações, procedimentos e projetos arquitetônicos e urbanísticos voltados à sustentabilidade, embora ainda seja pouco utilizado pelas universidades federais e possa incluir novos instrumentos como as análises de metabolismo urbano, dependendo das especificidades da instituição.

Palavras-chave: Saúde ambiental. Planejamento. Metabolismo urbano. Resíduos sólidos. São Paulo. 


\section{ABSTRACT}

HIGA, A. H. UNIVERSITY, CITY AND HEALTH: Sustainable institutional planning in consolidated urban context. 2019. 266 f. MSc Thesis - Faculdade de Saúde Pública, Universidade de São Paulo, São Paulo, 2019.

The way that university, city and public health are related through institutional planning is the main subject of the Infrastructure Masterplan (PDInfra) of Campus São Paulo (CSP) of Federal University of São Paulo (Unifesp) case study. Problem: How to plan university's activities and infrastructure aiming for sustainability? Objectives: To perform an interdisciplinary and critic analysis about which motions in the CSP's planning contribute effectively to sustainable development, in institutional, urbanistic, and environmental health aspects, in context with its implantation area in São Paulo city. As specific objectives, look forward to identify universities' planning instruments suited to sustainability and allows integration of university and the city. And identify urban metabolism components via solid waste management diagnosis, that can contribute to improve material flux and other processes. Methods: To analyze plan's scope via searching solid waste management related keywords. To analyze plans on which is possible to see possibilities of university and city integration. To analyze urban metabolism through solid waste management diagnosis. To analyze CSP's masterplan from the point of view of "leverage points". Results: A general picture of planning instruments used by selected federal universities, allowing comparisons between methods and proceedings that universities adopt in institutional planning. Description of motions and values developed in institutional plans that considers city's interfaces. With study case data, it drafts an inputs/outputs balance, flux diagram, maps and indicators. Also, it can identify leverage points in the masterplan. Conclusion: The PDInfra incorporating the diagnosis of solid waste management in the planning allied to a participatory process, an unprecedented procedure among the gathered plans, introduces the promotion of health by non-medical factors to institutional proposals, contemplating the environmental and behavioral dimensions of the social determinants of health. The master plan is the type used for institutional planning with the greatest potential to guide actions, procedures and architectural/urbanistic projects aiming sustainability, although it is still little used by federal universities and might include new instruments such as urban metabolism analyzes, depending on the specificities of the institution.

Key words: Environmental health. Planning. Urban metabolism. Solid waste. São Paulo. 


\section{LISTA DE SIGLAS E ABREVIATURAS}

ABNT - Associação Brasileira de Normas Técnicas

ANVISA - Agencia Nacional de Vigilância Sanitária

CEMPRE - Compromisso Empresarial para Reciclagem

CGU - Controladoria Geral da União

CISAP - Comissão Interministerial de Sustentabilidade na Administração Pública

CSP - Campus São Paulo da Universidade Federal de São Paulo

EGRS - Estabelecimento Gerador de Resíduo de Serviço de Saúde

EPE - Escola Paulista de Enfermagem

EPM - Escola Paulista de Medicina

GTBU - Grupo de Trabalho do Bairro Universitário

HSP - Hospital São Paulo

LAI - Lei de Acesso à Informação

LILACS - Literatura Latino-Americana e do Caribe em Ciências da Saúde

MEC - Ministério da Educação

MFA - Material Flow Analysis (Análise de fluxo de material)

MU - Metabolismo Urbano

NBR - Norma Brasileira de Regulamentação

NYU - New York University

ODM - Objetivos de Desenvolvimento do Milênio

ODS - Objetivos do Desenvolvimento Sustentável

OMS - Organização Mundial da Saúde

ONU - Organização das Nações Unidas

PD - Plano Diretor

PDCA - Plan Do Check Act

PDE - Plano Diretor Estratégico

PDI - Plano de Desenvolvimento Institucional

PDInfra - Plano Diretor de Infraestrutura

PLS - Plano de Logística Sustentável

PMSP - Prefeitura Municipal de São Paulo

RDC - Resolução de Diretoria Colegiada

RMA - Resource Management Agency (Agencia de gerenciamento de recursos)

RSS - Resíduos de Serviço de Saúde

SMUL - Secretaria Municipal de Urbanismo e Licenciamento

SPDM - Associação Paulista para Desenvolvimento da Medicina

SUS - Sistema Único de Saúde

TCU - Tribunal de Contas da União

TRSS -Taxa de Resíduos Sólidos de Serviços de Saúde

UFAL - Universidade Federal de Alagoas 
UFAM - Universidade Federal do Amazonas

UFBA - Universidade Federal da Bahia

UFC - Universidade Federal do Ceará

UFG - Universidade Federal de Goiás

UFMA - Universidade Federal do Maranhão

UFMG - Universidade Federal de Minas Gerais

UFMS - Universidade Federal do Mato Grosso do Sul

UFPA - Universidade Federal do Pará

UFPE - Universidade Federal de Pernambuco

UFPR - Universidade Federal do Paraná

UFRGS - Universidade Federal do Rio Grande do Sul

UFRJ - Universidade Federal do Rio de Janeiro

UFRN - Universidade Federal do Rio Grande do Norte

UFSC - Universidade Federal de Santa Catarina

UNB - Universidade de Brasília

Unifesp - Universidade Federal de São Paulo

USP - Universidade de São Paulo

ZEIS - Zona Especial de Interesse Social 


\section{LISTA DE ILUSTRAÇÕES}

Figura 1 - Mosaico de referências de Campus e Cidades Universitárias com área

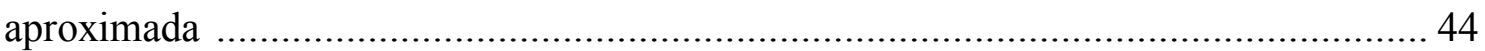

Figura 2 - MFA fluxo de produtos plásticos na Áustria (1996) .................................. 58

Figura 3 - Principais símbolos usados em diagramas de MFA ..................................... 61

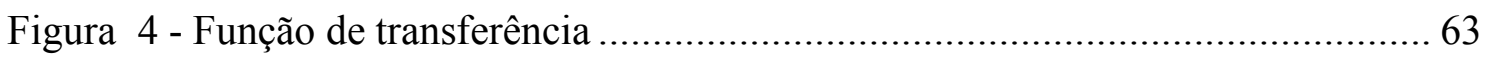

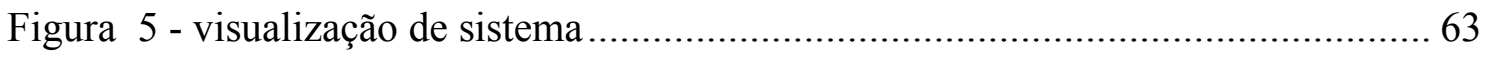

Figura 6 - Componentes dos determinantes sociais da saúde................................... 71

Figura 7 - Vista da entrada da cidade universitária "Ilha do Fundão" UFRJ ............... 75

Figura 8 - Implantação da Cidade Universitária em relação ao restante da cidade....... 77

Figura 9 - Centros de Convergência propostos para a cidade universitária UFRJ ....... 78

Figura 10 - Plano de uso e ocupação propostos para a Ilha do Fundão - UFRJ ............ 79

Figura 11 - Vista da entrada da UFMG........................................................ 81

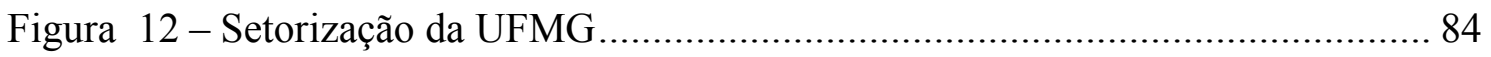

Figura 13 - Vista da rua na Cidade universitária da UNB........................................ 85

Figura 14 - zoneamento do Campus Darcy Ribeiro - UNB ...................................... 86

Figura 15 - Vista do Campus São Paulo .................................................................. 89

Figura 16 - Ilustração de incentivo para complexo de saúde .................................... 90

Figura 17 - Mapa do Campus São Paulo - Unifesp - com outros serviços de saúde - ano:

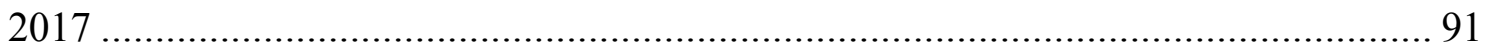

Figura 18 - Edifícios de uso Campus São Paulo e atividades predominantes (2017) ... 96

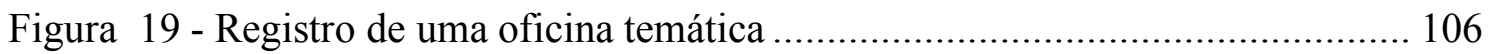

Figura 20 - registro de uma reunião temática........................................................ 107

Figura 21 - Análise participativa dos resíduos sólidos comuns (úmido, seco e liquido)Fonte: Documento Síntese do Processo Participativo - Etapa: Levantamento.

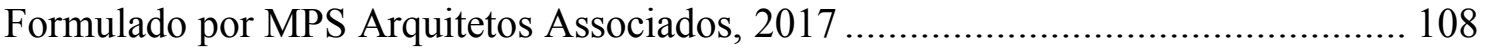

Figura 22 - Análise participativa dos resíduos sólidos infectantes............................ 109

Figura 23 - Comparação do zoneamento UFSC, UFMG e UNB .............................. 114

Figura 24 - situação existente da r. Varpa (Campus São Paulo) ............................... 115

Figura 25 - proposta para a r. Varpa (Campus São Paulo) ....................................... 116

Figura 26 - Projeto de desenho urbano para o Campus São Paulo (2018) .................. 117

Figura 27 - Vista de edifício da NYU ao lado da Washington Square....................... 119

Figura 28 - Zoneamento da cidade de Nova Iorque x implantação NYU .................. 121

Figura 29 - implantação da NYU e distritos históricos (2008) .................................. 121

Figura 30 - Diretrizes de projeto da NYU ............................................................ 122

Figura 31 - Proposta de novas "superquadras" para a NYU ................................... 124

Figura 32 - Vista da entrada sul do Homewood Campus - Johns Hopkins University 125

Figura 33 - zoneamento do Homewood Campus da Johns Hopkins University......... 127

Figura 34 - vista da entrada da UCL - Bloomsbury campus ................................ 129

Figura 35 - Croqui da proposta do campus Bloomsbury ..................................... 131 
Figura 36 - Ilustração da dinâmica entre Princípios Fundamentais e Eixos Estruturantes

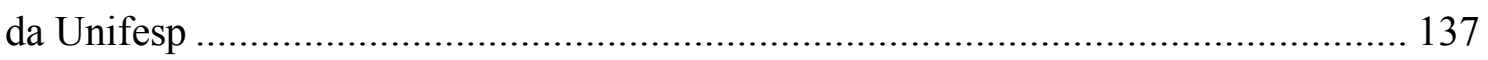

Figura 37 - Diagrama de Venn (PD, PDI e PLS) ................................................ 147

Figura 38 - Diagrama de Venn (PD, PDI, PLS e Campus)...................................... 148

Figura 39 - Diagrama de Venn (PDI, PD, PLS e Cidade universitária) ...................... 148

Figura 40 - Elementos do planejamento institucional e físico de uma universidade .. 150

Figura 41 - Diagrama de "principais fluxos de um campus universitário"................. 152

Figura 42 - Estudo de metabolismo urbano de Bruxelas (1977) .............................. 153

Figura 43 - Representação de um metabolismo sustentável para a Toronto Port Lands

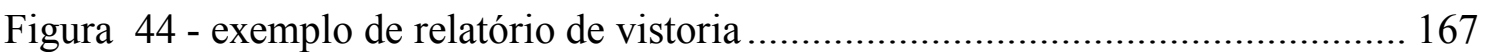

Figura 45 - Mapa dos grandes geradores de resíduo comum - ano: 2017................. 169

Figura 46 - abrigo de resíduos químicos inadequado localizado em edifício do Campus São Paulo................................................................................................... 171

Figura 47 - Mapa de geração de resíduo químico CSP - ano: 2017 ......................... 172

Figura 48 - Recipiente de resíduo perfurocortante indicando segregação incorreta ... 174

Figura 49 - Mapa geração de infectantes CSP - ano 2017 ................................... 175

Figura 50 - Mapa de vínculos dos edifícios (2017) ................................................ 176

Figura 51 - Fluxo de coleta de infectante no campus e outros estabelecimentos de saúde 179

Figura 52 - Gráfico de indicadores de geração de resíduos per capita no Campus São

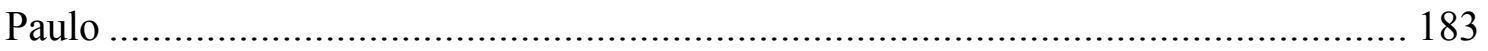

Figura 53 - Comparativo entre indicadores de geração de resíduo per capita e por $\mathrm{m}^{2}$ no

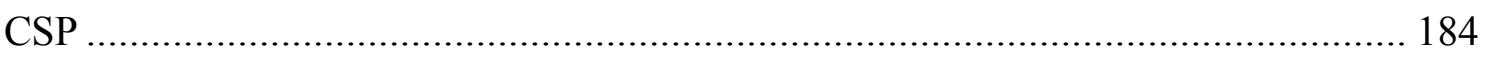

Figura 54 - Diagrama do fluxo de resíduos conhecidos do CSP (2017) .................. 185

Figura 55 - gráfico número de compras $\mathrm{x}$ ano no CSP .......................................... 188

Figura 56 - Diagrama do fluxo de resíduos conhecidos no CSP com estimativa de

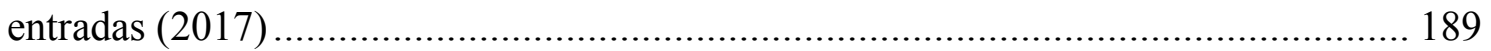

Figura 57 - MFA do sistema "Campus São Paulo" .................................................. 191

Figura 58 - Local de compostagem..................................................................... 192

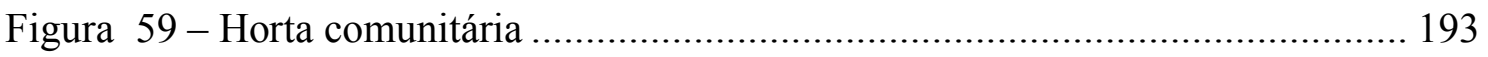

Figura 60 - Destaque para locais propícios a soluções consorciadas ......................... 199

Figura 61 - Zoneamento do bairro Vila Clementino ............................................ 236

Figura 62 - Locais de acidente na envoltória do CSP ........................................... 237

Figura 63 - Mapa de uso predominante da área envoltória do Campus São Paulo - Unifesp 238

Figura 64 - Mapa de densidade populacional da área envoltória do Campus São Paulo Unifesp..... 239

Figura 65 - Mapa com sobreposição dos tipos de resíduos, outros edifícios do campus e

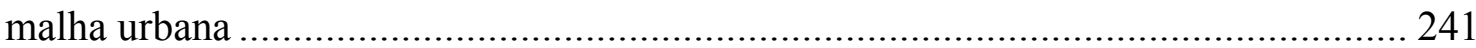

Figura 66 - Gestão dos imóveis do Campus São Paulo em 1982 .............................. 244

Figura 67 - Malha urbana do entorno do Campus São Paulo em 1982 ..................... 245 
Figura 68 - Infraestrutura urbana do entorno do Campus São Paulo em 1982 ........... 246

Figura 69 - Ocupação dos espaços do Campus São Paulo em 1982 .......................... 247

Figura 70 - Zoneamento proposto para o Campus São Paulo em 1982 ..................... 250

Figura 71 - Gestão dos imóveis do Campus São Paulo em 2007 .............................. 252

Figura 72 - Armazenagem inadequada de resíduos na R. Loefgreen - CSP (2007).. 253

Figura 73 - Mapa de desenvolvimento urbano do entorno do CSP (2004)............... 255

Figura 74 - Proposta de percursos e implantação do Campus São Paulo em 2010 .... 256

Figura 75 - Volumetria existente (2010) e proposta do Campus São Paulo .............. 256

Figura 76 - Projeto urbanístico - bairro universitário - Campus São Paulo (2010) ... 257 


\section{LISTA DE QUADROS}

Quadro 1 -Interpretações e debates do conceito de metabolismo urbano...................... 51

Quadro 2 - Revisão cronológica de Metabolismo urbano .............................................52

Quadro 3 - Métodos de análise de processos MU ...................................................... 56

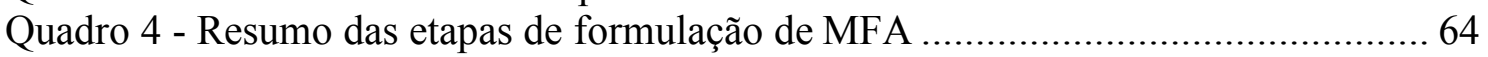

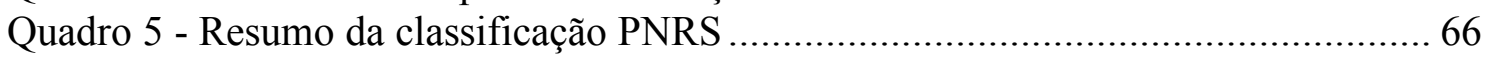

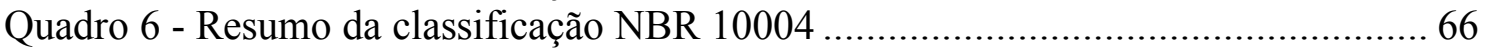

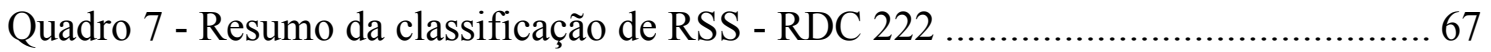

Quadro 8 - Municípios mais populosos e universidades federais ................................. 73

Quadro 9 - Propostas para gestão de resíduos - Geral ............................................... 110

Quadro 10 - Propostas para gestão de resíduos - resíduos infectantes....................... 111

Quadro 11 - Propostas para gestão de resíduos - resíduos químicos .......................... 112

Quadro 12 - Universidades federais, PDI com seu ano de publicação e menção a

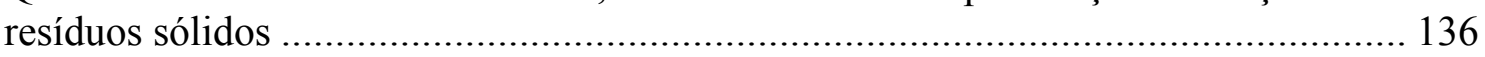

Quadro 13 - Universidades federais e PLS com ano de publicação ........................... 139

Quadro 14 - Práticas de sustentabilidade e metas do PLS - CSP ............................... 142

Quadro 15 - Universidades federais e planos diretores e relação com gerenciamento de

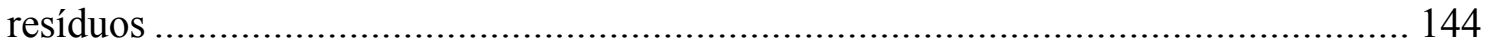

Quadro 16 - Universidades federais e tipos de plano (PDI, PD e PLS) ..................... 146

Quadro 17 - Instrumentos de planejamento utilizados no plano diretor das universidades

151

Quadro 18 - Resumo das etapas para formulação do MFA do "Campus São Paulo".. 190

Quadro 19 - Matriz de referências - Scielo ................................................................ 230

Quadro 20 - Matriz de referências - Emerald Insight .............................................. 231

Quadro 21 - Matriz de referências - Teses USP ...................................................... 232

Quadro 22 - Matriz de referências - LILACS .......................................................... 233

Quadro 23 - Matriz de referências - Google Acadêmico........................................... 234 


\section{LISTA DE TABELAS}

Tabela 1 - Valores de TRSS - pequenos geradores no Município de São Paulo, 2018.. 68

Tabela 2 - Valores de TRSS - grandes geradores no Município de São Paulo, 2018 .... 68

Tabela 3 - Participação da população em processos participativos de planos diretores 103

Tabela 4 - Quantidade de resíduos diários e respectivas taxas por atividade............. 180

Tabela 5 - Dados de área física e população do Campus São Paulo por atividade ..... 181

Tabela 6 - Indicadores de geração de resíduo per capita por atividade e tipo de resíduo

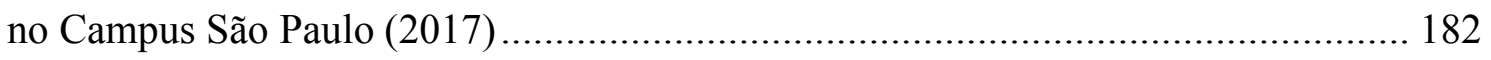

Tabela 7 - Geração de resíduo por área por atividade no Campus São Paulo............. 183 


\section{SUMÁRIO}

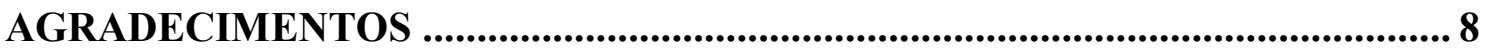

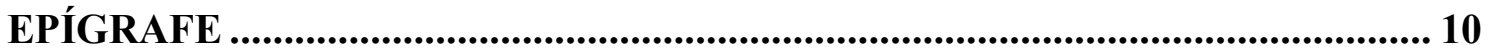

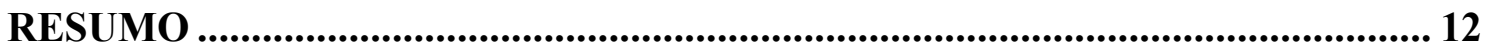

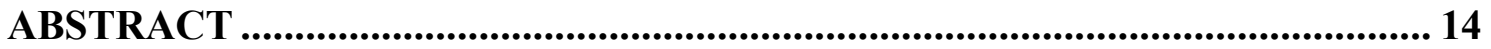

LISTA DE SIGLAS E ABREVIATURAS ........................................................... 16

LISTA DE ILUSTRAÇÕES............................................................................... 18

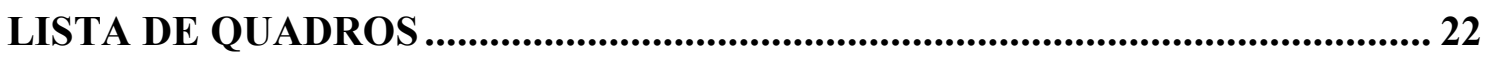

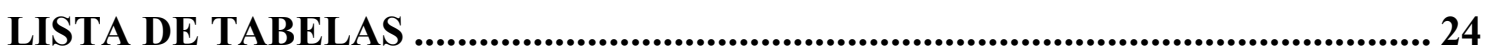

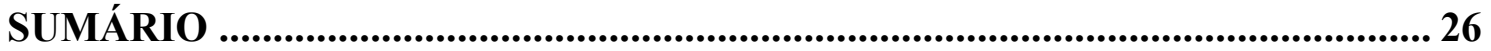

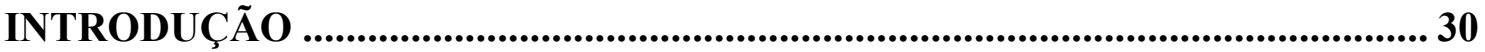

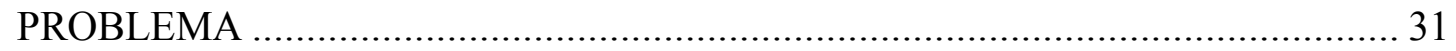

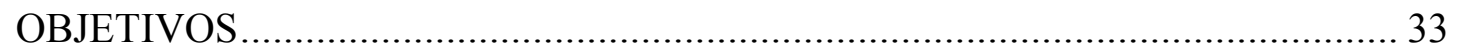

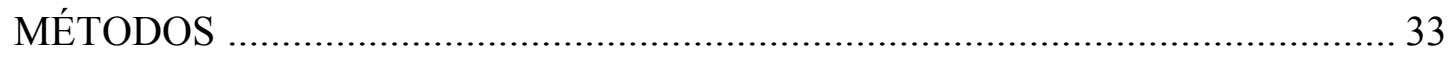

ORGANIZAÇÃO DA DISSERTAÇÃO ……................................................... 35

CAPÍTULO 1 - REFERENCIAL TEÓRICO PARA PESQUISA SOBRE UNIVERSIDADE, CIDADE E SAÚDE AMBIENTAL ..................................... 38

1.1. MEDIÇÃO DAS INTERFACES DE PESQUISA ENTRE

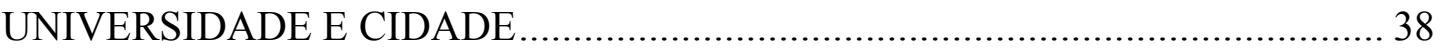

1.2. DEFINIÇÃO E DISCUSSÃO DE CONCEITOS SELECIONADOS ... 42

1.2.1. Campus e cidade universitária.................................................... 43

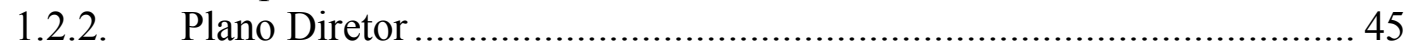

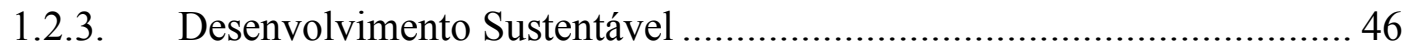

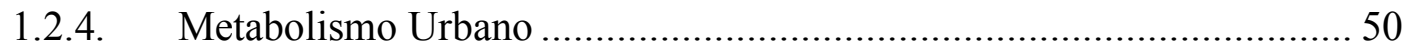

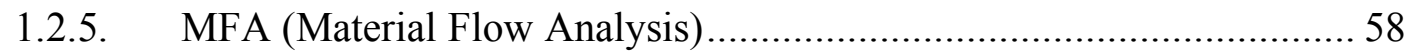

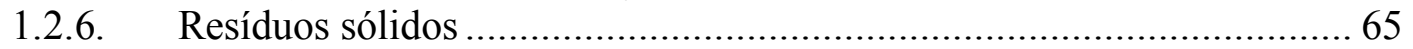

1.2.6.1. Classificação de resíduos sólidos................................................6 65

1.2.6.2. Diagnóstico do gerenciamento de resíduos sólidos .........................69 69

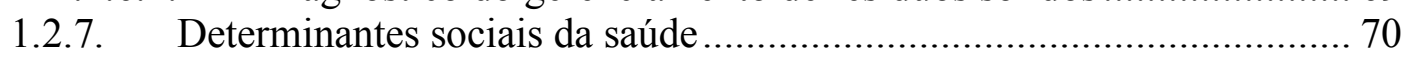

CAPÍTULO 2 - UNIVERSIDADES EM CIDADES: EXPERIÊNCIAS

NACIONAIS E INTERNACIONAIS .......................................................... 72

2.1. ANÁLISE DA IMPLANTAÇÃO DE UNIVERSIDADES FEDERAIS72

2.1.1. Universidade Federal do Rio de Janeiro .............................................. 75

2.1.2. Universidade Federal de Minas Gerais ........................................... 81

2.1.3. Universidade de Brasília ................................................................... 85

2.2. UNIVERSIDADE FEDERAL DE SÃO PAULO ............................... 89

2.2.1. Plano Diretor de Infraestrutura do Campus São Paulo......................... 93

2.2.2. Processo participativo ............................................................ 102 
2.2.3. Projeto de Desenho urbano 114

2.3. EXPERIENNCIAS INTERNACIONAIS DE CAMPUS UNIVERSITÁRIOS

2.3.1. New York University ................................................................. 119

2.3.2. Johns Hopkins University ........................................................... 125

2.3.3. University College London ......................................................... 129

2.4. PROJETOS DE CAMPUS COMO PROJETOS URBANOS E ARGUMENTOS PARA INTEGRAÇÃO COM ENTORNO .............................. 132

CAPÍTULO 3 - OS TIPOS DE PLANEJAMENTO DA UNIVERSIDADE NA

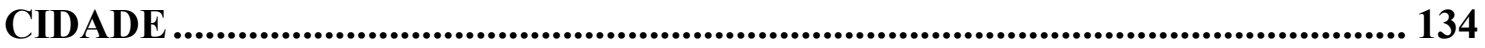

3.1. PLANO DE DESENVOLVIMENTO INSTITUCIONAL .................. 135

3.2. PLANO DE LOGÍSTICA SUSTENTÁVEL................................. 138

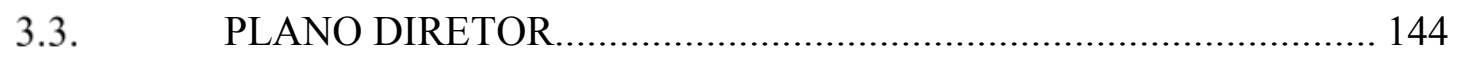

3.4. DISCUSSÃO DOS PLANOS E INSTRUMENTOS ABORDADOS . 146

3.5. METABOLISMO URBANO E O PLANEJAMENTO INSTITUCIONAL 151

CAPÍTULO 4 - UNIVERSIDADE, CIDADE $\quad$ E SAÚDE 156

4.1. A CIDADE, A UNIVERSIDADE E O DESENVOLVIMENTO SUSTENTÁVEL ......................................................................................... 157

4.2. UNIVERSIDADE E RESÍDUOS DE SERVIÇO DE SAÚDE........... 163

4.3. DIAGNÓSTICO DO GERENCIAMENTO DE RESÍDUOS SÓLIDOS NO CAMPUS SÃO PAULO ..................................................................... 164

4.4. ANALISE DE FLUXO DE MATERIAL DO SISTEMA CAMPUS SÃO PAULO 185

4.5. PONTOS DE INTERVENÇÃO EM UM SISTEMA OBJETIVANDO A SUSTENTABILIDADE - OS PONTOS DE ALAVANCAGEM......................... 193

4.6. POSSÍVEIS CONTRIBUIÇÕES DE PROJETOS URBANOS VISANDO

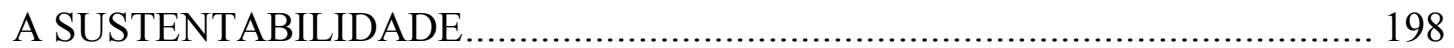

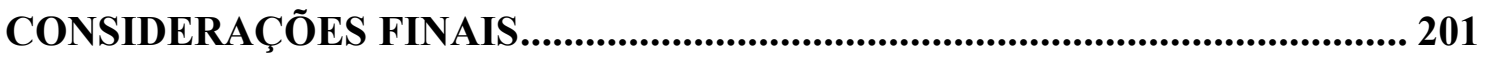

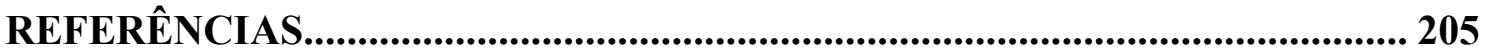

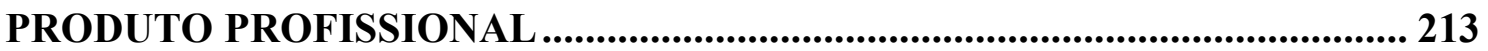

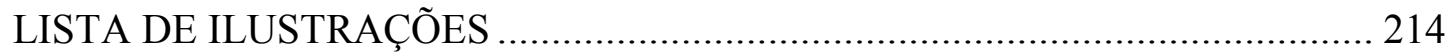

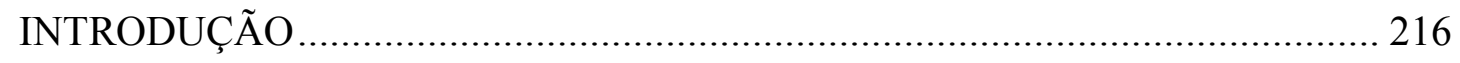

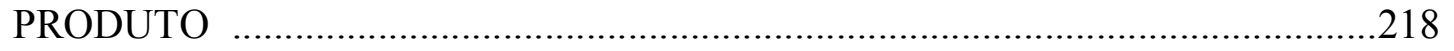


APÊNDICE A - MATRIZES DE REFERÊNCIA ............................................. 230 APÊNDICE B - MAPAS DO CONTEXTO URBANO DO CAMPUS SÃO PAULO

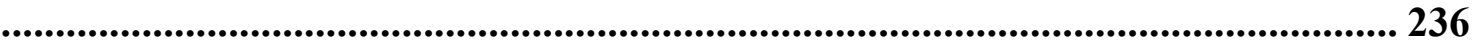

APÊNDICE C - PLANOS DIRETORES ANTERIORES DO CAMPUS SÃO PAULO (1982 E 2010) ..................................................................................... 242 APÊNDICE D - EXTRATOS DE LICITAÇÕES PARA AQUISIÇÕES DE PRODUTOS QUÍMICOS PELA UNIFESP NO PERÍODO DE 2010 A 2018..... 258 


\section{INTRODUÇÃO}

A responsabilidade das universidades brasileiras extrapola as funções de ensino, pesquisa e extensão. Serviços para a população relacionados às atividades assistenciais em saúde ficam ligados aos Hospitais-Escola e ambulatórios de especialidades, que ofertam atendimentos pelo Sistema Único de Saúde (SUS) e treinamento e capacitação de novos profissionais para compor os serviços de saúde.

O entendimento que a saúde de um indivíduo, grupo ou população tem fatores sociais, econômicos e ambientais começa a influenciar políticas públicas a partir do início do século XXI (CARVALHO, 2013). Os chamados determinantes sociais da saúde, pressupõem que fatores não médicos que melhorem a qualidade de vida, implicam também na melhoria da saúde da população.

O Campus São Paulo (CSP) da Universidade Federal de São Paulo (Unifesp), agrega estas duas dimensões da saúde, o do atendimento e o da preocupação ambiental. A referida preocupação ambiental inclui o ambiente urbano no qual o campus está inserido, uma vez que o novo Plano Diretor de Infraestrutura (PDInfra) contém propostas de desenho urbano e implantação baseadas em instrumentos de planejamento que contemplam e consideram a sustentabilidade como uma de suas diretrizes.

No CSP, como um campus voltado às atividades de ensino, pesquisa, extensão e assistência em saúde, identifica-se um elemento integrador destas interfaces, contexto urbano e planejamento institucional, que é o gerenciamento de resíduos sólidos de serviços de saúde. Se por um lado, as atividades de estabelecimentos de saúde são importantes para o bem-estar da população, por outro, os resíduos de serviços de saúde (RSS) se não bem gerenciados, oferecem risco à saúde do trabalhador, contaminação ou infecção.

Considerando a geração de resíduos como resultado de qualquer ação humana, pode-se dizer que, desde a casa alugada até o hospital-escola, é necessário gerenciar o resíduo corretamente. Este elemento integrador, para ser operacionalizado, precisa de um diagnóstico de gerenciamento de resíduos sólidos, que contém as informações a respeito de massa, classificação, procedimentos de segregação e descarte, entre outros.

Os resíduos sólidos, como resultado de transformações decorrentes das atividades humanas, pode ser um item a ser analisado sob o viés do metabolismo urbano, disciplina que considera a cidade como um fluxo de material e energia. A análise de fluxo de material é um instrumento de planejamento utilizado por cidades, mas que pode ser utilizado para instituições, como é o caso deste trabalho. 
Por outro lado, o diagnóstico de gerenciamento de resíduos não é um instrumento de planejamento comumente incorporado em planos institucionais mais abrangentes, cujo escopo envolve o planejamento e gestão patrimonial, infraestrutura e manutenção.

Ao investigar instrumentos de planejamento de outras universidades, pode-se verificar outras interfaces das universidades com suas cidades, e considerando que há outros componentes da saúde associados ao ambiente e bem-estar, entende-se que metas relacionadas à sustentabilidade contribuem para a saúde da população.

Considerando que os Objetivos do Desenvolvimento Sustentável (ODS), em vigor de 2016 a 2030, são as metas mais difundidas internacionalmente, utilizam-se referências de três objetivos, vida saudável e bem estar a todos (ODS 3), de cidades sustentáveis e resilientes (ODS 11) e produção e consumo sustentáveis (ODS 12) para comparar com as ações planejadas pelas instituições de ensino superior.

Pelo fato de a sustentabilidade ser uma expressão abrangente, com dimensões sociais, econômicas e ambientais, opta-se por analisar o PDInfra do CSP, de maneira sistêmica, utilizando a metodologia dos pontos de alavancagem (MEADOWS, 1999) ${ }^{1}$.

Com estes referenciais teóricos, busca-se por meio de análises interdisciplinares, contribuir para o debate e aprimoramento de instrumentos de planejamento visando a relação sustentável entre a universidade e a cidade.

\section{PROBLEMA}

Buscando articular Universidade, Cidade e Sustentabilidade nesta Dissertação, pergunta-se sobre a função social da instituição universitária frente à possibilidade de favorecer a sustentabilidade urbana por meio de seu planejamento institucional. Como planejar as atividades e infraestrutura da universidade almejando a sustentabilidade?

A sustentabilidade é um conceito em disputa por diversas narrativas, porém, podese dizer que no âmbito internacional, há maior difusão da definição de sustentabilidade associada ao desenvolvimento que "encontra as necessidades atuais sem comprometer a habilidade de futuras gerações de atender suas próprias necessidades" (ONU, 1987), o chamado "desenvolvimento sustentável"

O desenvolvimento sustentável, defendido pela primeira vez no cenário mundial no "Relatório Bruntland" em 1987, tem ecoado ao longo do final do século XX em conferências como a II Conferência Internacional do Meio Ambiente e Desenvolvimento

\footnotetext{
${ }^{1}$ Segundo a autora, em um sistema existem pontos em que o esforço aplicado é mais efetivo em provocar mudanças voltadas à sustentabilidade. Ela identifica doze pontos, sendo o menos efetivo é o que envolve alteração de constantes e parâmetros e o mais efetivo o que se refere ao poder de transcender paradigmas.
} 
(RIO-92), culminando na Agenda 21, que daria as diretrizes para formulação dos Objetivos de Desenvolvimento do Milênio (2000-2015), posteriormente substituído pelos Objetivos de Desenvolvimento Sustentável (2016-2030).

Concomitante a esse debate, a partir da década de 90 começavam a se formar redes de sustentabilidade formadas por universidades ao redor do mundo. A Declaração de Talloires (França, 1990), Halifax (Canadá, 1991), Kyoto (Japão, 1993), Swansea (Reino Unido, 1993), Barcelona (Espanha, 2004), Graz (Eslovênia, 2005), Abuja (Nigéria, 2009) e Turim (Itália, 2009) são referências de compromissos com criação de cultura institucional de sustentabilidade e envolvimento na educação, pesquisa, formação de políticas e intercambio de informação em ambiente e em desenvolvimento assumidos por instituições de ensino superior (UFSC, 2015)2.

Na primeira destas declarações há 52 universidades brasileiras signatárias, sendo possível afirmar, portanto, que o debate a respeito do potencial de instituições de ensino superior em promover a sustentabilidade não está restrito aos países desenvolvidos, mas que também tem ecos no Brasil.

Como a sustentabilidade deve considerar ao menos três dimensões, a social, econômica e a ambiental, pergunta-se, como uma instituição, cuja responsabilidade social está associada basicamente ao desenvolvimento do ensino, pesquisa e extensão, poderia ter entre suas atribuições a promoção do desenvolvimento sustentável e da cidade?

Além disso, questiona-se também se o próprio conceito de sustentabilidade é ou deveria ser indissociável dos objetivos de um planejamento, considerando que uma instituição planeja inclusive para continuar a existir e cumprir suas funções sociais.

Busca-se contribuir para o debate a respeito da sustentabilidade, planejamento urbano, universidade e saúde, ao trazer o estudo de caso de um planejamento institucional que incorpora o diagnóstico de gerenciamento de resíduos sólidos de serviço de saúde às bases de projeto, a partir das quais são feitas as propostas, metas e objetivos de infraestrutura para a universidade e, indiretamente, para a cidade.

\footnotetext{
${ }^{2}$ Conforme texto Universidades Sustentáveis, o autor cita ações da primeira das declarações, a de Talloires, que são aumentar a consciência para o desenvolvimento ambientalmente sustentável; criar uma cultura institucional da sustentabilidade; Educar para a cidadania ambientalmente responsável; incentivar a literatura ambiental; praticar a ecologia institucional; envolver todas as partes interessadas; colaborar para abordagens interdisciplinares; aumentar a capacidade das escolas primárias e secundárias; alargar o serviço e o alcance nacional e internacionalmente e manter o movimento.
} 


\section{OBJETIVOS}

Objetivo geral:

Realizar uma análise interdisciplinar e crítica de quais propostas e ações previstas no planejamento do Campus São Paulo da Universidade Federal de São Paulo contribuem efetivamente para o desenvolvimento sustentável, nos aspectos institucionais, urbanísticos e de saúde ambiental, contextualizada com a implantação física desta universidade no Município de São Paulo.

Objetivos específicos:

Identificar instrumentos de planejamento adequados à sustentabilidade de uma instituição universitária.

Identificar instrumentos de planejamento e elementos presentes nos planos diretores selecionados que permitem integração da Universidade com a Cidade.

Identificar, por meio do diagnóstico de gerenciamento de resíduos sólidos, componentes do metabolismo urbano que podem contribuir para melhorias de fluxos de materiais e outros processos, diminuindo o impacto e risco à saúde ambiental.

\section{MÉTODOS}

Os métodos embasam-se em: pesquisa bibliográfica, pesquisa documental e observação de campo, com registro de dados e registro fotográfico.

A pesquisa bibliográfica apresenta e discute conceitos abordados na pesquisa cuja seleção relaciona-se com a afinidade temática com universidade, cidade e saúde. A produção bibliográfica pressupõe a avaliação e validação científica de seus pares, diferentemente da produção documental que consiste em registros de fatos ou acontecimentos.

A pesquisa documental apresenta e discute material produzido por instituições, empresas e outras organizações disponibilizadas em formato digital. Dentre os documentos levantados estão leis, decretos, planos, projetos e relatórios fornecidos por outras empresas ou produzidos na própria instituição.

A observação de campo constitui nos registros de dados e fotográficos durante a atuação como Fiscal Técnico do contrato do Plano Diretor de Infraestrutura do Campus São Paulo da Universidade Federal de São Paulo. 
Para cada objetivo específico adota-se um procedimento metodológico para obtenção de resultados. Para estabelecer a amostra de instituições a serem analisadas, utiliza-se como critério de inclusão a natureza jurídica da instituição, que deve ser pública e da esfera federal, estar localizada em um dos 20 municípios mais populosos, conforme o censo mais recente e ter o material disponível em formato digital no portal institucional. Como critério de exclusão para análise, a repetição de instituições na ocasião de dois campi da mesma universidade constarem na lista, assim, o campus que estiver no município menos populoso é excluído da amostra para análise.

Para o primeiro objetivo específico, deve-se verificar nos portais institucionais de cada universidade a busca pelas expressões: "plano", "plano diretor", "plano de desenvolvimento institucional", "plano de logística sustentável", "PDI", "PLS" e "PD". Como primeiro resultado, produz-se um quadro informando quais universidades produziram quais planos e, para melhor visualização, um diagrama de Venn.

No segundo momento, deve-se analisar qualitativamente os planos, buscando a presença ou ausência de escopos relacionados ao gerenciamento de resíduos sólidos. No conteúdo destes documentos, verifica-se a existência ou não menções a resíduos sólidos, da meta de Plano de Gerenciamento de Resíduos Sólidos (PGRS) e da formulação de diagnóstico de gerenciamento de resíduos sólidos. Como resultado, são produzidos quadros com a síntese deste levantamento.

Para o segundo objetivo específico, aplicar na amostra de planos levantados critério de seleção em que se analisa apenas planos cujos instrumentos de planejamento permitam visualizar possibilidades de integração com a cidade, por exemplo, mapas, plantas arquitetônicas, croquis e maquetes eletrônicas. Como resultado, pode-se caracterizar as propostas e valores institucionais, considerando que são planos e não obras construídas.

Para o terceiro objetivo específico, aplicar a metodologia material flux analysis (MFA) (BRUNNER e RECHBERGER, 2005) (VILLENEUVE, MICHEL, et al., 2004) nos dados do diagnóstico do gerenciamento de resíduos sólidos de autoria da empresa MPS Arquitetos Associados no contexto do Plano Diretor de Infraestrutura (PDInfra), produzindo assim, um balanço de entradas e saídas e diagrama de fluxo de materiais.

Utilizar ferramentas de georreferenciamento para associar informações obtidas no diagnóstico de resíduos sólidos aos lotes e imóveis em uso da universidade. Assim, obtém-se mapas contendo informações a respeito da geração de resíduos sólido por tipo, conforme classificação da RDC 222 (ANVISA, 2018), que classifica resíduos sólidos de serviços de saúde. 
Formular indicadores com os dados institucionais de áreas por atividade, população por atividade e dados do diagnóstico de resíduos sólidos, que resulta em indicadores institucionais referentes às atividades universitárias de um período.

Analisar o Plano Diretor do Campus São Paulo conforme ótica dos "pontos de alavancagem" (MEADOWS, 1999), uma visão sistemática a respeito da efetividade de ações aplicadas a determinados pontos, ou seja, qual mudança em um ponto do sistema provoca maiores efeitos em prol da sustentabilidade. Como resultado desta análise verifica-se quais pontos de intervenção em um sistema são propostos no PDInfra.

Finalmente, com a visão mais ampliada pode-se realizar uma análise integrada do planejamento do Campus São Paulo como um todo, a fim de se ter uma revisão crítica do material produzido.

\section{ORGANIZAÇÃO DA DISSERTAÇÃO}

No capitulo 1 - Referencial teórico para pesquisa sobre Universidade, Cidade e Saúde Ambiental trata da pesquisa bibliográfica, no primeiro momento, sobre o questionamento a respeito de medições quantitativas de pesquisas interdisciplinares. $\mathrm{E}$ em um segundo momento, o debate sobre os conceitos utilizados.

No capítulo 2 - Universidades em cidades: experiências nacionais e internacionais são apresentadas as referencias nacionais e internacionais de planos diretores levantadas para comparar com o Plano Diretor de Infraestrutura do Campus São Paulo. Busca-se elaborar análises sobre a relação urbana entre os campi e cidades universitárias e seus entornos.

No Capítulo 3 - Os tipos de planejamento da universidade na cidade são apresentados instrumentos de planejamento e 3 tipologias em especial, o Plano de Desenvolvimento Institucional (PDI), o Plano de Logística Sustentável (PLS) e o Plano Diretor (PD). Discute-se a função e efetividades dos planos e sugere-se a incorporação do conceito do metabolismo urbano para aprimorar os planejamentos institucionais.

No Capítulo 4 - Universidade, cidade e saúde, apresenta-se argumentos relacionando sustentabilidade urbana e saúde, e com o estudo de caso do CSP, trazer para debate a relação da universidade e seus serviços de saúde com o gerenciamento de resíduos de serviço de saúde. Propõe-se visualizar estas relações de três formas, por mapas, por diagramas e por balanço de entradas e saídas. 
Questiona-se o que de fato é efetivo nos planejamentos universitários, dado o grande volume de material documental que é produzido pelas instituições. Para uma análise sistêmica a respeito do Plano Diretor de Infraestrutura do CSP, utiliza-se o método proposto por (MEADOWS, 1999), em que se verificam os "pontos de alavancagem" de um sistema.

As considerações finais discutem os resultados apresentados nos capítulos 2 a 4, embasados pelas definições apresentadas no Capítulo 1.

A proposta de Mestrado Profissional exige um produto de aplicação profissional relacionado ao material de pesquisa, e, após as considerações finais, apresenta-se o produto, um mapa interativo virtual do CSP, com as informações georreferenciadas do diagnóstico do gerenciamento de resíduos sólidos.

No intuito de tornar o texto mais fluido e objetivo, transfere-se para os anexos, na ordem que são mencionados, as Matrizes de referencia da medição quantitativa de interdisciplinariedade, Mapas do contexto urbano do CSP, Levantamento dos planos diretores anteriores ao PDInfra e os Extratos do Portal da Transparência da Unifesp, utilizado para criar o gráfico de compras institucionais. 


\section{CAPÍTULO 1 - REFERENCIAL TEÓRICO PARA PESQUISA SOBRE UNIVERSIDADE, CIDADE E SAÚDE AMBIENTAL}

Como pesquisa de tipo exploratória e aplicada (GIL, 2008), busca-se estabelecer processos metodológicos: a pesquisa bibliográfica, a pesquisa documental e a observação de campo para embasar a discussão a respeito das relações entre universidade e cidade.

No primeiro momento, a curiosidade a respeito de como medir a interação entre expressões textuais pré-selecionados em bases de dados resulta em uma proposta de matriz cujos valores se referem, quantitativamente, ao número de resultados de pesquisas simples realizadas em agosto de 2018 com as expressões textuais selecionadas.

As universidades têm uma produção documental importante para a fiscalização, controle social e acesso à informação do grande público, portanto, para a pesquisa documental, foram analisados apenas documentos em formato digital publicado nos portais institucionais oficiais.

Os servidores dessas universidades geram relatórios ou registros da fiscalização de projetos e serviços contratados por suas instituições. No caso do objeto de estudo, as observações, experiências e informações coletadas como fiscal técnico do contrato do Plano Diretor de Infraestrutura, são advindas da observação de campo.

Este capítulo, portanto, contextualiza os resultados que serão discutidos a partir dos próximos capítulos.

\subsection{MEDIÇÃO DAS INTERFACES DE PESQUISA ENTRE UNIVERSIDADE E CIDADE}

Busca-se construir uma visão interdisciplinar sobre o objeto da pesquisa, o Plano Diretor de Infraestrutura do Campus São Paulo, por meio da discussão em torno da revisão bibliográfica acerca dos temas de urbanismo, saúde e sustentabilidade aderente à proposta do programa de Mestrado Profissional Ambiente, Saúde e Sustentabilidade.

Propõe-se um método para medição quantitativa de interdisciplinaridade que consiste em realizar buscas em bancos de dados e coletar o número de resultados das buscas com uma e outra com duas palavras-chave, formando uma matriz com sete expressões e suas respectivas traduções em inglês. 
O recorte temático busca interfaces entre gestão de resíduos, planejamento urbano, saúde, ambiente e sustentabilidade, e consecutivamente, as expressões escolhidas já são direcionados ao objetivo da pesquisa. Posteriormente à medição quantitativa e critérios de seleção discute-se os conceitos destas expressões.

Para planejamento urbano a expressão "plano diretor" e "master plan" são conceitos consolidados como uma ferramenta de planejamento, principalmente no Brasil. O objeto do estudo de caso, o PDInfra, assim como outros planos institucionais também se denominam planos diretores, assim como exemplos de universidades inglesas e estadunidenses que também utilizam a expressão master plan. Neste tema, optou-se por incluir também as expressões "Planejamento" e "Planning" com intenção de verificar o quanto de diferença há entre planejamento, expressão mais amplo e plano diretor, que é mais relacionado à arquitetura e urbanismo, embora não exclusivo desta disciplina.

Os sentidos ampliados de saúde que "cidades saudáveis" e "determinantes sociais da saúde" já são utilizados para nomear e justificar, respectivamente, programas internacionais capitaneados por órgãos como a Organização Mundial da Saúde (OMS). Portanto, optou-se por estas duas expressões, em conjunto com suas traduções "healthy cities" e "social determinants of health".

No Brasil, há uma diferenciação entre planos de gestão de resíduos e planos de gerenciamento de resíduos. Por se tratar de um estudo a respeito de planejamento e não de procedimentos operacionais, opta-se por incluir na pesquisa "gestão de resíduos sólidos" e "waste management".

Dentre as ferramentas conceituais que permitem compreender, visualizar e analisar os fluxos de um sistema, tanto com visão crítica, quanto procedimental, foi selecionado o "metabolismo urbano" ou "urban metabolism".

As expressões citadas acima estão relacionadas ao objetivo da pesquisa ao buscar as interfaces do ambiente, saúde e sustentabilidade, focando na questão dos espaços urbanos.

Para visualizar quantitativamente as interações, foi proposta uma matriz, cujos eixos constam as expressões textuais. Os "nós interdisciplinares" ocorrem no cruzamento entre duas expressões diferentes e a diagonal representa os resultados de apenas uma das expressões.

Para realizar a pesquisa foi utilizada a expressão entre aspas, na pesquisa simples ou com todos os índices. Por se tratar de uma visualização quantitativa, a pesquisa não buscou ferramentas mais específicas, como busca de palavra-chave, assunto ou outros. As pesquisas para formulação das matrizes ocorreram em agosto de 2018. 
Foram utilizadas cinco bases de dados, a Google Acadêmico, Scielo, Teses USP, Emerald Insight e LILACS. As expressões buscadas foram nas línguas inglês e português.

Para selecionar bases de dados, foram utilizados critérios temáticos ou de tipo de acesso. A começar pela Scielo, que é um acrônimo para Scientific Electronic Library Online, é uma base de acesso aberto a todo o conteúdo, é, portanto, uma ferramenta importante de democratização do conhecimento.

A Emerald Insight é uma base de dados fundada na Inglaterra, de acesso restrito, que faz parte de um grupo editorial cujos temas principais são administração, negócios, educação, biblioteconomia, saúde e engenharias. Por se tratar de uma base de acesso restrito, porem com assinatura da Unifesp, foi possível consultar e incorporar textos desta base.

A Teses USP é o repositório institucional de dissertações e teses da Universidade de São Paulo, onde todo o conteúdo dessas publicações é disponibilizado gratuitamente em formato digital. Por se tratar de uma das maiores e melhores da América Latina e por onde se dará a defesa desta pesquisa, é interessante verificar na produção acadêmica quais temas tem maior interdisciplinaridade.

A LILACS (Literatura Latino-Americana e do Caribe em Ciências da Saúde) como o próprio nome diz, é uma base focada em ciências da saúde, mas nem todo material está disponível integralmente. Pela temática e pelo acesso, optou-se por inclui-la nesta pesquisa.

O Google Acadêmico é a ferramenta do buscador direcionada a trabalhos acadêmicos, a ferramenta é aberta, porém nem todo conteúdo o é. Espera-se que a quantidade de resultados espelhe uma busca mais ampliada, uma vez que este é a ferramenta de pesquisa mais utilizada no mundo.

Reforçando que esta análise buscou referencias, mas principalmente a visualização de quais temas estão sendo mais estudados e pesquisados de modo interdisciplinar.

Os "nós interdisciplinares" das matrizes revelam temas que podem ser muito recentes ou pouco pesquisados. Não é possível apenas através dessa matriz revelar quais seriam as razões. Isto dependeria de uma pesquisa mais aprofundada levando em consideração as datas de publicação, locais ou instituições de origem e dados bibliométricos que não são objeto desta análise. 
Sobre as interfaces da área de planejamento, percebe-se que "plano diretor" e "cidades saudáveis" não tem resultado na base da Scielo, mas nas outras bases em português Teses USP (69), LILACS (23) e Google Acadêmico (331) já aparecem referencias. Porém o número é significativamente menor que a expressão textual mais ampla "planejamento", sendo Scielo (4), Teses USP (176), LILACS (173) e Google Acadêmico (1410). Estes resultados são indícios de que há menos pesquisas que envolvem urbanismo no tema das cidades saudáveis. Já nas bases em inglês o fenômeno é semelhante, sendo "master plan" x "healthy cities" tendo significativamente menos resultados que "planning" $\mathrm{x}$ "healthy cities".

O padrão de mais resultados para "planejamento" do que "plano diretor" se repete na matriz nas interfaces com "determinantes sociais da saúde", "gestão de resíduos sólidos", "metabolismo urbano" e "sustentabilidade", inclusive nas bases em inglês. As maiores interações do tema planejamento são com o tema "sustentabilidade", chegando a ter no "plano diretor" x "sustentabilidade", Teses USP (1480) e Google Acadêmico (25.100) e em inglês, Emerald Insight (10.548) e Google Acadêmico (114.000).

O bloco "cidades saudáveis" e "determinantes sociais da saúde" apresentou poucos resultados em bases em português, chegando a não ter resultados na Scielo, Lilacs e Teses USP na relação com "metabolismo urbano" x "determinantes sociais da saúde", embora com resultados em inglês, Emerald Insight (33), Google Acadêmico (47). As maiores interações destas expressões são com as relacionadas à planejamento e sustentabilidade, tanto nas bases em português como em inglês, chegando a ter em "determinantes sociais da saúde" x "sustentabilidade", no Teses USP (298), Emerald Insight (2.946) e Google Acadêmico (25.600)

A "gestão de resíduos sólidos" como esperado, tem mais interfaces com "planejamento" e "sustentabilidade" e menos com "determinantes sociais da saúde" e "cidades saudáveis", chegando a ter nenhum resultado nas bases da Scielo e da LILCS e na Teses USP (6). Já nas bases em inglês aparecem resultados Emerald Insight (855) e Google Acadêmico (1.470). Neste sentido, aparentemente há menos pesquisas relacionando questões ambientais ligadas à problemática dos resíduos sólidos outros componentes ambientais da saúde.

O "metabolismo urbano" teve o menor número de resultados em todas as bases, sendo praticamente nulo no LILACS, com apenas 1 resultado na pesquisa com a palavrachave e sem referencia no Scielo. As maiores interfaces da expressão em português foram com "sustentabilidade" no Teses USP (70) e Google Acadêmico (476). Em inglês há referencias no Emerald Insight (189) e Google Acadêmico (7.700). Pelos resultados, percebe-se que os estudos interdisciplinares deste conceito ainda são incipientes, inclusive no resto do mundo. 
A "sustentabilidade" tem mais afinidade com "planejamento" em todas as bases em português, chegando a ter na base Teses USP (7.340). Nesta mesma base há resultados expressivos para as interfaces com "plano diretor" e "gestão de resíduos sólidos" também, com 1.480 e 1.120 entradas, respectivamente.

A visualização destas pesquisas demonstra não apenas quais são os temas mais pesquisados, ou com mais publicações aceitas, mas também dá indicativos do repertório conceitual e propositivo dos pesquisadores e pesquisadoras do conjunto lusófono e anglófono.

Em suma, textos que mencionam gestão de resíduos sólidos e metabolismo urbano com questões de saúde, como cidades saudáveis e determinantes sociais da saúde no mesmo texto ainda são incipientes e pode ser um tema mais explorado.

As matrizes se encontram no Apêndice A.

\subsection{DEFINIÇÃO E DISCUSSÃO DE CONCEITOS SELECIONADOS}

Buscando uniformizar as expressões textuais e conceitos que serão utilizados nesta pesquisa, apresentam-se os debates acerca dos conceitos selecionados na pesquisa bibliográfica. Pelo objeto de estudo ser um plano diretor de infraestrutura universitário, buscou-se conceituar o conceito de "campus" e "cidade universitária", inclusive para uma classificação mais precisa na pesquisa documental. Outro componente do objeto de estudo é o "plano diretor", cujos conceitos são abordados inclusive em lei federal, como veremos a seguir.

A "sustentabilidade" é um conceito abrangente, mas que nesta pesquisa será adotado como sinônimo do conceito "desenvolvimento sustentável". Este conceito está presente em programas governamentais ou de organizações civis como "Cidades saudáveis", "cidades resilientes", "cidades sustentáveis" e outras denominações estão muito relacionadas aos "determinantes sociais da saúde", ou seja, fatores ambientais, sociais e econômicos que, assim como os biológicos, influem na saúde do ser humano.

Um produto das atividades humanas, cujo planejamento é essencial para a sustentabilidade é a gestão de resíduos sólidos. Como instituição de assistência, ensino, extensão e pesquisa, o Campus São Paulo tem uma complexidade de resíduos, e que, portanto, também precisa de uma conceituação prévia.

O "metabolismo urbano" como uma ferramenta conceitual e o "material flow analysis" como ferramenta de análise, também é discutida. 


\subsubsection{CAMPUS E CIDADE UNIVERSITÁRIA}

O território universitário tem duas denominações consolidadas na literatura: campus ou cidade universitária (SILVEIRA, NEVES, et al., 2012). A definição varia no tempo e espaço conforme os contextos. Optou-se por apresentar os conceitos mais utilizados pela bibliografia brasileira consultada.

Integração entre unidades universitárias sob os critérios de economia e funcionalidade definem o que é campus, se as unidades se apresentam de formas isoladas seria uma cidade universitária (Atcon, 1974 apud SILVEIRA, NEVES, et al., 2012). Ainda segundo o autor, campus é fluido e orgânico, enquanto a cidade universitária é rígida, monumental e anti-funcional.

Os conceitos também teriam origens históricas distintas, o campus tem origem anglo-saxônica e cidade universitária, francesa (CUNHA, 2003). No Brasil, a cidade universitária se expressa na reunião de instalações universitárias em território próprio e circunscrito, comumente fora da cidade ou em sua periferia (ARAÚJO, 2002). O campus, por outro lado, define os espaços múltiplos de uma mesma universidade, em uma cidade ou em várias. (CUNHA, 2003).

A literatura consultada, portanto, considera o território universitário, seja campus ou cidade universitária, como dentro do campo urbano. Para esta discussão, será desconsiderado o conceito de universidade e escola rural.

Para ilustrar esse conceito, foi feito um mosaico de referências de 8 campi (ver Figura 1), Unifesp, UFRJ, UNB, UFBA, UFC, UFMG, UFMA e UFPR, respectivamente, com imagem de satélite na mesma escala e destacando a área aproximada dos principais corpos do território universitário. 
Figura 1 - Mosaico de referências de Campus e Cidades Universitárias com área aproximada
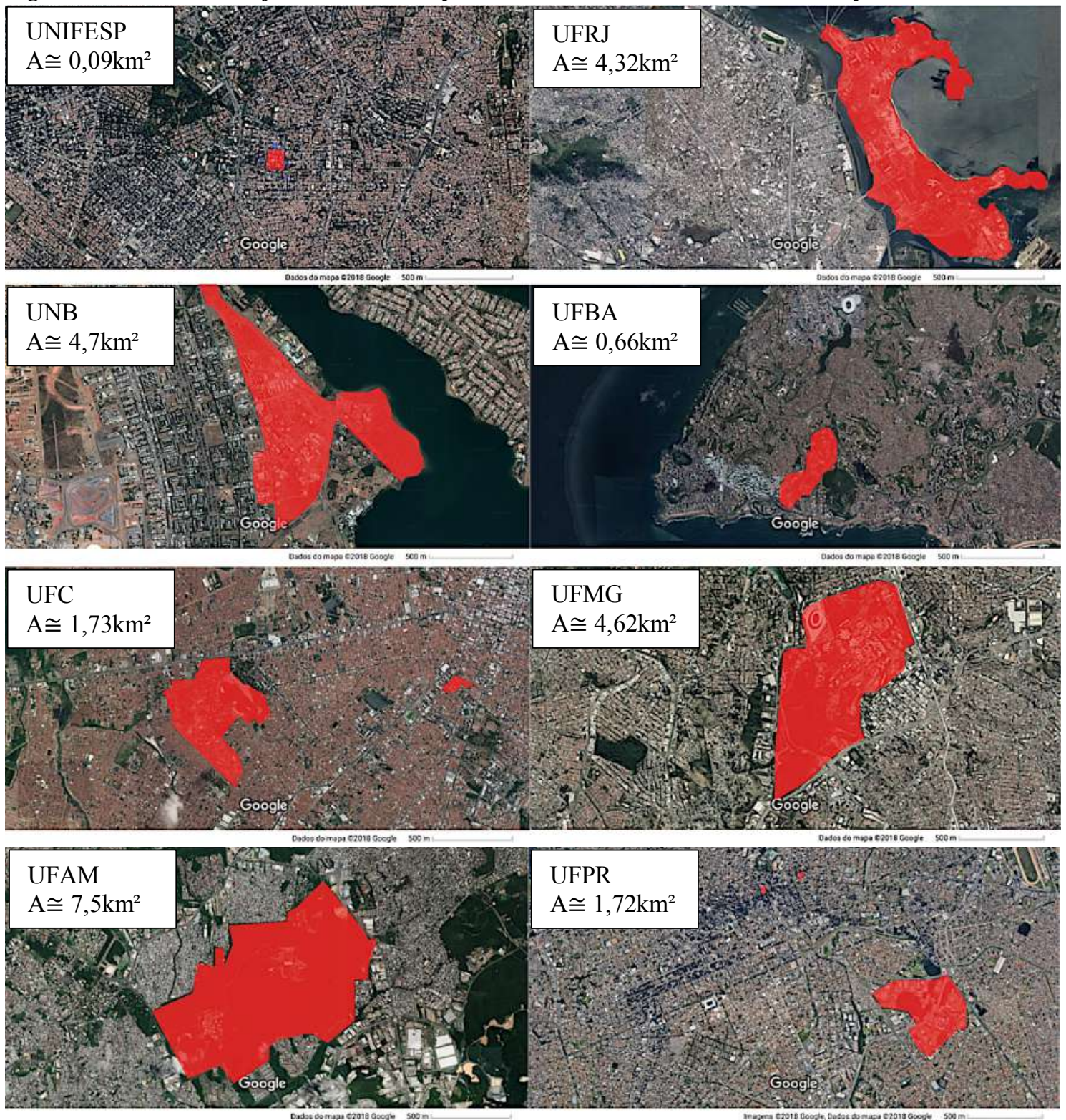

Fonte: Google Maps, estimativa de áreas e destaques do autor.

Para a definição de "cidade universitária" ou "campus universitário" no contexto brasileiro, portanto, verifica-se que as principais características envolvem a questão da dimensão e a flexibilidade territorial. A cidade universitária tem grandes dimensões e não tem flexibilidade territorial, ou seja, a delimitação do terreno se mantém por longos períodos. No caso do campus universitário, a ocupação se dá em territórios menores e não necessariamente contínuos, com dimensões máximas de alguns quarteirões e a desapropriação e aluguel de terrenos ou edifícios ao longo do tempo muda a dimensão do território ocupado por esse tipo de modalidade. 


\subsubsection{PLANO DIRETOR}

A expressão Plano Diretor comumente é associada ao planejamento e regulamentação do uso do solo de um Município ${ }^{3}$, como é o caso recente do Município de São Paulo, com seu Plano Diretor Estratégico (PDE) aprovado em 2014. Esta ferramenta está prevista na Lei 10.257/2001, também conhecida como Estatuto da Cidade (BRASIL, 2001).

O plano diretor é objeto de estudo ou faz parte de definições de normas e politicas diversas, dada a sua importância para o planejamento urbano no Brasil. Segundo o levantamento bibliográfico do professor Renato T. de Saboya:

[Plano diretor é o] Instrumento básico de um processo de planejamento municipal para a implantação da política de desenvolvimento urbano, norteando a ação dos agentes públicos e privados. (ABNT, 1991)

Seria um plano que, a partir de um diagnóstico científico da realidade fisica, social, econômica, política e administrativa da cidade, do município e de sua região, apresentaria um conjunto de propostas para o futuro desenvolvimento socioeconômico e futura organização espacial dos usos do solo urbano, das redes de infra-estrutura e de elementos fundamentais da estrutura urbana, para a cidade e para o município, propostas estas definidas para curto, médio e longo prazos, e aprovadas por lei municipal. (VILLAÇA, 1999, p. 238)

É plano, porque estabelece os objetivos a serem atingidos, o prazo em que estes devem ser alcançados [...], as atividades a serem executadas $e$ quem deve executá-las. É diretor, porque fixa as diretrizes do desenvolvimento urbano do Municipio. (SILVA, 1995, p. 124) (BRASIL, 2002)

O Plano Diretor pode ser definido como um conjunto de princípios e regras orientadoras da ação dos agentes que constroem e utilizam o espaço urbano. (BRASIL, 2002, p. 40) apud SABOYA, 2018

Em algumas ocasiões são usadas as expressões "desenho urbano" e "projeto urbano", não como sinônimos de plano diretor, mas como um dos componentes dele. Um projeto ou desenho urbano se expressa majoritariamente na linguagem arquitetônica (desenhos, plantas, cortes, volumetrias, entre outros) enquanto que o plano diretor não necessariamente se utiliza dessas linguagens.

\footnotetext{
${ }^{3}$ Ressalta-se que a expressão Plano Diretor não é exclusiva do campo da Arquitetura e Urbanismo, sendo esta utilizada também em administração e áreas afins.
} 
Estende-se para o planejamento institucional a expressão Plano Diretor, de forma aderente ao conceito utilizado pelo Guia de Implementação do Estatuto da Cidade (BRASIL, 2002), uma vez que o Campus é espaço urbano e os agentes que o constroem são os membros da comunidade universitária.

A Unifesp adota o nome "Plano Diretor de Infraestrutura (PDInfra)" desde o primeiro plano piloto, realizado para o Campus Diadema (UNIFESP, 2014), posteriormente também para o Campus Baixada Santista (UNIFESP, 2015).

Outras Instituições de Ensino Superior (IES) também realizaram Planos Diretores. O Plano Diretor Participativo da Universidade Federal de Santa Catarina (UFSC, 2005) e o Plano Diretor UFRJ 2020 (UFRJ, 2009) são exemplos de universidades que realizaram o planejamento para uso, expansão da ocupação e gestão do espaço físico.

Universidades de outros países também realizam masterplans, que são planejamentos institucionais nos moldes semelhantes a planos diretores. O plano da universidade estadunidense Homewood Campus Plan Update (JOHNS HOPKINS UNIVERSITY, 2009), a universidade inglesa UCL Masterplan Bloomsbury Campus (UCL, 2011) e a da Universidade de Nova Iorque (NYU, 2008), são exemplos de campi que podem ser usados como referência com as devidas ressalvas das diferenças institucionais e legais de cada contexto.

Os planos citados têm questões comuns de escala, de escopo e de linguagem. A escala tratada é a urbana, extrapola a escala do edifício, trazendo relações da implantação do campus com a cidade. O escopo é de planejamento do uso e ocupação de espaço físico com ou sem expansão, seja com a projeção de reforma ou aumento de área construída de edifícios existentes com alteração ou não dos seus usos, além de definir critérios de ocupação por atividades, o que no jargão urbanístico é chamado de "zoneamento". A linguagem arquitetônica e urbanística é a mais adequada pelo escopo e escala. Textos complementares são utilizados para trazer outras diretrizes ou reforçar intenções presentes nos mapas. Exemplo de diretrizes como integração com a vizinhança, política de imóveis e outros.

O uso de mesma expressão não é apenas coincidência de palavras, mas a consciência da escala urbana no qual as instituições de ensino estão inseridas.

\subsubsection{DESENVOLVIMENTO SUSTENTÁVEL}

Sustentabilidade é uma expressão que pode ser apropriada por diversas visões de mundo. A "sustentabilidade financeira" de um projeto pode levar em conta as questões orçamentárias, mas não as ambientais e sociais, por exemplo. O selo "sustentável" de um 
edifício pode ser mais uma ação de imagem pública do que ação efetiva, enfim, o conceito tem uma dimensão interdisciplinar sendo usado em diversas disciplinas, nas economias, engenharias, arquitetura e urbanismo, ciências ambientais, entre outras.

Ideias seminais de sustentabilidade poderiam estar na teoria econômica da fisiocracia, já no sec. XVIII (MIKHAILOVA, 2004) ${ }^{4}$, (NAREDO, 2004) $)^{5}$, em que a associação entre recursos naturais e riqueza começaram a ser teorizados.

Até o século XX não houve estudos impactantes relacionados à preocupação com degradação de meio ambiente. Quando se começa a ter os primeiros passos para o conceito atual de "desenvolvimento sustentável", após a Conferencia de Estocolmo, em 1972:

Historicamente, a preocupação com o meio ambiente teve maior ênfase a partir do século XX. Na sua segunda metade, um grupo de cientistas, reunidos no chamado Clube de Roma, elaboraram o relatório "Limites do Crescimento", publicado em 1972, com projeções assustadoras em virtude do crescimento econômico sem controle (VALLE, 2002). (GONTIJO, 2017)

O conceito de desenvolvimento sustentável surge no discurso internacional após a médica, mestre em saúde pública e ex-primeira ministra da Noruega, Gro Harlem Brundtland e sua comissão, apresentam o relatório "Nosso Futuro Comum" na Assembleia Geral da ONU de 1987. Neste documento, define-se que o "O desenvolvimento sustentável é o desenvolvimento que encontra as necessidades atuais sem comprometer a habilidade de futuras gerações de atender suas próprias necessidades" (ONU, 1987)

\footnotetext{
4 "Basta lembrar a sua história: a fisiocracia colocava os recursos naturais (a terra) em primeiro lugar dentre os fatores de crescimento econômico e a escola clássica considerava os três fatores em conjunto - a terra, o capital e o trabalho". (MIKHAILOVA, 2004, p. 2)

5 "Conseguir un mejor entendimiento entre los enfoques y las áreas de conocimiento diferentes que se ocupan de la problemática horizontal que la gestión de los recursos naturales o ambientales plantea, exige conocer en profundidad las razones que explican el divorcio entre economía y ecología, viendo cómo la noción de sistema económico sobre la que acostumbra a razonar la primera se consolidó echando por la borda las consideraciones sobre la economía de la naturaleza que preocupaban a los autores, hoy llamados «fisiócratas», que la idearon en el siglo XVIII. (NAREDO, 2004, p. 4)

"Obter um melhor entendimento entre os enfoques e as áreas de conhecimento diferentes que se ocupam da problemática horizontal que a gestão dos recursos naturais ou ambientais planta, exige conhecer em profundidade as razões que explicam o divórcio entre a economia e a ecologia, vendo como a noção de sistema econômico sobre a qual se acostuma a raciocinar a primeira se consolidando jogando fora as considerações sobre a economia da natureza que os autores se preocupavam, hoje chamados de "fisiocratas", que a idealizaram no século XVIII". (tradução nossa)
} 
Ainda no mesmo texto, os autores deixam claro que não são apenas os recursos naturais que estão em questão, mas também as necessidades da população em geral:

Um mundo onde a pobreza e a desigualdade são endêmicas estará sempre propenso à crises ecológicas, entre outras... O desenvolvimento sustentável requer que as sociedades atendam às necessidades humanas tanto pelo aumento do potencial produtivo como pela garantia de oportunidades iguais para todos. (ONU, 1987)

Os debates e trabalhos internacionais culminam em uma conferência realizada no Rio de Janeiro em 1992, que ficou conhecida como "Cúpula da Terra", em que se formulou e adotou a chamada "Agenda 21". Nela, os governos definem premissas objetivando o desenvolvimento sustentável considerando os aspectos sociais, ambientais e econômicos.

Essas três dimensões (social, ambiental e econômica) podem ser desdobradas em oito dimensões para o desenvolvimento sustentável, conforme proposta de (SACHS, 2002) ${ }^{6}$, complementando o conceito do Relatório Bruntland.

Apesar de outros conceitos de sustentabilidade, o mais difundido, principalmente no âmbito internacional, é o de aliar desenvolvimento e sustentabilidade. Na virada do

\footnotetext{
6 "1. Social: alcance de um patamar razoável de homogeneidade social; com distribuição de renda justa; emprego pleno e/ou autônomo com qualidade de vida decente; igualdade no acesso aos recursos e serviços sociais.

2. Cultural: mudanças no interior da continuidade (equilíbrio entre respeito à tradição e inovação); capacidade de autonomia para elaboração de um projeto nacional integrado e endógeno (em oposição às cópias servis dos modelos alienígenas); autoconfiança, combinada com abertura para o mundo.

3. Ecológica: preservação do potencial do capital natural na sua produção de recursos renováveis; à limitação do uso dos recursos não renováveis.

4. Ambiental: respeitar e realçar a capacidade de autodepuração dos ecossistemas naturais.

5. Territorial: configurações urbanas e rurais balanceadas (eliminação das inclinações urbanas nas alocações do investimento público); melhoria do ambiente urbano; superação das disparidades interregionais; estratégias de desenvolvimento ambientalmente seguras para áreas ecologicamente frágeis.

6. Econômica: desenvolvimento econômico intersetorial equilibrado; com segurança alimentar; capacidade de modernização contínua dos instrumentos de produção, razoável nível de autonomia na pesquisa científica e tecnológica; inserção soberana na economia internacional.

7. Política (Nacional): democracia definida em termos de apropriação universal dos direitos humanos; desenvolvimento da capacidade do Estado para implementar o projeto nacional, em parceria com todos os empreendedores; um nível razoável de coesão social.

8. Política (Internacional): eficácia do sistema de prevenção de guerras da ONU, na garantia da paz e na promoção da cooperação internacional; Pacote Norte-Sul de co-desenvolvimento, baseado no princípio da igualdade (regras do jogo e compartilhamento da responsabilidade de favorecimento do

parceiro mais fraco); controle institucional efetivo do sistema internacional financeiro e de negócios; controle institucional efetivo da aplicação do Princípio da Precaução na gestão do meio ambiente e dos recursos naturais, prevenção das mudanças globais negativas, proteção da diversidade biológica (e cultural), gestão do patrimônio global, como herança comum da humanidade; sistema efetivo de cooperação científica e tecnológica internacional e eliminação parcial do caráter commodity da ciência e tecnologia, também como propriedade da herança comum da humanidade." (SACHS, 2002) apud GONTIJO, 2017
} 
século, no ano 2000, ocorre em Nova Iorque a Cúpula do Milênio. Em que se lança os Objetivos de Desenvolvimento do Milênio (ODM) ${ }^{7}$. Os países signatários se comprometem com metas de desenvolvimento.

Com prazo até 2015, os ODM tiverem sucesso e comprometimento muito variado a depender do país analisado. No Brasil, com destaque ao combate a fome a à miséria, cumpre parte dos 8 objetivos e faz a adesão a novas metas. (IPEA/SNI, 2014)

Uma nova agenda é formalizada em setembro de 2015, novamente em Nova Iorque, na Cúpula de Desenvolvimento Sustentável. A chamada Agenda 2030, ou Objetivos do Desenvolvimento Sustentável (ODS), deve orientar as políticas públicas dos seus signatários.

As 17 ODS seguem o mesmo conceito de desenvolvimento sustentável que os ODM, agora incluindo novos temas e focos em questões contemporâneas. Para esta pesquisa, destaca-se os objetivos 03 (Assegurar uma vida saudável e promover o bemestar), 11 (Cidades e Comunidades Sustentáveis) e 12 (Consumo e Produção Responsáveis).

O fato de haver um objetivo específico sobre cidades demonstra a crescente importância dos estudos urbanos (e da projeção da população urbana mundial) na efetivação de ações que visem o desenvolvimento sustentável.

Por se tratar de um conceito que tem difusão internacional, pode-se dizer que há um mínimo consenso nas suas ideias. Ainda mais pelo fato de os ODS conterem indicadores e metas, é possível acompanhar a evolução mundial por esses métodos.

No entanto, é importante salientar que existem análises críticas a esse conceito e aos ODS, pois há contradições entre incentivar o crescimento econômico, modelo que é predominante hoje, e o respeito ao meio ambiente e às populações. Questiona-se, portanto, a real eficácia do ideal da sustentabilidade no atual sistema econômico. (GONTIJO, 2017, p. 25) ${ }^{8}$

\footnotetext{
${ }^{7}$ 1- acabar com a fome e a miséria, 2- educação básica de qualidade para todos, 3- igualdade entre sexos e valorização da mulher, 4- reduzir a mortalidade infantil, 5- melhorar a saúde das gestantes, 6- combater a aids, a malária e outras doenças, 7- qualidade de vida e respeito ao meio ambiente e 8- todo mundo trabalhando pelo desenvolvimento.

8 “A elaboração da ideia de desenvolvimento sustentável traz uma preocupação da preservação da sociedade e que depende dos recursos naturais que ordinariamente são destruídos. Porém, existe um amplo debate sobre os reais fundamentos e a eficácia da ideia de sustentabilidade num sistema econômico predominante capitalista." (GONTIJO, 2017, p. 25)
} 
A dúvida sobre a eficácia da ideia de desenvolvimento sustentável surge ao analisar as metas dos ODS, onde verifica-se que entre elas há objetivos que reforçam cenários mais alinhados ao status quo, como o acesso à serviços bancários, ou aumentar a participação da indústria, mesmo considerando que ela seja "inclusiva e sustentável"9.

A crítica ao desenvolvimento sustentável e aos ODS são necessárias para explicitar as contradições que cercam o debate a respeito da sustentabilidade no contexto social, econômico e político em que nos encontramos. Porém quando se trata de planos, há mínimos consensos que precisam ser considerados.

Portanto, na pesquisa utiliza-se a expressão "desenvolvimento sustentável” como sinônimo de sustentabilidade.

\subsubsection{METABOLISMO URBANO}

O Metabolismo Urbano (MU) é um conceito, assim como a Sustentabilidade, com diversas conotações e versada por várias disciplinas, como a ecologia, o ecologia industrial, ciências biofísicas, economia política e urbanismo, entre outras $(\text { KARVOUNIS, 2015 })^{10}$. Cada disciplina tem um viés para as interpretações a respeito do fenômeno do MU, sendo as principais, no momento, a ecologia urbana, a ecologia industrial, a economia ecológica, a ecologia política e a geografia política (DINARĖS, 2014). No Quadro 1, é possível visualizar de as disciplinas e suas interpretações:

\footnotetext{
${ }^{9}$ Conforme metas da ONU:

8.10. Fortalecer a capacidade das instituições financeiras nacionais para incentivar a expansão do acesso aos serviços bancários, de seguros e financeiros para todos

9.2. Promover a industrialização inclusiva e sustentável e, até 2030, aumentar significativamente a participação da indústria no setor de emprego e no PIB, de acordo com as circunstâncias nacionais, e dobrar sua participação nos países menos desenvolvidos. (ONU, 2015)

10 "The concept of urban metabolism was explored through ecology and industrial ecology, bio-physical sciences, political economy and urban planning studies, revealing in each case different aspects integrated in the concept (Pincetl et al. 2012)".(KARVOUNIS, 2015, p. 21)

"O conceito de metabolismo urbano foi explorado através da ecologia e da ecologia industrial, ciências biofísicas, economia política e estudos de planejamento urbano, revelando em cada caso, diferentes aspectos integrados no conceito" (tradução nossa)
} 
Quadro 1 -Interpretações e debates do conceito de metabolismo urbano

\begin{tabular}{|c|c|c|c|c|c|}
\hline \multirow[b]{2}{*}{ interpretações/ debates atuais } & \multicolumn{5}{|c|}{ Disciplina } \\
\hline & $\begin{array}{c}\text { ecologia } \\
\text { urbana }\end{array}$ & $\begin{array}{l}\text { ecologia } \\
\text { industrial }\end{array}$ & $\begin{array}{l}\text { economia } \\
\text { ecológica }\end{array}$ & $\begin{array}{c}\text { ecologia } \\
\text { política }\end{array}$ & $\begin{array}{c}\text { geografia } \\
\text { política }\end{array}$ \\
\hline Cidade como um ecossistema & $\mathrm{X}$ & & & & \\
\hline $\begin{array}{l}\text { Cidade como fluxo de } \\
\text { material e energia ou fluxos } \\
\text { de materiais e energia na } \\
\text { cidade }\end{array}$ & & $\mathrm{X}$ & & & \\
\hline $\begin{array}{l}\text { A base material da economia, } \\
\text { ou a quebra da ligação entre } \\
\text { urbanização, crescimento } \\
\text { econômico e consumo de } \\
\text { recursos }\end{array}$ & & $\mathrm{X}$ & $\mathrm{X}$ & & \\
\hline $\begin{array}{l}\text { Cidade como um sistema } \\
\text { sócio-ecológico }\end{array}$ & $\mathrm{X}$ & & $X$ & & \\
\hline $\begin{array}{l}\text { Condutores econômicos da } \\
\text { relação rural-urbana, e a } \\
\text { produção e reprodução da } \\
\text { inequidade }\end{array}$ & & & $\mathrm{X}$ & $\mathrm{X}$ & \\
\hline $\begin{array}{l}\text { Reprodução da inequidade } \\
\text { urbana e a governança dos } \\
\text { fluxos urbanos }\end{array}$ & & & $\mathrm{X}$ & $\mathrm{X}$ & \\
\hline $\begin{array}{l}\text { Ressignificação da cidade: } \\
\text { metabolismo urbano e } \\
\text { relações sociais, técnicas e } \\
\text { ecológicas }\end{array}$ & & & & $\mathrm{X}$ & $\mathrm{X}$ \\
\hline
\end{tabular}

Fonte: tradução nossa de (DINARÈS, 2014, p. 562)

Notas: opta-se pela disciplina da "ecologia industrial" neste texto

O conceito de metabolismo foi emprestado da biologia (DINARÈS, 2014) que se refere a "conjunto de transformações, num organismo vivo, pelas quais passam as substâncias que o constituem: reações de síntese (anabolismo) e reações de desassimilação (catabolismo) que liberam energia." Analogamente, o conceito de metabolismo urbano também se refere a transformações, e cada disciplina irá analisar à sua maneira como se dá e quais suas consequências.

Em um retrospecto histórico, Marx utiliza esta expressão já no séc. XIX (ZHANG, 2013, p. 463), (KARVOUNIS, 2015, p. 21), (DINARÈS, 2014, p. 556) ${ }^{11}$. O MU seria a noção de transformação da natureza através do trabalho e do sistema capitalista de trocas.

11 "Marx had been influenced by Justus von Liebig, a German soil chemist who used the concept of metabolism to describe the material exchanges and interdependent relationships between human society and nature (Fischer-Kowalski, 1998; Martinez-Alier, 1987; Wachsmuth, 2012). It was in this sense that Marx's use of the expression "metabolism between man and earth" referred specifically to the cycles of plant nutrients (Martínez- Alier, 1987: 220-221) in terms of fertility conditions, agricultural production systems and urbanization.” (DINARÈS, 2014, p. 556)

"Marx foi influenciado por Justus von Liebig, um químico de solos alemão que usou o conceito de metabolismo para descrever as trocas de material e as relações interdependentes entre a sociedade humana e a natureza. (Fischer-Kowalski, 1998; Martinez-Alier, 1987; Wachsmuth, 2012).Foi nesse sentido que o uso da expressão por Marx de "metabolism entre homem e terra"se referia especificamente dos ciclos de 
A partir deste conceito inicial de MU, lembrando do contexto do séc. XIX de crescente urbanização e industrialização em que Marx vivenciava, ele acreditava que o crescente deslocamento de populações do campo às cidades levaria a uma "ruptura metabólica" em que seria reduzida a interação entre a humanidade e a terra. O que seria um processo cíclico de fertilização da terra com resíduos humanos e animais, seria então quebrado pela urbanização.

A primeira publicação que aplica o conceito para modelar os fluxos de uma cidade foi somente em 1965, por Abel Wolman ${ }^{12}$. Ele utilizou o MU como método para analisar a quantificação de materiais e energia de entrada - água, energia, combustível, comida e saída - esgoto, resíduos e poluição. Interessante notar a dimensão doméstica abordada nesta simples frase, que traz o aspecto social desses processos de transformação.

Conforme revisão cronológica (ver Quadro 2) produzido por (KENNEDY, PINCETL e BUNJE, 2011), verificamos que a maior parte dos estudos ainda são a respeito de materiais e energia, sendo que apenas a partir de 1999, há contribuições a respeito de habitabilidade (liveability measures).

Quadro 2 - Revisão cronológica de Metabolismo urbano

\begin{tabular}{|l|l|l|}
\hline Autor (ano) & Cidade ou região de estudo & Notas/Contribuições \\
\hline Wolman (1965) & $\begin{array}{l}\text { Cidade hipotética de 1 milhão de } \\
\text { habitantes nos EUA }\end{array}$ & Estudo seminal \\
\hline Zucchetto (1975) & Miami & Abordagem energética \\
\hline Stanhill (1977); Odum (1983) & 1850 s Paris & Abordagem energética \\
\hline Hanya e Ambe (1976). & Toquio & $\begin{array}{l}\text { Inclusão de balanço de energia } \\
\text { natural }\end{array}$ \\
\hline $\begin{array}{l}\text { Duvigneaud e Denayeyer-De } \\
\text { Smet (1977) }\end{array}$ & Bruxelas & \\
\hline
\end{tabular}

Continua

nutrientes das plantas em termos de condições de fertilidade, sistemas de produção agrícola e urbanização (Martínez- Alier, 1987: 220-221)" (tradução nossa)

12 "Wolman defined metabolic needs as "all the materials and commodities needed to sustain the city's inhabitants at home, at work and at play" (Wolman, 1965:179; Decker et al., 2000; Kennedy et al., 2007)". (DINARÈS, 2014, p. 556)

"Wolman definiu necessidades metabólicas como "todos os materiais e insumos necessários para sustentar os habitantes da cidade em casa, trabalho e diversão." (Wolman, 1965:179; Decker et al., 2000; Kennedy et al., 2007). " (tradução nossa) 
continuação

\begin{tabular}{|c|c|c|}
\hline Autor (ano) & Cidade ou região de estudo & Notas/Contribuições \\
\hline $\begin{array}{l}\text { Newcombe et al. } \\
\text { (1978); Boyden et al. } \\
\text { (1981) }\end{array}$ & Hong Kong & $\begin{array}{l}\text { Estudo metabólico } \\
\text { particularmente abrangente }\end{array}$ \\
\hline Girardet (1992) & & $\begin{array}{l}\text { Reconhecida conexão com o } \\
\text { desenvolvimento sustentável } \\
\text { das cidades }\end{array}$ \\
\hline Bohle (1994) & & $\begin{array}{l}\text { Criticou perspectiva do } \\
\text { metabolismo para estudos sobre } \\
\text { alimentação em cidades em } \\
\text { desenvolvimento }\end{array}$ \\
\hline $\begin{array}{l}\text { European } \\
\text { Environment Agency } \\
\text { (1995) }\end{array}$ & Praga (estudo metabólico amplo) & $\begin{array}{l}\text { Dados do uso de energia para } \\
\text { Barcelona e outras sete cidades } \\
\text { europeias dados no relatório }\end{array}$ \\
\hline Nilson (1995) & Gävle, Suécia & Orçamento de fósforo \\
\hline Baccini (1997) & Planície suíça & \\
\hline Huang (1998) & Taipei & Abordagem energética \\
\hline $\begin{array}{l}\text { Newman (1999); } \\
\text { Newman et al. (1996) }\end{array}$ & Sydney & $\begin{array}{l}\text { Adiciona medidas de } \\
\text { habitabilidade }\end{array}$ \\
\hline Stimson et al. (1999) & Brisbane \& Sudeste de Queensland & $\begin{array}{l}\text { Estrutura relacionando } \\
\text { metabolism urbano à qualidade } \\
\text { de vida }\end{array}$ \\
\hline $\begin{array}{l}\text { Hermanowicz e } \\
\text { Asano (1999) }\end{array}$ & & Água \\
\hline Hendriks et al. (2000). & Vienna \& Planície suíça & \\
\hline $\begin{array}{l}\text { Warren-Rhodes e } \\
\text { Koenig (2001). }\end{array}$ & Hong Kong & \\
\hline Baker et al. (2001) & Phoenix \& Central Arizona & Balanço de nitrogenio \\
\hline Sörme et al. (2001) & Stockholm & Metais pesados \\
\hline $\begin{array}{l}\text { Svidén e Jonsson } \\
\text { (2001) }\end{array}$ & Stockholm & Mercúrio \\
\hline $\begin{array}{l}\text { Obernosterer e } \\
\text { Brunner (2001) }\end{array}$ & Vienna & Chumbo \\
\hline Færge et al. (2001) & Bangkok & Nitrogenio e fósforo \\
\hline
\end{tabular}

Continua 


\begin{tabular}{|c|c|c|}
\hline Autor (ano) & Cidade ou região de estudo & Notas/Contribuições \\
\hline $\begin{array}{l}\text { Chartered Institute of } \\
\text { Wastes Management } \\
\text { (2002) }\end{array}$ & London & \\
\hline Gasson (2002) & Cidade do Cabo & \\
\hline Barrett et al. (2002) & York, Reino Unido & Materiais \\
\hline Obernosterer (2002) & & Metais \\
\hline Sahely et al. (2003). & Toronto & \\
\hline $\begin{array}{l}\text { Emmenegger et al. } \\
(2003)\end{array}$ & Geneva & \\
\hline Burstrom et al. (2003) & Stockholm & Nitrogenio e fósfoto \\
\hline Gandy (2004) & & Água \\
\hline $\begin{array}{l}\text { Lennox e Turner } \\
\text { (2004) }\end{array}$ & & $\begin{array}{l}\text { Relatório de estado do meio } \\
\text { ambiente }\end{array}$ \\
\hline $\begin{array}{l}\text { Hammer e Giljum } \\
(2006)\end{array}$ & Hamburgo, Viena e Leipzig & Materiais \\
\hline Kennedy et al. (2007) & & $\begin{array}{l}\text { Revisão do metabolismo em } \\
\text { mudança }\end{array}$ \\
\hline Schulz (2007) & Singapura & Materiais \\
\hline Barles (2007a) & Paris & $\begin{array}{l}\text { Estudo histórico do nitrogênio } \\
\text { no metabolismo alimentar }\end{array}$ \\
\hline Forkes (2007) & Toronto & $\begin{array}{l}\text { Nitrogênio no metabolismo } \\
\text { alimentar }\end{array}$ \\
\hline Zhang e Yang (2007) & Shenzhen, China & $\begin{array}{l}\text { Desenvolve medições de eco- } \\
\text { eficiencia }\end{array}$ \\
\hline Ngo e Pataki (2008) & Los Angeles & \\
\hline Chrysoulakis (2008) & & $\begin{array}{l}\text { Novo projeto sob o sétimo } \\
\text { quadro de ações da União } \\
\text { Européia. }\end{array}$ \\
\hline $\begin{array}{l}\text { Schremmer e Stead } \\
(2009)\end{array}$ & & $\begin{array}{l}\text { Novo projeto sob o sétimo } \\
\text { quadro de ações da União } \\
\text { Européia. }\end{array}$ \\
\hline Barles $(2009,2007 b)$ & Paris & $\begin{array}{l}\text { Análise do centro, subúrbios e } \\
\text { região. }\end{array}$ \\
\hline Zhang et al. (2009) & Beijing & Abordagem energética \\
\hline Niza et al. (2009) & Lisboa & Materiais \\
\hline Deilmann (2009) & & $\begin{array}{l}\text { Estuda a relação entre } \\
\text { metabolismo e superfície urbana }\end{array}$ \\
\hline Baker et al. (2001) & & Água \\
\hline $\begin{array}{l}\text { Thériault e Laroche } \\
\text { (2009) }\end{array}$ & Greater Moncton, New Brunswick & Água \\
\hline Browne et al. (2009) & Limerick, Irlanda & $\begin{array}{l}\text { Desenvolve medições de } \\
\text { eficiência metabólica }\end{array}$ \\
\hline
\end{tabular}

Fonte: (KENNEDY, PINCETL e BUNJE, 2011) 
Os estudos metabólicos, portanto, começam ampliar as abordagens de seus estudos, incluindo indicadores de qualidade de vida ${ }^{13}$ à balanço de elementos específicos, como o nitrogênio. Estas revisões bibliográficas demonstram a variedade de estudos gerados pelo conceito de MU e como eles podem subsidiar importantes políticas públicas não só relacionados ao meio ambiente, mas também à economia e bem-estar dos habitantes das cidades.

Os estudos de MU têm que estabelecer a fronteira do sistema a ser analisado, pois é nesta delimitação que indica os fluxos de entrada e saída, lembrando que mesmo dentro de um sistema é possível desenhar sub fluxos de entrada e saída e sub fluxos dentro destes, aí por diante.

Os fluxos de energia e material são comumente classificados como lineares ou circulares (ZHANG, 2013) (KARVOUNIS, 2015), sendo lineares os sistemas em que os elementos de entrada (inputs) são consumidos ou transformados dentro da cidade e produzem como resultado (outputs) produtos e resíduos. Resíduos e rejeitos são retirados desse sistema, que neste caso é a cidade, e são levados para tratamento ou destinação em outro lugar. Se entendermos o planeta como um grande organismo, é inviável esses fluxos não sejam otimizados, pois não há “externo" ao sistema, de uma forma ou outra o impacto desse "catabolismo" será sentido em todo o organismo.

Por outro lado, os sistemas cíclicos buscam inverter os fluxos de energia e material para que produtos voltem para o sistema urbano para novas transformações. Nessa concepção estão programas como zero waste cities e outros que objetivam reduzir ou zerar o impacto de suas atividades no meio ambiente. Esses movimentos se baseiam na ideia de tentar se aproximar aos sistemas da natureza, igualmente cíclicos.

Os fluxos cíclicos são os desejáveis ${ }^{14}$, porém é preciso ressaltar que dentre os resíduos há também rejeitos, que por suas características físico-químicas ou de fonte

\footnotetext{
13 "He [Newman, P.W.G., 1999.] proposed an extended metabolism model, which included indicators of health, employment, income, education, housing, leisure and community activities." (KENNEDY, PINCETL e BUNJE, 2011)
}

Ele [Newman, P.W.G., 1999.] propos um modelo de extendido de metabolism, que inclui indicadores de saúde, emprego, renda, educação, habitação, lazer e atividades comunitárias. (tradução nossa)

14 "Concluding, most present day cities are based on unsustainable cycles that are open and imbalanced between inputs and outputs, with a relation between inputs and outputs that tends to be linear. In contrast, natural systems have a cyclical course of flows. Cities' goals are to concentrate attention on a decrease of inputs, or effective reuse and recycling of waste. Linearity of urban flow systems have to be brought to an end and need to be replaced by a cyclical course." (KARVOUNIS, 2015, p. 23)

Concluindo, muitas cidades atuais são baseadas em ciclos insustentáveis que são abertos e desequilibrados entre entradas e saidas, com uma relação entre entradas e saídas que tende a ser linear. Em contraste, sistemas naturais tem um fluxo cíclico. A meta das cidades é de concentrar atenção em diminuir entradas, 
geradora não podem voltar a ser utilizadas, como é o caso de resíduos de serviço de saúde. Esta pequena parcela de resíduos indica uma nova fronteira de pesquisas que permitam a reintrodução de materiais considerados perigosos ou contaminantes nas cadeias de produção e transformação, sem afetar a saúde ambiental.

Por fim, verifica-se também diferentes metodologias (ver Quadro 3 ) para a análise desses processos metabólicos podendo ter enfoque em materiais, energia, ciclo de vida, entre outros, conforme revisão bibliográfica de (KARVOUNIS, 2015, p. 565) ${ }^{15}$ :

Quadro 3 - Métodos de análise de processos $M U$

\begin{tabular}{|l|l|}
\hline Autor & Método \\
\hline $\begin{array}{l}\text { Brunner and Rechberger, 2004; Niza et } \\
\text { al., 2009; Zhang et al, 2013 }\end{array}$ & Material Flow Analysis -MFA \\
\hline Antikainen et al., 2005 & Substance Flow Analysis -SFA \\
\hline Liang et al., 2012 & $\begin{array}{l}\text { Input-Output analysis (and PIOT-physical input-output } \\
\text { tables) }\end{array}$ \\
\hline Huang et Hsu, 2003; Liu et al., 2011 & eMergy (energy flow) \\
\hline Holden, 2004; Muñiz and Galindo, 2005 & \begin{tabular}{l} 
Ecological footprint analysis \\
\hline (Li et al., 2012)
\end{tabular} \\
\hline D'Alisa et al., 2012 & Ecological network analysis \\
\hline Chester et al, 2012 & $\begin{array}{l}\text { MuSEM (Multi-Scale Integrated Analysis of Societal } \\
\text { and Ecosystem Metabolism) }\end{array}$ \\
\hline
\end{tabular}

Fonte: Adaptado de (KARVOUNIS, 2015, p. 565)

Nota: nesta pesquisa utiliza-se o método MFA

Dentre as metodologias de referência, o MFA (Material Flow Analysis) se mostrou aderente à proposta da pesquisa, considerando o procedimento metodológico envolve a simples comparação entre entradas, estoques e saídas de um processo ou sistema, sendo

ou reuso efetivo e reciclagem de resíduos. A linearidade de sistemas de fluxo urbano tem que ser levada a um fim e precisam ser substituídas por um cíclico. (tradução nossa)

15 "Different methodological approaches are used to account for and analyse urban metabolic processes (Barles, 2010). The studies of Daniels (2002), Daniels and Moore (2002), Hammer et al. (2003), Loiseau et al. (2012), Huang et al. (2012) and Zhang (2013), provide a comprehensive review and a classification of both research methodologies and UM studies conducted through these different methods. Material Flow Analysis -MFA- (Brunner and Rechberger, 2004; Niza et al., 2009; Zhang et al, 2013), Substance Flow Analysis -SFA-(Antikainen et al., 2005), Input-Output analysis (and PIOT-physical input-output tables) (Liang et al., 2012), eMergy (energy flow) analysis (Huang et Hsu, 2003; Liu et al., 2011); Ecological footprint analysis (Holden, 2004; Muñiz and Galindo, 2005), Ecological network analysis (Li et al., 2012), MuSIASEM (Multi-Scale Integrated Analysis of Societal and Ecosystem Metabolism) (D'Alisa et al., 2012) and LCA -Life Cycle Analysis- (Chester et al, 2012), are among the main tools used to conduct physical environmental accounting, based on the study, in variable depths, of material and energy flows (Eurostat, 2001; Loiseau et al., 2012). (KARVOUNIS, 2015, p. 565)" 
uma metodologia utilizada para gerir recursos, realizar gerenciamento de resíduos sólidos e gerenciamento ambiental. (BRUNNER e RECHBERGER, 2005) ${ }^{16}$

O exemplo da (Figura 2) demonstra as premissas da metodologia uma vez que a soma de entradas (import) é igual a uma parte do estoque mais o total de saídas (export). Esses diagramas permitem verificar, como se fosse um diagnóstico, os fluxos existentes e a dimensão de seus estoques, entradas e saídas.

\footnotetext{
16 "Because of the law of the conservation of matter, the results of an MFA can be controlled by a simple material balance comparing all inputs, stocks, and outputs of a process. It is this distinct characteristic of MFA that makes the method attractive as a decision-support tool in resource management, waste management, and environmental management." (BRUNNER e RECHBERGER, 2005)

Pela lei da conservação de matéria, os resultados de um MFA podem ser controlados por uma simples comparação entre todas as entradas, estoques e saídas de um processo. É essa característica do MFA que torna o método atrativo como ferramenta de apoio a decisões em gerenciamento de recursos, gerenciamento de resíduos e gerenciamento ambiental (tradução nossa)
} 
Figura 2 - MFA fluxo de produtos plásticos na Áustria (1996)

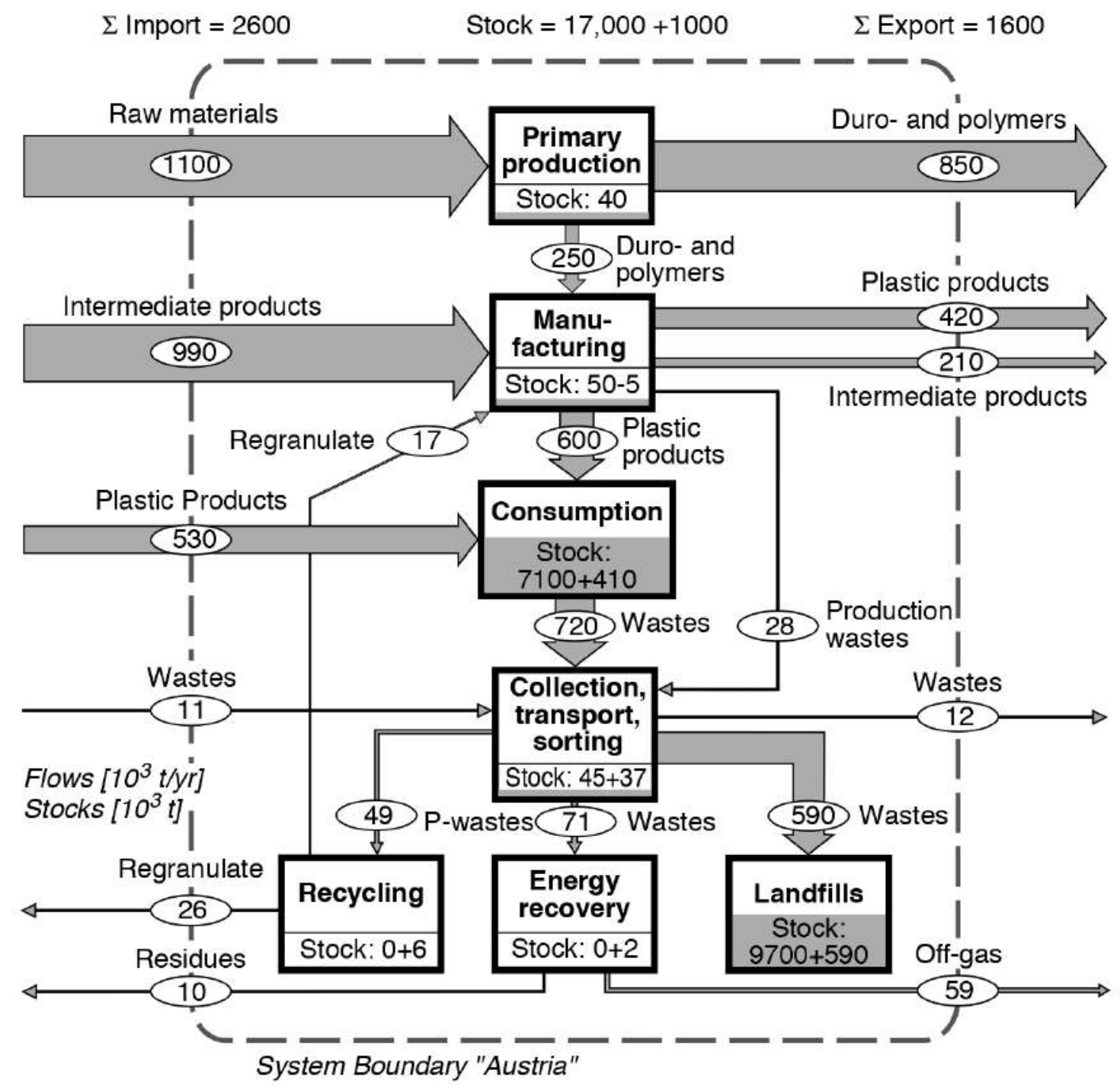

Fonte: (BRUNNER e RECHBERGER, 2005, p. 252)

\subsubsection{MFA (MATERIAL FLOW ANALYSIS)}

O método de Análise de Fluxo de Material, (MFA em inglês) é uma das metodologias aderentes à teoria do Metabolismo Urbano. Os objetivos deste método são investigar os fluxos e estoques de qualquer sistema baseado em materiais. (BRUNNER e RECHBERGER, 2005) ${ }^{17}$ :

17 "MFA is an appropriate tool to investigate the flows and stocks of any material-based system. It gives insight into the behavior of the system, and when combined with other disciplines such as energy-flow analysis, economic analysis, and consumer- oriented analysis, it facilitates the control of an anthropogenic system. The objectives of MFA are to:

1. Delineate a system of material flows and stocks by well-defined, uniform terms

2. Reduce the complexity of the system as far as possible while still guaranteeing a basis for sound decisionmaking

3. Assess the relevant flows and stocks in quantitative terms, thereby applying the balance principle and revealing sensitivities and uncertainties 
Esta ferramenta metodológica será utilizada com devidas adequações ao contexto do objeto de estudo, baseada nas orientações do livro Practical Handbook of Material Flow Analysis.

Os autores buscaram sugerir um glossário que pudesse basear outros estudos de MFA, embora reconheçam, que há uma verdadeira "Babel" no que se refere às expressões textuais utilizadas ao redor do mundo (BRUNNER e RECHBERGER, 2005, p. 35).

A expressão textual substância (substance) ${ }^{18}$ para os autores se refere à definição química, de elementos ou compostos que constituem um item, em outras palavras, uma substancia nesse entendimento consiste em elementos de partes idênticas. $\mathrm{O}$ exemplo dado é que madeira não é uma substancia, pois é composta por diferentes substancias tais como celulose, água, hidrogênio e outras.

4. Present results about flows and stocks of a system in a reproducible, understandable, and transparent way

5. Use the results as a basis for managing resources, the environment, and wastes, in particular for:

a. Early recognition of potentially harmful or beneficial accumulations and depletions of stocks, as well as for timely prediction of future environmental loadings

b. The setting of priorities regarding measures for environmental protection, resource conservation, and waste management (what is most important; what comes first?)

c. The design of goods, processes, and systems that promote environmen-tal protection, resource conservation, and waste management (green design, ecodesign, design for recycling, design for disposal, etc.)" (BRUNNER e RECHBERGER, 2005, p. 28)

MFA é uma ferramenta apropriada para investigar os fluxos e estoques de qualquer sistema baseado em materiais. Ele dá o conhecimento a respeito do comportamento do sistema, e quando combinando com outras disciplinas como a análise de fluxo de energia, análise econômica e análise direcionada ao consumidor, ela permite o controle de um sistema antropogênico. Os objetivos de um MFA são:

1. Delimitar um sistema de fluxos e estoques de material por termos uniformes e bem definidos.

2. Reduzir o quanto for possível a complexidade de um sistema, ao mesmo tempo em que se garante uma base para tomadas de decisão prudentes.

3. Avalia fluxos e estoques relevantes em termos quantitativos, para assim utilizar o princípio do balanço e revelar incertezas e sensibilidades.

4. Apresenta resultados sobre fluxos e estoques de um sistema de um modo reproduzível, entendível e transparente.

5. Usar os resultados como base para gerenciar recursos, o meio ambiente, os resíduos sólidos, em particular para:

a. Reconhecimento prévio de acumulações potencialmente danosas ou benéficas e esgotamento de estoques, assim como uma previsão oportuna de carregamentos ambientais futuros.

b. A definição de prioridades considerando medidas para proteção ambiental, conservação de recursos, e gerenciamento de resíduos (o que é mais importante; o que vem primeiro?)

c. O desenho de bens, processos, e sistemas que promovam a proteção ambiental, a conservação de recursos e o gerenciamento de resíduos (design verde, ecodesign, design para reciclagem, design para descarte, etc.) (tradução nossa)

18 "MFA relies on the term substance as defined by chemical science. A substance is any (chemical) element or compound composed of uniform units. All substances are characterized by a unique and identical constitution and are thus homogeneous." (BRUNNER e RECHBERGER, 2005) 
A expressão textual bens $(\mathrm{good})^{19}$ são entidades econômicas físicas com valores positivos ou negativos. Produtos são constituídos de várias substancias.

A expressão textual material (material) ${ }^{20}$ nesta metodologia, genericamente se refere tanto a substancia quanto bens.

Processo (process) ${ }^{21}$ é definido como a transformação, transporte ou estoque de materiais. Em geral, os processos são definidos como "caixas pretas", ou seja, processos dentro de um processo (subprocessos) não são levados em conta, apenas as entradas e saídas de material.

Movimentação e fluxo (flow and flux ${ }^{22}$ ) tem sentidos próximos, mas a movimentação (flow) seria definida pela taxa de movimentação de massa, em razão do tempo, de modo a ter como unidade $\mathrm{kg} / \mathrm{seg}$, to-no e outros. Já o fluxo é definido como movimentação por seção transversal, de modo a ter como unidade, por exemplo, $\mathrm{kg} /\left(\operatorname{seg}^{*} \mathrm{~m}^{2}\right)$. No MFA seções transversais podem ser uma pessoa, a área de um sistema ou uma instituição.

Sistema e fronteira do sistema (system and system boundaries) ${ }^{23}$ são definidos como um grupo de elementos, que interagem entre esses elementos, e as fronteiras entre esses elementos tanto no tempo quanto no espaço. Para os autores existem dois tipos de sistema, um fechado e um aberto. Um sistema aberto interage com seu entorno, com trocas de energia e matéria. Um fechado, por outro lado, é concebido para ser isolado, evitando trocas através de suas fronteiras. Os sistemas são compostos por um ou mais processos.

Em um diagrama de MFA, estes elementos podem ser traduzidos em símbolos (ver Figura 3), a padronização sugerida auxilia na melhor compreensão e comunicação quando se trata de estudos metabólicos de diferentes sistemas.

19 "Goods are defined as economic entities of matter with a positive or negative economic value. Goods are made up of one or several substances." (BRUNNER e RECHBERGER, 2005, p. 36)

20 "MFA material serves as an umbrella term for both substances and goods. So carbon as well as wood can be addressed as a material.”(BRUNNER e RECHBERGER, 2005, p. 37).

21 "Usually, processes are defined as black box processes, meaning that processes within the box are not taken into account. Only the inputs and the outputs are of interest "(BRUNNER e RECHBERGER, 2005, p. 38)

${ }^{22}$ In MFA, commonly used cross sections are a person, the surface area of the system, or an entity such as a private household or an enterprise (BRUNNER e RECHBERGER, 2005, p. 39)

${ }^{23}$ In MFA, the physical components are processes, and the connections/relations are given by the flows that link the processes. A single process or a combination of several processes can represent a system. (BRUNNER e RECHBERGER, 2005, p. 43) 
Figura 3 - Principais símbolos usados em diagramas de MFA

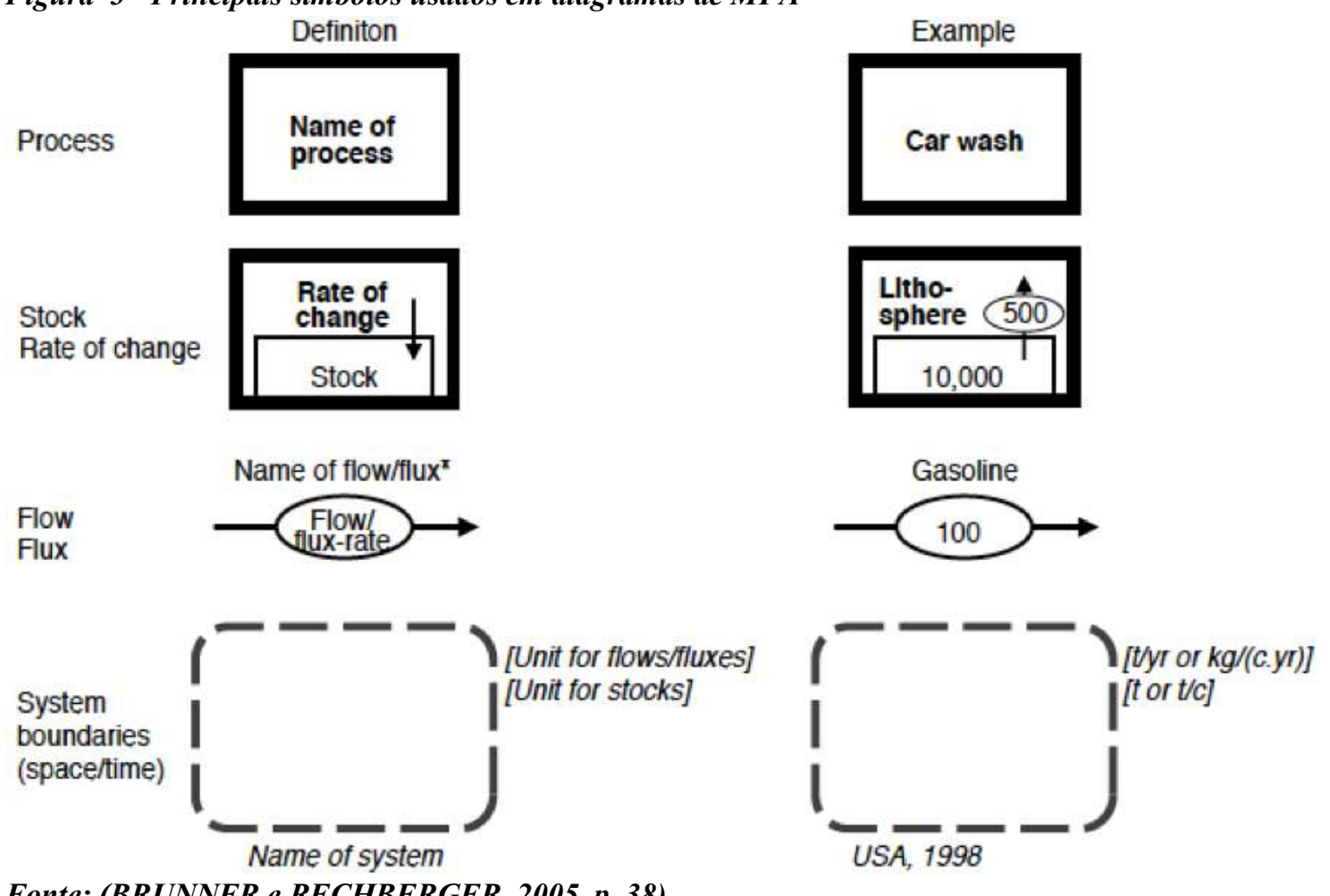

Fonte: (BRUNNER e RECHBERGER, 2005, p. 38)

Um guia prático do uso do MFA para resíduos sólidos urbanos foi publicado pela Resource Management Agency (RMA) (VILLENEUVE, MICHEL, et al., 2004) com passo-a-passo para utilizar o método. A primeira delas é identificar uma atividade para ser "nutrida", com o problema e o seu objetivo ${ }^{24}$ para então elaborar questões ${ }^{25}$ que indicam ações a serem tomadas.

A segunda etapa, resumidamente, envolve definir o "sistema" e suas fronteiras. O desenho desse sistema envolve a identificação de processos, bens, substancias e suas conexões, o espaço (que não precisa ser contínuo) e tempo (em geral um ano), subsistemas (se houver) e seleção de substancias para investigar. Um dos fatores que

\footnotetext{
24 "The problem: Quantifying the resource consumption and the waste yield caused by the activity "to nourish".

The goal: Assessment from the waste management viewpoint and elaboration of suggestions for measures to improve the activity in the private households." (VILLENEUVE, MICHEL, et al., 2004, p. 20)

25 " 1 . Which goods and processes are the crucial ones for describing the activity "to nourish"?

2. Which substances can be used as indicators for this activity?

3. How high are the goods and substance flows for the most important goods?

4. What is the significance of such "Hows" for the environment and for the conservation of resources?

5. Which measures can mostly contribute to a significant waste yield reduction?" (VILLENEUVE, MICHEL, et al., 2004, p. 21)
} 
influencia esse desenho é a disponibilidade de dados. Dentro dele, o princípio físico que impera é a da conservação de massa e energia.

O guia recomenda que seja feito um recorte mais generalista dos processos, que podem ser de transformação, transporte, estoque ou mudança de valor, pois dessa forma se percebe de forma mais clara as ligações entre o sistema e o meio ambiente ${ }^{26}$.

Essa simplificação do sistema, utilizando os fluxos de substancias e produtos principais, é utilizada para realizar um "balanço grosseiro" (rough balance), ou seja, conforme as leis de conservação de massa, a soma das entradas deve ser igual a soma das saídas mais a diferença de estoque.

Com esses fluxos definidos, pode-se aplicar uma análise de sensibilidade, ou seja, considerando o desenho do sistema praticamente completo, verificar em quais alterações de parâmetros causam mais mudanças nas variáveis do sistema. Esta análise interativa do sistema pode direcionar para uma optimização do sistema. Baseado nos resultados dessa análise é possível fazer um planejamento do programa de pesquisa, indicando caminhos para próximos estudos.

Com os dados disponíveis da atual pesquisa, pode-se calcular os fluxos de bens e materiais. Nesta etapa também há o enquadramento e calibragem dos dados. Enquadramento é traduzir o dado bruto em fluxos de entrada e saída. A calibragem é feita comparando os fluxos de entrada e saída onde tenha havia mudança de estoque, e caso o balanço não funcione (dentro da precisão de mais ou menos $20 \%$ ), pode ser feito novo teste de dados, ou até mesmo uma nova coleta.

Dentro do sistema, é possível que um bem ou substancia seja distribuída dentro de um processo em vários produtos, daí é necessário calcular e desenhar as funções de transferência (ver Figura 4). Com essa função, se encerram os procedimentos do MFA e pode-se propor a visualização e interpretação do estudo.

\footnotetext{
26 "This approach has three positive results: a sound understanding of the particular role of the investigated system, a discussion base for a prospective extension or reduction of the current system, and eventually, suggests further research issues for action measures." (VILLENEUVE, MICHEL, et al., 2004, p. 23)
} 


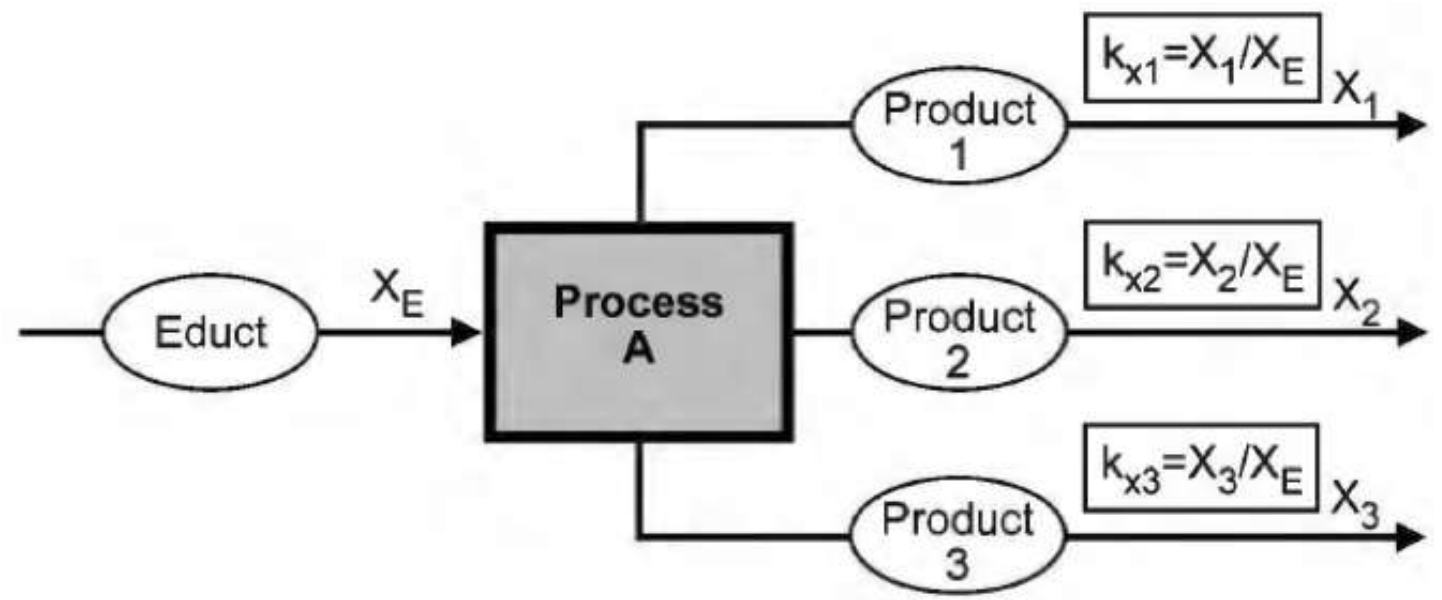

Fonte: (VILLENEUVE, MICHEL, et al., 2004, p. 32)

A visualização de um sistema (ver Figura 5) envolve os símbolos de bens, processos, fluxos e fronteiras do sistema, com valores das funções de transferência, que de maneira geral, podem ser resumidas nos valores totais de importação e exportação do sistema.

Figura 5 - visualização de sistema

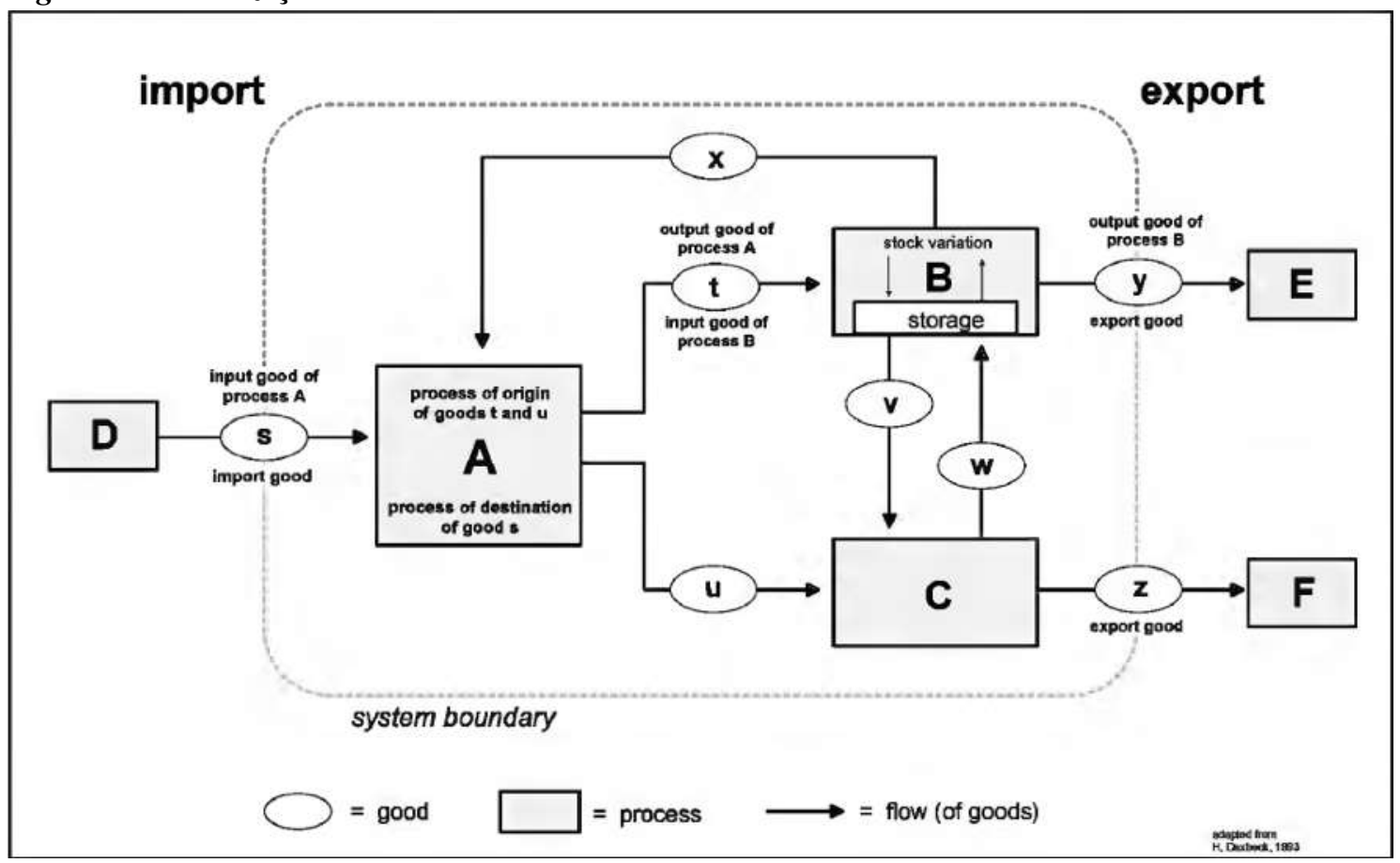

Fonte: (VILLENEUVE, MICHEL, et al., 2004, p. 27)

O resumo destas etapas, com seus fatores e resultados estão compilados no Quadro 4, conforme segue: 
Quadro 4 - Resumo das etapas de formulação de MFA

\begin{tabular}{|l|l|l|}
\hline Etapas & Fatores & Resultado \\
\hline a. Definir problema e objetivo & Conceito & Questões \\
\hline b. Definir o sistema & Dados disponíveis & Desenho de sistema \\
\hline $\begin{array}{l}\text { c. Selecionar e definir os } \\
\text { processos }\end{array}$ & Atividade & Desenho de processos \\
\hline d. Selecionar substancias & Objetivo & Indicadores \\
\hline e. “balanço grosseiro" & Pontos principais & Visão geral \\
\hline $\begin{array}{l}\text { f. Analise de sensibilidade } \\
\text { g. Planejamento da pesquisa }\end{array}$ & Parâmetros & $\begin{array}{l}\text { Quais parâmetros são mais } \\
\text { relevantes no sistema }\end{array}$ \\
\hline $\begin{array}{l}\text { h. Calculo dos fluxos de } \\
\text { material }\end{array}$ & Dados da analise de & $\begin{array}{l}\text { Indicações para próximos } \\
\text { estudos }\end{array}$ \\
\hline $\begin{array}{l}\text { i. Calculo da função de } \\
\text { transferência e coeficientes de } \\
\text { transferência }\end{array}$ & Fluxos & Balanço \\
\hline j. Apresentação dos resultados & Desenho do sistema & Função de transferência \\
\hline
\end{tabular}

Fonte: Adaptado de (VILLENEUVE, MICHEL, et al., 2004)

Embora estas recomendações tenham sido feitas para serem executadas municipalidades da União Europeia, algumas das limitações ${ }^{27}$ são comuns a contextos como o do município de São Paulo, como limitação de tempo e orçamento, assim como falta de dados à disposição.

Concluindo, as etapas de um plano de trabalho de MFA geram produtos que podem ser utilizados para análises diversas, como dimensionar estoques, verificar fluxos mais efetivos de intervenção, visualizações de um sistema complexo e recomendações para futuros estudos.

\footnotetext{
${ }^{27}$ The methodical approach for the construction of a MFA is divided into several work steps. The approach is not linear, the progress of each working step is iterative, i.e. it is being made by applying the knowledge gained in the rough balance (sub-step 3) or by practical limitations (e.g. time and finance budgets, data availability and plausibility). (VILLENEUVE, MICHEL, et al., 2004, p. 20)
} 


\subsubsection{RESÍDUOS SÓLIDOS}

A expressão "resíduo sólido" mencionado em leis, normas e pesquisas tem seu uso consolidado no Brasil. Porém, apesar de "sólido", a norma técnica brasileira considera também estado semissólido e alguns resíduos líquidos, conforme afirma a Profa. Dra. Wanda Gunther na sua tese de livre-docência:

(...) a definição brasileira para resíduos sólidos, dada em norma técnica nacional inclui, além daqueles no estado sólido e semi-sólido, também alguns resíduos líquidos com particularidades definidas (ABNT,2004). Essa norma inclui a categoria dos resíduos hospitalares, mas esquece os resíduos da construção e demolição. Na ausência de uma politica nacional para a questão, e considerando-se a Política Estadual de Resíduos Sólidos do Estado de São Paulo, depara-se com a seguinte definição: resíduos sólidos são os materiais decorrentes de atividades humanas em sociedade, e que se apresentam nos estados sólido ou semisólido, como líquidos não passiveis de tratamento de efluentes, ou ainda os gases contidos (GÜNTHER, 2008, p. 17)

Nesta revisão bibliográfica foram explorados os conceitos de "classificação" e “diagnóstico" de resíduos sólidos, pois nos resultados destes estudos é possível verificar interfaces buscadas no objetivo da pesquisa.

\subsubsection{CLASSIFICAÇÃO DE RESÍDUOS SÓLIDOS}

Uma classificação é uma ação de organizar itens em classes ou categorias conforme critérios, que no caso de resíduos sólidos podem ser dados por normas de diversos órgãos, uma vez que não há uma classificação universal.

Como esta classificação influencia os fluxos dos resíduos sólidos, esta é uma etapa que deveria ser feita adequadamente, no entanto, na prática, depende de recursos humanos e orçamentários que nem sempre estão disponíveis.

Na Política Nacional de Resíduos Sólidos (PNRS) se classifica os resíduos sólidos por origem, para assim, definir as responsabilidades relativas ao gerenciamento (ver Quadro 5). A origem já indica as atividades exercidas no local de geração. Segundo o levantamento de (SANTOS, 2015): 
Quadro 5 - Resumo da classificação PNRS

\begin{tabular}{|l|l|}
\hline Classificação PNRS & Responsabilidade \\
\hline Urbano & Município \\
\hline Industriais & \\
\hline Serviços de saúde & \\
\hline Construção civil & \multirow{2}{*}{ Gerador } \\
\hline Serviços de transportes & \\
\hline Resíduos sólidos de mineração & \\
\hline $\begin{array}{l}\text { Agrotóxicos e embalagens, pilhas e baterias; } \\
\text { pneus; óleos lubrificantes; embalagens; } \\
\text { lâmpadas fluorescentes, de vapor de sódio e } \\
\text { mercúrio e de luz mista e produtos } \\
\text { eletroeletrônicos e seus componentes }\end{array}$ & \\
\hline
\end{tabular}

Fonte: Adaptado de (SANTOS, 2015, p. 32)

A Associação Brasileira de Normas Técnicas (ABNT), classifica os resíduos sólidos pelo critério da periculosidade. São duas classes (ver Quadro 6), a de perigosos (classe I) e não perigosos (classe II). Deste último, temos a subdivisão em classe II A não perigosos e não inertes e II B - não perigosos e inertes.

Os resíduos classe I - perigosos são assim classificados caso tenham qualquer uma das características: inflamabilidade, corrosividade, reatividade, toxicidade ou patogenicidade.

Os resíduos de classe II - não perigosos, serão classificados como II $\mathrm{A}^{28}$ - Não inerte conforme suas características como biodegradabilidade, combustibilidade ou solubilidade em água. Ou como II $\mathrm{B}^{29}$ - inertes.

Quadro 6 - Resumo da classificação NBR 10004

\begin{tabular}{|l|l|}
\hline Classificação (NBR 10004) & Características \\
\hline Classe I - Perigoso & $\begin{array}{l}\text { inflamabilidade, corrosividade, reatividade, toxicidade ou } \\
\text { patogenicidade }\end{array}$ \\
\hline $\begin{array}{l}\text { Classe II A - Não perigoso, não } \\
\text { inerte }\end{array}$ & biodegradabilidade, combustibilidade ou solubilidade em água \\
\hline $\begin{array}{l}\text { Classe II B - Não perigoso, } \\
\text { inerte }\end{array}$ & Não apresenta solubilidade nos termos da norma. \\
\hline
\end{tabular}

Fonte: (ABNT, 2004)

\footnotetext{
28 “Aqueles que não se enquadram nas classificações de resíduos classe I - Perigosos ou de resíduos classe II B - Inertes, nos termos desta Norma. Os resíduos classe II A - Não inertes podem ter propriedades, tais como: biodegradabilidade, combustibilidade ou solubilidade em água.” (ABNT, 2004)

29 [resíduos]submetidos a um contato dinâmico e estático com água destilada ou desionizada, à temperatura ambiente, conforme ABNT NBR 10006, não tiverem nenhum de seus constituintes solubilizados a concentrações superiores aos padrões de potabilidade de água, excetuando-se aspecto, cor, turbidez, dureza e sabor, conforme anexo G. (ABNT, 2004)
} 
A depender da atividade do gerador, outras normas podem ser aplicadas, como é o caso do objeto de estudo, o Campus São Paulo da Universidade Federal de São Paulo. Por ser um gerador de resíduos de serviço de saúde (RSS), a principal classificação deve ser a adotada pela Resolução da Diretoria Colegiada (RDC) no 222 da Agencia Nacional de Vigilância Sanitária (ANVISA), conforme descrito:

Art. $2^{\circ}$ Esta Resolução se aplica aos geradores de resíduos de serviços de saúde- RSS cujas atividades envolvam qualquer etapa do gerenciamento dos RSS, sejam eles públicos e privados, filantrópicos, civis ou militares, incluindo aqueles que exercem ações de ensino e pesquisa. (ANVISA, 2018)

Para esta revisão bibliográfica já se adota a classificação da RDC 222, que substituiu no final de 2018, a RDC 306 da ANVISA de 2004 e Resolução do Conselho Nacional de Meio Ambiente (CONAMA) 358 de 2005.

A classificação de $\operatorname{RSS}^{30}$ de acordo com essa resolução, separa em cinco categorias conforme características dos resíduos. Ver Quadro 7 a seguir:

Quadro 7 - Resumo da classificação de RSS - RDC 222

\begin{tabular}{|c|c|}
\hline Classificação (RDC 222) & Características \\
\hline Grupo A & $\begin{array}{l}\text { Possível presença de agentes biológicos; risco de } \\
\text { infecção }\end{array}$ \\
\hline Grupo B & $\begin{array}{l}\text { Contém produtos químicos que podem trazer } \\
\text { dano à saúde pública ou ambiental }\end{array}$ \\
\hline Grupo C & Contém rejeitos radioativos \\
\hline Grupo D & $\begin{array}{l}\text { Contém resíduos que podem ser equiparados a } \\
\text { resíduos domiciliares por não trazer risco à saúde } \\
\text { pública ou ambiental }\end{array}$ \\
\hline Grupo E & Resíduos perfurocortantes ou escarificantes \\
\hline
\end{tabular}

Fonte: (ANVISA, 2018)

\footnotetext{
${ }^{30}$ LIV. resíduos de serviços de saúde do Grupo A: resíduos com a possível presença de agentes biológicos que, por suas características, podem apresentar risco de infecção, elencados no Anexo I desta Resolução; LV. resíduos de serviços de saúde do Grupo B: resíduos contendo produtos químicos que podem apresentar risco à saúde pública ou ao meio ambiente, dependendo de suas características de inflamabilidade, corrosividade, reatividade e toxicidade, elencados no Anexo I desta Resolução;

LVI. resíduos de serviços de saúde do Grupo C: rejeitos radioativos, elencados no Anexo I desta Resolução; LVII. resíduos de serviços de saúde do Grupo D: resíduos que não apresentam risco biológico, químico ou radiológico à saúde ou ao meio ambiente, podendo ser equiparados aos resíduos domiciliares, elencados no Anexo I desta Resolução;

LVIII. resíduos de serviços de saúde do Grupo E: resíduos perfurocortantes ou escarificantes, tais como: lâminas de barbear, agulhas, escalpes, ampolas de vidro, brocas, limas endodônticas, fios ortodônticos cortados, próteses bucais metálicas inutilizadas, pontas diamantadas, lâminas de bisturi, lancetas, tubos capilares, micropipetas, lâminas e lamínulas, espátulas e todos os utensílios de vidro quebrados no laboratório (pipetas, tubos de coleta sanguínea e placas de Petri), elencados no Anexo I desta Resolução; (ANVISA, 2018)
} 
Ainda relacionado a RSS, a Prefeitura de São Paulo classifica estabelecimentos geradores conforme porte e quantidade de geração potencial. Denominados de Estabelecimento Gerador de Resíduo de Serviço de Saúde (EGRS) são classificados por porte e por faixa de geração. Os Pequenos geradores recebem a classificação de EGRS especial de I a III, dependendo da geração de RSS, sendo até $5 \mathrm{~kg}, 5$ a $10 \mathrm{~kg}$ e 10 a $20 \mathrm{~kg}$ de geração potencial ao dia, respectivamente. Para os chamados grandes geradores, a classificação é EGRS 1 a 6, sendo as faixas estabelecidas também em ordem crescente: de 20 a $50 \mathrm{~kg} / \mathrm{dia}$, de 50 a $160 \mathrm{~kg} / \mathrm{dia}$, de 160 a $300 \mathrm{~kg} / \mathrm{dia}$, de 300 a 650kg/dia, 650 a $800 \mathrm{~kg} / \mathrm{dia}$ e acima de $800 \mathrm{~kg} / \mathrm{dia}$. Para cada faixa existe um valor de Taxa de Resíduos Sólidos de Serviços de Saúde (TRSS). Esta cobrança está prevista na Lei Municipal $\mathrm{N}^{\mathrm{o}}$ 13.478 de 30 de dezembro de 2002.

Ver Tabela 1 e Tabela 2 referentes aos valores por faixa de geração.

Tabela 1 - Valores de TRSS - pequenos geradores no Município de São Paulo, 2018

\begin{tabular}{l|l|l} 
Pequenos geradores de RSS & Faixa & \multicolumn{2}{l}{ Valor Mensal 2018 $^{\mathbf{3 1}}$} \\
\hline EGRS especial I & $0-5 \mathrm{Kg} / \mathrm{dia}$ & $\mathrm{R} \$ 52,58$ \\
\hline EGRS especial II & $5-10 \mathrm{Kg} / \mathrm{dia}$ & $\mathrm{R} \$ 70,10$ \\
\hline EGRS especial III & $10-20 \mathrm{Kg} / \mathrm{dia}$ & $\mathrm{R} \$ 105,16$
\end{tabular}

Fonte: Prefeitura de São Paulo, 2018

Tabela 2 - Valores de TRSS - grandes geradores no Município de São Paulo, 2018

\begin{tabular}{lll} 
Grandes geradores de RSS & Faixa & \multicolumn{1}{l}{ Valor Mensal 201832} \\
\hline EGRS 1 & $20-50 \mathrm{Kg} / \mathrm{dia}$ & $\mathrm{R} \$ 3.348,20$ \\
\hline EGRS 1 & $50-160 \mathrm{Kg} / \mathrm{dia}$ & $\mathrm{R} \$ 10.714,21$ \\
\hline EGRS 3 & $160-300 \mathrm{Kg} / \mathrm{dia}$ & $\mathrm{R} \$ 20.089,15$ \\
\hline EGRS 4 & $300-650 \mathrm{Kg} / \mathrm{dia}$ & $\mathrm{R} \$ 43.526,54$ \\
\hline EGRS 5 & $650-800 \mathrm{Kg} / \mathrm{dia}$ & $\mathrm{R} \$ 53.571,11$ \\
\hline EGRS 6 & $>800 \mathrm{~kg} / \mathrm{dia}$ & $\mathrm{R} \$ 80.358,01$
\end{tabular}

Fonte: Prefeitura de São Paulo, 2018

As classificações, como verificado, dependem de uma análise das características dos resíduos. Estas características tanto quantitativas quanto qualitativas irão subsidiar o diagnóstico da instituição geradora. 


\subsubsection{DIAGNÓSTICO DO GERENCIAMENTO DE RESÍDUOS SÓLIDOS}

Instituições que executam serviços de saúde, por exemplo, precisam realizar um Plano de Gerenciamento de Resíduos de Serviço de Saúde (PGRSS), o que complementaria o Plano de Gerenciamento de Resíduos Sólidos (PGRS), que também é obrigatório. Para o bom planejamento e elaboração destes planos é necessário que haja um diagnóstico da situação.

Segundo o Compromisso Empresarial para Reciclagem (CEMPRE), em seu manual para gerenciamento integrado, há uma série de informações que antecedem a formulação de um diagnóstico:

O diagnóstico da situação é essencial para a definição de um modelo de gerenciamento. $O$ diagnóstico de qualquer situação só pode ocorrer após o levantamento de vários dados, de modo a se conhecer:

- a dimensão atual do problema;

- os prognósticos para o futuro;

- os recursos humanos, materiais e financeiros que se dispõe ou que poderão ser obtidos. (VILHENA, 2018)

Esta dimensão pragmática de que para executar um diagnóstico são necessários recursos humanos, materiais e financeiros é importante para o bom dimensionamento de equipe e alocação de recursos para o melhor desenho de processos de coleta e tratamento de dados.

Não existe uma metodologia única para a formulação de um diagnóstico. $\mathrm{O}$ CEMPRE propõe um questionário para conhecer a realidade do objeto de estudo.

Para os diagnósticos, as informações são coletadas de diversas formas, amostragem, censo, questionários e outros. Essas informações são então tratadas, na busca de inconsistências ou ausência de dados, por meio de análise automática e manual, ou por meio de cruzamento de informações.

Uma vez compiladas, as informações podem gerar mapas, planilhas, indicadores, e outras formas que os autores entenderem necessárias para demonstrar a suas análises. No entanto, para os pesquisadores é interessante também ter acesso aos dados brutos, de forma que novas análises e interpretações podem decorrer desses mesmos dados.

Portanto, conhecer o processo no qual o diagnóstico foi produzido ajuda a entender qual o grau de detalhamento, quais possíveis falhas e como melhor interpretar essas informações. 


\title{
1.2.7. DETERMINANTES SOCIAIS DA SAÚDE
}

A saúde de um indivíduo ou de uma população é influenciada por diversos fatores, dentre eles, os econômicos, sociais e ambientais. Este é um conceito que, no plano global, começa a ser praticado em políticas e estratégias a partir de 2003, com a criação da Comissão Global sobre Determinantes Sociais da Saúde (CARVALHO, 2013).

\begin{abstract}
A maior parte da carga das doenças - assim como as iniquidades em saúde, que existem em todos os países - acontece por conta das condições em que as pessoas nascem, vivem, trabalham e envelhecem. Esse conjunto. denominado "determinantes sociais da saúde", um termo que resume os determinantes sociais, econômicos, políticos, culturais e ambientais da saúde. (CARVALHO, 2013).
\end{abstract}

Outro conceito comumente utilizado, que envolve este conceito ampliado de saúde, é o "Saúde ambiental”, com maior foco nas questões do meio ambiente, no entanto, não ignora os fatores sociais que também são determinantes na saúde humana:

"Saúde ambiental são todos aqueles aspectos da saúde humana, incluindo a qualidade de vida, que estão determinados por fatores físicos, químicos, biológicos, sociais e psicológicos no meio ambiente. Também se refere à teoria e prática de valorar, corrigir,

controlar e evitar aqueles fatores do meio ambiente que, potencialmente, possam prejudicar a saúde de gerações atuais e futuras" (OMS, 1993). (RIBEIRO, 2004)

Ambas abordagens dão valor a questões que não estão necessariamente ligadas ao setor de saúde. E assim, como o conceito de desenvolvimento sustentável, exige que economia esteja alinhada com sensibilidade social e ambiental.

Seguindo a lógica dos determinantes sociais da saúde, para alcançar metas de melhoria da saúde e ampliação do bem-estar, não basta investimentos na área de "cuidados da saúde".

No relatório elaborado para a Yale Global Health Leadership Institute, (TAYLOR, COYLE, et al., 2005), os autores constatam que há uma extensa literatura cientifica que indica que, no caso de promoção de saúde e redução de mortes prematuras, fatores não médicos (como sociais, ambientais e comportamentais) têm um papel maior que os fatores médicos ${ }^{33}$.

\footnotetext{
33 "First, the existing literature is clear about the importance of social determinants of health in improving the health of populations. Extensive scientific literature has investigated the relative contributions of
} 
Dessa forma, existem argumentos científicos de que investimento em outros serviços sociais, que não são comumente associados à saúde, tem influencia na qualidade de vida e consequentemente na saúde dos indivíduos.

Na Figura 6 é apresentado o diagrama (McGinnis et al., 2002) que traduz estes argumentos em componentes dos determinantes sociais da saúde, a genética, cuidados da saúde e fatores sociais, ambientais e comportamentais.

Figura 6-Componentes dos determinantes sociais da saúde

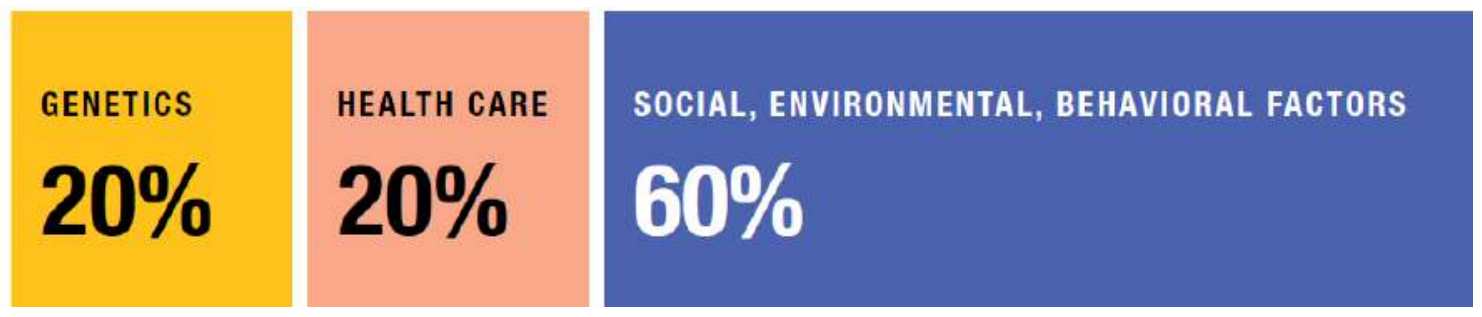

Fonte: (TAYLOR, COYLE, et al., 2005, p. 3) diagrama adaptado de (McGinnis et al., 2002)

Estes argumentos se somam às metas dos ODS, que contemplam saúde, justiça social, desenvolvimento econômico, meio ambiente saudável, entre outros, que devem ser almejados em conjunto, buscando políticas menos setorizadas.

genetics, health care, and social, environmental, and behavioral factors in promoting health and reducing premature mortality (Chiu et al., 2009; Lee \& Paxman, 1997). These studies uniformly suggest that nonmedical factors play a substantially larger role than do medical factors in health." (TAYLOR, COYLE, et al., 2005, p. 3-6)

"Primeiramente, a bibliografia existente é clara a respeito da relevância dos determinantes sociais da saúde no aprimoramento da saúde de populações. Extensa bibliografia científica investigou a contribuição da genética, atendimento da saúde e fatores sociais, ambientais e comportamentais na promoção de saúde e redução de morte prematura (Chiu et al., 2009; Lee \& Paxman, 1997). Estes estudos, uniformemente, sugerem que fatores não médicos tem um papel substancialmente maior que os fatores médicos na saúde. (tradução nossa) 


\section{CAPÍTULO 2 - UNIVERSIDADES EM CIDADES: EXPERIÊNCIAS NACIONAIS E INTERNACIONAIS}

As universidades são equipamentos urbanos com grande projeção dentro dos seus municípios, seja pela sua função social, seja pela dimensão do território ocupado. A relação entre estas esferas tem diversas complexidades. Em geral, uma universidade pública ou é federal ou estadual, sendo, portanto, uma relação entre diferentes entes federativos.

A depender da dimensão do território da universidade, ela pode impactar em questões do planejamento municipal e até estadual, como o dimensionamento de transporte público, locais de estações de metrô, estoque de potencial construtivo, entre outros.

A relação entre as universidades e a cidade foi analisada sob a ótica dos planos diretores formulados pelas instituições. Pois é possível extrair das propostas e das diretrizes de projeto como cada universidade se insere em seu contexto urbano, se há negação ou se há envolvimento do entorno no seu planejamento.

Neste capítulo, buscou-se apresentar as análises relativas às diferentes formas de relação entre universidade e cidade, com casos específicos no Brasil e no exterior.

\subsection{ANÁLISE DA IMPLANTAÇÃO DE UNIVERSIDADES FEDERAIS}

Pelo objeto de estudo se tratar de uma universidade federal, buscou-se fazer um panorama das instituições de ensino superior federal no Brasil, utilizando os critérios demográficos e de natureza jurídica.

Existem 56 universidades federais no Brasil (MEC, 2018). Pelo critério demográfico, foram listados os 20 municípios mais populosos, e pelo critério de natureza jurídica, quais universidades são federais.

No levantamento, realizado no início de 2018, dentre os municípios selecionados 18 tinham no seu território uma universidade federal (ver Quadro 8). Duas instituições aparecem repetidas: Unifesp e UFRJ, pois tem campi em mais de uma cidade. 
Quadro 8 - Municípios mais populosos e universidades federais

\begin{tabular}{|c|c|c|c|c|}
\hline Município & Estado & População ${ }^{34}$ & $\begin{array}{l}\text { Universidade } \\
\text { federal }\end{array}$ & Tipo $^{35}$ \\
\hline São Paulo & SP & 12106920 & Unifesp & Campus \\
\hline Rio de Janeiro & $\mathrm{RJ}$ & 6520266 & UFRJ & $\begin{array}{l}\text { Campus / Cid. } \\
\text { Univ. }\end{array}$ \\
\hline Brasília & $\mathrm{DF}$ & 3039444 & UNB & Cid. Univ. \\
\hline Salvador & $\mathrm{BA}$ & 2953986 & UFBA & Cid. Univ. \\
\hline Fortaleza & $\mathrm{CE}$ & 2627482 & UFC & $\begin{array}{l}\text { Campus / Cid. } \\
\text { Univ. }\end{array}$ \\
\hline Belo Horizonte & $\mathrm{MG}$ & 2523794 & UFMG & $\begin{array}{l}\text { Campus / Cid. } \\
\text { Univ. }\end{array}$ \\
\hline Manaus & $\mathrm{AM}$ & 2130264 & UFAM & Cid. Univ. \\
\hline Curitiba & PR & 1908359 & UFPR & $\begin{array}{l}\text { Campus / Cid. } \\
\text { Univ. }\end{array}$ \\
\hline Recife & $\mathrm{PE}$ & 1633697 & UFPE & $\begin{array}{l}\text { Campus / Cid. } \\
\text { Univ. }\end{array}$ \\
\hline Porto Alegre & RS & 1484941 & UFRGS & Campus \\
\hline Goiânia & GO & 1466105 & UFG & Cid. Univ. \\
\hline Belém & PA & 1452275 & UFPA & $\begin{array}{l}\text { Campus / Cid. } \\
\text { Univ. }\end{array}$ \\
\hline Guarulhos & $\mathrm{SP}$ & 1349113 & Unifesp & Campus \\
\hline Campinas & SP & 1182429 & - & \\
\hline São Luís & MA & 1091868 & UFMA & Cid. Univ. \\
\hline São Gonçalo & $\mathrm{RJ}$ & 1049826 & - & \\
\hline Maceió & $\mathrm{AL}$ & 1029129 & UFAL & Cid. Univ. \\
\hline Duque de Caxias & $\mathrm{RJ}$ & 890997 & UFRJ & Campus \\
\hline Natal & $\mathrm{RN}$ & 885180 & UFRN & Cid. Univ. \\
\hline Campo Grande & MS & 874210 & UFMS & Cid. Univ. \\
\hline
\end{tabular}

Fontes: (IBGE, 2016); (MEC, 2018); Levantamento do autor

Nota: havendo dois tipos de implantação, a estrutura principal da universidade analisada é uma cidade universitária.

Com relação à implantação destas, verifica-se que a predominância é a do tipo cidade universitária. Uma ressalva importante é que, quando há no mesmo município, cidade e campus universitário, a corpo principal é a de cidade universitária, considerando que a sua dimensão é maior, comportando mais alunos, cursos e estruturas de ensino, pesquisa e extensão.

Das 16 instituições selecionadas, apenas 4 delas são unicamente campus, enquanto as demais são caracterizadas como cidades universitárias. A maneira como está implantada a universidade influencia também a forma como a instituição planeja e se relaciona com a cidade à sua volta.

34 Estimativas de 2016 do IBGE - planilha pode ser acessada em: https://www.ibge.gov.br/estatisticasnovoportal/sociais/populacao/9103-estimativas-de-populacao.html?edicao $=9112 \& \mathrm{t}=$ resultados

${ }^{35}$ A classificação se baseia na análise visual da localização das universidades. 
A metodologia escolhida para verificar a relação da cidade com a universidade é por meio do planejamento institucional. $\mathrm{O}$ instrumento de planejamento que melhor permite a visualização destas interfaces do urbano com o universitário é o Plano diretor, por utilizar de instrumentos como mapas, plantas arquitetônicas, croquis e diagramas que permitem melhor compreensão desta relação.

$\mathrm{Na}$ amostra de 16 instituições, 6 tinham publicações de plano diretor, porém apenas 3 delas, UFRJ, UFMG e UNB continham elementos suficientes para uma análise mais aprofundada, ou seja, continham ao menos um mapa ou planta da implantação do campus ou cidade universitária. O plano diretor do Campus São Paulo da Unifesp está em formulação e os dados apresentados são fruto das entregas parciais para físcalização e observação de campo.

Dentre as três referencias, não é intenção da pesquisa verificar o que foi executado dos planos diretores, mas analisar conceitualmente suas propostas e como estas se relacionam com a cidade. 


\subsubsection{UNIVERSIDADE FEDERAL DO RIO DE JANEIRO}

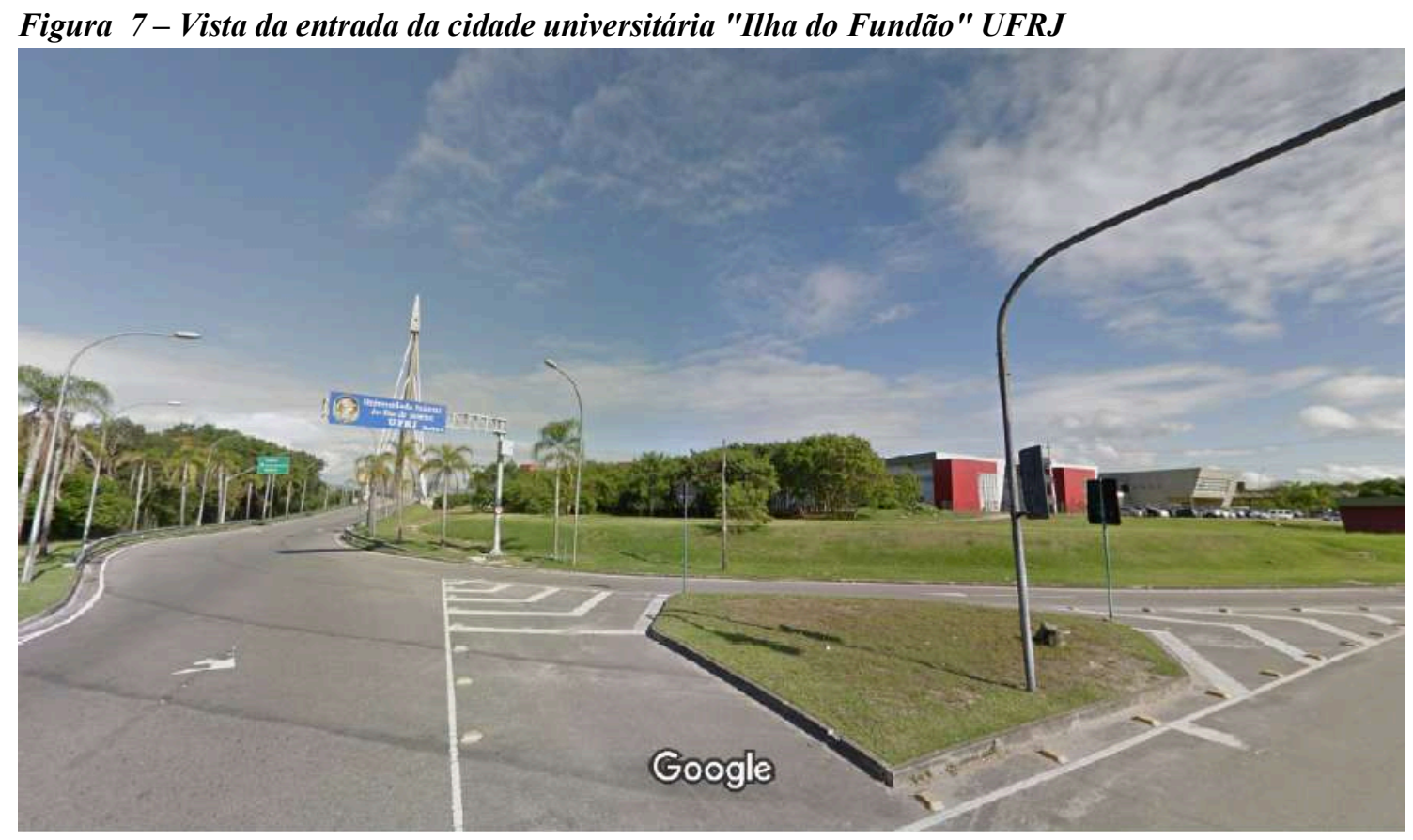

Fonte: Google Maps

A Universidade Federal do Rio de Janeiro foi fundada em sete de setembro de 1920, com o nome de Universidade do Rio de Janeiro. Em 1937 passou a se chamar Universidade do Brasil e em 1965 adquire seu nome atual. ${ }^{36}$

Especificamente sobre a cidade universitária, ainda no regime do Estado Novo, a Lei n ${ }^{\circ} 452$ estabelece como meta a implantação de uma nova estrutura universitária na Ilha do Fundão (ver Figura 7). A construção se inicia em 1949 e a inauguração ocorre em 1972 .

A Cidade Universitária, de clara inspiração do urbanismo modernista, de grandes edifícios isolados ligados por vias para automóveis, teve supervisão do arquiteto Jorge Machado Moreira. ${ }^{37}$ Desde então houveram diversas adições como a expansão do Centro de Pesquisa ENPES e a Ponte do Saber, porém sem levar em conta o planejamento de todo o conjunto urbanístico da cidade universitária.

Em 2008 é formado um Comitê Técnico que formulará o Plano Diretor da UFRJ, denominado UFRJ 2020. O programa de necessidades surge do Programa de

\footnotetext{
${ }^{36}$ https://ufrj.br/historia

${ }^{37} \mathrm{http}$ ://arqguia.com/obra/cidade-universitaria/?lang=ptbr
} 
Reestruturação e Expansão, que indica objetivos e prioridades que nortearam o planejamento da instituição.

Dentre as diretrizes presentes na Resolução CONSUNI 09/2007, destaca-se a consolidação da implantação da cidade universitária, da ampliação da assistência estudantil, melhoria de acesso e transporte, segurança pública e integração dos espaços universitários com a sociedade.

O plano é baseado em três princípios, o princípio da administração integrada dos espaços e edificações, o princípio do planejamento de longo prazo, e o principal que será abordado neste texto, o princípio da dupla integração, em que a integração interna é inseparável da integração da UFRJ à cidade. (UFRJ, 2009, p. 18).

Para o debate das propostas, o Comitê Técnico promoveu 6 oficinas temáticas, "Estudar na Cidade Universitária, Morar na Cidade Universitária - Política de Residência Universitária"; "Cidade Universitária. Cidade Responsável em Energia e Meio Ambiente"; "Cidade Universitária, Cidade da Inovação e Experimentação"; "Cidade Universitária, Cidade do Conhecimento e da Arte"; "Cidade Universitária, Cidade Saudável e Esportiva" e "Cidade Universitária, Cidade Acessível”.

E o Conselho Participativo do Plano Diretor reuniu-se 5 vezes para oferecer um canal de diálogo com órgãos governamentais e representações da sociedade civil. Estas duas instancias de consulta e proposição ocorreram em 2009.

No município do Rio de Janeiro, a Universidade Federal do Rio de Janeiro, conforme seu Plano Diretor, têm três conjuntos principais, a Cidade Universitária, o Campus Praia Vermelha e Unidades Isoladas (ver Figura 8). Por se tratar do maior território gerido pela universidade, o foco do plano é a Ilha do Fundão.

Muitas atividades que hoje estão no Campus Praia Vermelha, têm no PD UFRJ a previsão de transferência para a Ilha do Fundão ${ }^{38}$, uma vez que neste campus há muitos edifícios de importância histórica e não estão adequados para atividades regulares.

\footnotetext{
38 “1.5. Já está mais que comprovado que o uso continuado e estressante do Palácio Universitário para atividades didáticas regulares e outros usos indiferentes, ou em clara agressão, à sua história e importância como Patrimônio Arquitetônico, acaba por descaracterizar ambientes. Rever, rejeitar e redefinir os usos atuais é, pois, passo essencial, e inadiável, para que possamos recuperar a integridade e a dignidade de um dos melhores exemplos de expressão da arquitetura neoclássica brasileira.” (UFRJ, 2009, p. 75)
} 
Uma das atividades que deve permanecer, segundo o plano39, é o Polo de Saúde, pois o local é muito mais acessível que a cidade universitária, embora o Centro de Ciências da Saúde da UFRJ continue na Ilha do Fundão.

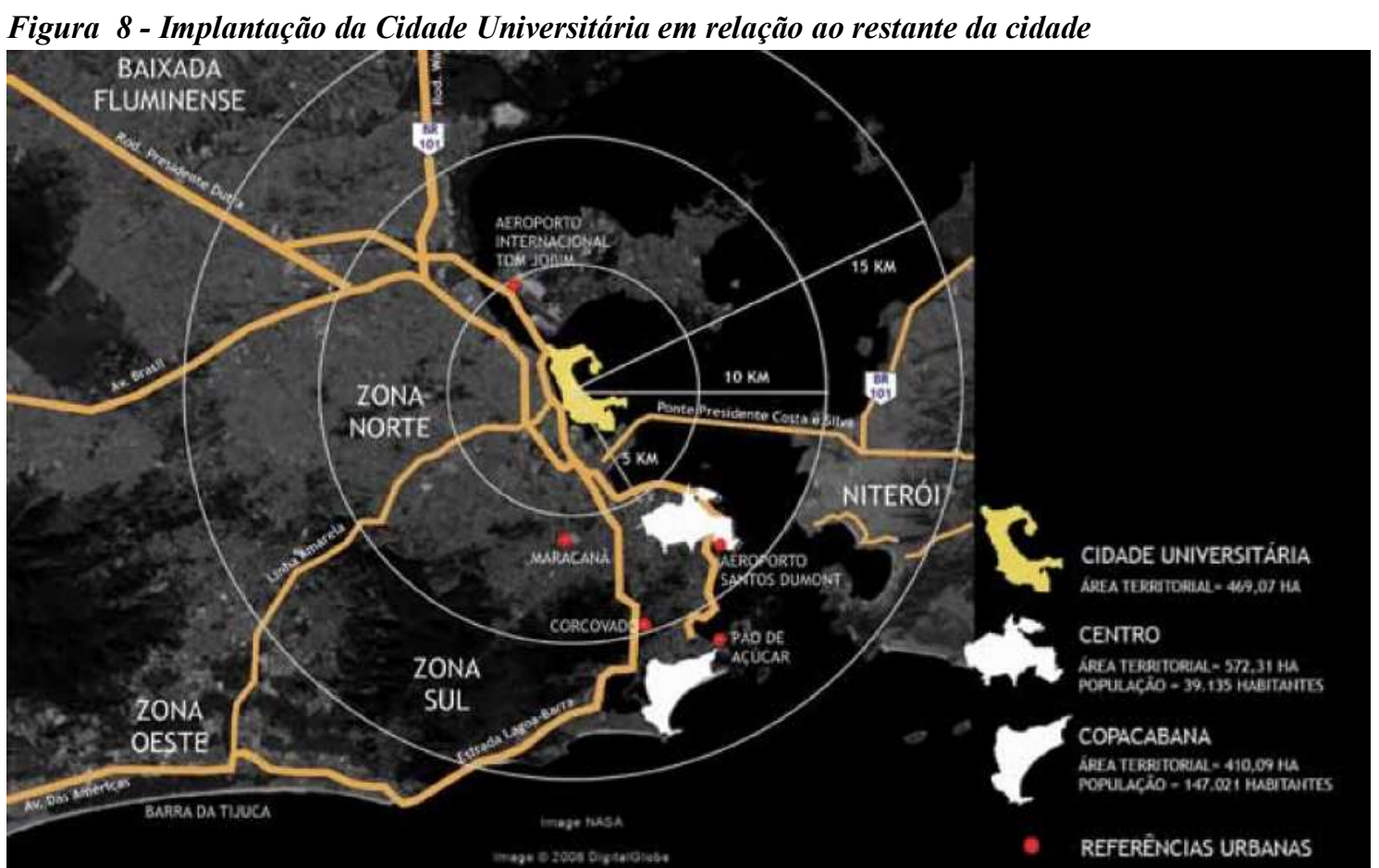

Fonte: (UFRJ, 2009, p. 19)

Especificamente sobre a relação da universidade com a cidade, existe o reconhecimento do distanciamento da cidade universitária com o restante da cidade de maneira explícita, ao incluir, dentro de suas diretrizes gerais, o desafio de se integrar à cidade $^{40}$ :

Como resposta a esse desafio, o plano diretor propõe os chamados "Centros de Convergência" (ver Figura 9), que seriam como bairros implantados na Ilha do Fundão,

\footnotetext{
39 “3.2. O Pólo de Saúde. Os Hospitais Universitários (Instituto de Neurologia Deolindo Couto - INDC e Instituto de Psiquiatria -IPUB) deverão permanecer no campus da Praia Vermelha, por sua integração ao SUS no atendimento de serviços básicos, procedimentos de alta complexidade e serviços complementares. Há que ressaltar igualmente a proximidade com o Pinel, que conforma, naquele espaço, polo de referência para a saúde mental no Rio de Janeiro." (UFRJ, 2009, p. 78)

40 "Isso significa que estamos desafiados a levar adiante, simultaneamente, dois processos de integração: integração intrauniversitária e integração universidade-cidade. Não seremos capazes de integrar acadêmica e físico-territorialmente a UFRJ se não formos capazes de integrar a Universidade, em primeiro lugar a Cidade Universitária, à Cidade do Rio de Janeiro.

Dessa forma, a integração físico-territorial a ser buscada pelo PD UFRJ-2020 deve contemplar de maneira decidida questões como acessibilidade, segurança, densificação da nova Cidade Universitária, usos universitários e usos urbanos de seus espaços e edificações, integração social, democratização do acesso com incorporação mais expressiva de estudantes de camadas populares." (UFRJ, 2009, p. 23)
} 
com características de densidade, diversidade e ambiência urbana (UFRJ, 2009, p. 39), ou seja, não é exatamente integração, mas criação de ambiente urbano.

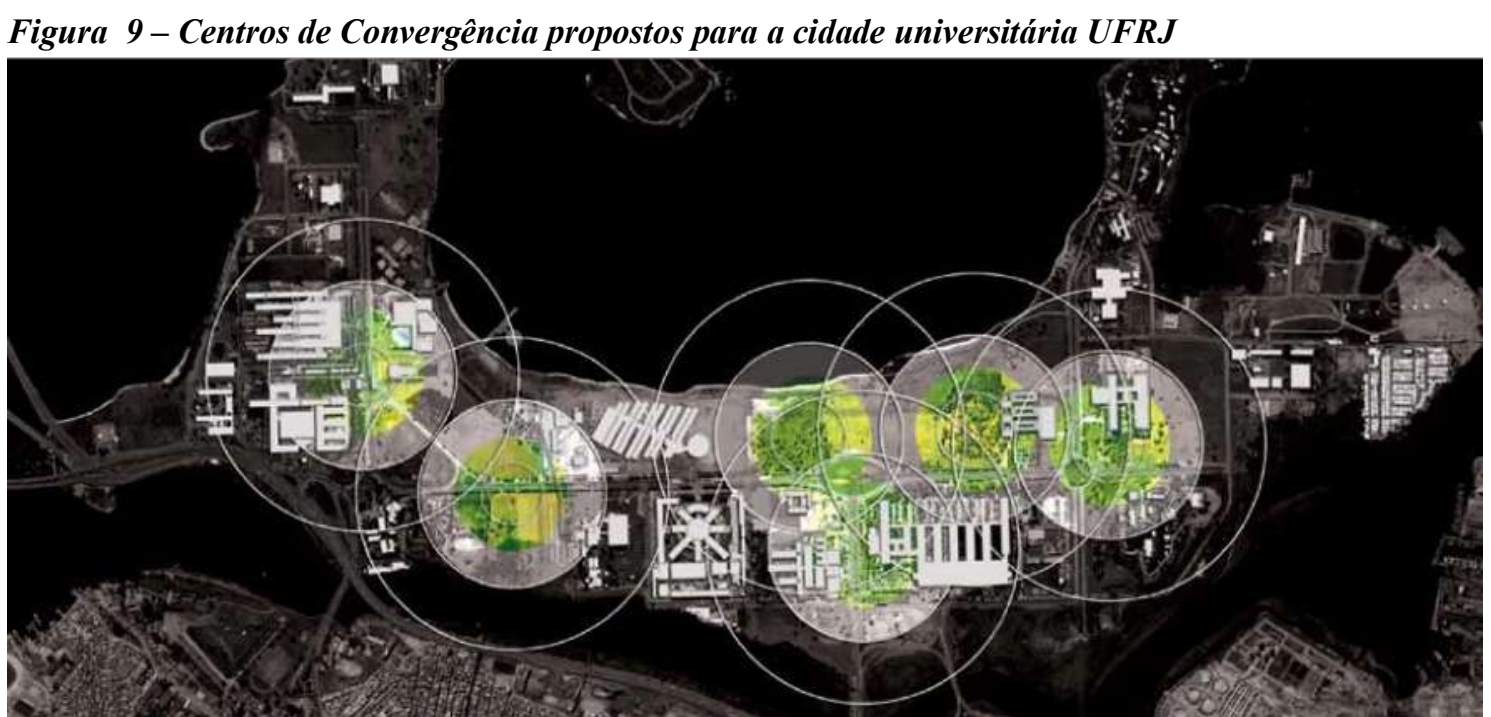

Fonte: (UFRJ, 2009, p. 21)

Para ilustrar o conceito de centro de convergência, uma série de novos edifícios, reformas e requalificações foram propostas para viabilizar essa nova configuração da cidade universitária. Entre elas, estão restaurante satélite, residências universitárias e a biblioteca unificada do Centro Tecnológico.

As propostas apresentadas dependem de grandes investimentos, que, no contexto em que se fazia o planejamento, com o Brasil anunciado como sede da Copa do Mundo e a cidade do Rio anunciada como sede das Olimpíadas, poderiam fazer sentido. Dentre as infraestruturas que constam no plano diretor (ver Figura 10), está uma linha de Maglev, uma espécie de trem de levitação magnética que estaria conectada à cidade universitária e uma usina de geração de energia elétrica por meio de queima de resíduos sólidos urbanos.

Além da questão orçamentária, existem também dificuldades políticas e administrativas em se transferir atividades de outros locais para a cidade universitária, o que pode ocasionar mudanças, atrasos ou cancelamento de projetos relacionados ao plano diretor. 


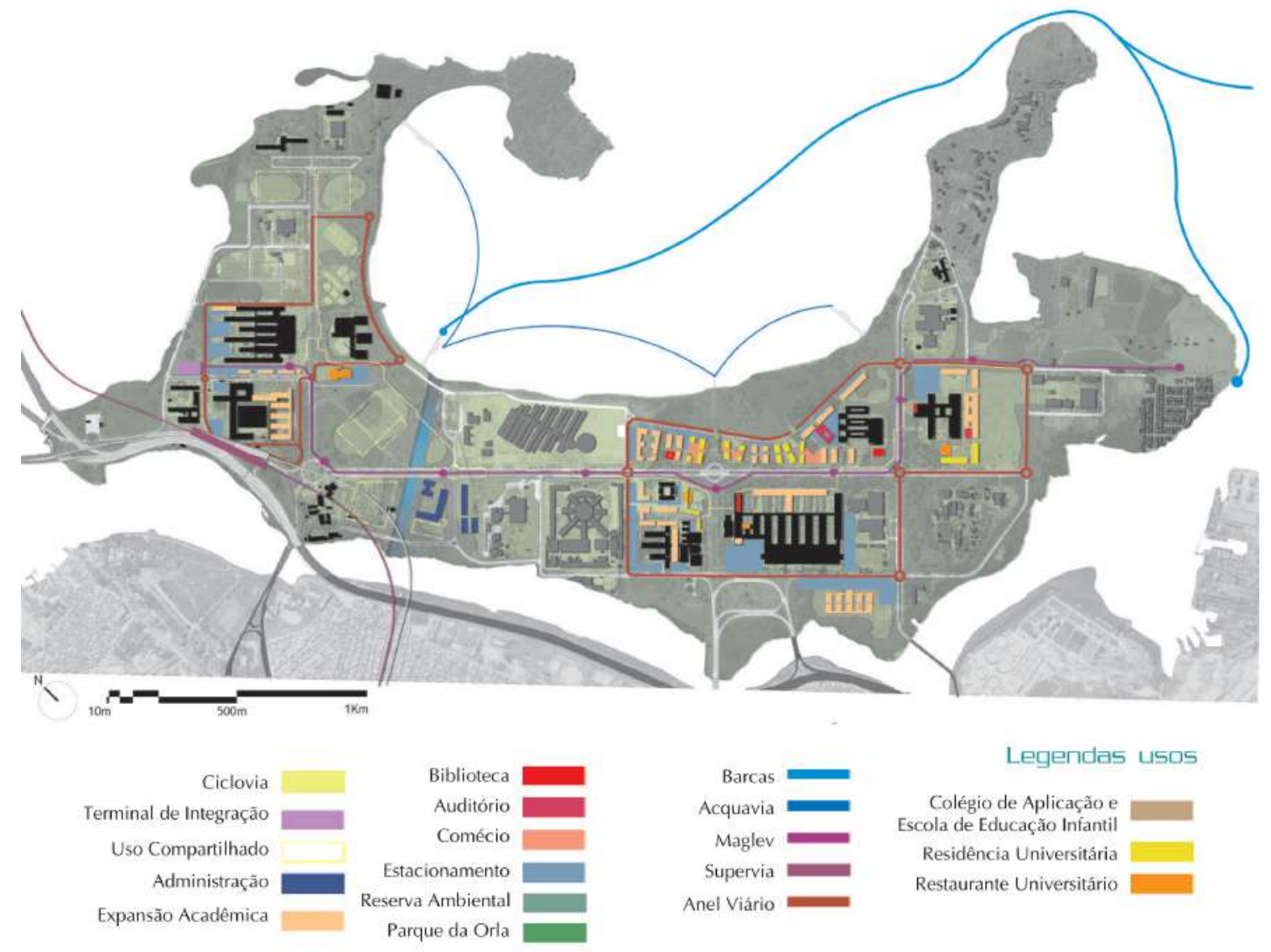

Fonte: adaptado de (UFRJ, 2009, p. 102)

Embora seja mencionada a intenção de integração com a cidade, muitas das propostas são voltadas para o público interno. Uma exceção aparenta ser o projeto de geração de energia ${ }^{41}$ a partir da queima de resíduo sólido urbano, que tanto poderia valorizar energeticamente os resíduos provenientes da cidade quanto alimentar parte dela com a energia gerada.

Não foi identificado no projeto o local previsto para esta usina, porém, este seria um serviço que, se verificado a eficiência, economicidade e atendimento às exigências ambientais anunciadas, poderia servir também para redução de resíduos dispostos em aterros sanitários.

O discurso do Plano Diretor não nega a cidade, inclusive admite o desafio de se integrar a ela, principalmente através dos "centros de convergência". No entanto, as

41 “Projeto Usina de Lixo: Construção de usina de incineração de resíduo sólido urbano, a partir de tecnologia patenteada por pesquisador da UFRJ, com garantia de atendimento às exigências ambientais, alta eficiência térmica e viabilidade econômica para a geração acoplada de energia elétrica, com economia de $40 \%$ em relação ao custo atual." (UFRJ, 2009, p. 69) 
edificações e as infraestruturas propostas são em sua maioria voltadas ao público acadêmico. É preciso uma pesquisa posterior à implantação desta proposta para verificar sua efetividade em criar vida urbana dentro de uma cidade universitária.

Para além das atividades acadêmicas, é salutar que pela dimensão da cidade universitária, outros serviços, como os ambientais possam ser oferecidos à população, seja na forma de parque, como o "Parque da Orla", na forma de reserva ambiental ou mesmo de serviço da usina de lixo.

Por fim, foi possível extrair do plano diretor da UFRJ, as intenções e propostas de ampliar a sua relação com a cidade, mesmo sendo uma ilha, em destaque para a proposta de criar dinâmicas urbanas induzidas dentro da cidade universitária. Estas propostas exigem grandes investimentos e de certa forma refletem um otimismo de investimentos públicos na época em que o plano foi formulado. 


\subsubsection{UNIVERSIDADE FEDERAL DE MINAS GERAIS}

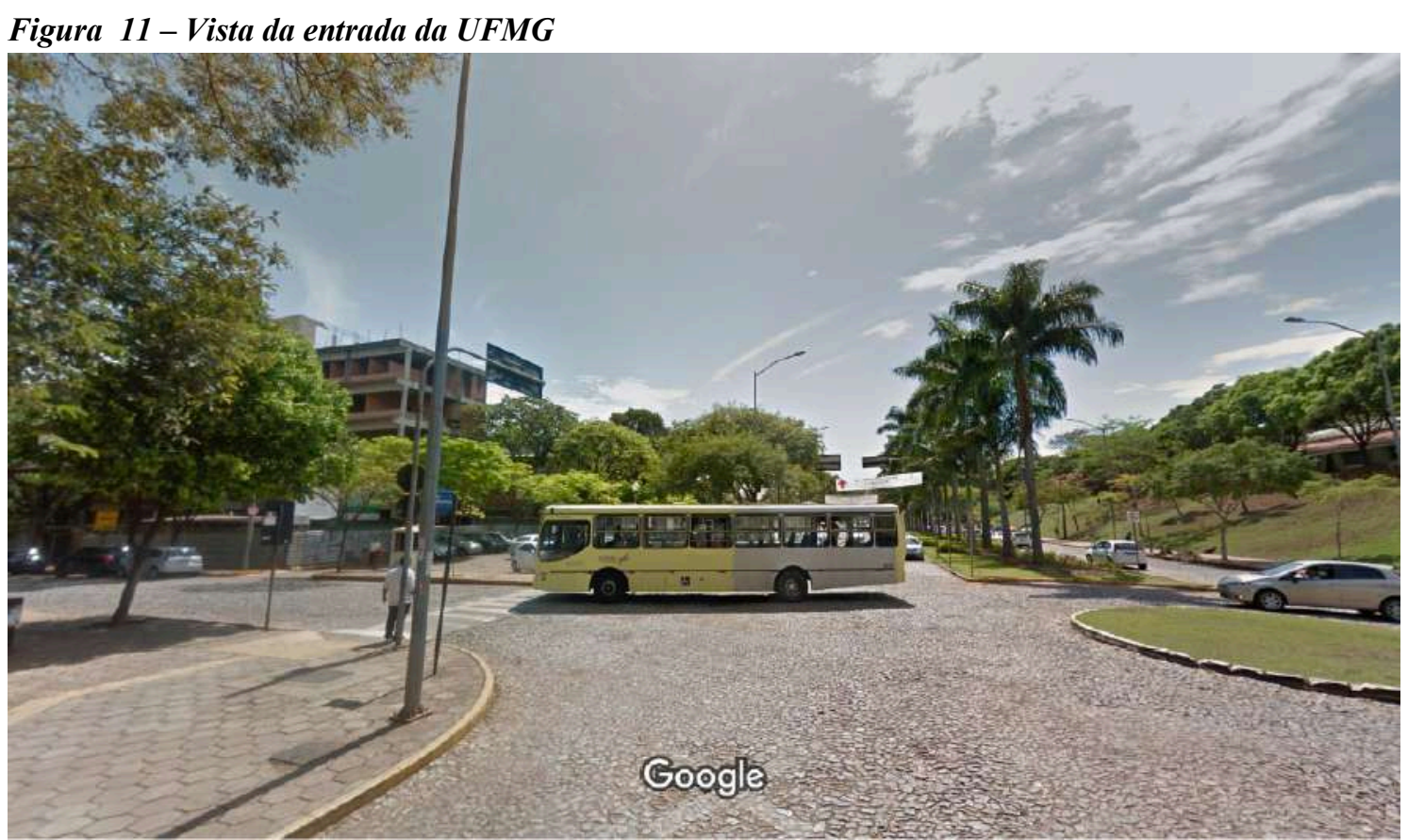

Fonte: Google Maps

A Universidade Federal de Minas Gerais ${ }^{42}$ considera sua fundação em sete de setembro de 1927, sob o nome de Universidade de Minas Gerais, ao reunir as faculdades de Direito, Medicina, Odontologia, Farmácia e Engenharia. Esta universidade era de caráter privado, apesar de ser beneficiária de subvenções estaduais, até 1949, quando ocorre o processo de federalização.

A Universidade Federal de Minas Gerais, na capital Belo Horizonte, tem como principal estrutura a cidade universitária "Campus Pampulha" (ver Figura 11), que, segundo Departamento de Planejamento e Projetos ${ }^{43}$, teve sua definição em 1942 e definitivamente ocupado em 1962, com a construção da Reitoria.

O primeiro plano de ocupação, de Eduardo Pederneiras (1943-1955) não foi executado e a atual implantação está mais relacionada ao Plano do Escritório Técnico (1955-1966) e pelo Plano Cordeiro (1966-1975), que foi desenhada pelo arquiteto Waldemar Cordeiro.

Em 2009, a equipe técnica interna formula o Plano Diretor da UFMG. Não foram encontrados registros do processo de discussão deste debate, porém ao menos, este plano teve de ser trazido ao Conselho de Campus, que o aprovou.

\footnotetext{
${ }^{42} \mathrm{https}: / /$ www.ufmg.br/90anos/historia-da-ufmg/

${ }^{43} \mathrm{https}: / /$ planejamentoeprojetos.wordpress.com/466-2/
} 
Diferentemente do Plano Diretor da UFRJ, o da UFMG é mais simplificado. Há menos propostas de desenho e projeto e mais diretrizes para uso e ocupação do solo. Analogamente, é como a Lei de Uso e Ocupação do Solo, mais conhecida como Zoneamento, de um município, que também decorre da lei que institui o Plano Diretor Municipal.

Os parâmetros de uso e ocupação do solo dão diretrizes ${ }^{44}$ para atuais e futuras ações da universidade. A nível da calçada, da edificação ou da cidade universitária, estas diretrizes podem contribuir para o desenvolvimento sustentável, ao estimular o deslocamento de pedestres redução do trânsito na malha interna e executar obras seguindo princípios da sustentabilidade, eficiência energética e acessibilidade.

Do Zoneamento é possível extrair a lógica de implantação que está ligada às áreas do conhecimento. Há uma clara distinção entre a área ligada às ciências biomédicas, às engenharias e às humanidades, com espaços destinados a áreas de apoio entre elas. Esta visão setorizada, muito relacionada ao planejamento urbano modernista.

Com relação à cidade, existe pouca menção no mapa ao entorno da universidade, constando apenas as vias principais que circundam a cidade universitária, sem aparecer no desenho as quadras, ruas e edificações que estão na proximidade. Este pode ser um indício sintomático do isolamento das cidades universitárias.

A dimensão da cidade universitária, no entanto, oferece um serviço ambiental importante que é o de apoio à preservação ambiental, tendo grandes áreas do seu território que são destinadas à esta atividade.

Outra preocupação ambiental proveniente das atividades realizadas na universidade é o gerenciamento de resíduos, pois ao considerar os parâmetros estabelecidos para construção de novos edifícios ${ }^{45}$, os depósitos especiais de produtos químicos ${ }^{46}$ ou resíduos são algumas das categorias em que se admitem edificações com

\footnotetext{
44 .o espaço intersticial das edificações, as calçadas e as áreas verdes devem ser paisagisticamente tratados, de modo a estimular os deslocamentos de pedestres; .a redução do trânsito de veículos na malha viária interior deve levar em conta múltiplas intervenções. . os princípios da sustentabilidade, da eficiência energética e da acessibilidade ambiental para todos deverão ser assegurados nas edificações do Campus. (UFMG, 2009)

${ }^{45} \S 20$ As edificações prediais atípicas que, por razões técnicas, construtivas, funcionais ou ambientais não admitam outros pavimentos poderão ter apenas o piso térreo, mediante proposta fundamentada da Administração Central, ouvido o Conselho de Diretores. (UFMG, 2009)

46 I - Enquadram-se nessa categoria os ginásios de esportes, auditórios, plantas-piloto, laboratórios especiais, restaurantes universitários, depósitos especiais de produtos químicos ou resíduos, instalações especiais para animais de grande porte, viveiros de plantas e assemelhados, guaritas e outras pequenas instalações de apoio às edificações. (UFMG, 2009)
} 
apenas pavimento térreo. Estes parâmetros fazem sentido quando há à disposição grandes áreas, como é o caso da cidade universitária da UFMG.

Pela grande dimensão do "Campus Pampulha", assim como a cidade universitária da UFRJ, grandes espaços estão abertos à população para atividades de recreação, porém grande parte da frequência desses espaços está condicionada às atividades acadêmicas, já que aos fins de semana e feriados a entrada é limitada por exigência de registro em formulário para visitantes, conforme preconiza a portaria 01372 de $2004^{47}$.

Com relação aos demais espaços, há pouco material de projetos e propostas para se analisar, pois diferentemente do plano diretor da UFRJ, o plano diretor da UFMG se ateve a indicar mais diretrizes que projetos, e a única planta da cidade universitária se refere ao zoneamento.

Conforme (Figura 12) pode-se verificar que a planta de setorização da UFMG tem dois tipos de informação, um que se refere à atividade (artes, ciências biomédicas, recreação, etc) e outra que se refere à parâmetros de uso e ocupação (zona non edificandi, zona edificandi de reserva técnica estratégica, etc). Não há indicação de acessos e dos lotes e malha urbana vizinha à universidade.

A conclusão que se faz a respeito do plano diretor da UFMG é que não há preocupação em propor novas relações com a cidade, o foco é mais administrativo e de ordenamento das atividades acadêmicas e da comunidade acadêmica, sem ter uma intenção de projetos que integrem mais a cidade universitária com as áreas vizinhas.

\footnotetext{
${ }^{47}$ https://www.ufmg.br/dlo/arquivo/DSU/norma_fimdesemana.PDF
} 
Figura 12 - Setorização da UFMG

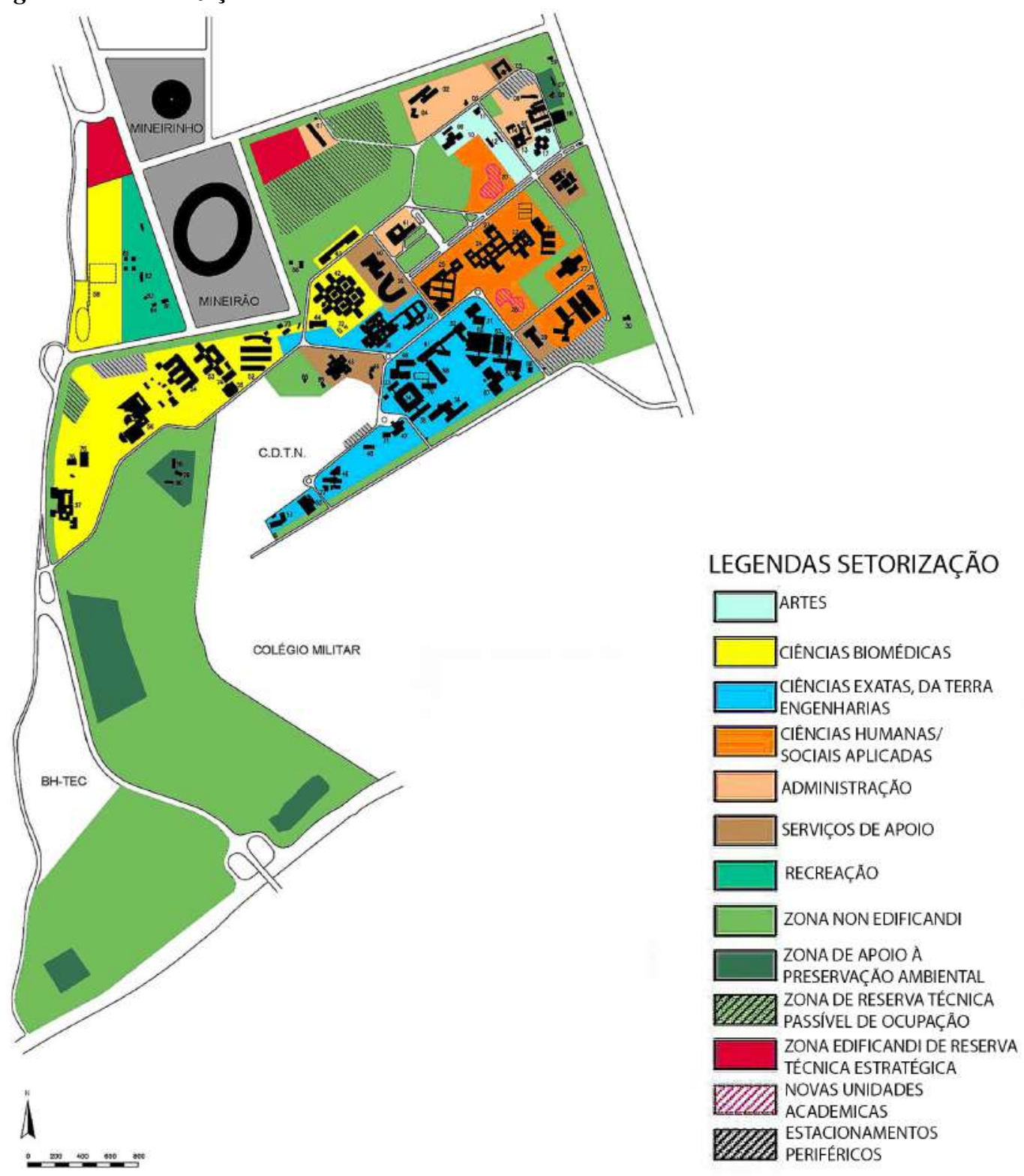

Fonte: Adaptado de (UFMG, 2009) 


\subsubsection{UNIVERSIDADE DE BRASÍLIA}

\section{Figura 13 - Vista da rua na Cidade universitária da UNB}

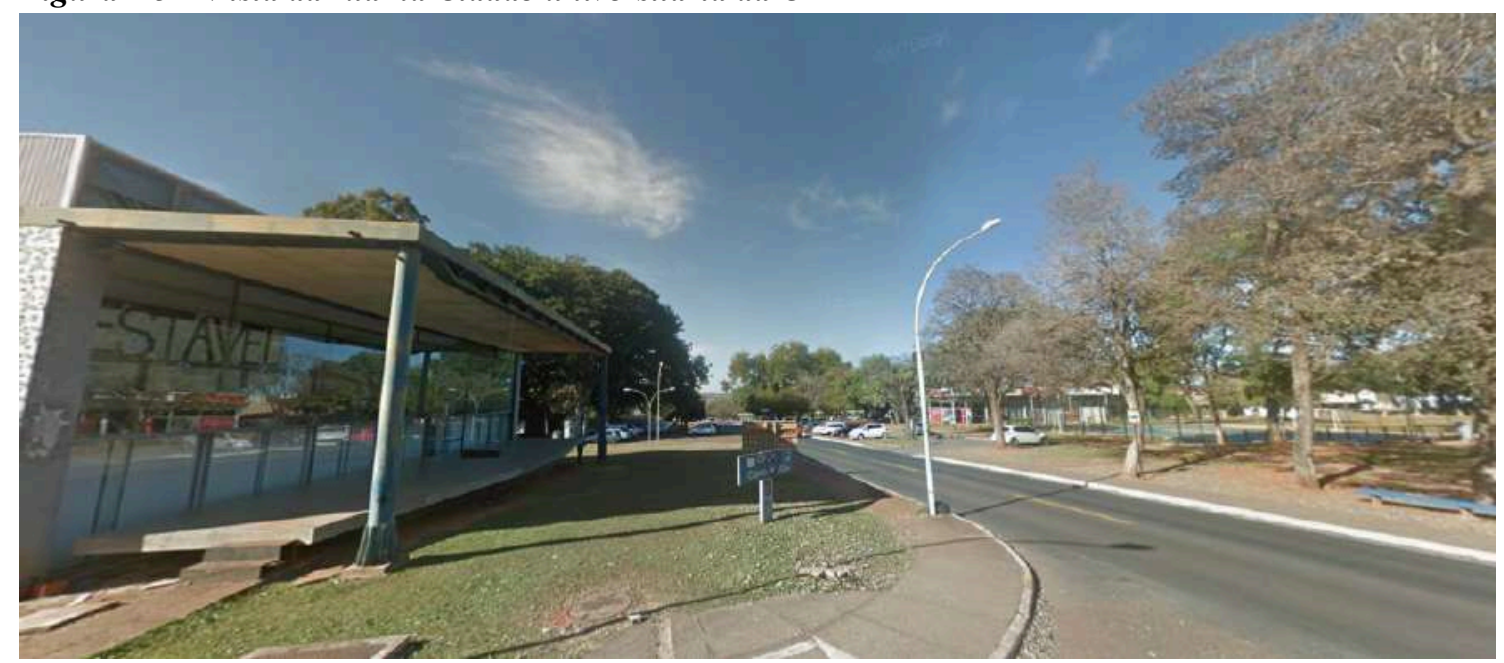

Fonte: Google Maps

A Universidade de Brasília é fundada em 21 de abril de 1962, dois anos após a fundação da Capital. O local de implantação já constava no projeto do Plano Piloto, desenhado pelo arquiteto e urbanista Lucio Costa.

A referência que Lúcio Costa faz, no Relatório do Plano-piloto, à Cidade Universitária é singela e colocada no mesmo parágrafo em que descreve a Esplanada dos Ministérios (UNB, 1998)

O projeto de implantação da cidade universitária, assim como a da capital, é de inspiração modernista ${ }^{48}$. Um contexto que deve ser preservado pela sua importância histórica, como Patrimônio da Humanidade ${ }^{49}$, a cidade de Brasília é detentora da maior área tombada do mundo, com 112,25 $\mathrm{km}^{2}$ e está na lista da UNESCO de bens do Patrimônio Mundial desde 7 de dezembro de 1967.

Dado que a cidade e a cidade universitária, neste caso estão integradas tanto conceitualmente na sua concepção, quanto fisicamente, pois não há divisão explicita entre o campus do restante da cidade (ver Figura 13), diferentemente do que ocorre na UFRJ e na UFMG, em que há a separação física (por ser uma ilha) e a separação por muros e grades no perímetro da universidade, respectivamente.

48 “O padrão de distribuição dos demais edifícios assemelhava-se à proposta de Lúcio Costa: isolados, num mosaico para o setor urbano em que o sistema viário seria o principal delimitador dos espaços, na escala geral da nova cidade universitária.” (UNB, 1998, p. 22)

${ }^{49} \mathrm{http}$ ://www4.planalto.gov.br/restauracao/brasilia-patrimonio-cultural-da-humanidade 
Pode-se ver que o zoneamento ou setorização do "Campus Darcy Ribeiro" (ver Figura 14), assim como no da UFMG, o desenho dos lotes e viário vizinhos à universidade foram desconsiderados.

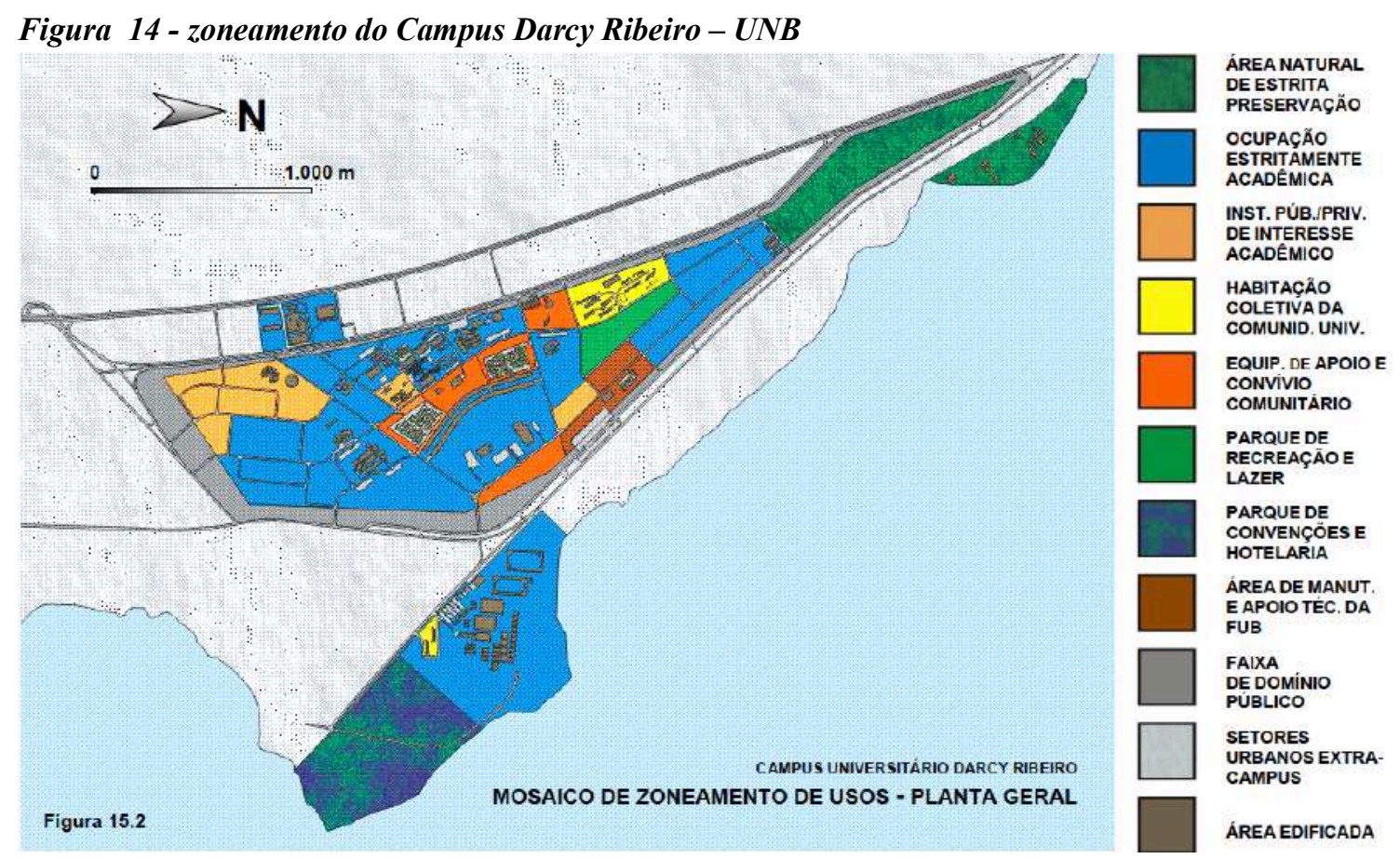

Fonte: (UNB, 1998, p. 211)

Em comum às duas instituições citadas, a UNB também produziu um Plano Diretor, publicado em 1998, formulado internamente por um grupo de trabalho. Neste plano, constam as diretrizes de planejamento físico e institucional (parte 1), de projeto e ocupação (parte 2) e setorização e zoneamento do campus (parte 3).

Segundo o texto do plano, as deliberações ocorrem nas instancias colegiadas da Universidade e há participação comunitária quando o regimento assim permitir.

Sobre as diretrizes do plano, na parte 1, pode-se destacar os aspectos comunitários e urbanísticos, que deverão orientar o desenho institucional. Pautas como acessibilidade, segurança, espaços de encontro e conforto ambiental constam nesse documento. Muitas destas pautas já estão alinhadas à normativas e legislações vigentes no período, porém explicita-las reforça a necessidade de se contemplar nos projetos.

Como aspectos urbanísticos, existem as premissas da legislação urbanística do Distrito Federal que podem ser incorporadas no projeto institucional, criando assim, uma coesão entre políticas públicas de diferentes esferas. O Plano Diretor de Ordenamento Territorial do Distrito Federal de 1996 tem objetivos comuns, como a defesa do meio ambiente e dos recursos naturais, equilíbrio entre atividades e infraestrutura disponível, 
equilíbrio na distribuição de serviços urbanos e equipamentos comunitários e implantação de um processo de planejamento permanente e participativo ${ }^{50}$.

Na parte 2 do plano diretor, sobre projeto e ocupação, destacam-se as análises referentes aos impactos possíveis que as atividades podem gerar. Os impactos ambientais, na acessibilidade, nas condições ambientais, nos sistemas de segurança e controle, na circulação viária, na paisagem, nos recursos humanos, nos sistemas de manutenção, na organização físico-espacial do campus e no ordenamento territorial.

Os impactos ambientais devem ser mitigados ou anulados pelo planejamento adequado da implantação de atividades dentro da universidade. As Áreas de Proteção Ambiental (APA), sob responsabilidade da universidade devem ser mantidas, e se possível, ampliar a recuperação de biomas. Além da consciência da contribuição de projetos para condições microclimáticas.

A acessibilidade não deve ser tomada como valor apenas edilício, mas urbanístico. As calçadas, os acessos aos edifícios e todos os seus pavimentos devem ser acessíveis universalmente.

As condições ambientais que os locais de longa permanência devem fornecer podem trazer conforto ambiental e psicológico se bem dimensionados e desenvolvidos os projetos das atividades.

Os sistemas de segurança e controle, cuja prioridade deve ser a segurança dos usuários e proteção do patrimônio público. Para efetivação de políticas de segurança, não é necessário apenas contratação de guardas e construção de guaritas, mas todo um projeto integrado e interdisciplinar onde haja sensação de segurança, iluminação adequada, comunicação visual e canais de comunicação.

Os impactos na circulação viária, em que determinadas atividades são consideradas como polos geradores de tráfego, reforçando assim a necessidade de

\footnotetext{
50 _" contribuir para a implementação de fato do Sistema de Planejamento Territorial e Urbano, de modo a torná-lo operante, integrado e eficaz;

- contribuir para a implantação de um processo de planejamento permanente e participativo, no sentido da democratização da gestão territorial;

- buscar equilíbrio na distribuição de serviços urbanos e equipamentos comunitários, de forma compatível com a preservação ambiental e cultural, e no sentido de minimizar a segregação socioespacial;

- ampliação da oferta de habitação a todos os segmentos sociais e prioritariamente às faixas de renda média e baixa;

- a distribuição de atividades e a definição de intensidades de ocupação do solo de forma equilibrada em relação à infra-estrutura disponível, aos transportes e ao meio ambiente;

- a defesa do meio ambiente e dos recursos naturais em harmonia com a implantação e expansão dos assentamentos humanos e das atividades econômicas;" (UNB, 1998, p. 71)
} 
articulação com os sistemas de transporte público e outros meios de transporte ativos, como bicicleta e a pé.

Na paisagem, a avaliação da implantação de uma atividade deve levar em conta o contexto da paisagem urbana e ambiental à sua volta. A integração com a paisagem pode se dar estabelecendo eixos e sequencias visuais, na qualidade arquitetônica e na composição de volumetrias.

Nos recursos humanos, o planejamento do espaço físico deve considerar as etapas de ocupação que estejam relacionadas à disponibilidade de servidores, para evitar duplicação de serviços e a subutilização ou ociosidade de recursos humanos. Como uma via de mão dupla, a organização física impacta no uso de recursos humanos, principalmente no que se refere à manutenção, segurança, limpeza e outras e o as novas atividades ou novas demandas devem ser incorporadas pela organização física.

Sobre o impacto nos sistemas de manutenção, é preciso que as soluções arquitetônicas considerem a manutenção predial nas especificações, nos mobiliários, nos detalhamentos, na distribuição de elementos construtivos, entre outros, que facilitem ou que tornem econômicas a utilização da infraestrutura existente. Dentre as atividades de manutenção, a coleta de resíduos e limpeza podem ser melhoradas com a disciplina e racionalidade gerada de projetos edilícios.

$\mathrm{Na}$ organização físico-espacial, além dos argumentos referentes aos recursos humanos, as diretrizes de projeto e ocupação devem evitar, obras cujos espaços sejam pouco adaptáveis ou que o prédio não viabilize expansões.

E há o impacto sobre o ordenamento territorial, que mais tem a ver com a cultura institucional de desconsiderar o comprometimento de um planejamento de longo prazo, realizando atividades não planejadas ou irregulares.

Por fim, na parte 3, sobre a proposta de setorização e zoneamento, é possível verificar através dos diagnósticos e das propostas, como a cidade universitária se relaciona com a cidade.

Concluindo, o plano diretor da UNB tem um conteúdo abrangente, mencionando não somente o ordenamento territorial, mas também de questões referentes à sistemas, procedimentos e recursos humanos. No caso específico da UNB, embora as plantas desconsiderem o desenho do entorno, o conteúdo do plano leva em conta o Macrozoneamento do Plano Diretor de Ordenamento Territorial do Distrito Federal e busca harmonização do campus Darcy Ribeiro com a paisagem urbana, esse fato se deve principalmente ao fato da universidade constar desde o início no Plano Piloto de Brasília. 


\subsection{UNIVERSIDADE FEDERAL DE SÃO PAULO}

Figura 15 - Vista do Campus São Paulo

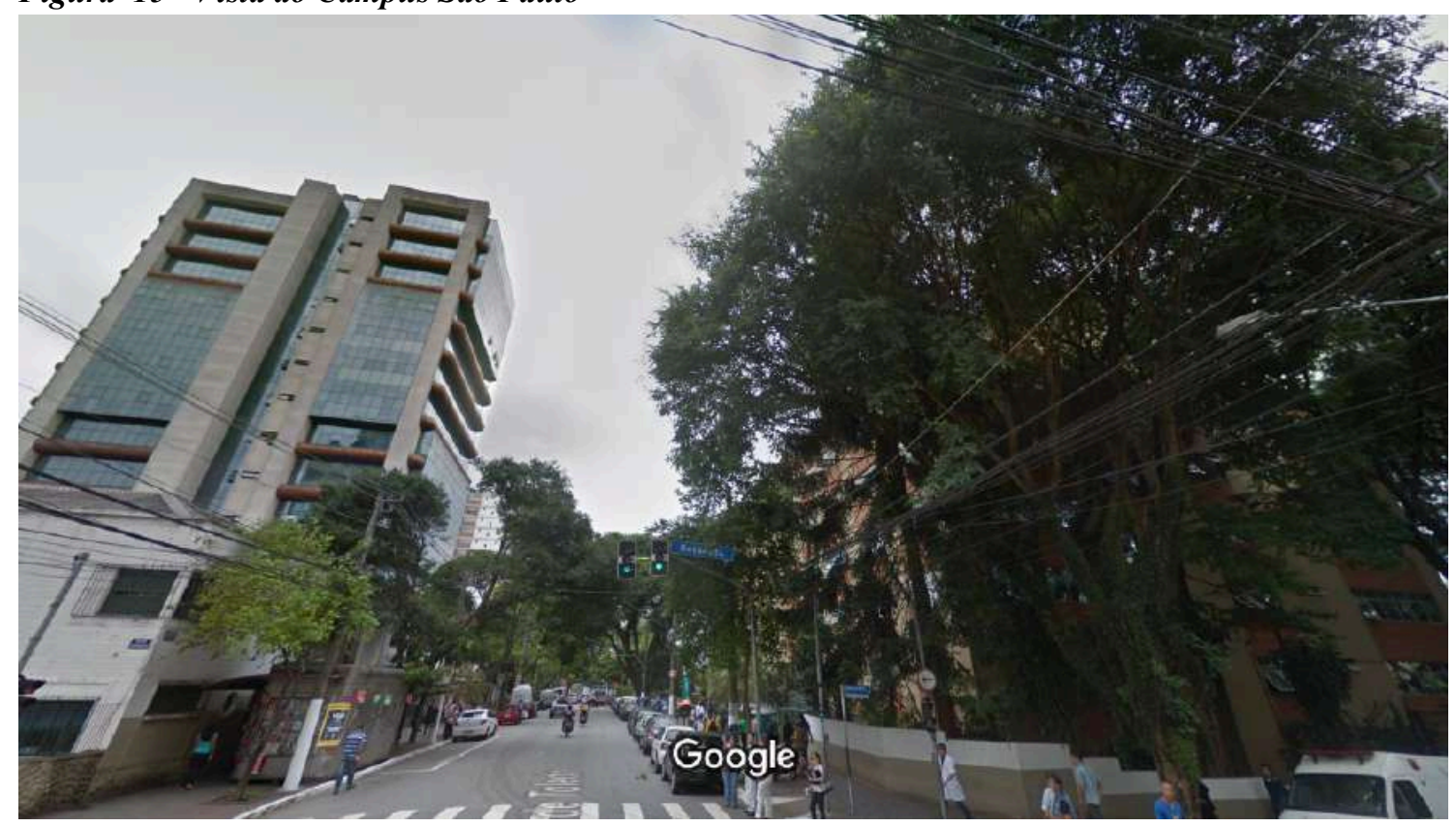

Fonte: Google maps

A Universidade Federal de São Paulo sete campi, São Paulo (ver Figura 15), São José dos Campos, Osasco, Diadema, Guarulhos, Baixada Santista e Zona Leste. Considerando que o estudo de caso é o Plano Diretor de Infraestrutura do Campus São Paulo, enfatizou-se o contexto urbano e do processo de formulação do plano.

O Campus São Paulo da Universidade Federal de São Paulo está localizado no bairro Vila Clementino, da Subprefeitura da Vila Mariana, uma das subprefeituras do Município de São Paulo.

A origem do CSP se inicia em 1933 a partir da criação da Escola Paulista de Medicina (EPM), da Escola Paulista de Enfermagem (EPE) e do Hospital São Paulo (HSP), ainda como instituições privadas. Em 1956 a EPM é federalizada e em 1994 se transforma em Universidade Federal de São Paulo.

O bairro aparenta ter uma vocação para atividades voltadas à saúde, tendo centros hospitalares, como o próprio HSP, além do Hospital Paulista, o Hospital do Servidor Público Estadual, o Instituto do Sono e o Hospital do Rim e Hipertensão, além de organizações não-governamentais como a Fundação Dorina Norwill, a APAE, AACD, Associação Cruz Verde, GRAAC e o Amparo Maternal. Muitos destes, nas proximidades do complexo universitário (ver Figura 17), que indica no mapa onde estes serviços hospitalares estão localizados em comparação com o CSP. 
Mais especificamente sobre a área do complexo, em conformidade com instrumentos do Plano Diretor Estratégico (PDE), a área no entorno no CSP é intitulada "Complexo de Saúde, Educação em Saúde e Pesquisa em Saúde"51 (ver Figura 16). É a primeira instituição a receber da Prefeitura de São Paulo o incentivo da categoria complexo de saúde.

Figura 16 - Ilustração de incentivo para complexo de saúde

Definição de faixa envoltória para os Complexos de Saúde onde é incentivada a instalação de usos relativos a serviços de saúde e de educação em saúde. O perimetro do Complexo de Saúde é sugerido pelo interessado e reconhecido pelo órgăo municipal competente.

NA FAIXA ENVOLTORIA PERMITE-SE:

- Novas construçбes, regularizaç̄es ou reformas com ampliaçăa de área dos usos relativos a servicos de saúde e educaçắ em saúde. independente da zona de usa com exceçăo de imoveis localizados nas áreas do SAPAVEL.

- Majorar Taxa de Ocupaçăo (TO) em $50 \%$ do estabelecido no Quadro 3 desta Lei

- Majorar Coeficiente de Aproveitamento (CA) em $50 \%$ do estabelecido no Quadro 3 desta Le

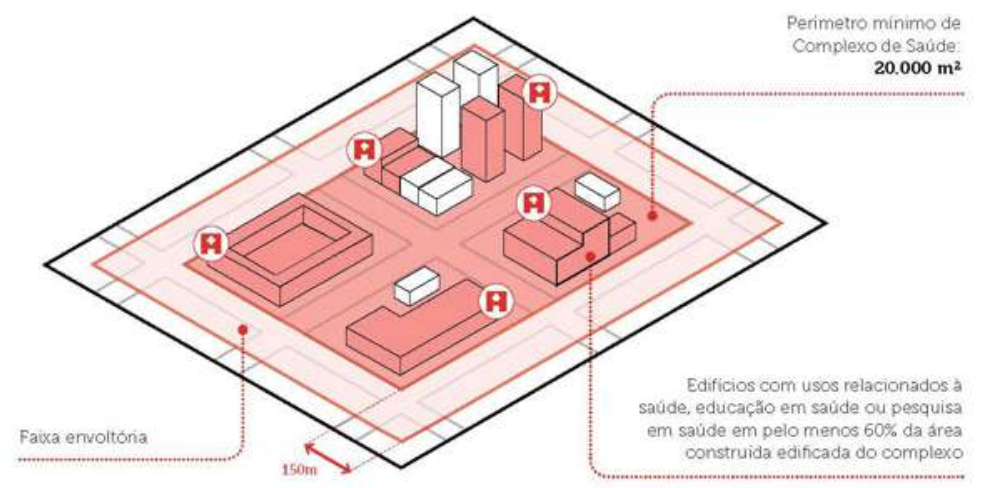

Fonte: (PREFEITURA DE SÃO PAULO, 2016, p. 94)

Na Figura 17 pode-se ver que dentro do Polo de Saúde, em verde tracejado, contempla a maioria dos edifícios geridos pelo CSP (EDIFICACOES_CSP_ATRIBUTOS), e além disso, engloba outras instituições que são serviços de saúde.

Estabelecimento de serviços de saúde, como laboratórios, farmácias, clínicas, ambulatórios e hospitais que estão dentro do perímetro do "complexo de saúde" ganham incentivos urbanísticos, porém, não foi identificado ainda movimentos para melhor planejamento do complexo como um todo.

Com uma ocupação próxima de um quarto da área do complexo de saúde, o Campus São Paulo é uma das instituições mais privilegiadas por esse incentivo urbanístico. Apesar disso, questiona-se se o incentivo não acarreta em especulação imobiliária na região, o que, considerando que o instrumento de incentivo via polo de saúde ser recente, pesquisas posteriores podem ser feitas para refutar ou confirmar esta hipótese.

\footnotetext{
${ }^{51}$ Conforme despacho 317/2017 da Secretaria Municipal de Urbanismo e Licenciamento (SMUL)
} 
Por se tratar de um campus, a política e custos imobiliários da região impactam no orçamento e no planejamento do CSP. Por isso desde o primeiro plano diretor da instituição, em $1982^{52}$, já havia a preocupação de incluir análises do entorno nos planos.

Figura 17 - Mapa do Campus São Paulo - Unifesp - com outros serviços de saúde - ano: 2017

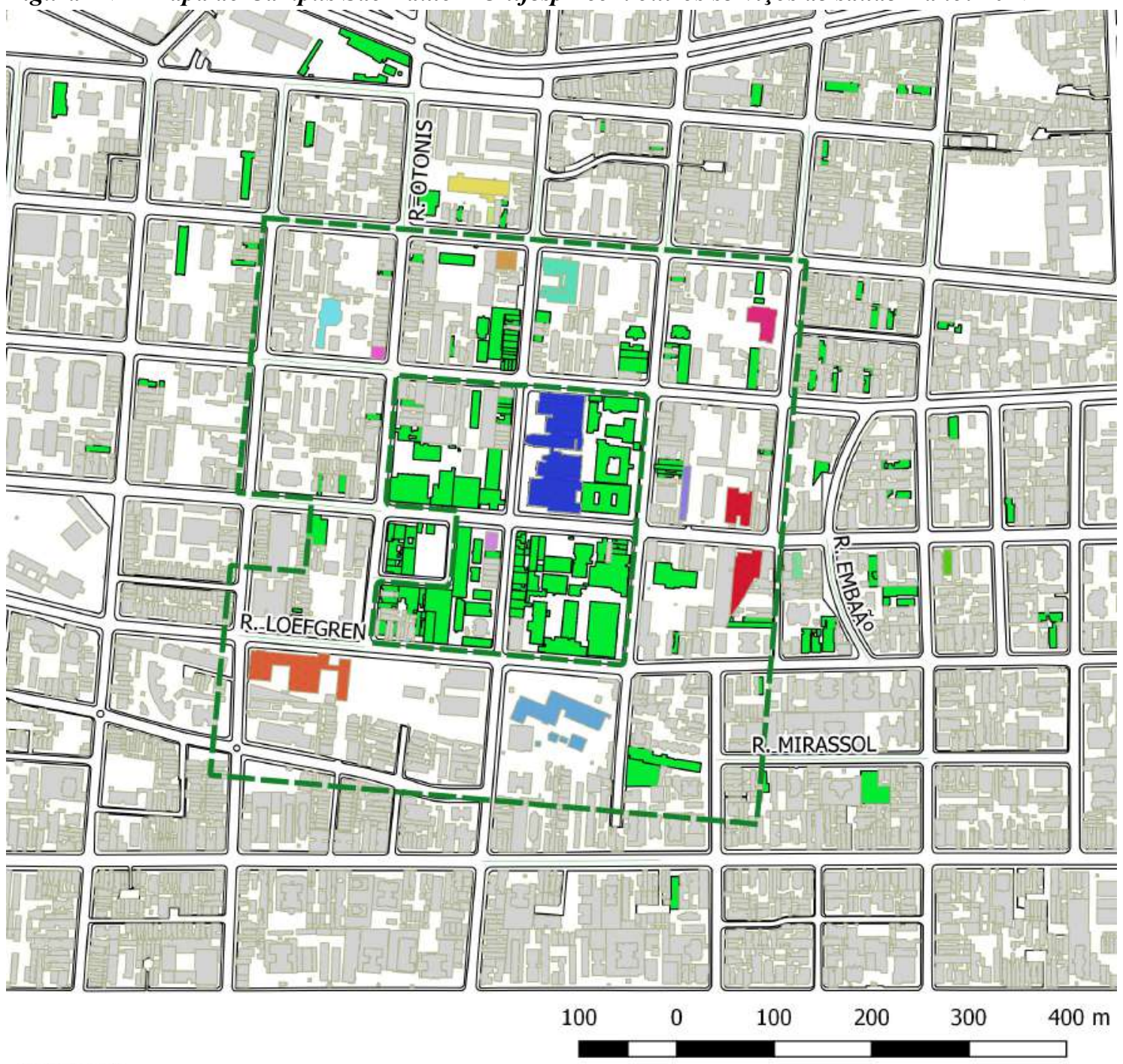

LEGENDA

TECIDO URBANO

NOME_RUAS_PRINCIPAIS

- $=$ POLO_SAUDE_ENSINO_PESQUISA_SIRGAS200

OUTROS SERVIÇOS DE SAÚDE_com nomes
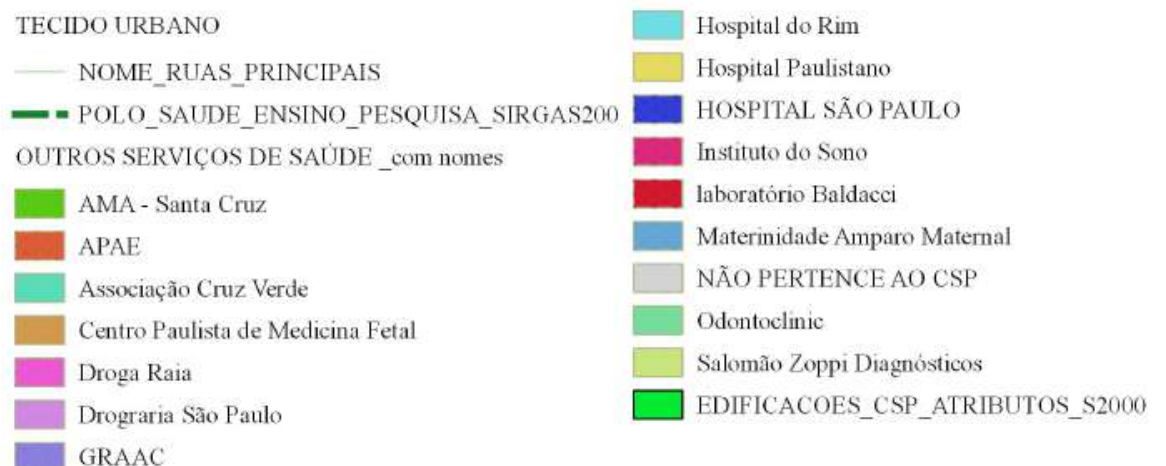

Fonte: Base georreferenciada formulada por MPS Arquitetos Associados, 2017

${ }^{52}$ Ver Apêndice $\mathrm{C}$ para mais detalhes dos planos diretores anteriores 
Ainda a respeito do contexto urbano do CSP, verifica-se que os principais usos do entorno, segundo a Prefeitura, são de uso residencial vertical médio e alto padrão, seguido pelo uso misto de residencial e comércio/serviço, como verificado no mapa localizado no Apêndice B.

Este conjunto edificado, uma área de urbanização consolidada, propiciou uma característica marcante do CSP, que são as "casinhas", em outras palavras, sobrados ou pequenos edifícios que foram alugados e adaptados para uso de pesquisa, assistencial ou administrativo.

Adaptar as atividades a um edifício existente ao invés de utilizar todo o potencial construtivo do terreno pode ter sido uma estratégia para a falta de recursos, ou mesmo da falta de alguma diretriz de longo prazo para resolução dos problemas de espaço, porém, esse modelo visto em retrospecto, se mostrou problemático.

Atualmente os problemas relacionados à essa ocupação dispersa são de altos custos de aluguel, aumento da necessidade de contratos de segurança, de manutenção e de outros recursos humanos. Além disso, a adaptação desses edifícios não resulta necessariamente no atendimento de normas de acessibilidade, de segurança contra incêndios ou outras normas relativas à serviços de saúde e pesquisa.

O uso do máximo possível do potencial construtivo de um terreno parece ser uma das soluções viáveis para a Universidade, uma vez que o campus se encontra em uma Zona de Estruturação Urbana $(\mathrm{ZEU})^{53}$, cuja principal característica é direcionar crescimento nas proximidades a transporte público de massa.

Como equipamento urbano, um campus universitário influencia as dinâmicas da cidade, socialmente e culturalmente pela sua função de ensino, pesquisa e extensão; economicamente, por ser um polo de atração de público e de serviços e ser uma das variáveis na flutuação de preços de imóveis e valor de terreno do entorno.

Pela relevância do tema, universidades e outras instituições de ensino tem maiores incentivos, como se verifica na lei de Parcelamento, Uso e Ocupação do Solo decorrente do Plano Diretor Estratégico (PDE) do Município de São Paulo, além do caso específico do instrumento de polo de centralidade. Estes incentivos se encontram nos artigos $114 \mathrm{e}$ 115 da Lei do PDE (PREFEITURA DE SÃO PAULO, 2016).

\footnotetext{
${ }^{53}$ Para otimizar a ocupação das áreas com boa oferta de transporte público coletivo e fomentar centralidades locais, o Plano Diretor instituiu os Eixos de Estruturação da Transformação Urbana Existentes e Previstos próximos às estações de trem, metrô e corredores de ônibus. No zoneamento, essas quadras foram demarcadas como as Zonas Eixo de Estruturação (ZEU) e Zonas Eixo de Estruturação Previsto (ZEUP). (PREFEITURA DE SÃO PAULO, 2016)
} 
Neste caso, é possível que haja uma convergência entre as demandas institucionais e o planejamento municipal, pois há interesse em expandir atividades acadêmicas de um lado, e orientação de adensamento de atividades próximas a transporte público de massa do outro.

A Unifesp declara orientações a respeito do seu planejamento através do Plano de Desenvolvimento Institucional (PDI), em que se verifica aderência a essa premissa de urbanidade:

Integração com o entorno. A universidade deve ser um modelo de relação com a cidade e seu entorno, proporcionando um ambiente em que os membros da comunidade possam conviver. A construção do campus deve refletir a ideia de abertura e interpenetração entre o espaço urbano e o espaço educacional. (UNIFESP, 2016, p. 137)

Portanto, o contexto urbano no qual se encontra o Campus São Paulo, com entorno consolidado, porém com alto potencial construtivo latente, de perfil residencial e grande presença de estabelecimentos de serviço de saúde, é pouco semelhante às demais referencias nacionais apresentadas, ainda mais porque são de tipologias de implantação diferentes.

\subsubsection{PLANO DIRETOR DE INFRAESTRUTURA DO CAMPUS SÃO} PAULO

O PDInfra teve início em 2016, porém não foi o único plano diretor desenvolvido para a instituição. O primeiro registro encontrado de um plano foi o "Plano Geral de Desenvolvimento" de 1982, à época ainda como Escola Paulista de Medicina. Décadas depois, em 2010, em convenio com a Prefeitura de São Paulo, foi formado o "Grupo de Trabalho Bairro Universitário" para um novo plano diretor da instituição.

Os planos que antecederam o PDInfra, da (EPM, 1982) e (GTBU, 2010) se encontram no Apêndice $\mathrm{C}$, com maiores detalhes de cada projeto institucional.

Apesar da experiência do GTBU, não houve continuidade do projeto urbano preliminar, de modo que a Universidade optou por realizar um novo plano. Após debates a respeito do escopo que seria colocado no edital de concorrência, inclusive pesando as questões orçamentárias associadas a estas escolhas, e de duas experiências de Plano Diretor de Infraestrutura (PDInfra) em campus menores, o do Campus Diadema (UNIFESP, 2014) e Campus Baixada Santista (UNIFESP, 2015), foi realizada licitação 
para contratação de empresa especializada em planos diretores para prestar consultoria ao Campus São Paulo na formulação de seu PDInfra ${ }^{54}$.

Em 2016, a empresa vencedora do certame, MPS Arquitetos Associados firmou o contrato com a Unifesp, cujo escopo consistia, resumidamente, em:

- 2 Relatórios Preliminares da situação existente sendo:

○ Levantamento de documentos, legislação e normas técnicas

- Cadastramento da situação existente

- 1 Estudo de visão de futuro e cenários estratégicos;

- 5 Planos temáticos:

- Política de Imóveis e programa de necessidades

- Desenho urbanístico e estudo preliminar das edificações

- Mobilidade e Acessibilidade

- Plano de regularização de imóveis

- Campus sustentável

- 1 Plano de investimentos e cronograma físico-financeiro consolidado.

Outro fator do edital que indica a priorização destes produtos é a exigência de Equipe Técnica Mínima, que consiste em:

- Arquiteto ou Engenheiro (para Coordenação)

- Arquiteto e Urbanista

- Engenheiro de transporte ou civil ou arquiteto (para mobilidade)

- Engenheiro ambiental

- Arquiteto ou Engenheiro (para conforto ambiental)

- Engenheiro civil ou Economista ou Administrador (para orçamento)

- Cientista social, Pedagogo, Psicólogo ou Assistente social (para planejamento)

- Arquiteto ou Engenheiro civil (para regularização)

Verifica-se então que o edital busca trazer ao PDInfra uma visão ampla do Campus São Paulo, com planos voltados exclusivamente a fatores internos, como a regularização e acessibilidade, até planos urbanos de desenho, mobilidade e sustentabilidade. Embora separados por temas, os planos têm que ser convergentes nas suas proposições.

Outro fator que se destaca dos planos anteriores é a exigência, em edital, de haver processo participativo orientado por profissional especializado no assunto. Os projetos

\footnotetext{
${ }^{54}$ Concorrência - Técnica e Preço 04/2015 - Processo número 23089.000639/2013-91: Edital de licitação na modalidade concorrência do tipo técnica e preço para contratação de empresa especializada em planejamento para elaboração do Plano Diretor de Infraestrutura do Campus São Paulo
} 
anteriores são o que poderia se chamar de "projetos de gabinete" em que participações são mais restritas.

Ressalta-se que os levantamentos, informações e propostas aqui apresentadas do PDInfra são relacionadas ainda ao processo de formulação, não sendo necessariamente, a versão final aprovada em todas as instancias de decisão da Universidade.

A respeito do diagnóstico da situação, esta é muito semelhante à do constatado em 2010, com atividades ainda espalhadas pelo bairro, embora com número menor de edifícios ou "casinhas" alugadas. Baixo uso do potencial construtivo, apesar da inauguração de um edifício vertical de pesquisas novo em $2007^{55}$, predominam os prédios baixos.

Uma situação que havia sido diagnosticada em 1982 que de certa forma se mantém é a aparente descontinuidade física de atividades do mesmo tipo. Em levantamento realizado pela empresa, em 2017, verificou-se os usos predominantes de cada edifício, embora alguns tenham mais de uma predominância, e que atividades afins que poderia compartilhar de mesmas infraestruturas, estavam distantes ou dispersas.

Foram considerados usos acadêmicos nos edifícios onde estão áreas de estudo, bibliotecas, sala de professores, departamentos acadêmicos, salas de aula e outras atividades relacionadas. Há pelo menos este tipo de atividade em pelo menos 7 quadras diferentes,

O uso assistencial ocorre nos edifícios onde há ambulatórios, posto de coleta, farmácias, alguns tipos de pesquisa clínica e departamentos clínicos. Ao menos 14 quadras tem um edifício com este tipo de atividade, sendo esta a atividade com maior dispersão.

A pesquisa ocorre nos edifícios onde há laboratórios, dos mais diversos tipos, entre eles o biotério, que acabou sendo colocado como categoria separada por ter especificidades e regulamentações próprias. Em 6 quadras há pelo menos 1 edifício com esta atividade.

Os edifícios com uso administrativo estão mais relacionados aos departamentos administrativos, aos escritórios e salas de reunião. Também 6 quadras têm ao menos 1 edifício com atividades correlatas.

Em “outros", estão atividades como estacionamentos, creche, atlética, restaurante universitário, edifícios alugados a terceiros, entre outros. 55 http://www.saopaulo.sp.gov.br/spnoticias/ultimas-noticias/unifesp-inaugura-edificio-para-pesquisa-e-
desenvolvimento-de-tecnologia/ 
Na Figura 18 pode-se ver na maquete eletrônica as atividades predominantes de cada edifício no momento do diagnóstico, em 2017, e a localização e volumetria das edificações utilizadas pela universidade.

Figura 18 - Edificios de uso Campus São Paulo e atividades predominantes (2017)

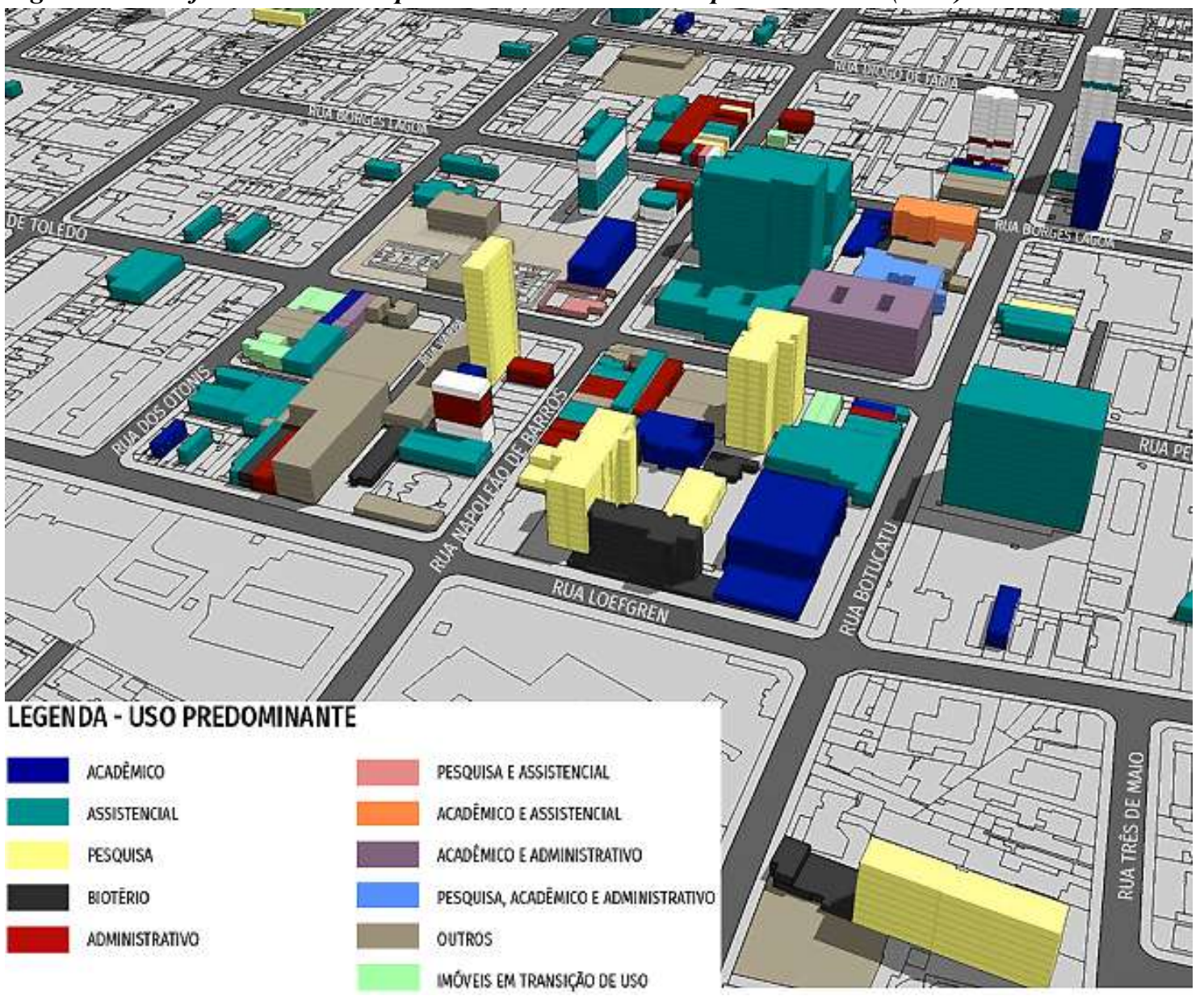

Fonte: MPS Arquitetos Associados

Dos relatórios preliminares propostos, contendo os aspectos legais, normativos e os cadastro do existente, é uma demanda que remete ao plano de $1982^{56}$, quando se verifica que a falta de um cadastro, ou seja, das plantas dos projetos arquitetônicos, de instalações e de leiaute seria prejudicial a um processo de planejamento.

O destaque no edital para que sejam produzidos dois relatórios preliminares antes de proposições faz jus ao conceito de plano diretor defendido pelo professor Flávio

56 “Acrescente-se a este quadro o fato de que grande parte dos edifícios e a totalidade da infra-estrutura não mais possuem um cadastro confiável, impossibilitando qualquer projeto ou orçamento de alguma reforma, com certa precisão". (EPM, 1982, p. 44) 
Villaça, que no caso, eram para cidades, porém, analogamente podem ser aplicadas também a universidades.

O cronograma proposto no edital, que previa 7 quinzenas para a produção destes dois relatórios, para, somente a partir da $3^{\circ}$ quinzena iniciar o plano de política de imóveis, com estudos de visão de futuro a partir da $5^{\text {a }}$ quinzena foi frustrado por razões de ordem prática, pois a atualização cadastral de mais de $100.000 \mathrm{~m}^{2}$ se mostrou inviável em menos de 2 meses, além da dificuldade de acessos por parte da empresa a alguns edifícios, pelas atividades que ocorrem, como assistência e certos tipos de pesquisa, ou mesmo pela exigência de algumas chefias, da presença de um servidor da instituição para acompanhar a empresa durante todo o levantamento.

Um dos produtos deste relatório preliminar o cadastramento de todos os recintos (salas e ambientes) em todos os imóveis do Campus São Paulo no formato numérico na forma [campus].[unidade].[edifício].[pavimento].[sala] por exemplo, 12.34.567.89.1234. Além disso, essas informações deverão estar georreferenciadas com coordenadas tridimensionais. Além de servir como base para o planejamento, estas informações, podem ser a base de um sistema de gestão de espaço físico, englobando tanto informações administrativas, quanto de infraestrutura futuramente.

O diagnóstico, portanto, como base do plano diretor é um dos fatores que orienta as análises que posteriormente também irão influenciar nas decisões e propostas. $\mathrm{O}$ escopo do diagnóstico, sobre quais informações e dados deverão ser levantados, compilados e analisados é um dos itens a se analisar em um plano.

No caso do PDInfra do Campus São Paulo, em edital, foi exigido uma série de levantamentos de informações com destaque a:

- Caracterização do espaço, com localização, tamanho, uso, vinculação (departamento, disciplina, seção, etc), propriedade, matricula e número de usuários;

- Resíduos sólidos, o volume de geração, acondicionamento e descarte;

- Acessibilidade;

- Conforto ambiental (térmico, acústico, luminoso);

- Ergonomia;

- Segurança contra incêndio;

- Infraestrutura peatonal, cicloviária, transporte público, viário e estacionamentos;

- Legislação urbana.

Por exigir uma base de informações consistente e diversa, o PDInfra apresenta característica de um plano de expansão e de consolidação, pois sabe-se de antemão, que há possibilidade de uso de potencial construtivo, porém, que não se deve esquecer a necessidade de regularização e readequação da estrutura existente. 
Os assuntos abordados pelos planos temáticos também são indicativos de um planejamento ampliado, não limitado às questões programáticas de uma universidade, pois inclui no escopo desenho urbano e sustentabilidade.

O Plano Temático de Política de Imóveis e programa de necessidades, que chamaremos de plano temático 1, é um tema comum a todos os planos diretores analisados nesta pesquisa. Em geral, o planejamento institucional fica limitado ao programa de necessidades para adequação, ampliação e construção de imóveis.

O Plano Temático 1 contou com um diagnóstico, por edifício, de demandas de regularização de bombeiros, de conforto ambiental, de ergonomia, de acessibilidade, de resíduos, de ar condicionado e de medição de água. A partir deste diagnóstico a empresa deveria propor configurações espaciais e funcionais do campus para ser debatidas através de um processo participativo.

A política de imóveis, deste mesmo plano temático, deve considerar o patrimônio imobiliário da universidade e estabelecer estratégias para definição de uma política de locações, compras, desapropriações, permutas ou venda de imóveis do Campus.

Os cenários propostos devem seguir diretrizes do edital para este plano, tais como considerar usos complementares de atendimento à comunidade acadêmica (lanchonetes, bancos comerciais, etc), avaliar patrimônio arquitetônico (valores culturais, urbanísticos, paisagísticos e ambientais), propor espaços de encontro e reunião, promover flexibilidade e capacidade de adaptação a novas tecnologias, promover integração entre espaços universitários e a cidade.

Em suma, o Plano Temático 1 se refere ao ambiente construído, seu uso e as diretrizes de uso e ocupação em cenários estipulados para 5, 10 e 20 anos dentro de premissas e valores que estejam declaradas em documentos oficiais como o Plano de Desenvolvimento Institucional (PDI).

O Plano Temático 2 - Desenho urbanístico e estudo preliminar das edificações, como um produto decorrente do primeiro, desenvolve estudos preliminares das edificações propostas e como será a relação com a cidade através do desenho urbanístico.

Os estudos preliminares deverão considerar as interfaces dos edifícios com o sistema viário e entorno, como acessos, sistemas de segurança, carga e descarga, barreiras físicas, equipamentos urbanos, entre outros. Estes estudos deverão também estar conformes com a legislação, normativas e códigos vigentes. 
Com relação à volumetria e implantação, as edificações deverão ser propostas buscando o melhor posicionamento solar, ventilação e iluminação, contemplando assim condições mais próximas possíveis para conforto ambiental urbano.

Adoção de partido de projeto arquitetônico e urbanístico que contemple flexibilidade, modularidade, padronização, otimização construtiva considerando a facilidade de manutenção e capacidade de adaptação a modificações futuras.

O Plano Temático 2, portanto, dá a volumetria e visão preliminar das propostas, a partir de premissas comuns a outros planos, em quesitos de eficiência energética, sustentabilidade, regularização e outros.

O Plano Temático 3 - Mobilidade e Acessibilidade deve realizar uma série de estudos referentes aos resultados do Origem-Destino, desenvolvido a cada 10 anos pelo Metrô de São Paulo, as condições da infraestrutura existente na região do campus, deslocamento interno, demandas e marcos jurídicos que regulam as políticas de mobilidade. Da parte de acessibilidade, que já deve estar contemplada em novos projetos, deve-se formular um plano de incremento de acessibilidade dos edifícios existentes.

Neste plano estão também diretrizes para um projeto básico de comunicação visual, desde indicação de placas de trânsito até sistema de comunicação visual interna, com a localização de edifícios e de recintos, que pode estar integrado a preceitos de sinalização de segurança de rotas de fuga, por exemplo.

Estes estudos compõem o diagnóstico da situação do campus, nos quesitos de mobilidade e acessibilidade, de forma a ter possibilidade de pleitear melhorias em linhas ou oferecimento de modais de transporte público ou mesmo projetos de intervenção.

O Plano Temático 3, portanto, dá ao desenho urbano mais uma camada qualitativa, considerando questões de mobilidade, que geralmente não são contempladas em planos diretores universitários. E o tema da acessibilidade faz uma ponte com o próximo plano, que está relacionado com a regularização dos imóveis.

O Plano Temático 4 - Plano de Regularização de imóveis foca na conformidade legal dos seus edifícios e de suas atividades. No quesito edificações e imóveis, deve-se verificar se estes atendem as legislações e normas de segurança contra incêndio, acessibilidade, segurança sanitária e outras exigências que porventura sejam feitas por órgãos pertinentes. No quesito atividades, deve-se verificar se há pendencias e devidas adequações de laboratórios, no que se refere a uso de elementos radioativos, biossegurança, experimentação em animais e resíduos especiais, entre outros. 
Complementando o diagnóstico sobre a conformidade dos edifícios e atividades, se deu um enfoque maior a projetos legais de segurança e prevenção de incêndios, como um dos primeiros passos para obtenção do Auto de Vistoria do Corpo de Bombeiros, em edital foram exigidos projetos para 50 mil metros quadrados de edifícios, cerca de $40 \%$ da área construída do campus.

O Plano Temático 4, portanto, busca a consolidação do campus existente, com projetos legais para os principais e diretrizes para continuidade de ações necessárias para o restante dos edifícios. Entre os levantamentos, a questão de resíduos sólidos se mostra importante não só para este plano, quanto para o próximo, relacionado à sustentabilidade.

O Plano Temático 5 - Campus Sustentável, também contempla os aspectos internos e externos ao campus. Internamente, deve-se verificar a regularização dos imóveis nos quesitos de conforto ambiental, e das atividades especificas como laboratórios, biotérios, reagentários, abrigos de resíduos, entre outros.

Este plano tem afinidades com outras políticas institucionais como o Políticas de Excelência em Sustentabilidade (PENSA-UNIFESP), o Agenda Ambiental da Administração Pública (A3P), Plano de Logística Sustentável (PLS) e a Política de Resíduos Sólidos (PRS). Todos estes planos estão alinhados ao tema, porém tem níveis diferentes de proposição, alguns mais detalhados, outros com diretrizes. O edital cita alguns destes planos para que os planejadores busquem compatibilizar e complementar essas políticas com as informações levantadas e com o contexto dos outros planos em consideração.

Aspectos externos à universidade estão relacionados a diminuição do impacto ou do consumo de recursos naturais pelo campus. Isso se dá pelas diretrizes estipuladas para o plano, que é a elaboração de plano de gerenciamento de resíduos sólidos, de um plano de uso racional de água e um plano de uso racional de energia elétrica.

Considerar os aspectos internos e externos ao campus, coincide com um dos princípios declarados no Plano de Desenvolvimento Institucional (PDI) o da Sustentabilidade, bem viver social e ambiental (UNIFESP, 2016), o PDI orienta os demais planos a serem formulados durante sua vigência, que é o caso do PDInfra.

O caráter propositivo do PDInfra direciona a projetos, obras e ações que deverão contemplar orçamento ou fonte de recurso, por isso, como fio condutor dos planos temáticos, o Plano de Investimentos e cronograma físico-financeiro, traz aos cenários de visão de futuro o planejamento e avaliação de custos. A avaliação do investimento necessário para contratação e gerenciamento de projetos de reformas e novas construções; de aquisições de terrenos; de urbanização; de mobiliário; de equipamentos; de contratos de manutenção; de programas de gestão ambiental e sustentabilidade; e de transportes. 
Encerrando o plano com o planejamento financeiro reforça a intenção da universidade em querer viabilizar as propostas de maneira estruturada, considerando a construção, mas também sua manutenção.

Este destaque aos itens do edital tem intenção de demonstrar o conteúdo mínimo que será apresentado na versão final do PDInfra, a ser colocado para consulta e deliberação de conselhos locais e centrais da Universidade, como o Conselho de Campus e o Conselho Universitário.

O material exigido no edital, conforme exposto, demonstra a consolidação de um processo anterior de discussão a respeito de custos de contratação, de escopo, de cronograma de execução, ou seja, de preparação do edital. Por se tratar de uma consultoria externa, a qualidade do plano também exige um edital bem estruturado.

Comparando o processo dos três projetos, de 1982, 2010 e 2016 podemos perceber que a visão mais programática para atender a demandas de espaço, vai dando espaço para novas disciplinas, já a partir do plano de 2010, preocupadas com questões ambientais e urbanísticas.

A ampliação das análises, escopos e propostas gera mudanças na operação e execução do planejamento institucional. Na operação, a mudança começa pela equipe de formulação, sendo necessário mais profissionais de outras áreas e expertises, não apenas de arquitetos e engenheiros. No caso do plano de 2010, houve participação da Secretaria Municipal de Planejamento, da Secretaria Municipal de Transportes, da Universidade Federal de São Paulo, da Agencia de Desenvolvimento de São Paulo, da Subprefeitura da Vila Mariana, do Gabinete do Prefeito, da Câmara Municipal de São Paulo, da Secretaria Municipal de Desenvolvimento Urbano e da Assessoria Técnica de Operação Urbana ${ }^{57}$, ao mesmo tempo em que, no caso do PDInfra, além da equipe técnica exigida em edital, haveria a fiscalização técnica da Universidade.

$\mathrm{Na}$ formulação e na execução do plano, também há maior necessidade de negociação por parte da Instituição em propor mudanças e melhorias em áreas públicas (como calçadas), de contratos de concessão públicos (como os de transporte) ou mesmo com outros entes, públicos ou privados, para levantar recursos ou estabelecer parcerias. Diferentemente de propostas que exigem apenas recursos, terrenos e edifícios próprios para serem concretizados.

As comparações dos 3 planos também podem ser contextualizadas historicamente, o de 1982 estava sob outra Constituição Federal, enquanto as duas últimas sob a

\footnotetext{
${ }^{57}$ Grupo de Trabalho BAIRRO UNIVERSITÁRIO: Portaria 3089 de 07 de Agosto de 2006.
} 
“Constituição Cidadã” de 1988. No contexto municipal, os 3 planos estiveram sob Planos Diretores municipais diferentes. No contexto institucional, o primeiro plano ainda era como escola de medicina, e os dois últimos como universidade.

O quadrilátero principal entre as ruas Loefgreen, Borges Lagoa, Botucatu e Otonis dado hoje como núcleo do Campus São Paulo é o objeto comum entre os planos referenciados.

Os processos do planejamento também foram distintos, o de 1982 foi realizado por equipe técnica interna, o de 2010 foi realizado por convenio entre Prefeitura e Universidade e o de 2016 via contratação de empresa especializada. Outro fator é que os dois primeiros realizaram consultas aos interessados na ocupação das áreas, enquanto que no último, houve a proposta de processo participativo.

\subsubsection{PROCESSO PARTICIPATIVO}

Quando se fala de planejamento, pode-se associar a um processo puramente técnico, o que é uma concepção equivocada. Ao criticar o urbanismo moderno, o filósofo e sociólogo Henri Lefebvre fala sobre o "mito da tecnocracia":

os tecnocratas estão lá para dissimular o fato de que é um mínimo de tecnicidade que é aplicada por toda parte. O publico crê que se elabora soluções técnicas e que há razoes profundas para aceitá-las, para impôlas, mas na realidade há um mínimo de tecnicidade em urbanismo e em arquitetura." (LEFEBVRE, H. [1970]2001: 220) (COLOSSO, 2016)

Esta concepção de planejamento tecnocrático, ao menos no Brasil, é amenizada pela exigência, em lei, de processos participativos na formulação de planos diretores (BRASIL, 2001). A sociedade civil ter possibilidade de participação do planejamento não se refere à capacidade técnico-científica de análise e proposição, mas principalmente de uma participação política:

Mas participação não se resume a um acesso ao solo e aos bens da cidade, o que é fundamental, mas não suficiente. Diz respeito também a ter voz ativa nas questões do destino comum, aquelas que impactam as vidas individuais e ao mesmo tempo a de todos. Nesta acepção, a participação diz respeito primordialmente ao campo do político. (COLOSSO, 2016)

No contexto do processo participativo do PDE, em audiências públicas e oficinas, demandas locais como a definição de polos de centralidade ou de incentivos para 
equipamentos de educação e saúde foram apresentadas ao poder municipal para serem contempladas nas discussões da formulação da lei.

A participação popular nos processos de planejamento é obrigatória por lei, embora não seja explícito qual número de audiências e quais procedimentos mínimos para efetivação dessa participação. Como referência, o $\mathrm{PDE}^{58}$ teve 114 audiências públicas e 25.692 participantes, com propostas presenciais e via web. Ou seja, considerando a população do Município de São Paulo, houve participação efetiva de 0,21\% dos habitantes.

De maneira análoga, o PDInfra teve no seu edital de concorrência a exigência de equipe especializada em desenvolver processos participativos. Considerando a população efetiva do campus de $16.409^{59}$ e com total de participantes $141^{60}$, houve participação de $0,86 \%$. (ver Tabela 3)

Tabela 3 - Participação da população em processos participativos de planos diretores

\begin{tabular}{llll}
\hline & População & Participações & Part./Pop. \\
\hline PMSP & 12.106 .920 & 25.692 & $0,21 \%$ \\
\hline Unifesp & 16.409 & 141 & $0,86 \%$ \\
\hline
\end{tabular}

Fonte: Prefeitura de São Paulo; Documento Síntese do processo participativo formulado por MPS Arquitetos Associados, 2017.

Nota: população Unifesp estimada a partir de dados do PDI (UNIFESP, 2016)

O processo participativo do PDInfra teve dois momentos, o de Oficinas de Trabalho e Reuniões Temáticas. A consolidação destas etapas consta no site da instituição ${ }^{61}$, por onde também foram divulgados as datas e assuntos abordados em cada encontro.

As Oficinas de Trabalho foram divididas em 5 temas:

- Tema 1 - Desafios da organização das atividades assistenciais para o ensino no século XXI no contexto do sistema de saúde - perspectivas para 5, 10 e 20 anos.

- Tema 2 - Organização de espaços dos departamentos clínico-cirúrgicos (áreas de docentes e área administrativa) - perspectivas para 5, 10 e 20 anos.

- Tema 3 e 4 - Organização de espaços para atividades didáticas e de pesquisa perspectivas para 5, 10 e 20 anos.

- Tema 5 - Espaços técnicos, admirativos e de apoio à infraestrutura - perspectivas para 5, 10 e 20 anos.

\footnotetext{
${ }^{58}$ Fonte: https://gestaourbana.prefeitura.sp.gov.br/marco-regulatorio/plano-diretor/processo-participativo/

${ }^{59}$ Considerando corpo discente, docente e técnico, fonte: PDI Campus São Paulo (2016)

${ }^{60}$ Fonte: Documento síntese do processo participativo formulado por MPS Arquitetos Associados

${ }^{61}$ (https://www.unifesp.br/campus/sao/pdinfra-csp),
} 
Cada tema teve reuniões específicas, em que se discutiam conceitos, ideias e propostas a partir da apresentação. A equipe contratada, então buscava nestas audiências, encontrar consensos e estabelecer encaminhamentos para as próximas etapas.

O teor das reuniões foi decidido por comissão designada para acompanhar o processo do PDInfra e os palestrantes são membros da comunidade acadêmica. As audiências eram abertas à participação, questionamentos e falas em geral.

O Tema 1 teve 5 reuniões:

- 08/09/16 - O que somos e como nos sustentamos: o SUS e as Diretrizes Curriculares; o HSP/HU, a SPDM

- 23/09/16 - Situação atual e perspectivas das atividades nos imóveis do Campus O Edifício dos Ambulatórios/Hospital-Dia (Rua Botucatu, 821) e Hospital da Criança e do Adolescente.

- 13/10/16 - Oncologia: como estruturar nosso serviço e a atuação baseada na convergência de práticas e saberes. Linhas de cuidado na abordagem ao paciente oncológico no HU/HSP.

- 27/10/16 - Reorganização do sistema ambulatorial: da organização por especialidade à atuação interdisciplinar e multiprofissional - Doenças Crônicas do Adulto, novas necessidades e demandas em saúde. A pesquisa na Assistência

- 10/11/16 - Organização dos serviços de Saúde Mental e de Reabilitação.

Os assuntos abordados neste tema indicaram quais direções a assistência do campus poderia ou deveria tomar. Como verificado nas primeiras análises de atividades predominantes dos edifícios, o setor mais espalhado pelo bairro era o de assistência.

O Tema 2 teve 1 reunião:

- 18/11/16 - Situação atual e necessidades dos departamentos clínicos e cirúrgicos: como queremos esses espaços? MPS: o processo de construção do PDInfra.

No diagnóstico, não há distinção das áreas administrativas de departamentos clínicos e cirúrgicos, esta demanda acaba se destacando pelas alterações realizadas internamente no Hospital São Paulo e que acabam aumentando a demanda por espaços no campus.

Os Temas 3 e 4 foram aglutinados, pois em discussões internas acabou se entendendo que espaços de ensino e pesquisa são afins. Foram 4 reuniões: 
- 07/10/16 - O Ensino e a Pesquisa nas Unidades Universitárias do CSP: o Plano de Desenvolvimento Institucional (PDI) 2016-2020 e perspectivas

- 14/10/16 - Situação atual de infraestrutura didática. Centro de Habilidades e Simulação; Centro Multidisciplinar de Cirurgia Experimental. Perspectivas.

- 21/10/16 - Novas tecnologias no Ensino na área de saúde e suas implicações na infraestrutura do CSP.

- 04/11/16 - Atuais espaços de Pesquisa e o Novo Complexo de Pesquisa e Ensino. Perspectivas para a Pesquisa Clínica. MPS: o processo de construção do PDInfra.

As áreas de pesquisa no campus, durante o processo participativo, eram menos dispersas que a área assistencial e a proximidade com edifícios acadêmicos importantes, de salas de aula e anfiteatros se mostrou determinante para aglutinar essas duas atividades, ao menos nas discussões para o plano. A lógica programática e da localização dos edifícios também é complementada por uma lógica didática, em que se busca o ensino através da prática (basicamente laboratórios).

Pelo próprio diagnóstico, as áreas administrativas, já estavam mais bem estruturadas e concentradas. No entanto, como demanda interna, os departamentos clínicos e cirúrgicos ainda não estavam com espaços definidos. Aproveitando o tema menos extenso, a empresa apresentou o processo de construção.

O Tema 5 teve apenas 1 reunião:

- 25/11/16 - Situação atual e necessidades para atividades administrativas das Escolas e do Campus. MPS: O processo de construção do PDInfra.

Pelo próprio diagnóstico, as áreas administrativas não estavam em situação dispersa, porém, nem por isso, menos necessitadas de adequações. Nesta reunião foram levantadas demandas dessas áreas.

O problema deste primeiro processo, é que as discussões e propostas estavam limitadas aos mesmos grupos de interesse. Em geral, houve consensos com relação às demandas levantadas, e os encaminhamentos se referiam a melhor detalhamento destas primeiras propostas.

Como pode-se verificar pelo registro fotográfico da Figura 19, as "oficinas temáticas" tinham o formato mais expositivo, os encontros eram em locais do tipo anfiteatro, com distinção entre platéia e palco, se aproximando do formato de uma palestra, com um período dedicado para debate a respeito do tema apresentado. 
Figura 19 - Registro de uma oficina temática

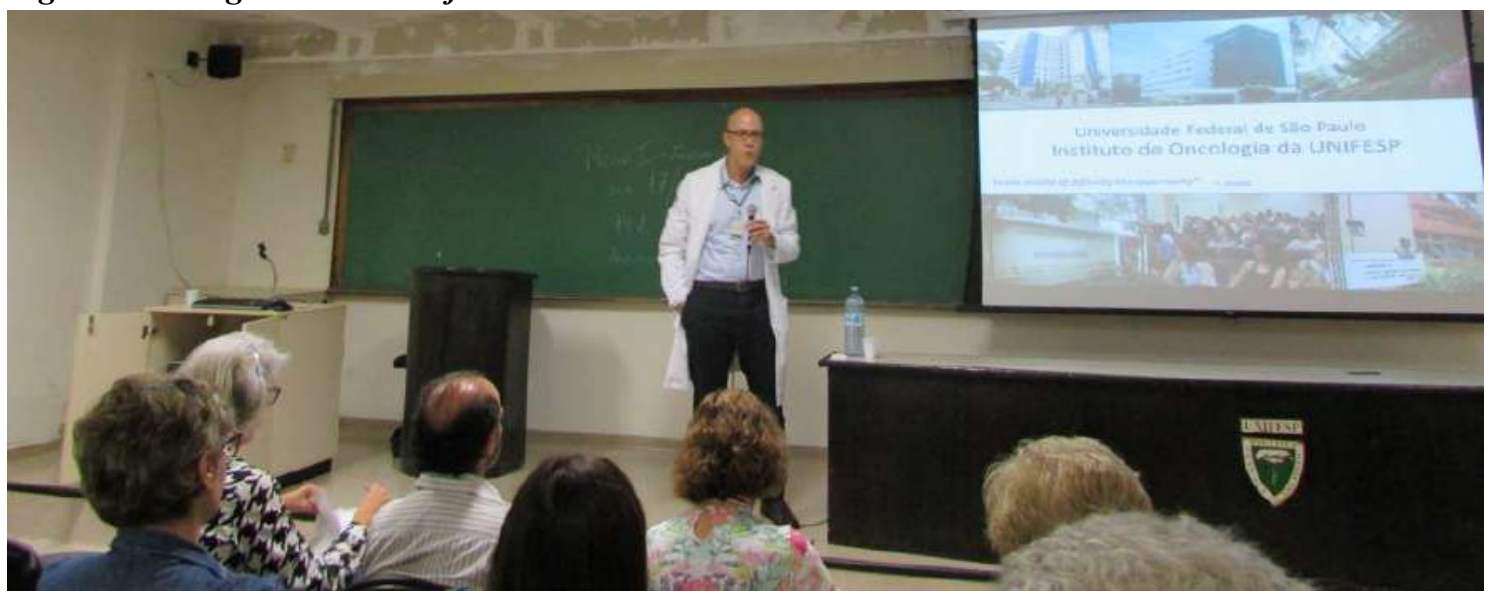

Fonte: https://www.unifesp.br/campus/sao/noticias/497-oficina-do-pdinfra-discute-estrutura-e-linhasde-cuidado-no-servico-oncologico

Complementando esta primeira fase, a empresa MPS Arquitetos Associados, propõe uma outra dinâmica, que no site foi publicada como "Reuniões Temáticas". As reuniões consistiam em 3 momentos: Levantamento, Discussões e Diagnósticos e Proposições. Em cada momento, serão abordados 5 temas:

- Tema 1 - Espaços de convivência para a comunidade

- Tema 2 - Estratégias para integração das atividades de pesquisa e otimização de seus espaços físicos

- Tema 3 - Estratégias para espaços de ensino e extensão

- Tema 4 - Estratégias de convergência de atividades acadêmicas e administrativas dos departamentos da EPM e da EPE e dos setores do Campus, e seus espaços físicos

- Tema 5 - Articulação das atividades e espaços de convergência intracampus e intercampi.

As reuniões temáticas tiveram um caráter mais "horizontal", fisicamente, por ser uma sala plana apenas com cadeiras, sem palco. E também menos apresentações e mais dinâmicas através de mapas, formulários e outras metodologias, como pode ser verificado pelo registro fotográfico da Figura 20. 


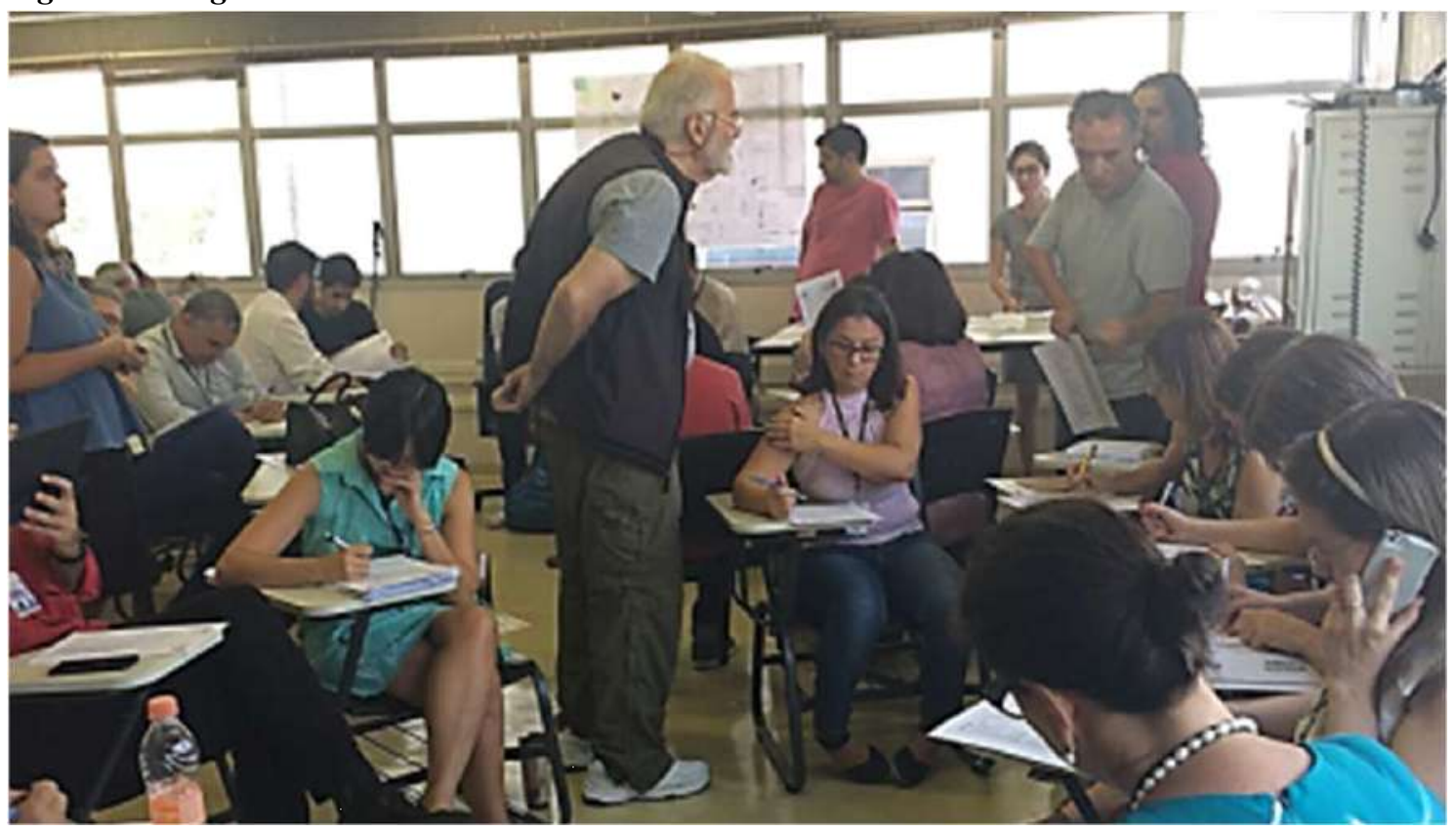

Fonte: MPS Arquitetos Associados

O objetivo destas reuniões era ampliar a discussão e o entendimento do campus como um todo, menos focado nas questões da própria área ou atividade. Esta fase do processo participativo foi baseada nas oficinas anteriores, nos documentos institucionais, como o PDI e os levantamentos técnicos exigidos em edital.

As reuniões se pretendiam curtas, de aproximadamente uma hora e meia, sempre às segundas e no mesmo local. As reuniões seriam divididas em 4 etapas: aquecimento, contrato, dinâmica e compartilhamento ${ }^{62}$. O aquecimento é uma atividade para promover a interação, o contrato é a apresentação das atividades programadas para a reunião, a dinâmica é a atividade em si, realizada em grupos, e o compartilhamento encerra com a troca de conclusões entre os grupos.

O processo participativo, além de servir de canal de abertura para proposições da comunidade acadêmica, o próprio processo levou a sensibilização de temas como as diferentes classificações de resíduos sólidos, necessidade de segregação correta, abrigo e transporte interno correto destes resíduos.

Na Figura 21 são apresentados os resultados da análise participativa de resíduos sólidos, que consistiu no questionamento dos presentes a respeito da conformidade no Campus de etapas do gerenciamento de resíduos sólidos. Destaca-se que o maior índice de "sem informação" se refere às áreas de transbordo do resíduo, ou seja, uma etapa anterior à coleta, em que os resíduos já não estão próximos do usuário. O mesmo não

\footnotetext{
${ }^{62}$ Metodologia apresentada no caderno Visão de futuro e cenários estratégicos
} 
ocorre no momento de segregação ("separação de resíduos") e circulação dos resíduos no edifício.

Figura 21 - Análise participativa dos resíduos sólidos comuns (úmido, seco e liquido)

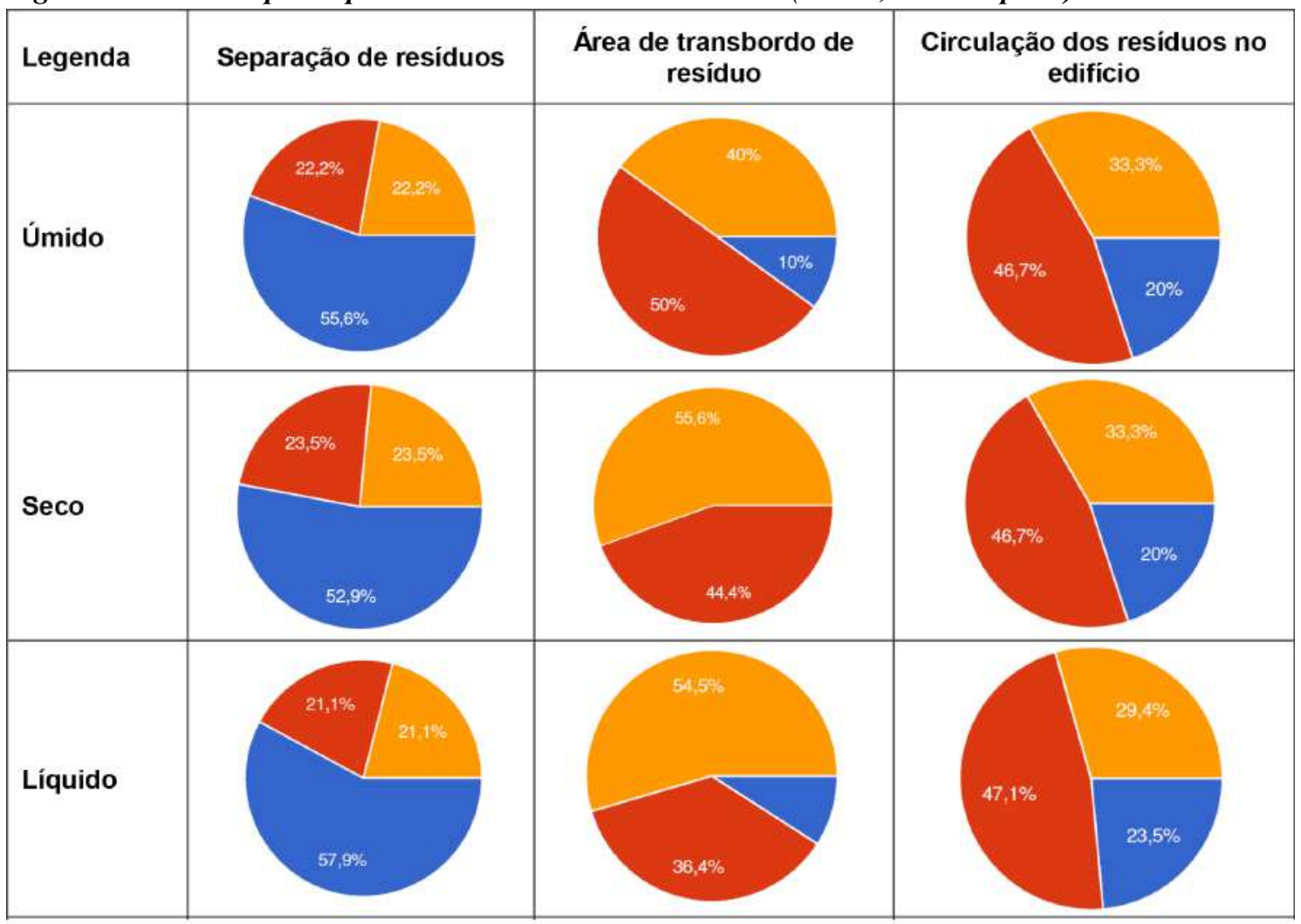

\section{Legenda:}

\section{Existente / Adequada}

\section{Inexistente / Inadequada}

\section{Sem informação}

Fonte: Documento Síntese do Processo Participativo - Etapa: Levantamento. Formulado por MPS Arquitetos Associados, 2017

Na Figura 22 a metodologia utilizada é a mesma da análise participativa de resíduos sólidos comuns. O que se destaca nesta análise é o alto índice de adequado para a segregação de resíduos sólidos infectantes. Como resíduos de serviço de saúde (RSS) podem oferecer risco de contaminação, os trabalhadores destas áreas já são mais instruídos e treinados para a adequada segregação, porém ainda não sabem informar como são as condições nas áreas de transbordo.

Por se tratar de um campus voltado às ciências da saúde, os resíduos infectantes tiveram um grande interesse por parte dos participantes. E embora a análise seja subjetiva, contando com a opinião dos participantes, pode-se intuir onde faltam campanhas de sensibilização e em quais áreas pode-se focar as primeiras ações do plano. 
Figura 22 - Análise participativa dos resíduos sólidos infectantes

\begin{tabular}{|c|c|c|c|}
\hline Legenda & Separação de resíduos & $\begin{array}{l}\text { Área de transbordo de } \\
\text { resíduo }\end{array}$ & $\begin{array}{c}\text { Circulação dos residuos no } \\
\text { edifício }\end{array}$ \\
\hline Infectante & & & $52,9 \%$ \\
\hline & & $27,3 \%$ & 170 \\
\hline
\end{tabular}

Legenda:

Existente / Adequada

Inexistente / Inadequada

Sem informação

Fonte: Documento Síntese do Processo Participativo - Etapa: Levantamento. Formulado por MPS Arquitetos Associados, 2017

Espera-se que estas oficinas e audiências tenham sensibilizado a comunidade a respeito de diversos temas relativos à sustentabilidade, relacionando questões importantes para a saúde ambiental à melhoramentos e novos espaços que são demandados.

A finalização do processo participativo ocorre com 3 reuniões de imersão ${ }^{63}$ de duração mais longa, das 08:30 às 16:30 com uma hora de intervalo. As três reuniões foram 1- Diagnosticar e Propor, 2- Pactuar e 3 - Estratégias para viabilizar.

No intuito de consolidar propostas e estabelecer prioridades, foram analisados 7 subtemas, de modo a não permitir que apenas um assunto sobressaia nos debates. Os subtemas foram Desenho Urbanístico, Sinalização do Campus, Gestão de Resíduos, Eficiência Energética, Eficiência no Consumo de água, Conforto Ambiental, Ciclos de Ações dos Imóveis.

As propostas foram apresentadas na forma de meta, diretriz, ações, responsável, público alvo, indicadores e prazo, metodologia semelhante ao do PLS, para cada um dos subtemas. Especificamente sobre a gestão de resíduos, as propostas envolvem questões administrativas, de pessoal, de infraestrutura e de espaço para serem resolvidas. Em destaque 3 propostas gerais, de resíduos infectantes e de resíduos químicos, que constam no Visão de Futuro e Cenários Estratégicos (ver Quadro 9, 10 e 11).

\footnotetext{
${ }^{63} \mathrm{https} / /$ www.unifesp.br/campus/sao/objetivos-e-acoes/processo-participativo/consolidacao-do-processoparticipativo
} 
Quadro 9 - Propostas para gestão de resíduos - Geral

\begin{tabular}{|c|c|c|c|}
\hline Meta & $\begin{array}{l}\text { Estruturação da equipe } \\
\text { de gestão dos resíduos } \\
\text { sólidos }\end{array}$ & $\begin{array}{l}\text { Regularização do uso dos imóveis } \\
\text { do campus }\end{array}$ & $\begin{array}{l}\text { Implementação de } \\
\text { sistema de controle de } \\
\text { resíduos para todos os } \\
\text { imóveis, incluindo } \\
\text { controle de geração } \\
\text { individualizado para } \\
\text { cada grupo }\end{array}$ \\
\hline Diretriz & $\begin{array}{l}\text { Definir forma de } \\
\text { ampliação do quadro } \\
\text { de funcionários } \\
\text { responsáveis pela } \\
\text { gestão de resíduos e } \\
\text { limpeza interna do } \\
\text { campus }\end{array}$ & $\begin{array}{l}\text { Esclarecer e reorganizar a } \\
\text { distribuição das atividades, } \\
\text { responsabilidades e atribuições } \\
\text { pelos imóveis. Distinguir } \\
\text { Reitoria, Hospital e Campus SP }\end{array}$ & $\begin{array}{l}\text { Criar sistema integrado } \\
\text { de informações sobre a } \\
\text { gestão dos resíduos de } \\
\text { uso compartilhado da } \\
\text { gestão administrativa } \\
\text { do campus e gestores } \\
\text { dos imóveis } \\
\text { individualizados }\end{array}$ \\
\hline \multirow[t]{3}{*}{ Ações } & \multirow[t]{3}{*}{$\begin{array}{l}\text { Realizar concurso } \\
\text { público para ampliação } \\
\text { das equipes ou } \\
\text { terceirizar atividade. }\end{array}$} & $\begin{array}{l}\text { Realizar levantamento de } \\
\text { atividades e seus vínculos } \\
\text { administrativos }\end{array}$ & $\begin{array}{l}\text { Contratar empresa } \\
\text { especializada em } \\
\text { sistemas eletrônicos de } \\
\text { controle de resíduos } \\
\text { adequado à Unifesp } \\
\text { CSP, garantindo a } \\
\text { gestão e } \\
\text { monitoramento das } \\
\text { informações }\end{array}$ \\
\hline & & $\begin{array}{l}\text { Redistribuir atividades nos } \\
\text { imóveis, de forma a garantir o } \\
\text { manejo dos resíduos pela } \\
\text { instituição responsável }\end{array}$ & Implantar o sistema \\
\hline & & & $\begin{array}{l}\text { Disponibilizar e } \\
\text { veicular as informações } \\
\text { sobre os impactos } \\
\text { econômicos da geração } \\
\text { de resíduos, de forma a } \\
\text { corresponsabilizar os } \\
\text { geradores }\end{array}$ \\
\hline Responsável & $\begin{array}{l}\text { Diretoria do } \\
\text { Campus. }\end{array}$ & $\begin{array}{l}\text { Diretoria do } \\
\text { Campus. }\end{array}$ & $\begin{array}{l}\text { Departamentos de } \\
\text { Infraestrutura e Divisão } \\
\text { de Tecnologia da } \\
\text { Informação }\end{array}$ \\
\hline $\begin{array}{l}\text { Público } \\
\text { Alvo }\end{array}$ & $\begin{array}{l}\text { Usuários: alunos, } \\
\text { professores, } \\
\text { funcionários, pacientes, } \\
\text { terceirizados }\end{array}$ & $\begin{array}{l}\text { Usuários: alunos, professores, } \\
\text { funcionários, pacientes, } \\
\text { terceirizados }\end{array}$ & $\begin{array}{l}\text { Comunidade } \\
\text { acadêmica, } \\
\text { fundamentalmente } \\
\text { gestores dos imóveis }\end{array}$ \\
\hline
\end{tabular}

Continua 


\begin{tabular}{|l|l|l|l|}
\hline Indicadores & $\begin{array}{l}\text { Redução das } \\
\text { inconformidades } \\
\text { apontadas, gestão } \\
\text { adequada de contratos, } \\
\text { monitoramento de } \\
\text { indicadores, } \\
\text { aprimoramento } \\
\text { completo do sistema de } \\
\text { manejo de resíduos. }\end{array}$ & $\begin{array}{l}\text { Redução de inconformidades, } \\
\text { distinção de responsabilidades } \\
\text { administrativas, redução de } \\
\text { acúmulo de resíduos, organização } \\
\text { das finanças. }\end{array}$ & $\begin{array}{l}\text { Sistema implantado, } \\
\text { relatórios mensais }\end{array}$ \\
\cline { 2 - 4 } & Curto & Médio & $\begin{array}{l}\text { Relatórios } \\
\text { disponibilizados no } \\
\text { sitio eletrônico da } \\
\text { UNIFES P e em } \\
\text { painéis e materiais } \\
\text { informativos }\end{array}$ \\
\hline Prazo & Curto \\
\hline
\end{tabular}

Fonte: Plano Temático - Visão de Futuro e Cenários Estratégicos (2017)

Nota: Planos Temáticos compõem o Plano Diretor de Infraestrutura do Campus São Paulo, a ser publicado.

Nas propostas gerais para gestão de resíduos há muitas questões administrativas, como contratação e regularização. A meta de estruturação de equipe de gestão de resíduos e de implementação de sistema de controle (ou monitoramento) reflete a falta de informações que o campus dispunha antes do processo de planejamento, que interfere na capacidade de planejamento de outras ações, vide PLS.

Quadro 10 - Propostas para gestão de resíduos - resíduos infectantes

\begin{tabular}{|c|c|c|c|}
\hline Meta & $\begin{array}{l}\text { Redução dos resíduos } \\
\text { infectantes }\end{array}$ & $\begin{array}{l}\text { Redução de riscos e } \\
\text { acidentes de trabalho }\end{array}$ & $\begin{array}{l}\text { Redução do volume de } \\
\text { resíduos oriundos da } \\
\text { maravalha dos } \\
\text { biotérios de criação }\end{array}$ \\
\hline Diretriz & $\begin{array}{l}\text { Promover a segregação } \\
\text { adequada dos resíduos } \\
\text { infectantes, de forma } \\
\text { que materiais não } \\
\text { infectantes sejam } \\
\text { descartados } \\
\text { corretamente. } \\
\text { Exemplo: embalagens } \\
\text { de materiais, materiais } \\
\text { defeituosos não } \\
\text { utilizados, etc }\end{array}$ & $\begin{array}{l}\text { Garantir a aquisição periódica de } \\
\text { caixas para materiais } \\
\text { perfurocortantes em proporção } \\
\text { adequada às atividades realizadas }\end{array}$ & $\begin{array}{l}\text { Adotar tratamento para } \\
\text { a maravalha oriunda } \\
\text { dos biotérios de criação } \\
\text { para redução de } \\
\text { volume } \\
\text { do resíduo }\end{array}$ \\
\hline \multirow[t]{4}{*}{ Ações } & \multirow[t]{4}{*}{$\begin{array}{l}\text { Estabelecer } \\
\text { cronograma de } \\
\text { treinamentos e reforçar } \\
\text { sinalização adequada }\end{array}$} & \multirow{4}{*}{$\begin{array}{l}\text { Rever contrato com empresa } \\
\text { responsável pelo manejo interno } \\
\text { dos resíduos garantindo a } \\
\text { quantidade necessária de } \\
\text { recipientes adequados }\end{array}$} & $\begin{array}{l}\text { Identificar local para } \\
\text { implantação dos } \\
\text { equipamentos de } \\
\text { tratamento do resíduo }\end{array}$ \\
\hline & & & $\begin{array}{l}\text { Adequar o local para } \\
\text { recepção dos } \\
\text { equipamentos e } \\
\text { atividades, bem como } \\
\text { treinamento da equipe } \\
\text { responsável }\end{array}$ \\
\hline & & & $\begin{array}{l}\text { Adquirir e instalar os } \\
\text { equipamentos }\end{array}$ \\
\hline & & & Iniciar a operação \\
\hline
\end{tabular}


continuação

\begin{tabular}{|l|l|l|l|}
\hline Responsável & $\begin{array}{l}\text { Departamento de } \\
\text { Infraestrutura } \\
\text { (Divisão de Gestão } \\
\text { Ambiental) }\end{array}$ & $\begin{array}{l}\text { Departamento de Administração - } \\
\text { Divisão de Serviços Gerais }\end{array}$ & $\begin{array}{l}\text { Departamento de } \\
\text { Administração } \\
\text { (Divisão de Serviços } \\
\text { Gerais), com o apoio } \\
\text { do Departamento de } \\
\text { Infraestrutura (Divisão } \\
\text { de Gestão Ambiental) e } \\
\text { responsáveis pelos } \\
\text { biotérios }\end{array}$ \\
\hline $\begin{array}{l}\text { Público } \\
\text { Alvo }\end{array}$ & $\begin{array}{l}\text { Usuários: alunos, } \\
\text { professores, } \\
\text { funcionários, pacientes, } \\
\text { terceirizados }\end{array}$ & $\begin{array}{l}\text { Usuários: alunos, professores, } \\
\text { funcionários, pacientes, } \\
\text { terceirizados }\end{array}$ & $\begin{array}{l}\text { Equipes dos biotérios: } \\
\text { pesquisadores e } \\
\text { terceirizados da } \\
\text { limpeza especializada } \\
\text { em biotérios. }\end{array}$ \\
\hline Indicadores & $\begin{array}{l}\text { Redução do volume de } \\
\text { resíduos infectantes. }\end{array}$ & $\begin{array}{l}\text { Aumento do número de caixas } \\
\text { disponíveis para a coleta }\end{array}$ & $\begin{array}{l}\text { - Redução dos resíduos } \\
\text { infectantes. }\end{array}$ \\
\cline { 2 - 4 } & Médio & Imediato & $\begin{array}{l}\text { - Possível aumento dos } \\
\text { resíduos comuns. }\end{array}$ \\
\hline Prazo & Curto \\
\hline
\end{tabular}

Fonte: Plano Temático - Visão de Futuro e Cenários Estratégicos (2017)

Nota: Planos Temáticos compõem o Plano Diretor de Infraestrutura do Campus São Paulo, a ser publicado.

Os resíduos infectantes em um estabelecimento de saúde, tem grande volume de produção. A meta de reduzir a geração através da segregação correta, está alinhada a meta de reduzir também maravalhas dos biotérios de criação (em algumas bibliografias, são chamados de biotérios de produção). Importante que estas ações estejam em conformidade com a RDC 222, ou seja, necessário treinamento e orientação. O treinamento inclusive poderia ser ação da meta de reduzir riscos de acidentes de trabalho com materiais infectantes.

Quadro 11 - Propostas para gestão de resíduos - resíduos químicos

\begin{tabular}{|l|l|l|l|}
\hline Meta & $\begin{array}{l}\text { Redução de riscos e } \\
\text { acidentes de trabalho }\end{array}$ & $\begin{array}{l}\text { Otimização da utilização dos } \\
\text { produtos químicos adquiridos, } \\
\text { reduzindo os resíduos gerados }\end{array}$ & $\begin{array}{l}\text { Padronização dos } \\
\text { recipientes e } \\
\text { equipamentos de } \\
\text { acondicionamento de } \\
\text { resíduos }\end{array}$ \\
\hline Diretriz & $\begin{array}{l}\text { Adequar a sala de } \\
\text { resíduos químicos do } \\
\text { Edifício Lemos Torres, } \\
\text { em conformidade com } \\
\text { as normas aplicáveis }\end{array}$ & $\begin{array}{l}\text { Implementar sistema de controle } \\
\text { e informação de um banco de } \\
\text { excedentes de produtos } \\
\text { químicos, de forma a reduzir a } \\
\text { geração de resíduos por meio do } \\
\text { seu uso/ reaproveitamento em } \\
\text { outras pesquisas }\end{array}$ & $\begin{array}{l}\text { Implemtar a } \\
\text { padronização de } \\
\text { recipientes de resíduos } \\
\text { químicos devidamente } \\
\text { identificados para a } \\
\text { correta segregação, } \\
\text { garantindo sua } \\
\text { reposição }\end{array}$ \\
\hline
\end{tabular}

continua 


\begin{tabular}{|c|c|c|c|}
\hline \multirow[t]{3}{*}{ Ações } & $\begin{array}{l}\text { Adequar } \\
\text { provisoriamente a sala } \\
\text { de resíduos até } \\
\text { transferência das } \\
\text { atividades geradoras } \\
\text { para o imóvel do } \\
\text { hospital }\end{array}$ & $\begin{array}{l}\text { Criar sistema eletrônico de } \\
\text { controle de produtos químicos, } \\
\text { garantindo a gestão e } \\
\text { monitoramento das informações }\end{array}$ & $\begin{array}{l}\text { Garantir que todos os } \\
\text { usuários adotem o } \\
\text { padrão de recipientes e } \\
\text { identificação } \\
\text { desenvolvidos no } \\
\text { projeto de } \\
\text { comunicação visual }\end{array}$ \\
\hline & & Implementar o sistema & $\begin{array}{l}\text { Exigir dos } \\
\text { pesquisadores o } \\
\text { dimensionamento de } \\
\text { recipientes necessários } \\
\text { para o descarte de } \\
\text { resíduos químicos } \\
\text { oriundos das pesquisas } \\
\text { desenvolvidas }\end{array}$ \\
\hline & & $\begin{array}{l}\text { Disponibilizar e veicular as } \\
\text { informações sobre o banco de } \\
\text { excedentes }\end{array}$ & $\begin{array}{l}\text { Definir responsável } \\
\text { pela orientação para a } \\
\text { aquisição de } \\
\text { recipientes para } \\
\text { resíduos químicos } \\
\text { oriundos das atividades } \\
\text { geradoras }\end{array}$ \\
\hline Responsável & $\begin{array}{l}\text { Departamento de } \\
\text { Infraestrutura } \\
\text { - Coordenadoria de } \\
\text { Edificações }\end{array}$ & $\begin{array}{l}\text { Departamento de Infraestrutura } \\
\text { (Divisão de Gestão Ambiental), } \\
\text { com o apoio da Divisão de } \\
\text { Tecnologia da Informação }\end{array}$ & Diretoria do Campus \\
\hline $\begin{array}{l}\text { Público } \\
\text { Alvo }\end{array}$ & $\begin{array}{l}\text { Usuários: alunos, } \\
\text { professores, } \\
\text { funcionários, pacientes, } \\
\text { terceirizados }\end{array}$ & $\begin{array}{l}\text { Usuários e geradores de } \\
\text { produtos/resíduos químicos: } \\
\text { responsáveis pelos laboratórios }\end{array}$ & $\begin{array}{l}\text { Usuários: alunos, } \\
\text { professores, } \\
\text { funcionários, pacientes, } \\
\text { terceirizados }\end{array}$ \\
\hline Indicadores & Adequação realizada & $\begin{array}{l}\text { Redução de acúmulo de produtos } \\
\text { e resíduos químicos nos } \\
\text { laboratórios. }\end{array}$ & $\begin{array}{l}\text { Uso de recipientes } \\
\text { adequados, redução de } \\
\text { acidentes, redução do } \\
\text { acúmulo de resíduos } \\
\text { químicos nos } \\
\text { laboratórios. }\end{array}$ \\
\hline Prazo & Curto & Curto & Curto \\
\hline
\end{tabular}

Fonte: Plano Temático - Visão de Futuro e Cenários Estratégicos (2017)

Nota: Planos Temáticos compõem o Plano Diretor de Infraestrutura do Campus São Paulo, a ser publicado.

As propostas para gerenciamento dos resíduos químicos envolvem principalmente questões de procedimento e padronização. A saúde do trabalhador, seja ele pesquisador, aluno, terceirizado ou professor, depende do bom manejo dos produtos e do seu descarte. Adicionalmente, um sistema para gerenciar a quantidade e tipo dos produtos químicos pode reduzir a quantidade de resíduos químicos por prazo de validade, por exemplo.

O processo participativo, com os diversos formatos de audiência, de consulta, de oficina e de reuniões, permitiu uma abordagem holística do planejamento, considerando indissociável a demanda por adequação ou aumento de espaço de questões legais, administrativas, ambientais e de saúde pública. 


\subsubsection{PROJETO DE DESENHO URBANO}

Considerando que nas diretrizes institucionais da Unifesp ${ }^{64}$ existe o enfoque na integração com o entorno, essa diretriz deve estar presente nos planos e projetos que desenvolvidos para os campi.

No caso de cidades universitárias, entre as federais, apesar de ser a tipologia com mais exemplos de planos diretores, em algumas delas, a base só considera o próprio território, não estabelecendo, portanto, dialogo com a cidade no momento do planejamento. Como pode-se constatar no zoneamento da Universidade Federal de Santa Catariana (UFSC, 2005), da Universidade Federal de Minas Gerais (UFMG, 2009) e da Universidade de Brasília (UNB, 1998). (ver Figura 23)

Figura 23 - Comparação do zoneamento UFSC, UFMG e UNB
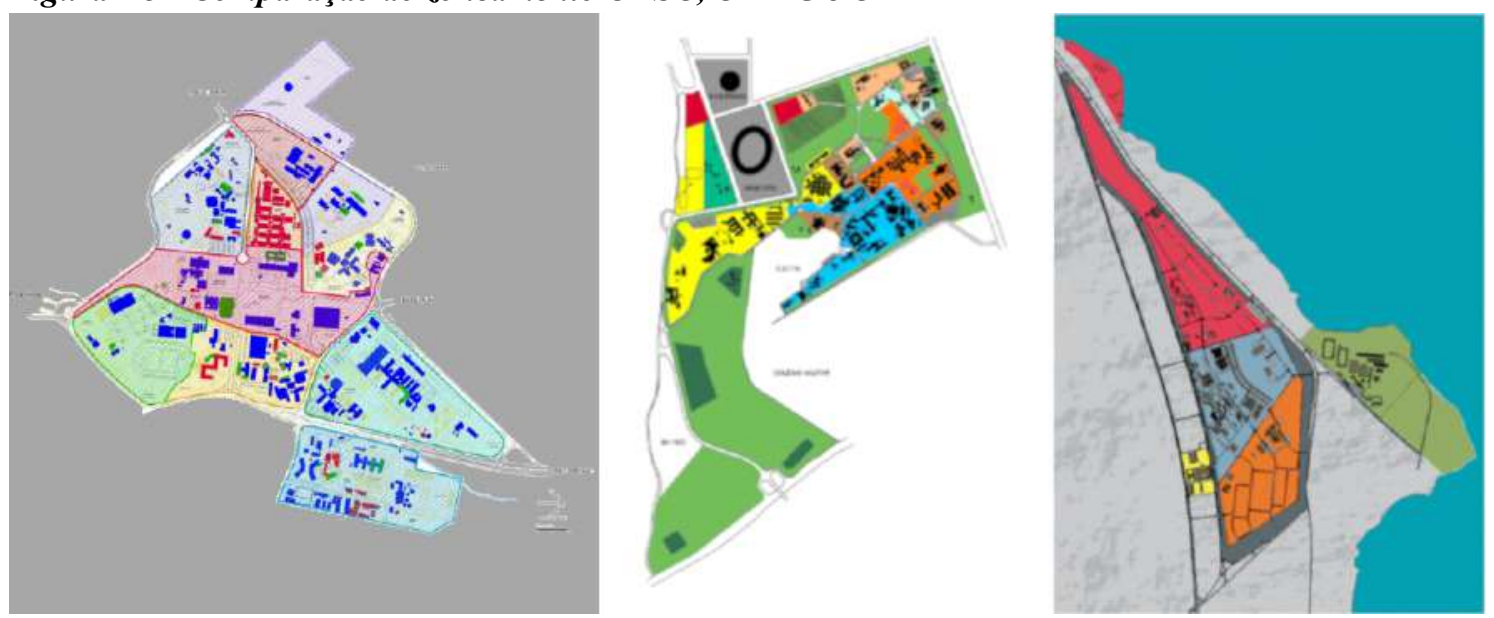

Fonte: (UFSC, 2005) (UFMG, 2009) (UNB, 1998)

Como verificado nas referências, as universidades têm uma presença urbana importante pela sua dimensão e por ser polo de atração dentro da cidade e podem propor desenhos urbanos que permitam maior fruição pública ou novas relações com a cidade, por razões econômicas, sociais, ambientais ou pedagógicas.

Mais especificamente no caso da Unifesp, desde o plano de 1982, o contexto urbano é considerado, mas somente a partir do plano de 2010 é que se cogita incluir o desenho urbano no planejamento institucional.

O contexto político-econômico de 2016, ano em que se iniciou o processo do PDInfra, influencia a extensão das propostas urbanas, uma vez que provavelmente as

64 "Integração com o entorno. A universidade deve ser um modelo de relação com a cidade e seu entorno, proporcionando um ambiente em que os membros da comunidade possam conviver. A construção do campus deve refletir a ideia de abertura e interpenetração entre o espaço urbano e o espaço educacional" (UNIFESP, 2016, p. 137) 
ações necessárias para concretização do desenho urbano teriam que vir da municipalidade. Dessa forma, a proposta de desenho urbano se limitou às 4 quadras principais.

E são nestas quadras que concentram a maior parte das atividades, que se decidiu focar o desenho urbano. As premissas são parecidas com a versão de 2010, em que se verticaliza atividades para liberar espaços no térreo, criando espaços abertos, praças e possibilidade de fruição intraquadra.

Uma inovação desse projeto em relação ao anterior é a proposição de lombofaixas (ou travessia em nível), a ampliação das calçadas e tornar uma rua inteira de uso de pedestre, com possibilidade de travessia de veículos em baixa velocidade, como se propõe para a rua Varpa. (ver Figura 24 e 25).

A proposta da rua Varpa associada a um estacionamento subterrâneo, criaria uma nova área de estar na cidade, conjugando a pedestrialização da rua mais a ampliação da calçada nos terrenos da Unifesp e uma fonte de recursos advinda da exploração dos estacionamentos (a ser discutida com a Municipalidade ou com potenciais parceiros privados).

Figura 24 - situação existente da r. Varpa (Campus São Paulo)

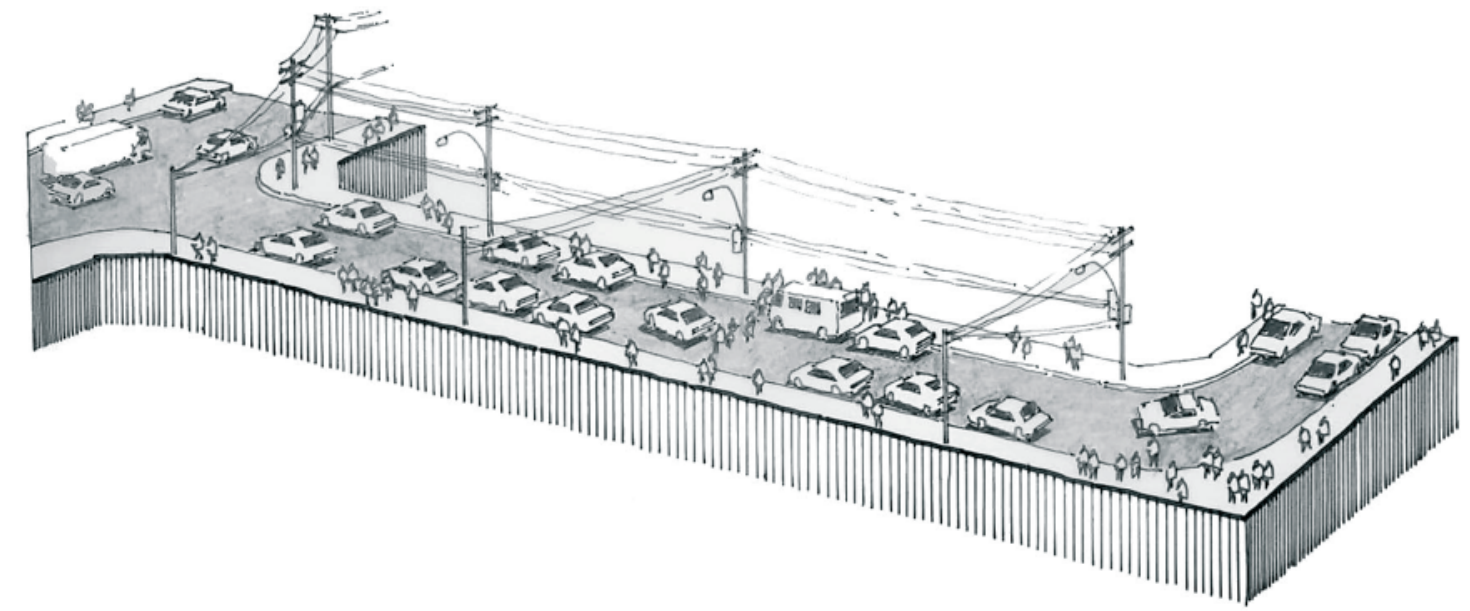

Fonte: MPS Arquitetos Associados (2018) 


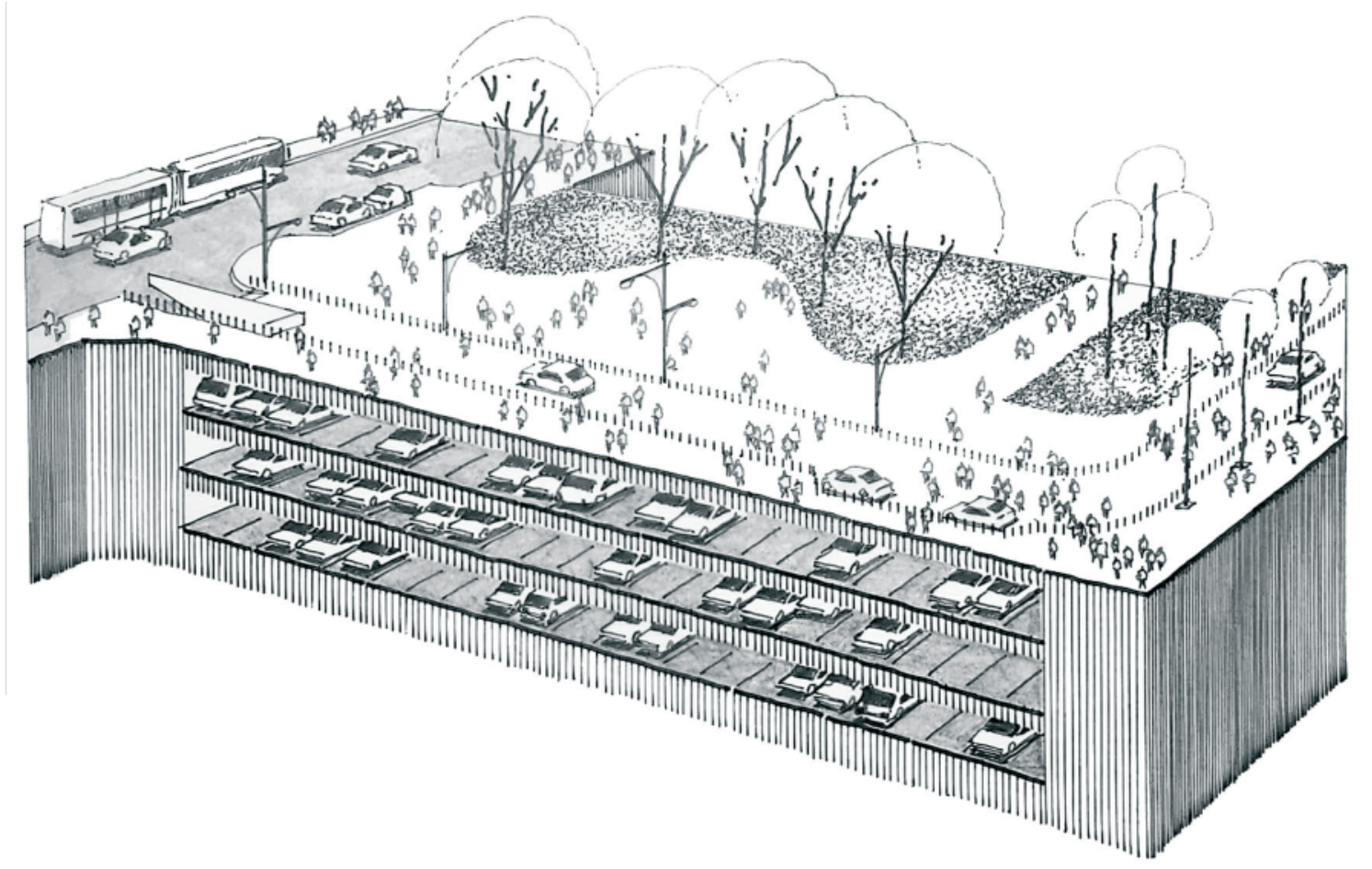

Fonte: MPS Arquitetos Associados (2018)

Considerar também esta parte do campus como parte de um sistema de transporte integrado leva a proposição de traçado de rota de ciclovia e faixa exclusiva de ônibus, além de analisar demanda que será gerada pela presença de uma nova estação de metrô. Estas propostas precisam ser consolidadas com os diversos órgãos competentes como o Metrô, a SPTrans, a Companhia de Engenharia de Tráfego, as Secretarias Municipais e outras.

No projeto de desenho urbano do Campus São Paulo em versão preliminar (ver Figura 26) são feitas proposições de alargamento de calçada, arborização e abertura de praças no interior das quadras da universidade, travessia de rua em nível (melhora acessibilidade e segurança do pedestre) e faixa bidirecional de ciclofaixa para integrara a estrutura cicloviária existente.

Parte das proposições dependem da execução de edifícios propostos, porém no projeto há infraestruturas urbanas que dependem de outros órgãos governamentais, Prefeitura, Governo do Estado e até mesmo empresas privadas que se interessem em revitalizar o bairro. 
Figura 26 - Projeto de desenho urbano para o Campus São Paulo (2018)

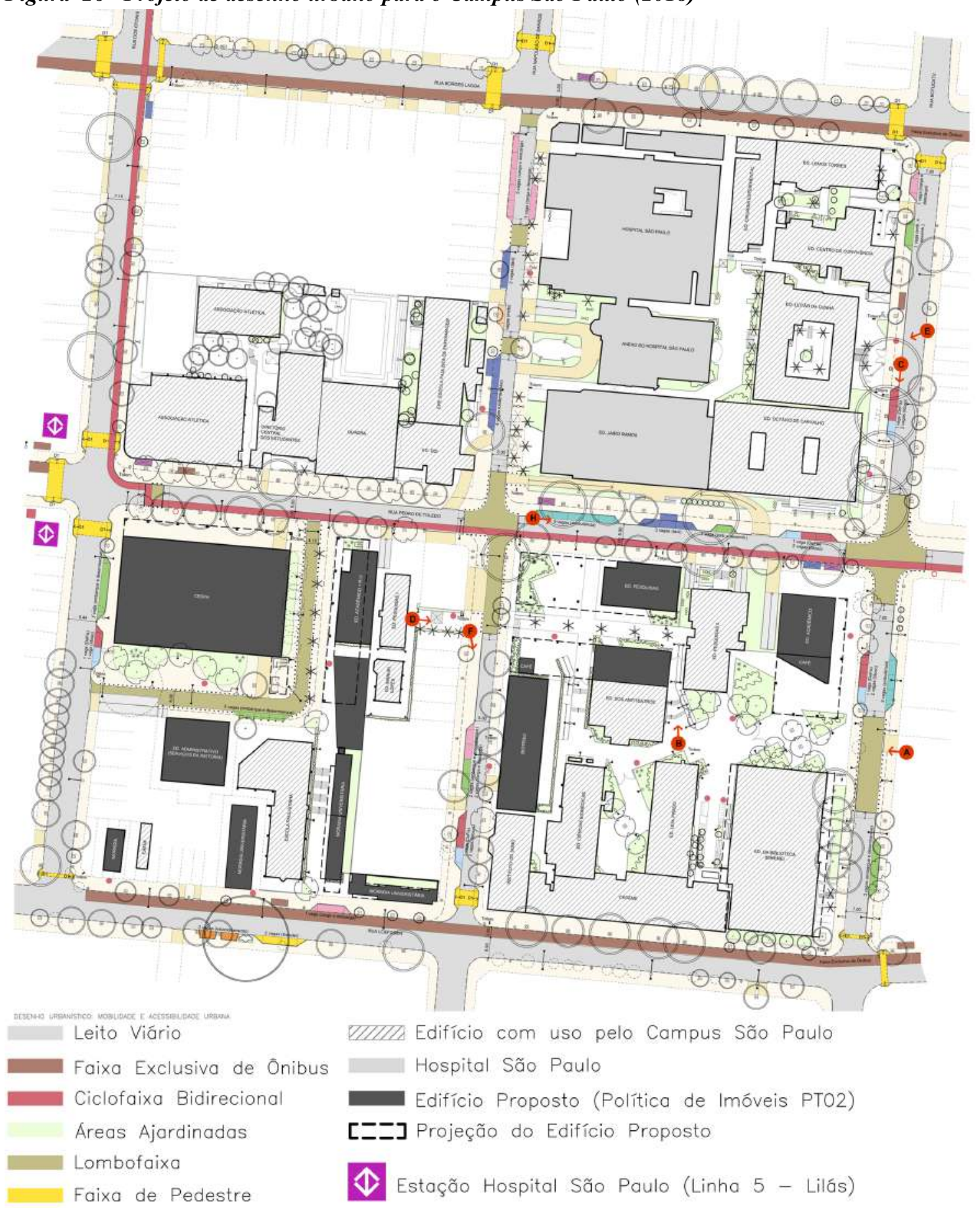

Fonte: Versão preliminar do projeto: MPS Arquitetos Associados.

O entendimento do campus como parte da cidade, integrando-se nos temas de mobilidade, de infraestrutura urbana, de fluxos de materiais e outros que foram mencionados sucintamente neste texto, está alinhado a preceitos do desenvolvimento sustentável, que podem ser visualizados através do metabolismo urbano. 
Experiências internacionais de campi universitários que tenham contextos urbanos semelhantes podem servir de referência para comparações entre propostas e instrumentos de planejamento, complementando a falta de referências de planos diretores para campus universitário dentre as universidades federais.

\subsection{EXPERIÊNCIAS INTERNACIONAIS DE CAMPUS UNIVERSITÁRIOS}

Como as referências nacionais são majoritariamente cidades universitárias, buscase exemplos de experiências internacionais que se enquadrem na categoria de campus universitário e que estejam em contextos urbanos consolidados.

As três experiências internacionais, a New York University, a Johns Hopkins University e a University College London, se encontram em um contexto urbano semelhante ao Campus São Paulo da Unifesp, ou seja, a estrutura urbana do entorno está consolidada.

O material analisado consiste nos planos diretores (master plan) ou similares mais recentes que foram disponibilizados por cada instituição. 


\subsubsection{NEW YORK UNIVERSITY}

Figura 27 - Vista de edifício da NYU ao lado da Washington Square

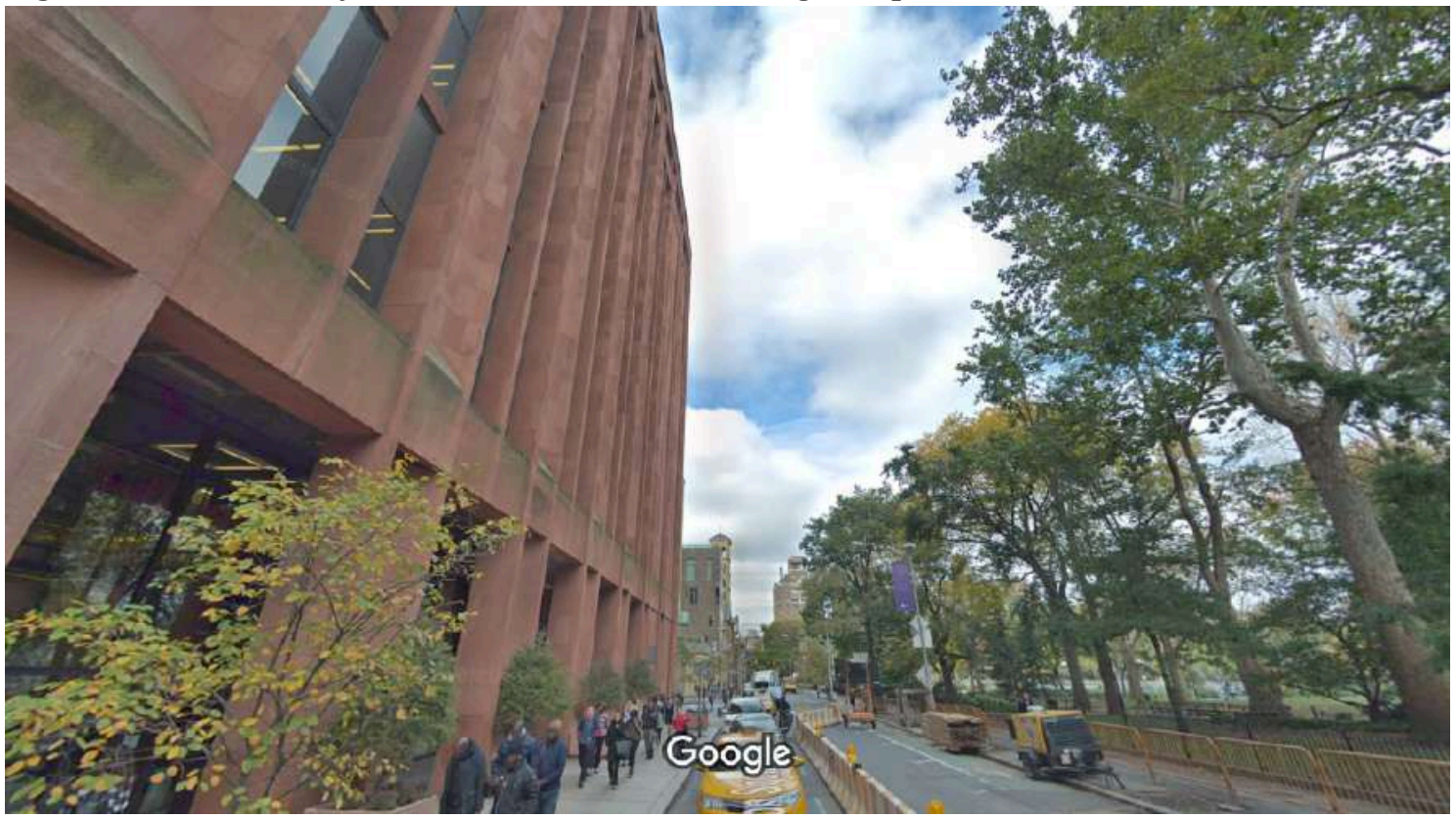

Fonte: Google maps

Houveram menções à NYU durante o processo de formulação do edital de contratação do PDInfra, por ser uma referência de campus universitário em contexto urbano consolidado. Além disso, o plano almejava requalificação urbana e outras ações que não dependem apenas do orçamento e das responsabilidades da instituição.

A Universidade de Nova Iorque foi fundada em 1831, à época chamada de "University of the City of New-York"65, cujas primeiras aulas foram em áreas alugadas próximas à Prefeitura.

Em 1835 foi construído o edifício em estilo gótico existente até hoje, que era de uso diversificado, com espaços acadêmicos nos andares inferiores e apartamentos para alugar nos pavimentos superiores.

No decorrer desses mais de 180 anos, a universidade cresceu tanto na cidade, com criação de novos campi, quanto em escala mundial, abrindo filiais em outros países. Os

\footnotetext{
${ }^{65} \mathrm{https}$ //www.nyu.edu/faculty/governance-policies-and-procedures/faculty-handbook/theuniversity/history-and-traditions-of-new-york-university/a-brief-history-of-new-york-university.html
} 
fundadores queriam uma instituição de aprendizado que fosse "dentro e da cidade" agora seria também "dentro e do mundo".

A respeito dos campi na cidade de Nova Iorque, como verificado, desde a sua fundação há integração com a cidade. O planejamento institucional atual, chamado " $A$ University as Great as Its City: NYU's Strategy for Future Growth", consiste nas diretrizes e projetos a planejados para até 2031.

Curiosamente, no seu texto introdutório, a instituição não considera o seu plano um "plano diretor" (master plan) ${ }^{67}$, o que demonstra que, assim como no contexto brasileiro, a expressão textual tem diversos sentidos.

Como a cidade é um dos temas centrais desse planejamento, há muitos exemplos de como a universidade se relaciona com o seu entorno. Pode-se citar a relação com as normativas e planejamento municipal, os projetos urbanos e arquitetônicos e a sustentabilidade urbana.

Na cidade de Nova Iorque há legislação sobre uso e ocupação de solo urbano, o zoneamento, em que se definem parâmetros para construções e atividades. $\mathrm{O}$ campus principal, localizado nas proximidades da Washington Square (ver Figura 27), está em área predominantemente residencial (residential), embora o único zoneamento impeditivo de atividades acadêmicas seja o industrial (manufacturing).

O plano diretor da NYU indica que pretende seguir diretrizes do planejamento a nível municipal, uma vez que o zoneamento é formulado por uma autoridade municipal ou metropolitana.

O mapa do zoneamento (ver Figura 28) já indica que há imóveis pertencentes à universidade, que estão em zona industrial (que não permite salas de aula nem usos de residência estudantil). O que demonstra o desafio de planejar expansão, consolidação ou manutenção de uma instituição em uma área urbana consolidada.

Outras limitações ou incentivos fornecidos por outros zoneamentos influenciam no planejamento institucional. Por exemplo, parte dos imóveis que estão na área

\footnotetext{
${ }^{66}$ In 1831, NYU's founders chose to create an institution of learning that would be "in and of the city." In the ensuing years, New York City has become the world's first truly international city, [...] [...] Still vitally "in and of the city," NYU is now, too, "in and of the world." (NYU, 2018)

67 "NYU 2031 is not a "master plan," for the University does not have a large, contiguous campus over which it can exert control. Instead, NYU 2031 is a citywide strategy for how to provide the physical space needed for NYU's long-range academic goals." (NYU, 2008, p. 13)
} 
residencial com potencial construtivo (FAR, em inglês) menor que os imóveis que estão na área comercial.

Figura 28 - Zoneamento da cidade de Nova Iorque $x$ implantação NYU

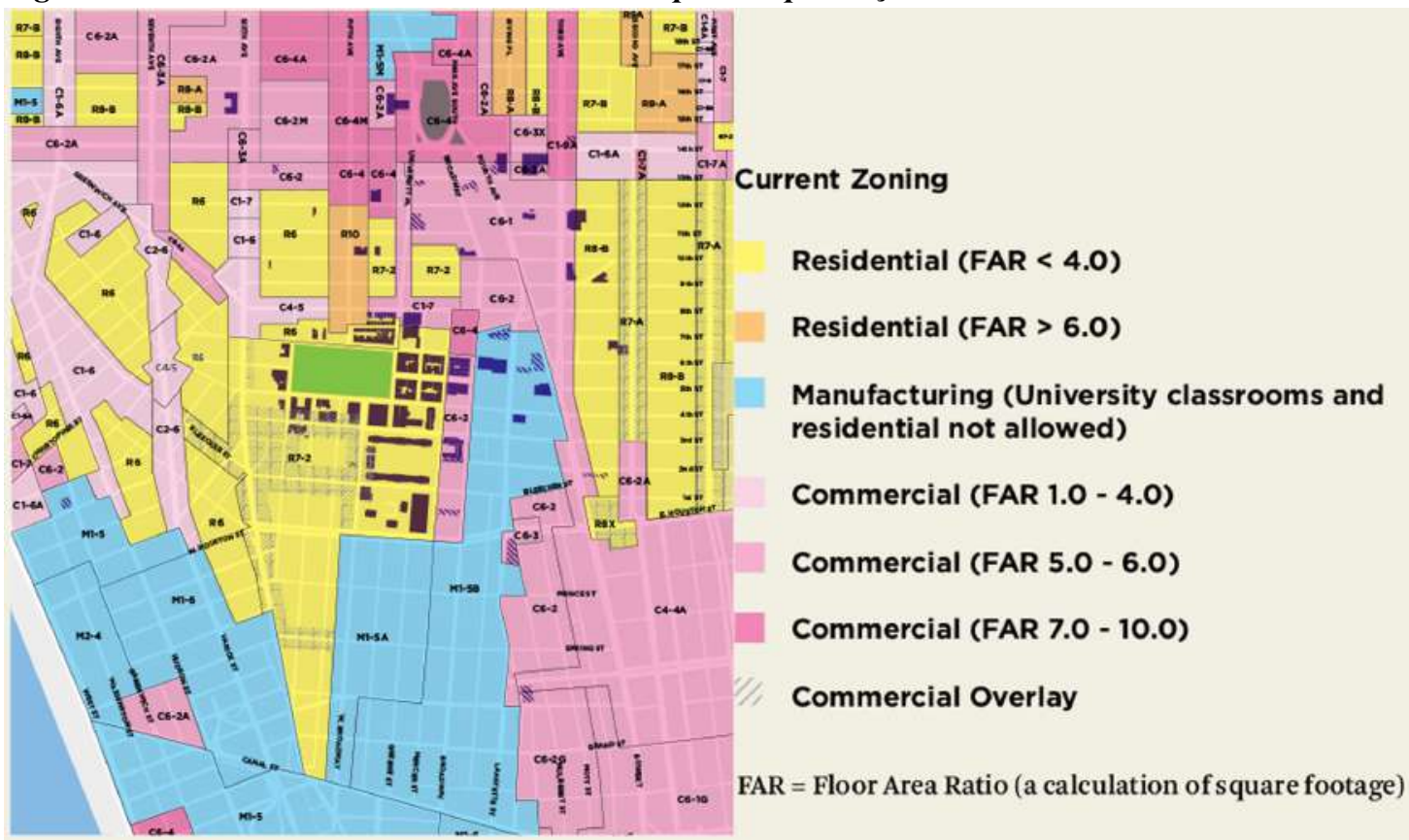

Fonte: adaptados de (NYU, 2008)

Figura 29 - implantação da NYU e distritos históricos (2008)

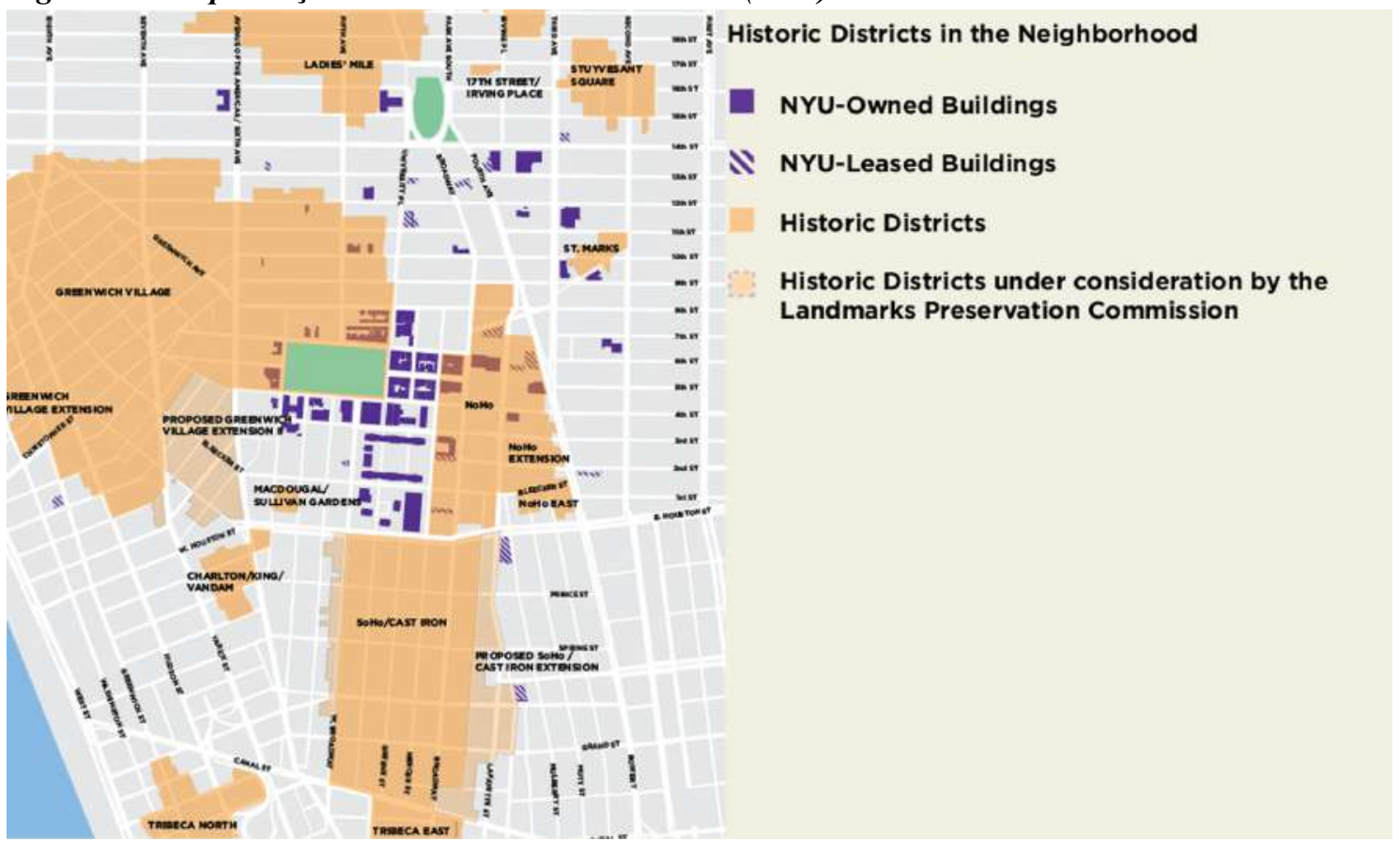

Fonte: Mapas adaptados de (NYU, 2008) 
Outro quesito a se considerar da paisagem urbana existente é que a área, cercada por distritos históricos (ver Figura 29), pode ter acrescida novas quadras por comissão municipal. Estas questões devem ser contempladas no planejamento para atender a legislação, mas também respeitar a paisagem urbana e a história da cidade da qual a universidade faz parte.

O planejamento contextualizado, em que se considera abordagens relativas a situação existente para realçar potenciais de uso público, uso misto e rede peatonal foi o mote da diretriz de desenvolvimento dos projetos para esta primeira área central.

A partir do diagnóstico de que existe uma área consolidada da universidade e que se planeja o crescimento, desenvolve-se o estudo para integrar os espaços abertos ao público, conectando ou complementando parques públicos.

O uso misto será incentivado para que no nível térreo não haja inatividade e que estes espaços sejam convidativos para dentro dos edifícios, criando assim uma rede para uso do pedestre, que é uma tentativa de quebrar a escala de superblocos e altas torres que é característica da cidade.

$\mathrm{Na}$ apresentação do planejamento (ver Figura 30) estas diretrizes estão apresentadas didaticamente.

\section{Figura 30 - Diretrizes de projeto da NYU}
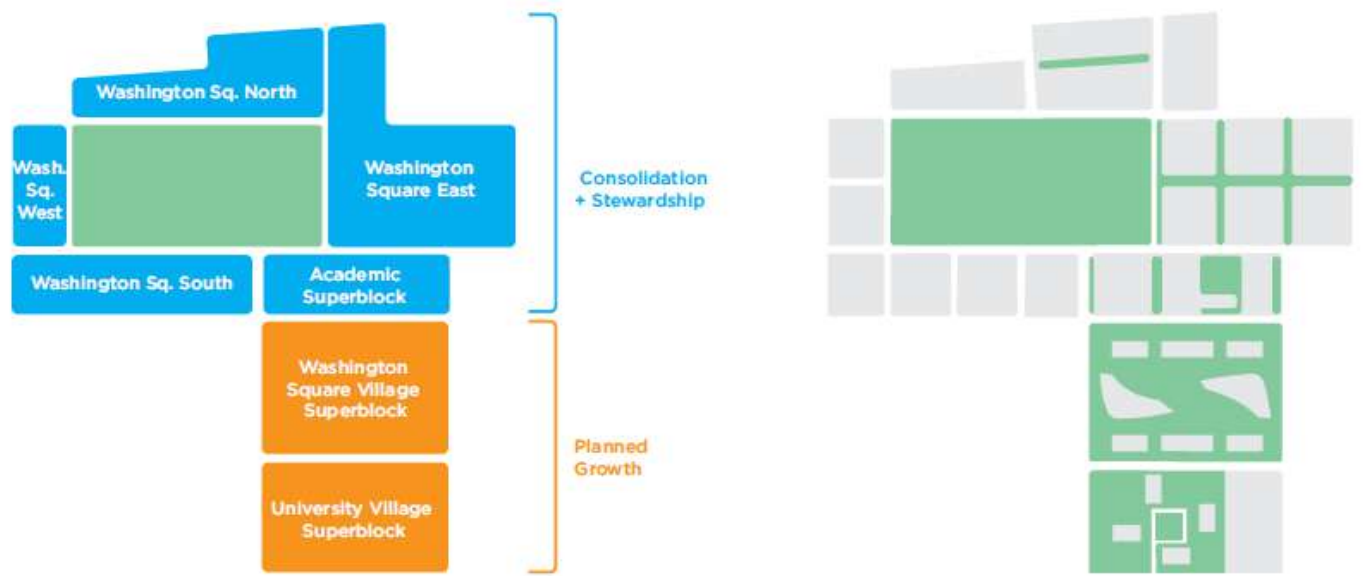

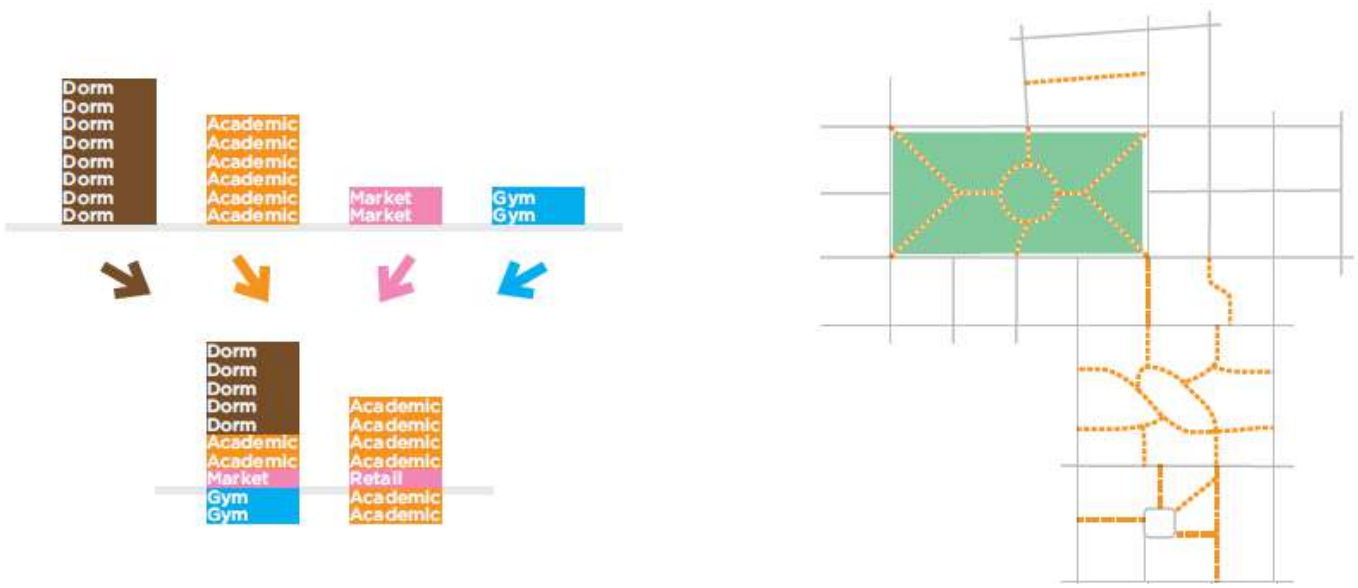

Fonte: (NYU, 2008, p. 74)

A expressão superquadra (superblock) escolhido pelos planejadores da NYU, remete a tipologia proposta no contexto do urbanismo moderno, similares àqueles implantados em Brasília, no Plano Piloto, cujas principais características são o zoneamento monofuncional e o rodoviarismo, diferentemente do declarado no plano, que são usos mistos e redes peatonais. Cientes desse fato, os planejadores provavelmente buscam novos significados e abordagens para uma superquadra.

Segundo críticos como Henri Lefebvre $(1970)^{68}$, o urbanismo moderno na sua lógica cartesiana, ignorando a complexidade da vida urbana, leva a projetos urbanos completamente estranho a seus moradores. Outra crítica ao urbanismo moderno, Jane Jacobs (1961) ${ }^{69}$ também atuou contra projetos à época que construiriam uma rodovia em cima de uma praça que está próxima à NYU.

Os planejadores, cientes destas críticas, porém, tinham como dado as limitações impostas ao desenvolvimento imobiliário da universidade. O fato de a NYU dispor de duas quadras orientou a solução de superquadras, uma vez que nestas poderia se ter o potencial construtivo desejado.

68 "Segundo Lefebvre, este foi o procedimento do urbanismo moderno, isto é, dissociou as funções e atividades que se encontravam tecidas orgânica e espontaneamente nas cidades históricas e as projetou isoladamente sobre o território “(COLOSSO, 2016)

69 "starting with a group of mothers, among them, Jane Jacobs - that became the first to promote publicly a contrasting vision of American urbanism: the importance of diverse neighborhoods, public spaces, streetscapes, and pedestrians and mass transit over cars." (NYU, 2008)

“começando com um grupo de mães, entre elas, Jane Jacobs - que se tornou a primeira a defender publicamente uma visão contrastante do urbanismo americano: a importância de vizinhança diversificada, espaços públicos, paisagem urbana e pedestrialização e transporte de massa sobre carros." (tradução nossa) 
O território universitário, como também um espaço de experimentação, pode ser uma ousada tentativa de redesenhar e ressignificar o sentido de superquadra (ver Figura 31 , que causou tantos danos às comunidades vizinhas ${ }^{70}$ à época.

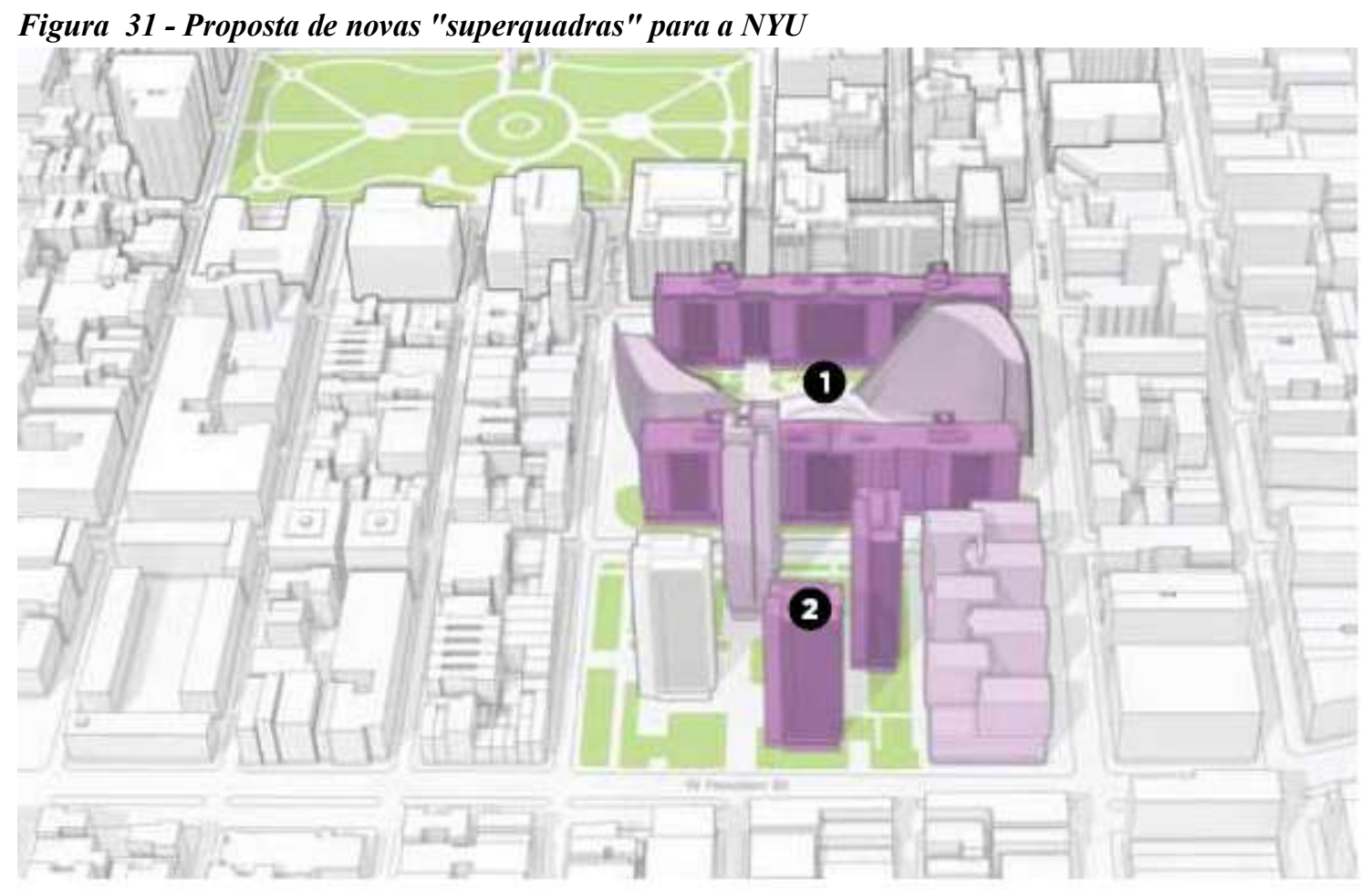

\author{
1 Washington Square Village \\ $(2)$ University Village \\ Fonte: (NYU, 2008, p. 86)
}

NYU Existing Buildings

NYU Proposed Buildings

70 "It [NYU's core] concentrates academic and residential space at the University's core: this builds a strong sense of community and allows for the most efficient use of space, resulting in improved traffic and pedestrian flow and reduced impact on surrounding neighborhoods. It also reconnects the superblock landscape to the urban fabric of its surrounding neighborhoods, while reinvigorating the area with a series of new and enhanced public spaces. It honors the architectural significance of a transformational period in city history and provides a rare opportunity to mend some of the ways in which the creation of the superblocks damaged the rich texture of neighborhood life." (NYU, 2008, p. 64)

"[O núcleo da NYU] concentra os espaços acadêmicos e residenciais: isto constrói um forte senso de comunidade e permite um uso de espaço mais eficiente, resultando em um melhor tráfico e fluxo de pedestres e reduz impacto na vizinhança. E também reconecta o paisagismo das superquadras à trama urbana, ao mesmo tempo em que revigora a área com uma série de novos e melhorados espaços públicos. Isto homenageia a significância arquitetônica de um período histórico da cidade e permite uma rara oportunidade de corrigir de alguma forma os danos que as superquadras fizeram à rica textura da vida da vizinhança." (tradução nossa) 


\subsubsection{JOHNS HOPKINS UNIVERSITY}

Figura 32 - Vista da entrada sul do Homewood Campus - Johns Hopkins University

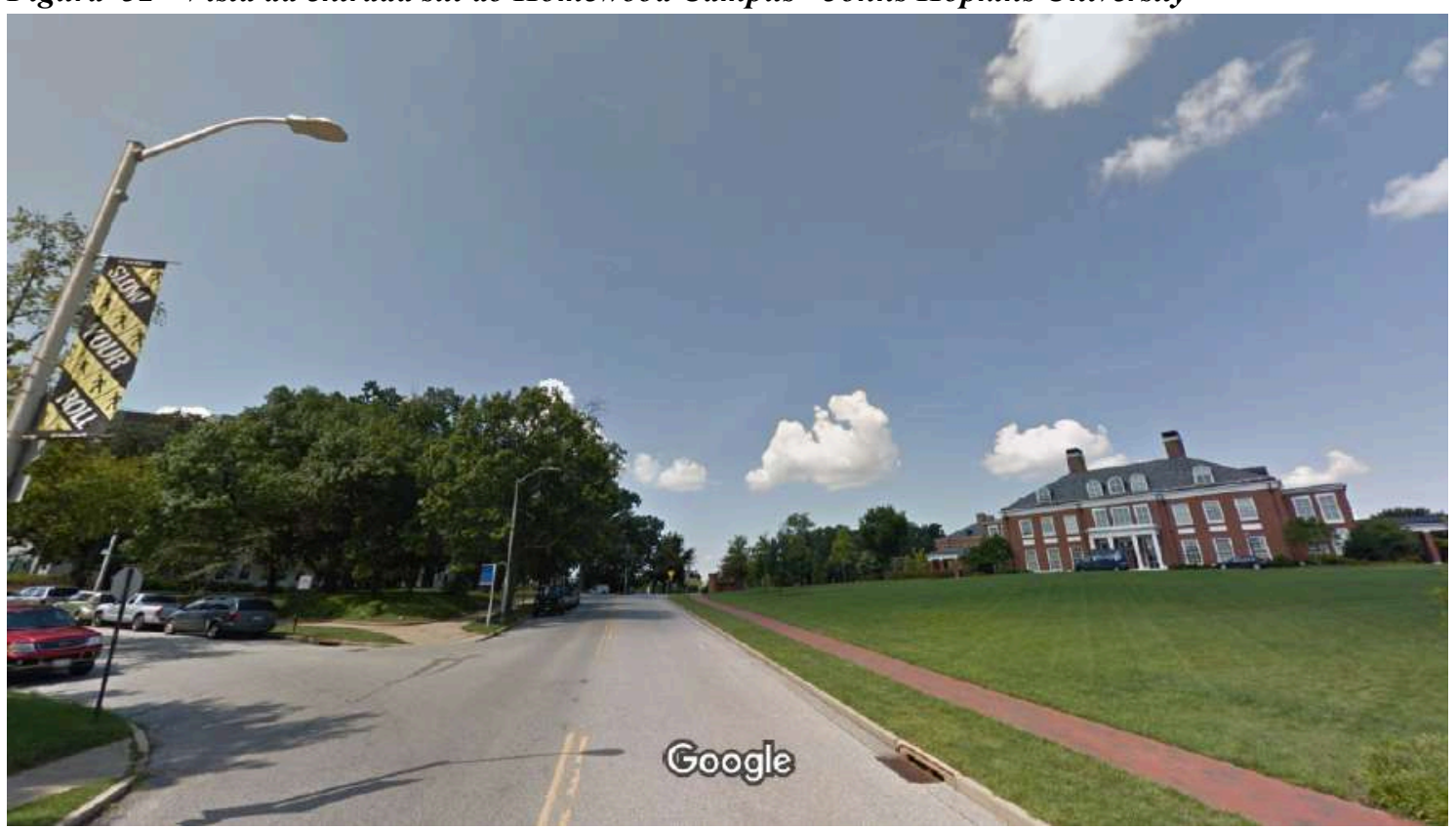

Fonte: google maps

A Universidade Johns Hopkins é referenciada como instituição de ensino superior das áreas de saúde e a associação direta de um hospital universitário com as escolas de medicina e de enfermagem que lhe deram origem faz com que se tenha uma identificação com o contexto do Campus São Paulo.

Apesar do plano diretor mais recente não contemplar a área originária (onde se encontra o hospital universitário), o debate sobre a relação da universidade com o espaço urbano se mantém.

A Johns Hopkins é nomeada em homenagem ao filantropo que, em seu testamento, destinou a quantia de 7 milhões de dólares, à época a maior doação dos Estados Unidos, para construção de um hospital, faculdades, um orfanato e uma universidade. A Universidade foi aberta em 1876, na cidade de Baltimore. ${ }^{71}$

Atualmente, a Universidade tem outros campi nos Estados Unidos e duas unidades avançadas, uma na Itália e outra na China ${ }^{72}$. Na cidade de Baltimore, há três estruturas universitárias, o conjunto do Hospital Johns Hopkins com a Escola de Saúde Pública e Medicina, a Hopkins Bayview e a Homewood Campus (ver Figura 32).

\footnotetext{
${ }^{71} \mathrm{https}: / /$ www.jhu.edu/about/history/

${ }^{72}$ https://web.archive.org/web/20140728125434/http://e-catalog.jhu.edu/about-the-university/historydivisions/
} 
O Homewood Campus, que recentemente teve sua expansão e consolidação como objeto de um plano diretor, é o principal centro acadêmico e administrativo da universidade.

Formalizado em fevereiro de 1902, o campus teve um plano de ocupação definido em novembro de 1904, após a concorrência de 5 escritórios de arquitetura. A proposta escolhida foi a de Parker and Thomas. ${ }^{73}$

Ao longo dos anos, faculdades, laboratórios e outras estruturas acadêmicas, administrativas e estudantis que ficavam no campus central foram sendo realocadas em novos edifícios no novo campus, inclusive em prédios vizinhos alugados que margeiam o terreno estipulado inicialmente para a universidade.

O plano original ${ }^{74}$ foi seguido rigorosamente de 1914 a meados dos anos 80 , porém, a partir dessa década, principalmente por causa do alto fluxo de automóveis no núcleo do campus, os espaços livres começam a ficar desconexos. Um novo processo de planejamento só será iniciado em 1999, culminando no 2001 Homewood Campus Plan.

O 2008 Homewood Campus Plan Update, realizado pelo escritório Ayers Saint Gross é uma atualização do plano de 2001, cujo processo foi estruturado em observações, desenvolvimento de conceitos, estudos de pequenas áreas e um plano final. Para este capítulo, é interessante a parte que contém um diagnóstico que envolve o contexto urbano para embasar o planejamento.

Foram elaboradas bases com as informações topográficas, áreas livres (open space), conservação florestal, sistemas construídos, vizinhança, paisagem, acessos, uso e ocupação (ver Figura 33), circulação de pedestres, circulação de automóveis, serviços e carregamento e área de estacionamentos. No entanto, não foram encontradas menções às legislações urbanas locais.

\footnotetext{
${ }^{73} \mathrm{https}: / /$ archive.ph/20121210095039/http://www.library.jhu.edu/collections/specialcollections/archives/b uildinghist.html\#selection-861.950-861.1168

74 “1914 - 1980: The development of new buildings and grounds rigorously follows the original Parker and Thomas campus plan

1980 - 1999: Vehicular traffic becomes increasingly invasive in the campus core; disordered service areas develop; open spaces become disconnected; tradition of space-making through building placement is diminished

1999 Year-long planning process begins that will yield 2001 Homewood Campus Plan 2001 Landscape of most major open spaces is revitalized; vehicular traffic is prohibited in the campus core 2001 - 2008 New buildings on Decker Quadrangle and elsewhere on campus re-establish the practice of space-making through building placement" (JOHNS HOPKINS UNIVERSITY, 2009, p. 12)
} 
Figura 33 - zoneamento do Homewood Campus da Johns Hopkins University

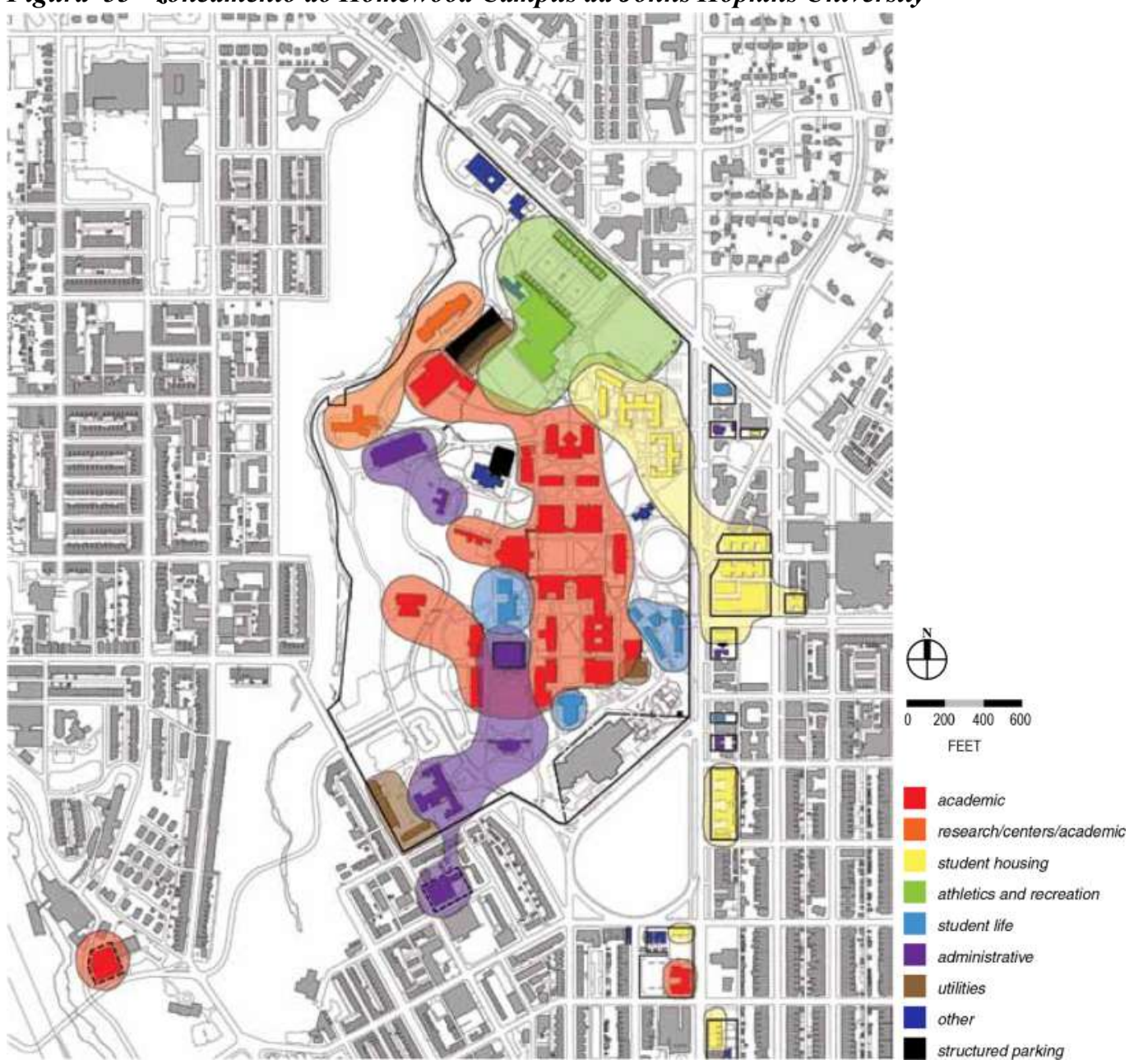

Fonte: (JOHNS HOPKINS UNIVERSITY, 2009)

Estas informações subsidiam melhor as decisões de projeto que buscam atender aos objetivos institucionais. Entre eles, estão metas relacionadas a questões urbanas e sustentáveis, como desenvolver e implantar usos recreativos, educativos e de conservação do bosque e rio próximo ao campus ${ }^{75}$. E fortalecer a relação com a Charles Village,

75 "Make sustainable and efficient use of the Stoney Run valley as a visual, recreational, and educational natural resource.

- Develop a comprehensive path network that connects the stream valley to the campus core

- Develop a comprehensive forest conservation and improvement plan and water resources plan

- Prepare an assessment of the university's impacts on the water quality of Stoney Run

- Minimize additional impervious surface areas

- Stop development encroachment into Stoney Run valley

- Initiate replacement of woodland tree canopy

- Manage invasive, exotic species of vegetation

- Extend woodland fingers in the campus core" (JOHNS HOPKINS UNIVERSITY, 2009, p. 32) 
apoiando revitalização e redesenho de ruas e que atendam a universidade e a comunidade ${ }^{76}$.

A preocupação com o melhoramento estético, paisagístico e ambiental do campus, além de fortalecer os laços com a vizinhança e promove uma referência de qualidade urbana que pode servir de modelo a outras instituições. Esta requalificação também reflete no número de matrículas, que cresceu $26 \%$ após a implantação de algumas dessas melhorias ${ }^{77}$.

\footnotetext{
76 "Apply the university's energy and resources to improve the vitality and character of Charles Village as a college town within the city.

- Strengthen the campus's physical relationship with Charles Village

- Expand and diversify the programmatic use of university properties in Charles Village

- Support the retail vitality of 33rd and St. Paul Streets

- Collaborate with the City of Baltimore to improve pedestrian connections across and along Charles Street

- Engage in the Charles Street redesign effort to promote university and neighborhood concerns" (JOHNS HOPKINS UNIVERSITY, 2009, p. 32)

${ }^{77}$ https://asg-architects.com/portfolio/jhuh-homewood-campus-plan-update-2/
} 


\subsubsection{UNIVERSITY COLLEGE LONDON}

Figura 34 - vista da entrada da UCL - Bloomsbury campus

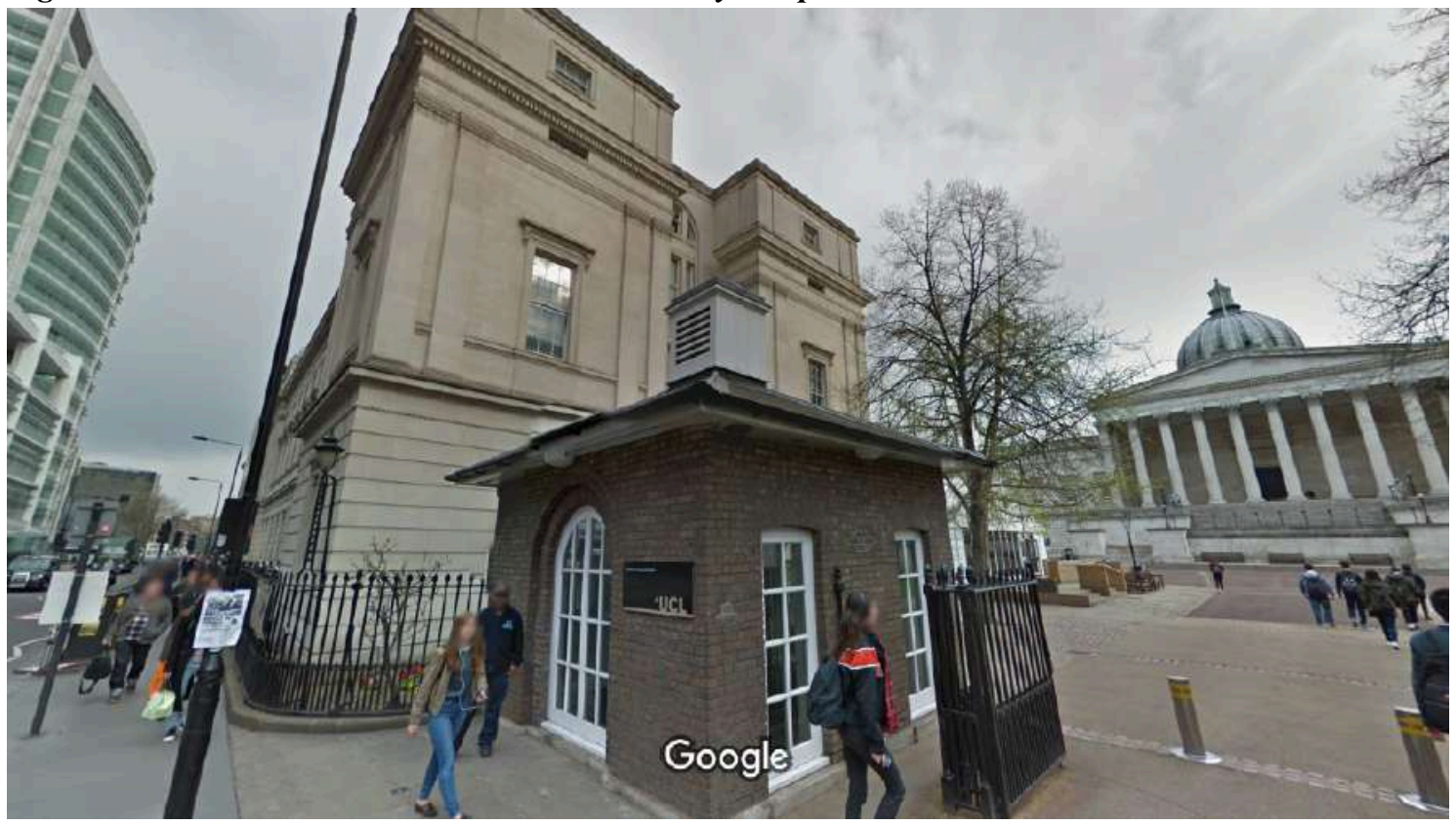

Fonte: Google maps

A University College London foi citada em um estudo a respeito de novas tipologias de edifícios universitários (BORSI e SCHULTE, 2018), e recentemente publicou seu planejamento institucional (UCL, 2011), além de estar em contexto urbano consolidado, sendo portanto, uma referência para esta Dissertação.

A University College London foi fundada em 1828, ainda como "University of London", foi a primeira universidade secular da cidade, como descrito por Thomas Arnold como "a instituição sem deus da rua Gower"78.

O local escolhido para sua sede foi em Bloomsbury (ver Figura 34), e antes da sua fundação, o college teve projeto desenvolvido pelo arquiteto Willian Wilkins já em 1825. O arquiteto é conhecido pelo projeto da National Gallery na Trafalgar Square, ambas de inspiração neo-clássica.

As expansões foram sendo construídas ao longo dos edifícios existentes, como novas alas, ou edifícios novos. Algumas adições foram planejadas com diretrizes pedagógicas, como foi o caso do Edifício de Anatomia, pensada para ser integrada à Escola de Medicina para incentivar atividades correlatas ${ }^{79}$.

\footnotetext{
${ }^{78}$ http://discovery.ucl.ac.uk/10048692/1/World-of-UCL.pdf

79 "The third stage of Starling's plans for medical sciences achieved completion with the opening of the Anatomy Building in 1923. This was funded by the Rockefeller Foundation as an expression of American
} 
Nos anos de guerra, edifícios foram danificados ou destruídos, e, pós-guerra, houveram movimentos para restaura-los e posteriormente amalgamar institutos ou faculdades na estrutura da universidade. E atualmente, como várias universidades deste porte, buscar uma posição e posicionamento global de suas atividades.

Assim como outras instituições em contexto urbano consolidado, o plano diretor atual foi concebido para ajudar a universidade a moldar seu "ambiente acadêmico, social e urbano" (UCL, 2011).

As transformações com que o campus passou refletem também a postura de ensino que a instituição quer ou pretende transmitir à comunidade. O modelo de "ilhas do conhecimento" ao "distrito de inovação" (BORSI e SCHULTE, 2018) está baseado principalmente na presença urbana da instituição, que se pretende dinamizar com cafés e novos espaços públicos agradáveis ao passeio, propiciando encontros de pessoas e ideias $^{80}$ (ver Figura 35).

Este plano diretor, portanto, conjuga um posicionamento didático-pedagógico com o desenho urbano e arquitetônico que viabiliza a interação não mediada, o encontro inesperado e um ambiente urbano dinâmico. Diferente do tradicional ambiente de claustro ou isolamento que resulta de outros espaços.

friendship towards the British Empire. The $£ 370,000$ given was the College's largest benefaction up to that time. The building adjoins a further extension to the Institute of Physiology and faces the Medical School across Gower Street. All these buildings are physically linked, with the intention of encouraging the correlation of their activities; even the Medical School is connected by a tunnel under Gower Street“ (HARTE, NORTH e BREWIS, 2018, p. 81)

O terceiro estágio dos projetos para as ciências médicas de Starling foi completada com a abertura do edifício de Anatomia em 1923. Esta foi fundada pela Fundação Rockefeller como uma expressão de amizade entre americanos e o império britânico. As 370 mil libras doadas foram a maior benfeitoria do College naquele tempo. O prédio continua uma extensão ao Instituto de Psicologia e faceia a Escola de Medicina do outro lado da rua Gower. Todos estes edifícios são conectados fisicamente, com a intenção de incentivar a correlação de suas atividades; até a Escola de Medicina é conectada por um túnel sob a rua Gower. (tradução nossa)

80 "The plan offers schemes for improving landscaping to all existing public spaces, animating them with cafés and restaurants; there is also a project to add an entirely new public space above the Physics Yard. The ease and pleasure with which one can navigate the campus and the quality of its public spaces (interior and exterior) will pay dividends in the serendipitous meeting of colleagues and the intellectual discourse that ensues" (UCL, 2011, p. 4)

O projeto oferece esquemas de aprimorar o paisagismo de todos os espaços públicos existentes, dinamizando-os com cafés e restaurantes, também há um projeto de incluir um espaço público completamente novo acima do Pátio da Física. A navegação fácil e agradável das pessoas e a qualidade dos seus espaços públicos (internos e externos) pagará dividendos nos encontros de feliz acaso dos colegas e do discurso intelectual que resulta. (tradução nossa). 
Figura 35 - Croqui da proposta do campus Bloomsbury

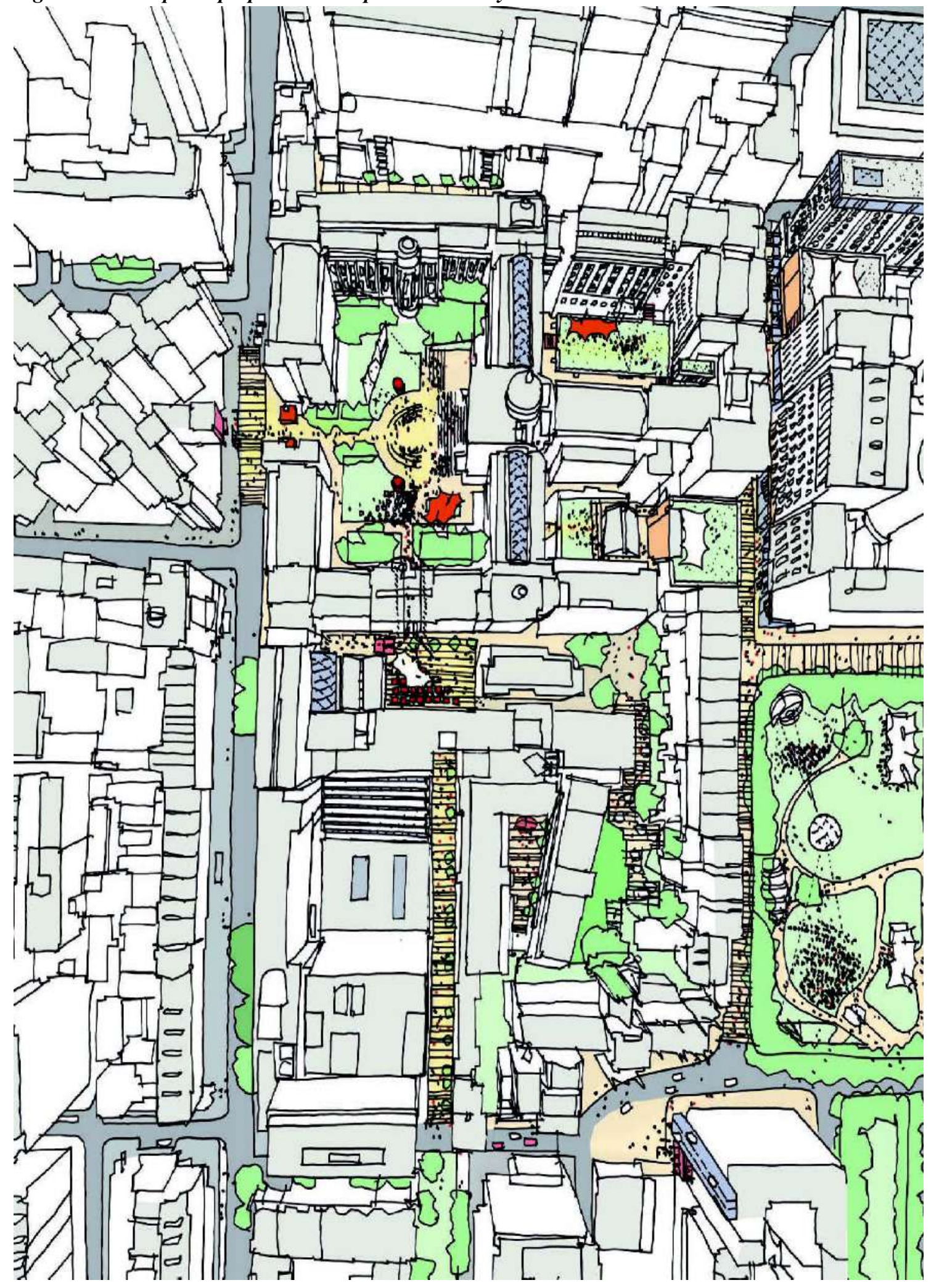

Fonte: (UCL, 2011) 


\subsection{PROJETOS DE CAMPUS COMO PROJETOS URBANOS E ARGUMENTOS PARA INTEGRAÇÃO COM ENTORNO}

Um projeto de um campus universitário, assim como o de uma cidade universitária, são projetos urbanos, independente da dimensão do seu território. A primeira indicação provém da linguagem arquitetônica e urbanística que dá suporte a esses projetos. E usam de mesmo instrumento que o planejamento urbano municipal, que é o Plano Diretor. Além disso, há necessidades de equipamentos e infraestruturas urbanas comuns a qualquer cidade, como vias, fornecimento de energia, coleta de resíduos, entre outras.

A implantação de um campus universitário abre possibilidades de integração com seu entorno por meio do compartilhamento de equipamentos urbanos, de abertura de espaços de acesso público, atendimento à população e outras ações.

Uma cidade universitária, como implantação, tem outros efeitos. Há elevados custos na execução de obras de infraestrutura e manutenção no local onde ela foi instalada.

[...]a implantação do campus segregado consome investimentos elevados, pois demandam obras de infra-estrutura específicas que essas áreas não têm. Além disso, o campus distante do centro da cidade gera desconforto para a comunidade acadêmica já que os serviços de transporte coletivo são, em geral, deficitários e os serviços complementares oferecidos nos campi são precários e pouco diversificados se comparado ao comércio vigoroso do centro da cidade. (SILVEIRA, NEVES, et al., 2012, p. 20)

No entanto, diferentemente do postulado na citação acima, o argumento deste capítulo é a integração da universidade com a cidade, não necessariamente que ela seja central. Uma vez que o modelo de cidade universitária não precisa ser replicado em periferias para um projeto universitário de qualidade.

Por outro lado, um campus universitário não ter espaços contíguos ou de dimensão suficiente para atender necessidades programáticas ou normativas, torna a expansão ou regularização desta tipologia mais complexa, considerando ainda, pressões imobiliárias que influenciam os preços de terrenos e da construção.

O planejamento institucional deve contemplar estas complexidades de modo a evitar propostas inexequíveis ou mesmo não contemplar as mudanças necessárias para corrigir situações irregulares em questão de acessibilidade, de segurança contra incêndio, de conforto ambiental, entre outras. 
Esta complexidade, em escala reduzida no campus, pode ser um laboratório para a cidade em si. Uma vez que a proximidade do campus com a cidade facilita o contato da população com a universidade, seja através da extensão, da assistência ou mesmo por compartilhar espaços. Esta situação é desejável para implementação de sistemas de gestão ambiental:

O modelo apresentado por Fouto aponta quatro niveis de intervenção para as IES [Instiuição de Ensino Superior]:

I. Educação dos tomadores de decisão para um futuro sustentável;

II. Investigação de soluções, paradigmas e valores que sirvam uma sociedade sustentável;

III. Operação dos campi universitários como modelos e exemplos práticos de sustentabilidade à escala local; $e$

$I V$. Coordenação e comunicação entre os niveis anteriores e entre estes e a sociedade. (TAUCHEN e BRANDLI, 2006)

Do ponto de vista pedagógico, a UCL foi objeto de um artigo intitulado "Universities and the City: from islands of knowledge to districts of innovation" (BORSI e SCHULTE, 2018) ${ }^{81}$ que cita a evolução das tipologias dos edifícios do campus desde o projeto "torre de marfim" da década de 30 até o atual "cenário urbano de aprendizado e inovação". Ou seja, argumentando que a integração com a cidade é um melhor ambiente para o aprendizado.

Considerando as referências apresentadas, pode-se afirmar que há argumentos a favor de projetos que contextualizem o planejamento com o entorno, inclusive, com maior integração à cidade. Há razões econômicas, sociais, ambientais e pedagógicas para que as universidades, ou até mesmo outras instituições se utilizem dessas premissas para visar o desenvolvimento sustentável.

\footnotetext{
81 "These typological principles have the capacity to complicate, multiply and engender changing occupations of urban space, helping to forge temporary or more long-term communities of association, of learning, of knowledge sharing or other forms of communality and association. In other words, they can help to promote a changing, flexible ecology of urban coexistence.” (BORSI e SCHULTE, 2018, p. 36)

"Estes princípios tipológicos tem a capacidade de complicar, multiplicar e produzir mudanças na ocupação do espaço urbano, ajudando a forjar comunidades de associação, aprendizado e compartilhamento de conhecimento, que sejam temporárias ou de longo prazo. Em outras palavras, eles podem ajudar a promover a mutável e flexível ecologia de coexistência urbana "(tradução nossa).
} 


\section{CAPÍTULO 3 - OS TIPOS DE PLANEJAMENTO DA UNIVERSIDADE NA CIDADE}

Não existe uma modalidade única de planejamento institucional. E muitas vezes, as nomenclaturas não coincidem, dificultando a comparação entre elas. No entanto, verificou-se que no sistema federal de ensino superior, há sim, tipos de planejamento que são comuns entre as instituições. Neste capítulo serão abordados os resultados obtidos da pesquisa a respeito de três tipos: o Plano de Desenvolvimento Institucional (PDI), o Plano de Logística Sustentável (PLS) e o Plano Diretor (PD).

Existem 56 universidades federais (MEC, 2018) no Brasil. Mantendo o tema de universidade e cidade, foram verificados os 20 municípios mais populosos do território nacional, e neste conjunto, 18 cidades tinham uma universidade federal.

Nos 18 municípios, duas instituições aparecem, cada uma, duas vezes. A Unifesp e a UFRJ têm campus em mais de uma cidade, portanto, serão analisadas 16 universidades federais, tendo representantes de todas as 5 regiões do Brasil.

As universidades federais formulam diversos tipos de planos ${ }^{82}$, como o Plano de Desenvolvimento Institucional (PDI), o Plano Estratégico de Tecnologia da Informação (PETI), Plano de Desenvolvimento da Tecnologia da Informação (PDTI), o Plano de Logística Sustentável (PLS), o Projeto Político-Pedagógico (PPP), Projeto Pedagógico Institucional (PPI), Plano Diretor (PD), entre outros.

Destes, o PDI, PLS e PD, envolvem planejamento de ações que podem visar a sustentabilidade, no que tange ações institucionais de projetos, ações, compras e diretrizes.

Os planos ${ }^{83}$ são meios das instituições declararem valores e ideais, não apenas por meio discursivo, mas também propositivo, trazendo análises, projetos e diretrizes para efetivação de suas funções sociais. Para analisar um plano, também se leva em consideração quais instrumentos de planejamento e tipos são utilizados.

\footnotetext{
${ }^{82} \mathrm{https}: / /$ www.unifesp.br/reitoria/transparencia/institucional/planejamento-e-estruturas-organizacionais

83 “Por meio do planejamento institucional, a organização universitária expressa o que deve e o que pretende fazer, explicitando o como, o quanto, o quando - e ainda o com quem, para quem e o porquê faz. O planejamento físico passa a definir com total clareza e controle de custos o programa de obras, de manutenção e crescimento do ambiente construído universitário - o que exige a discussão e determinação de sua escala de valores e objetivos, e de uma estrutura ordenada de ações." (UNB, 1998, p. 14)
} 


\subsection{PLANO DE DESENVOLVIMENTO INSTITUCIONAL}

Inicia-se a apresentação dos tipos de plano pelo PDI, pois é um documento de formulação obrigatória, sendo exigido para credenciamento de instituição de educação superior (IES), conforme decreto $\mathrm{n}^{\circ} 5.773$ de 9 de maio de 2006.

O conteúdo exigido no decreto inclui missão, objetivos e metas institucionais, com seu respectivo cronograma de implantação, organização administrativa, infraestrutura física, plano de promoção de acessibilidade e demonstrativo de capacidade e sustentabilidade financeira ${ }^{84}$.

O conteúdo mínimo de um PDI, portanto, indica quais elementos institucionais serão previstos no decorrer de um período de vigência desse plano. Das instituições analisadas, todas realizaram PDIs e publicaram digitalmente seu conteúdo (ver Quadro 12). Embora não conste no conteúdo mínimo exigido, muitos $\operatorname{PDI}^{85}$ trazem questões de sustentabilidade como diretrizes para o planejamento a exemplo de (UNIFESP, 2016, p. 189)"integrar ações de infraestrutura com as de gestão ambiental e sustentabilidade“.

Percebe-se que quando mencionado, o conceito de sustentabilidade está muito associado ao conceito do desenvolvimento sustentável. Outros casos de uso são o de "sustentabilidade financeira", ou ainda, a sustentabilidade como integrante da grade curricular.

84 "I - missão, objetivos e metas da instituição, em sua área de atuação, bem como seu histórico de implantação e desenvolvimento, se for o caso;

III - cronograma de implantação e desenvolvimento da instituição e de cada um de seus cursos, especificando-se a programação de abertura de cursos, aumento de vagas, ampliação das instalações físicas e, quando for o caso, a previsão de abertura dos cursos fora de sede;

VI - Organização administrativa da instituição, identificando as formas de participação dos professores e alunos nos órgãos colegiados responsáveis pela condução dos assuntos acadêmicos e os procedimentos de auto avaliação institucional e de atendimento aos alunos;

VII - infraestrutura física e instalações acadêmicas, especificando:

a) com relação à biblioteca: [...];

b) com relação aos laboratórios: instalações e equipamentos existentes e a serem adquiridos, identificando sua correlação pedagógica com os cursos e programas previstos, os recursos de informática disponíveis, informações concernentes à relação equipamento/aluno; e descrição de inovações tecnológicas consideradas significativas; e

c) plano de promoção de acessibilidade e de atendimento prioritário, [...];

$\mathrm{X}$ - Demonstrativo de capacidade e sustentabilidade financeiras. "(BRASIL, 2006)

85 "afirmar valores e práticas que atendam à sustentabilidade como princípio sistêmico que integre âmbitos ambientais, sociais e econômicos;” (UNB, 2017, p. 48)

"Com estas ações voltadas para a maximização na utilização dos recursos naturais, uso mais racional de recursos e reutilização dos mesmos acredita-se que a UFPE tornará mais sustentável melhorando o meio ambiente e, por conseguinte a qualidade de vida dos que habitam e usufruem o seu entorno." (UFPE, 2015, p. 97) 
No que tange a preocupação com resíduos sólidos (ver Quadro 12), não são todos os PDIs que indicam explicitamente essa questão, e mesmo o PDI da Unifesp não menciona esta expressão no texto, porém, estes documentos remetem ou indicam a necessidade de realizar outros planos, como o PLS.

Quadro 12 - Universidades federais, PDI com seu ano de publicação e menção a resíduos sólidos

\begin{tabular}{|c|c|c|c|c|}
\hline Município & $\begin{array}{l}\text { Universidade } \\
\text { federal }\end{array}$ & PDI & Ano & Menciona resíduos sólidos? \\
\hline São Paulo & Unifesp & $\mathrm{X}$ & 2016 & Não \\
\hline Rio de Janeiro & UFRJ & $\mathrm{X}$ & 2018 & Não \\
\hline Brasília & UNB & $\mathrm{X}$ & 2018 & $\mathrm{X}$ \\
\hline Salvador & UFBA & $\mathrm{X}$ & 2018 & $\mathrm{X}$ \\
\hline Fortaleza & UFC & $\mathrm{X}$ & 2018 & $\mathrm{X}$ \\
\hline Belo Horizonte & UFMG & $\mathrm{X}$ & 2013 & $\mathrm{X}$ \\
\hline Manaus & UFAM & $\mathrm{X}$ & 2016 & Não \\
\hline Curitiba & UFPR & $\mathrm{X}$ & 2017 & $\mathrm{X}$ \\
\hline Recife & UFPE & $\mathrm{X}$ & 2014 & $\mathrm{X}$ \\
\hline Porto Alegre & UFRGS & $\mathrm{X}$ & 2016 & $\mathrm{X}$ \\
\hline Goiânia & UFG & $\mathrm{X}$ & 2011 & Não \\
\hline Belém & UFPA & $X$ & 2016 & $X$ \\
\hline Guarulhos & Unifesp & $X$ & 2016 & Não \\
\hline Campinas & - & & & \\
\hline São Luís & UFMA & $\mathrm{X}$ & 2017 & $\mathrm{X}$ \\
\hline São Gonçalo & - & & & \\
\hline Maceió & UFAL & $\mathrm{X}$ & 2013 & $\mathrm{X}$ \\
\hline Duque de Caxias & UFRJ & & & \\
\hline Natal & UFRN & $X$ & 2010 & $X$ \\
\hline Campo Grande & UFMS & $\mathrm{X}$ & 2015 & Não \\
\hline
\end{tabular}

Fonte: (UNIFESP, 2016); (UFRJ, 2018); (UNB, 2018); (UFBA, 2018); (UFC, 2018); (UFMG, 2013); (UFAM, 2016); (UFPR, 2017); (UFPE, 2014); (UFRGS, 2016); (UFG, 2011); (UFPA, 2016); (UFMA, 2017); (UFAL, 2013); (UFRN, 2010); (UFMS, 2015)

O PDI da Unifesp, aprovado pelo seu Conselho Universitário em 2017, foi estabelecida a partir de 5 princípios e 5 eixos estruturantes, conforme visto na ilustração a seguir. Destaque como princípio a Democracia, Transparência e Equidade e a Sustentabilidade. E como Eixos estruturantes a Democracia Direta e Governança Participativa e Promoção de Bem-viver Social e Ambiental (ver Figura 36).

Estes são os valores declarados da comunidade acadêmica ao formular uma série de diretrizes que deverão orientar outros planos e ações da Universidade pelos próximos anos. 


\section{Princípios Eixos}

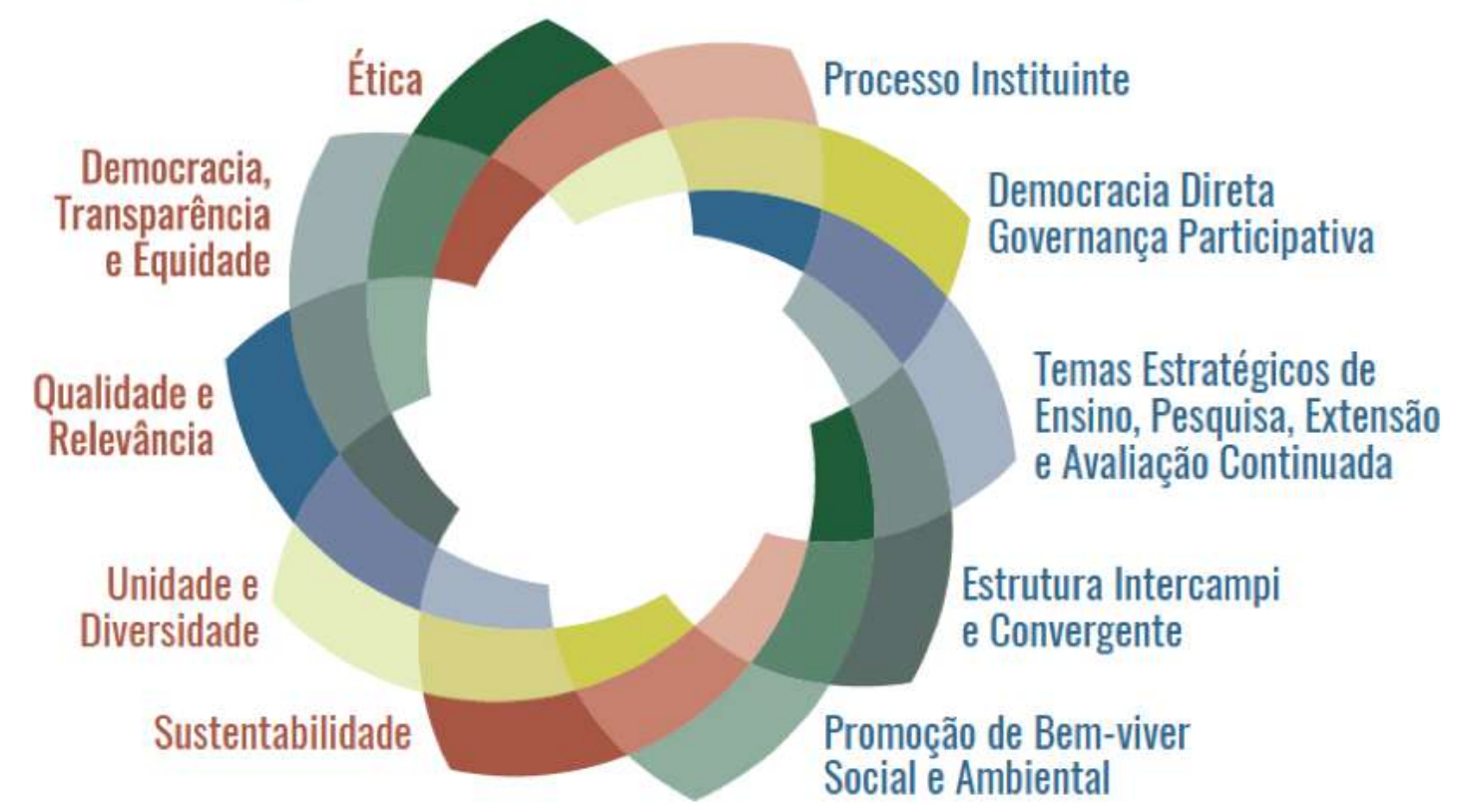

Fonte: (UNIFESP, 2016)

Vale destacar o que a instituição entende por princípio da sustentabilidade, em quatro dimensões (ambiental, econômica, social e cultural), que é aderente a um conceito predominante de sustentabilidade, que vem desde o relatório Bruntland, até o atual Objetivos do Desenvolvimento Sustentável:

De caráter abrangente e integrador, o princípio de sustentabilidade visa à manutenção, em patamar satisfatório, da eficiência de ações individuais, coletivas e institucionais. Implicando respeito ao conteúdo de premissas ambientalmente corretas, economicamente viáveis, socialmente justas e culturalmente aceitas, a observância do princípio de sustentabilidade requer a progressiva assimilação de seus conceitos e o crescente engajamento na sua consecução pelos membros da comunidade acadêmica. (UNIFESP, 2016, p. 11)

O PDI da Unifesp propõe a sustentabilidade como um dos valores para a sua visão de futuro, sendo esta, fruto do compromisso de construção coletiva de uma universidade pública favorável à promoção da equidade e da sustentabilidade.

No ensino, pesquisa e extensão, através das práticas acadêmicas, do aperfeiçoamento e a flexibilização de suas matrizes curriculares, da garantia de gestão participativa dos recursos humanos e materiais, nas políticas de inovação, empreendedorismo e cooperativismo entre estudantes, na colaboração da universidade com o setor produtivo e na participação do desenvolvimento local e regional. 
Estas são premissas institucionais para a consolidação e expansão de atividades necessitam de organização do espaço físico, de forma que no PDI Unifesp está contemplado a contratação e implementação de planos diretores de infraestrutura e de projetos.

O PDI, portanto, tem uma característica mais de orientação, com as diretrizes e valores institucionais. Este é um plano que deve gerar ou induzir novos projetos e planos, uma vez que o PDI não tem um nível de detalhamento necessário para licitações e compras.

\subsection{PLANO DE LOGÍSTICA SUSTENTÁVEL}

O PLS foi implementado como obrigatório a partir de Decreto federal $\mathrm{n}^{\mathrm{0}} 7.746 \mathrm{de}$ 5 de junho de 2012, no entanto, ainda em 2018 algumas instituições não publicaram digitalmente estes planos e, portanto, não constam no levantamento desta pesquisa.

O PLS, assim como o PDI, é um documento obrigatório cujo conteúdo mínimo ${ }^{86}$, dado por decreto exige atualização de inventário de bens e materiais, práticas de sustentabilidade e racionalização do uso de materiais entre outros.

A formulação de PLS teve grande adesão por parte das universidades analisadas (ver Quadro 13), sendo encontradas várias publicações sucessivas, de um a quatro anos de vigência. Na planilha resumo, foram consideradas as últimas versões digitais encontradas.

A necessidade de realizar um plano de gerenciamento de resíduos sólidos (PGRS) é praticamente consenso entre os PLS analisadas, apenas uma das instituições que publicou este plano não menciona como meta a formulação de uma PGRS.

\footnotetext{
${ }^{86}$ Art. 16. A administração pública federal direta, autárquica e fundacional e as empresas estatais dependentes deverão elaborar e implementar Planos de Gestão de Logística Sustentável, conforme ato editado pela Secretaria de Gestão do Ministério do Planejamento, Desenvolvimento e Gestão, que preverá, no mínimo:

(Redação dada pelo Decreto $\mathrm{n}^{\circ} 9.178$, de 2017)

I - atualização do inventário de bens e materiais do órgão e identificação de similares de menor impacto ambiental para substituição;

II - práticas de sustentabilidade e de racionalização do uso de materiais e serviços;

III - responsabilidades, metodologia de implementação e avaliação do plano; e

IV - ações de divulgação, conscientização e capacitação. (BRASIL, 2012)
} 
Quadro 13 - Universidades federais e PLS com ano de publicação

\begin{tabular}{|c|c|c|c|c|}
\hline Município & $\begin{array}{l}\text { Universidade } \\
\text { federal }\end{array}$ & PLS & Ano & $\begin{array}{l}\text { Tem meta } \\
\text { PGRS? }\end{array}$ \\
\hline São Paulo & Unifesp & $\mathrm{X}$ & 2017 & Não \\
\hline Rio de Janeiro & UFRJ & Não & & Não \\
\hline Brasília & UNB & $X$ & 2018 & $X$ \\
\hline Salvador & UFBA & $\mathrm{X}$ & 2016 & $\mathrm{X}$ \\
\hline Fortaleza & UFC & $\mathrm{X}$ & 2013 & $\mathrm{X}$ \\
\hline Belo Horizonte & UFMG & Não & & Não \\
\hline Manaus & UFAM & Não & & Não \\
\hline Curitiba & UFPR & $X$ & 2016 & $\mathrm{X}$ \\
\hline Recife & UFPE & Não & & $\mathrm{X}$ \\
\hline Porto Alegre & UFRGS & $\mathrm{X}$ & 2016 & $\mathrm{X}$ \\
\hline Goiânia & UFG & $X$ & 2014 & $X$ \\
\hline Belém & UFPA & $\mathrm{X}$ & 2013 & $\mathrm{X}$ \\
\hline Guarulhos & Unifesp & $X$ & 2017 & $X$ \\
\hline Campinas & - & & & \\
\hline São Luís & UFMA & $X$ & 2014 & Não \\
\hline São Gonçalo & - & & & \\
\hline Maceió & UFAL & Não & & Não \\
\hline Duque de Caxias & UFRJ & Não & & Não \\
\hline Natal & UFRN & $\mathrm{X}$ & 2017 & $\mathrm{X}$ \\
\hline Campo Grande & UFMS & $X$ & 2016 & $X$ \\
\hline
\end{tabular}

Fonte: (UNIFESP, 2017); (UNB, 2018); (UFBA, 2016); (UFC, 2013); (UFPR, 2016); (UFRGS, 2016); (UFG, 2014); (UFPA, 2013); (UFMA, 2014); (UFRN, 2017); (UFMS, 2016)

Nota: No PLS da Unifesp a meta de ter um PGRS se refere somente ao campus Diadema.

Um Plano de Gestão de Resíduos Sólidos (PGRS) deve conter conforme a Lei Federal $n^{0} 12.305 / 2010$ :

I - descrição do empreendimento ou atividade;

II - diagnóstico dos resíduos sólidos gerados ou administrados, contendo a origem, o volume e a caracterização dos resíduos, incluindo os passivos ambientais a eles relacionados;

III - observadas as normas estabelecidas pelos órgãos do Sisnama, do SNVS e do Suasa e, se houver, o plano municipal de gestão integrada de resíduos sólidos:

a) explicitação dos responsáveis por cada etapa do gerenciamento de resíduos sólidos;

b) definição dos procedimentos operacionais relativos às etapas do gerenciamento de resíduos sólidos sob responsabilidade do gerador;

IV - identificação das soluções consorciadas ou compartilhadas com outros geradores;

$V$ - ações preventivas e corretivas a serem executadas em situações de gerenciamento incorreto ou acidentes; 
$V I$ - metas e procedimentos relacionados à minimização da geração de resíduos sólidos e, observadas as normas estabelecidas pelos órgãos do Sisnama, do SNVS e do Suasa, à reutilização e reciclagem;

VII - se couber, ações relativas à responsabilidade compartilhada pelo ciclo de vida dos produtos, na forma do art. 31;

VIII - medidas saneadoras dos passivos ambientais relacionados aos resíduos sólidos;

$I X$ - periodicidade de sua revisão, observado, se couber, o prazo de vigência da respectiva licença de operação a cargo dos órgãos do Sisnama. (BRASIL, 2010)

Os itens I, II, IV e V, podem subsidiar decisões relacionadas a questões de implantação, expansão, reforma e reorganização espacial de uma instituição. Primeiro, pois explicita-se quais atividades são realizadas e quais são os resíduos que estão relacionadas a elas. O diagnóstico, ou seja, caracterizar, dimensionar e identificar origem do volume de resíduos, permite estudos para otimizar, remanejar ou consolidar atividades. Soluções consorciadas ou compartilhadas são desejáveis para redução de custos operacionais, melhor prevenção de acidentes do trabalhador, atendimento às normas e racionalização de recursos naturais neste processo. Por fim, o planejamento do espaço físico pode ser entendido como uma ação preventiva ao dimensionar corretamente abrigos e organizar fluxos, de forma a reduzir riscos à saúde do trabalhador e saúde ambiental.

A integração de preceitos e procedimentos de PGRS ao planejamento institucional de espaço físico pode subsidiar o corpo técnico de projeto na proposição e as instancias tomadoras de decisão com uma visão holística.

Embora o PLS não tenha como foco o planejamento de espaço físico, no Plano Diretor diversas questões que estão contempladas no PGRS podem ser retomadas. E a instituição que não tiver como objetivo formular esse plano provavelmente não fará as ações necessárias para um adequado diagnóstico. 
Dentre as universidades que formularam o PLS, tiveram entre seus objetivos, redução de consumo de materiais, sensibilização da comunidade e implementação de sistema de gestão ambiental, entre outros (UFC, 2013) ${ }^{87}(\mathrm{UFPR}, 2016)^{88}(\mathrm{UNB}, 2018)^{89}$

Os destaques mencionados demonstram a diversidade de métodos para o envolvimento, sensibilização e participação da comunidade acadêmica nas questões da gestão dos resíduos sólidos. Em paralelo, os PLS buscam gerar indicadores para verificar o cumprimento de objetivos estipulados.

No caso do CSP, o PLS apresenta as metas, ações, áreas envolvidas e responsáveis, cronograma, previsão de recursos, indicador e apuração para práticas de sustentabilidade e de uso racional para materiais de consumo, de energia elétrica, de água e geração de esgoto, para fortalecimento do programa de coleta seletiva, de programas de qualidade de vida no trabalho, nos processos de compras e contratação e de uso de frota de veículos.

Alguns exemplos de metas do Campus São Paulo com seus detalhamentos, áreas envolvidas e responsáveis, cronograma, previsão de recursos e indicadores foram compilados para referencias. (ver Quadro 14)

\footnotetext{
87 "Os objetivos do PLS-UFC consistem em criar princípios e projetos de acordo com as políticas estabelecidas pelas normas e resoluções vigentes, além de formalizar e expandir para todos os campi, procedimentos já adotados pela UFC. Os objetivos específicos são:

Redução do consumo de energia elétrica e de água e esgoto; Redução do consumo de papel A4, copos descartáveis e cartuchos de tintas para impressoras; Gerenciamento dos resíduos sólidos, com foco na redução, reuso e reciclagem; Programa de capacitação para servidores e terceirizados; Manuais que especificam os requisitos para compra de materiais de consumo sustentáveis; Manuais atualizados com vários requisitos para obras e projetos sustentáveis; Sensibilização da comunidade acadêmica em relação à sustentabilidade" (UFC, 2013)

88 - Uso racional de materiais de consumo, energia elétrica, água, madeira, copos plásticos, etc., reduzindo consumo e combatendo desperdícios;

- Curso de capacitação de 40 h para terceiros na área de resíduos (limpeza e manutenção); (UFPR, 2016)

89 "O eixo integrador do NS [Núcleo de Sustentabilidade] se assentava nos espaços e saberes em conjunto com os órgãos executivos da Universidade, planejando e assessorando a implementação de um sistema de gestão ambiental na UnB, cujos objetivos eram: i) promover ações para a conscientização e mobilização da comunidade para a sustentabilidade na Universidade; ii) criar e auxiliar projetos e campanhas ambientais desenvolvidas pela comunidade universitária; [...] iv) planejar de forma aberta e participativa o processo de adesão aos termos da Política Nacional de Resíduos Sólidos, Lei nº. 12.305, de 2 de agosto de 2010, nos campi da UnB;"' (UNB, 2018)
} 
Quadro 14 - Práticas de sustentabilidade e metas do PLS - CSP

\begin{tabular}{|c|c|c|c|c|c|c|}
\hline \multirow[t]{2}{*}{ Metas } & \multirow{2}{*}{$\begin{array}{l}\text { Detalhame } \\
\text { nto de } \\
\text { implement } \\
\text { ação das } \\
\text { ações }\end{array}$} & \multirow{2}{*}{$\begin{array}{l}\text { Áreas } \\
\text { envolvidas e } \\
\text { responsáveis }\end{array}$} & \multicolumn{2}{|c|}{$\begin{array}{l}\text { Cronograma de } \\
\text { Implementação }\end{array}$} & \multirow{2}{*}{$\begin{array}{l}\text { Previsão de } \\
\text { recursos } \\
\text { financeiros, } \\
\text { humanos, } \\
\text { instrumentais }\end{array}$} & \multirow[t]{2}{*}{ Indicador } \\
\hline & & & Início & Fim & & \\
\hline $\begin{array}{l}\text { Reduzir } \\
10 \% \text { no } \\
\text { consumo } \\
\text { de água }\end{array}$ & $\begin{array}{l}\text { Instalar } \\
\text { medidores } \\
\text { individualiz } \\
\text { ados }\end{array}$ & $\begin{array}{l}\text { Depto. } \\
\text { Administração / } \\
\text { Depto. } \\
\text { Infraestrutura / } \\
\text { Div. } \\
\text { Manutenção }\end{array}$ & $\mathrm{jan} / 17$ & dez/17 & $\begin{array}{l}\text { Humano, } \\
\text { instrumental e } \\
\text { financeiro }\end{array}$ & $\begin{array}{l}\text { Instalação de } \\
\text { medidores } \\
\text { Individuais } \\
\text { de água }\end{array}$ \\
\hline $\begin{array}{l}\text { Redução } \\
\text { do } \\
\text { custo/volu } \\
\text { me da } \\
\text { operação } \\
\text { de coleta e } \\
\text { destinação } \\
\text { de resíduos }\end{array}$ & $\begin{array}{l}\text { Implementa } \\
\text { r a } \\
\text { compostage } \\
\text { m do } \\
\text { resíduo } \\
\text { orgânico }\end{array}$ & $\begin{array}{l}\text { Depto. } \\
\text { Administração / } \\
\text { Depto. } \\
\text { Infraestrutura / } \\
\text { Div. Gestão } \\
\text { Ambiental }\end{array}$ & $\mathrm{jan} / 17$ & dez/17 & $\begin{array}{l}\text { Humano, } \\
\text { instrumental e } \\
\text { financeiro }\end{array}$ & $\begin{array}{l}\text { Destinação } \\
\text { de resíduos } \\
\text { (operação de } \\
\text { coleta, } \\
\text { transporte e } \\
\text { destinação } \\
\text { de resíduos) }\end{array}$ \\
\hline \multirow[t]{2}{*}{$\begin{array}{l}\text { Redução } \\
\text { do } \\
\text { custo/volu } \\
\text { me da } \\
\text { operação } \\
\text { de coleta e } \\
\text { destinação } \\
\text { de resíduos }\end{array}$} & $\begin{array}{l}\text { Revisão de } \\
\text { contrato de } \\
\text { coleta e } \\
\text { destinação } \\
\text { de resíduos }\end{array}$ & $\begin{array}{l}\text { Depto. } \\
\text { Administração / } \\
\text { Depto. } \\
\text { Infraestrutura / } \\
\text { Div. Gestão } \\
\text { Ambiental }\end{array}$ & $\mathrm{jan} / 17$ & $\operatorname{dez} / 17$ & $\begin{array}{l}\text { Humano, } \\
\text { instrumental e } \\
\text { financeiro }\end{array}$ & $\begin{array}{l}\text { Destinação } \\
\text { de resíduos } \\
\text { (operação de } \\
\text { coleta, } \\
\text { transporte e } \\
\text { destinação } \\
\text { de resíduos) }\end{array}$ \\
\hline & $\begin{array}{l}\text { Implementa } \\
\text { ção da } \\
\text { coleta } \\
\text { seletiva } \\
\text { solidária }\end{array}$ & $\begin{array}{l}\text { Depto. } \\
\text { Administração / } \\
\text { Depto. } \\
\text { Infraestrutura / } \\
\text { Div. Gestão } \\
\text { Ambiental }\end{array}$ & $\mathrm{jan} / 17$ & $\operatorname{dez} / 17$ & $\begin{array}{l}\text { Humano, } \\
\text { instrumental e } \\
\text { financeiro }\end{array}$ & $\begin{array}{l}\text { Destinação } \\
\text { de resíduos } \\
\text { (operação de } \\
\text { coleta, } \\
\text { transporte e } \\
\text { destinação } \\
\text { de resíduos) }\end{array}$ \\
\hline $\begin{array}{l}\text { Reduzir } \\
10 \% \text { das } \\
\text { compras de } \\
\text { papel para } \\
\text { impressora } \\
\text { (Quantidad } \\
\text { e) }\end{array}$ & $\begin{array}{l}\text { Analisar a } \\
\text { distribuição } \\
\text { de } \\
\text { equipament } \\
\text { os e } \\
\text { insumos de } \\
\text { impressão }\end{array}$ & $\begin{array}{l}\text { Diretoria } \\
\text { Administrativa / } \\
\text { Div. T.I. / Div. } \\
\text { Contratos / Div. } \\
\text { Suprimentos }\end{array}$ & $\mathrm{jan} / 17$ & $\operatorname{dez} / 17$ & $\begin{array}{l}\text { Humano, } \\
\text { instrumental e } \\
\text { financeiro }\end{array}$ & $\begin{array}{l}\text { Papel para } \\
\text { impressora }\end{array}$ \\
\hline
\end{tabular}

Continua 


\begin{tabular}{|c|c|c|c|c|c|c|}
\hline \multirow[t]{2}{*}{ Metas } & \multirow{2}{*}{$\begin{array}{l}\text { Detalhamen } \\
\text { to de } \\
\text { implementa } \\
\text { ção das } \\
\text { ações }\end{array}$} & \multirow{2}{*}{$\begin{array}{l}\text { Áreas } \\
\text { envolvidas e } \\
\text { responsáveis }\end{array}$} & \multicolumn{2}{|c|}{$\begin{array}{l}\text { Cronograma de } \\
\text { Implementação }\end{array}$} & \multirow{2}{*}{$\begin{array}{l}\text { Previsão de } \\
\text { recursos } \\
\text { financeiros, } \\
\text { humanos, } \\
\text { instrumentais }\end{array}$} & \multirow[t]{2}{*}{ Indicador } \\
\hline & & & Início & Fim & & \\
\hline $\begin{array}{l}\text { Redução na } \\
\text { aquisição de } \\
\text { copos } \\
\text { descartáveis }\end{array}$ & $\begin{array}{l}\text { Monitorame } \\
\text { nto das } \\
\text { aquisições }\end{array}$ & $\begin{array}{l}\text { Almoxarifado } \\
\text { / Div. Gestão } \\
\text { Ambiental }\end{array}$ & $\mathrm{jan} / 17$ & $\operatorname{dez} / 17$ & $\begin{array}{l}\text { Humano, } \\
\text { instrumental e } \\
\text { financeiro }\end{array}$ & $\begin{array}{l}\text { Aquisição } \\
\text { de copos } \\
\text { descartável }\end{array}$ \\
\hline $\begin{array}{l}\text { Monitorar } \\
\text { as } \\
\text { aquisições } \\
\text { sustentáveis }\end{array}$ & $\begin{array}{l}\text { Monitorar } \\
\text { aquisições }\end{array}$ & $\begin{array}{l}\text { Div. Compras } \\
\text { / Div. Gestão } \\
\text { Ambiental }\end{array}$ & $\mathrm{jan} / 17$ & dez/17 & $\begin{array}{l}\text { Humano e } \\
\text { instrumental }\end{array}$ & $\begin{array}{l}\text { Aquisições } \\
\text { sustentáveis } \\
\text {. }\end{array}$ \\
\hline
\end{tabular}

Fonte: (UNIFESP, 2017)

A apresentação das ações com indicadores é necessária, pois ao final de cada ano é feito o "Relatório de Monitoramento Semestral" que é publicado no site e enviados à Comissão Interministerial de Sustentabilidade na Administração Pública (CISAP) e posteriormente, avaliando as metas, ações e indicadores no momento de elaboração do Plano para o próximo ano. Realizando assim, o ciclo PDCA (Plan, Do, Check, Act), uma ferramenta de qualidade muito utilizada por organizações.

Tanto a formulação, quanto o acompanhamento do PLS se consolidou como um indicador administrativo para fiscalização de órgãos como o Tribunal de Contas da União (TCU), que, em 2016, determinou que a UFC aprove o plano para se adequar às boas práticas $^{90}$.

O PLS aliando a questão ambiental à redução (ou racionalização) do consumo de materiais e eficiência do uso de recursos, se tornou uma metodologia consolidada para as instituições e órgãos de controle, mobilizando corpo técnico periodicamente para sua formulação e fiscalização. No entanto tem uma atuação limitada pelo próprio escopo do plano, que não envolve a organização espacial da instituição e não foram identificados processos participativos para este tipo de plano.

\footnotetext{
${ }^{90}$ Disponível em https://portal.tcu.gov.br/imprensa/noticias/universidade-federal-do-ceara-deve-melhorarprocessos-de-aquisicoes.htm (acesso em ago. 2018)
} 


\subsection{PLANO DIRETOR}

O PD não é de formulação obrigatória por parte de IES. No entanto, muitas universidades tem uma "população", ou seja, alunos, técnicos, professores e visitantes superior a 20.000 pessoas. Em outras palavras, se uma universidade fosse um município, seria obrigatória a formulação de plano diretor, conforme estabelecido na Constituição e no Estatuto da Cidade (BRASIL, 2001).

A elaboração espontânea por algumas universidades pode indicar que esta modalidade de projeto é uma ferramenta útil para a organização espacial e planejamento institucional. No que tange o escopo destes planos, para o objetivo desta pesquisa, foi analisado se nos PDs elaborados há alguma menção a resíduos sólidos.

Nos PDs da (UFMG, 2009) e (UFRJ, 2009) os planejadores demonstram a preocupação em destinar corretamente ou prever infraestrutura para abrigo (depósito) dos resíduos. No entanto, como verificado em levantamento nos documentos, não constam diagnósticos dos resíduos sólidos produzidos na instituição. Dessa forma fica evidente nesses planos que não há dimensionamento de abrigos ou previsão de espaço para locação dessas infraestruturas (ver Quadro 15).

Quadro 15 - Universidades federais e planos diretores e relação com gerenciamento de resíduos

\begin{tabular}{|c|c|c|c|c|c|c|c|}
\hline Município & Estado & $\begin{array}{l}\text { Univ. } \\
\text { Fed. }\end{array}$ & Tipo & P.D. & Ano & $\begin{array}{l}\text { Diagnóstico } \\
\text { de resíduos? }\end{array}$ & $\begin{array}{l}\text { PD fala } \\
\text { de Res. } \\
\text { Sólidos? }\end{array}$ \\
\hline São Paulo & SP & Unifesp & Campus & $\mathrm{X}$ & 2018 & $\mathrm{X}$ & $\mathrm{X}$ \\
\hline $\begin{array}{l}\text { Rio de } \\
\text { Janeiro }\end{array}$ & RJ & UFRJ & $\begin{array}{l}\text { Campus / } \\
\text { Cid. Univ. }\end{array}$ & $X$ & 2009 & Não & $X$ \\
\hline Brasília & DF & UNB & Cid. Univ. & $X$ & 1998 & $X$ & $X$ \\
\hline Salvador & BA & UFBA & Cid. Univ. & $X$ & 2009 & Não & $\mathrm{X}$ \\
\hline Fortaleza & $\mathrm{CE}$ & UFC & $\begin{array}{l}\text { Campus / } \\
\text { Cid. Univ. }\end{array}$ & Não & & Não & \\
\hline $\begin{array}{l}\text { Belo } \\
\text { Horizonte }\end{array}$ & $\mathrm{MG}$ & UFMG & $\begin{array}{l}\text { Campus / } \\
\text { Cid. Univ. }\end{array}$ & $X$ & 2009 & Não & $\mathrm{X}$ \\
\hline Manaus & $\mathrm{AM}$ & UFAM & Cid. Univ. & Não & & Não & \\
\hline Curitiba & PR & UFPR & $\begin{array}{l}\text { Campus / } \\
\text { Cid. Univ. }\end{array}$ & Não & & Não & \\
\hline Recife & $\mathrm{PE}$ & UFPE & $\begin{array}{l}\text { Campus / } \\
\text { Cid. Univ. }\end{array}$ & Não & & Não & \\
\hline $\begin{array}{l}\text { Porto } \\
\text { Alegre }\end{array}$ & $\mathrm{RS}$ & UFRGS & Campus & Não & & Não & \\
\hline Goiânia & $\mathrm{GO}$ & UFG & Cid. Univ. & Não & & Não & \\
\hline Belém & PA & UFPA & $\begin{array}{l}\text { Campus / } \\
\text { Cid. Univ. }\end{array}$ & Não & & Não & \\
\hline
\end{tabular}

\section{Continua}


continuação

\begin{tabular}{|l|l|l|l|l|l|l|l|}
\hline Município & Estado & $\begin{array}{l}\text { Univ. } \\
\text { Fed. }\end{array}$ & Tipo & P.D. & Ano & $\begin{array}{l}\text { Diagnósti } \\
\text { co de } \\
\text { resíduos? }\end{array}$ & $\begin{array}{l}\text { PD fala } \\
\text { de Res. } \\
\text { Sólidos? }\end{array}$ \\
\hline Guarulhos & SP & Unifesp & Campus & Não & & Não & \\
\hline Campinas & SP & - & & & & Não & Não \\
\hline São Luís & MA & UFMA & Cid. Univ. & Não & & Não & \\
\hline $\begin{array}{l}\text { São } \\
\text { Gonçalo }\end{array}$ & RJ & - & & & & Não & \\
\hline $\begin{array}{l}\text { Maceió } \\
\text { Duque de } \\
\text { Caxias }\end{array}$ & RJ & UFAL & Cid. Univ. & Não & & Não & \\
\hline $\begin{array}{l}\text { Campo } \\
\text { Grande }\end{array}$ & MS & UFRJ & Campus & Não & & Não & \\
\hline
\end{tabular}

Fonte: (UFRJ, 2009); (UNB, 1998); (UFBA, 2009); (UFMG, 2009)

Nota 1: Plano Diretor de Infraestrutura do Campus São Paulo - Unifesp em formulação no período da pesquisa.

Nota 2: O diagnóstico de resíduos sólidos da UNB está no PLS (UNB, 2018).

Nota 3: O Plano Diretor da UFBA publicado está na fase de termo de referência.

Excetuando o plano diretor da UFBA, que é um termo de referência para futuras contratações, os PDs universitários estão mais alinhados ao campo da arquitetura e urbanismo. Mas o escopo dos PDs não se limitou a questões construtivas e de uso e ocupação do território, pois há menção da problemática dos resíduos sólidos em todos os 4 PDs levantados.

No entanto, apenas 2 instituições realizaram em algum momento o diagnóstico de gerenciamento de resíduos a UNB e a Unifesp. A UNB, porém, publicou o diagnóstico no PLS de 2018, e o PD foi publicado em 1998, portanto, não houve, como é o caso da Unifesp, incorporação dos dados do diagnóstico de gerenciamento no escopo do plano diretor.

Como os planos diretores definem diretrizes e parâmetros que orientam os projetos urbanos e arquitetônicos a serem licitados, contratados e executados, pode-se dizer que dentre os 3 instrumentos de planejamento, o PD é o mais adequado para concretização de mudanças necessárias para uma instituição. 


\subsection{DISCUSSÃO DOS PLANOS E INSTRUMENTOS ABORDADOS}

Considerando o levantamento dos 3 instrumentos de planejamento em 16 instituições de ensino superior federal, pode-se afirmar que as universidades incorporaram ao seu fluxo de trabalho a atividade de planejar:

O planejamento institucional é parte indissociável da administração da instituição, e não se "para de administrar para se planejar" ou, inversamente, "se planeja para controlar a administração". (UNB, $1998, p .5)$

Ao comparar cada modalidade de plano, verifica-se que o PDI é o com mais adesão, com a realização por parte de todas as universidades. Em segundo lugar, o PLS, com 12 de 16 instituições e, por fim, PD com 6 de 16 universidades (ver Quadro 16).

Verifica-se também que as instituições mantêm a prática de formulação de planos, sendo que há muitos planos recentemente publicados, a maioria destes feitos ainda nesta década.

Quadro 16 - Universidades federais e tipos de plano (PDI, PD e PLS)

\begin{tabular}{|l|l|l|l|l|l|l|}
\hline Universidade federal & PDI & Ano & PD & Ano & PLS & Ano \\
\hline Unifesp & $\mathrm{X}$ & 2016 & $\mathrm{X}$ & 2018 & $\mathrm{X}$ & 2017 \\
\hline UFRJ & $\mathrm{X}$ & 2018 & $\mathrm{X}$ & 2009 & Não & \\
\hline UNB & $\mathrm{X}$ & 2018 & $\mathrm{X}$ & 1998 & $\mathrm{X}$ & 2018 \\
\hline UFBA & $\mathrm{X}$ & 2018 & $\mathrm{X}$ & 2009 & $\mathrm{X}$ & 2016 \\
\hline UFC & $\mathrm{X}$ & 2018 & Não & & $\mathrm{X}$ & 2013 \\
\hline UFMG & $\mathrm{X}$ & 2013 & $\mathrm{X}$ & 2009 & Não & \\
\hline UFAM & $\mathrm{X}$ & 2016 & Não & & Não & \\
\hline UFPR & $\mathrm{X}$ & 2017 & Não & & $\mathrm{X}$ & 2016 \\
\hline UFPE & $\mathrm{X}$ & 2014 & Não & & Não & \\
\hline UFRGS & $\mathrm{X}$ & 2016 & Não & & $\mathrm{X}$ & 2016 \\
\hline UFG & $\mathrm{X}$ & 2011 & Não & & $\mathrm{X}$ & 2014 \\
\hline UFPA & $\mathrm{X}$ & 2016 & Não & & $\mathrm{X}$ & 2013 \\
\hline Unifesp & $\mathrm{X}$ & 2016 & Não & & $\mathrm{X}$ & 2017 \\
\hline- & & & & & & \\
\hline UFMA & $\mathrm{X}$ & 2017 & Não & & $\mathrm{X}$ & 2014 \\
\hline- & & & & & & \\
\hline UFAL & $\mathrm{X}$ & 2013 & Não & & Não & \\
\hline UFRJ & - & & - & & - & \\
\hline UFRN & $\mathrm{X}$ & 2010 & $\mathrm{X}$ & 2007 & $\mathrm{X}$ & 2017 \\
\hline UFMS & $\mathrm{X}$ & 2015 & Não & & $\mathrm{X}$ & 2016 \\
\hline Fonte Org & & & & & \\
\hline
\end{tabular}

Fonte: Org. do autor 
Para visualizar as interfaces entre as modalidades de planejamento, usando Diagrama de Venn, criado através de uma ferramenta on-line (OLIVEROS, 2007-2015). Foram realizadas 3 análises. Uma considerando quantas instituições formularam Plano Diretor (PD), Plano de Desenvolvimento Institucional (PDI) e Plano de Logística Sustentável (PLS). A segunda, considera quais destas são campus universitários, considerando inclusive as instituições que na mesma cidade tem implantação do tipo cidade universitária e campus. E a terceira, inclui a cidade universitária, incluindo nesse grupo, analogamente, as que também tem campus no mesmo município. Importante notar que a soma dos elementos é 16 e não 18, pois duas instituições aparecem duas vezes, Unifesp (Campus Guarulhos) e UFRJ (Campus Duque de Caxias).

\section{Figura 37 - Diagrama de Venn (PD, PDI e PLS)}

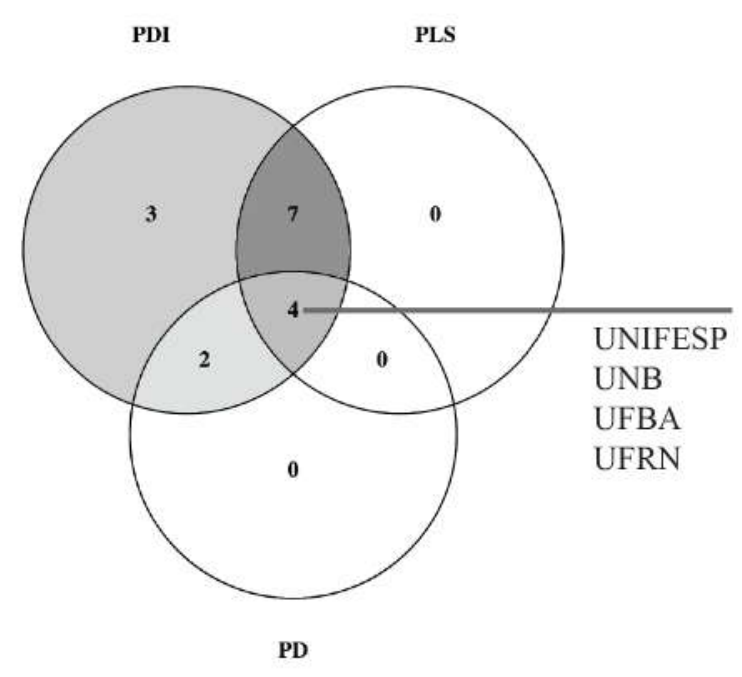

Fonte: autor

No primeiro diagrama (ver Figura 37) percebe-se que o maior conjunto é o de instituições que formularam PDI e PLS, justamente os documentos obrigatórios. Não há instituições que formularam apenas o PD ou PLS, mas 3 instituições publicaram apenas o PDI. O objeto de estudo desta pesquisa está na intersecção dos 3 conjuntos, 4 instituições formularam e publicaram os 3 planos.

A segunda análise se dá inserindo mais um conjunto, o de Campus universitário. Dentre as 18 maiores cidades brasileiras, a tipologia de implantação universitária de campus é a menos comum, 8 de 16. Embora tenham sido consideradas também as instituições que no mesmo município constam os dois tipos de implantação. Se fosse considerado apenas as universidades que são exclusivamente campus, o número seria de 3 , apenas. 


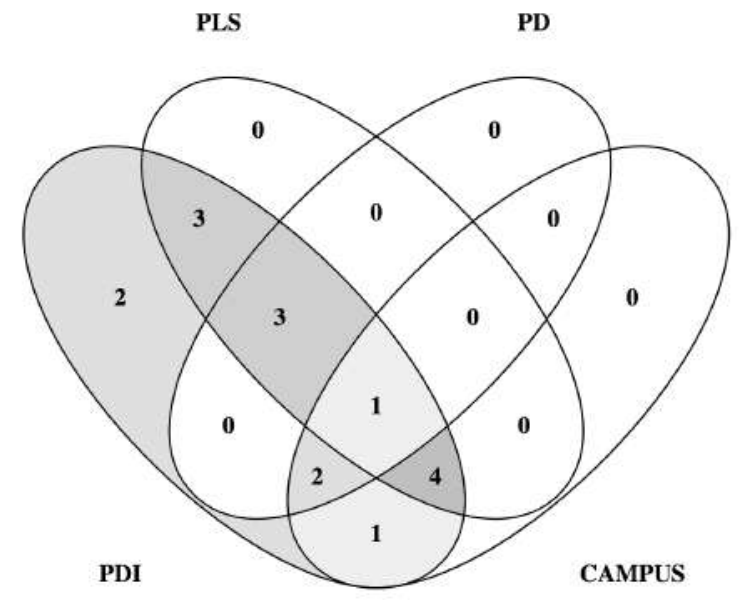

Fonte: autor

Ao incluir o conjunto "campus" (ver Figura 38), agora o maior conjunto é o de instituições que são campus e formularam PDIs e PLSs. Percebemos também que só há uma instituição que seja campus e tenha formulado os 3 planos, que no caso, é a Unifesp.

Figura 39 - Diagrama de Venn (PDI, PD, PLS e Cidade universitária)

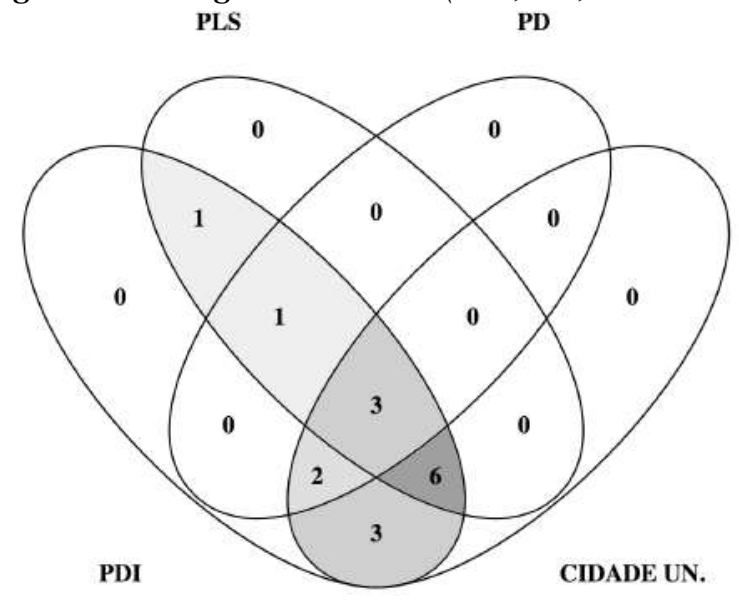

Fonte: autor

Ao incluir o conjunto da "cidade universitária" (ver Figura 39), que é a tipologia mais comum, 14 de 16, um novo diagrama é formado. Mais uma vez, o conjunto com mais elementos é formado por cidades universitárias que formularam PDIs e PLSs, 6 instituições. Outra análise relevante é que o número de instituições que formulam todos os planos é maior entre cidades universitárias, sendo 3 universidades: UNB, UFBA e UFRN.

Para entrar em vigência, planos devem passar por instancias de consulta e deliberação, geralmente no formato de Conselhos compostos por representantes eleitos 
dentro da comunidade acadêmica das 3 categorias, discentes, técnicos e docentes. A questão política de consultar a comunidade acadêmica para aprovar é diferente da de envolver a comunidade acadêmica no planejamento, que caracterizaria como um processo participativo.

Nos Planos de Desenvolvimento Institucional (PDI) da (UNIFESP, 2016) ${ }^{91} \mathrm{e}$ (UNB, 2017) ${ }^{92}$, por exemplo, ter o planejamento com processos participativos são postas como diretrizes institucionais que devem orientar a formulação de outros planos.

O processo participativo é um instrumento de planejamento que foi aplicado na formulação do PDInfra de forma a captar demandas da comunidade ao mesmo tempo em que a envolve no processo, compartilhando os diagnósticos, buscando soluções conjuntas e em mínimo consenso. Em suma, evitando ser um projeto de cima para baixo.

Considerando que as instituições participam dos processos de planejamento municipal, tanto propondo, quanto fazendo assessoramento técnico é interessante notar que como instrumento de planejamento, as universidades incorporaram os parâmetros e diretrizes dos planos diretores municipais no escopo do planejamento institucional.

Esta postura pode indicar a intenção de contribuir com o cumprimento das metas municipais, regularizar suas instalações frente aos órgãos de controle, estreitar a relação das universidades as Prefeituras das suas cidades, entre outras razões.

Ao incorporar diretrizes do planejamento municipal no seu próprio plano, esperase que para isso os planejadores tenham à disposição ou façam os próprios mapeamentos do entorno imediato da instituição. Percebe-se que este instrumento não é comum a todos os planos que incorporam o planejamento municipal (ver Quadro 17), mas a maioria das universidades que aplicam diretrizes municipais, também fazem mapeamento do entorno.

O mapeamento do entorno pode se limitar ao desenho de quadras e viário, ou ampliar a análise para critérios econômico-sociais, do relevo, dos sistemas naturais, fluxo de pessoas, atividades, entre outros aspectos que os planejadores julgarem relevantes.

\footnotetext{
91 "Com um olhar no futuro e no contexto atual de grandes desafios para as universidades públicas brasileiras, o Plano de Desenvolvimento Institucional 2018-2022 da Universidade de Brasília foi concebido por meio de um processo participativo envolvendo a comunidade universitária" (UNB, 2017, p. 151)

92 "Entre suas múltiplas atribuições, o planejamento institucional visa promover análises estratégicas, definir prioridades e elaborar cenários futuros, de modo a possibilitar a construção conjunta da universidade. Além disso, o planejamento deve integrar e alinhar as propostas oriundas de unidades acadêmicas e pró-reitorias, com vista à elaboração de planos institucionais coerentes. Para tanto, o principal foco recai sobre a ampliação do planejamento participativo na definição das políticas universitárias, bem como sua relação com a sociedade." (UNIFESP, 2016, p. 107)
} 
No estudo de caso do PDInfra, além do mapeamento do entorno, também foi feito o mapeamento da geração de resíduos de serviços de saúde da instituição complementando o diagnóstico de resíduos sólidos. Usar o diagnóstico do gerenciamento de resíduos sólidos como instrumento de planejamento, entre as referencias levantadas, é incomum. (ver Quadro 17)

Apesar de incomum, a aplicação deste instrumento perpassa o planejamento institucional e físico de uma universidade (ver Figura 40), uma vez que todas as atividades produzem resíduos e todos os projetos devem estar compatíveis com normas referentes à adequado manejo e abrigo de resíduos.

Figura 40 - Elementos do planejamento institucional e físico de uma universidade

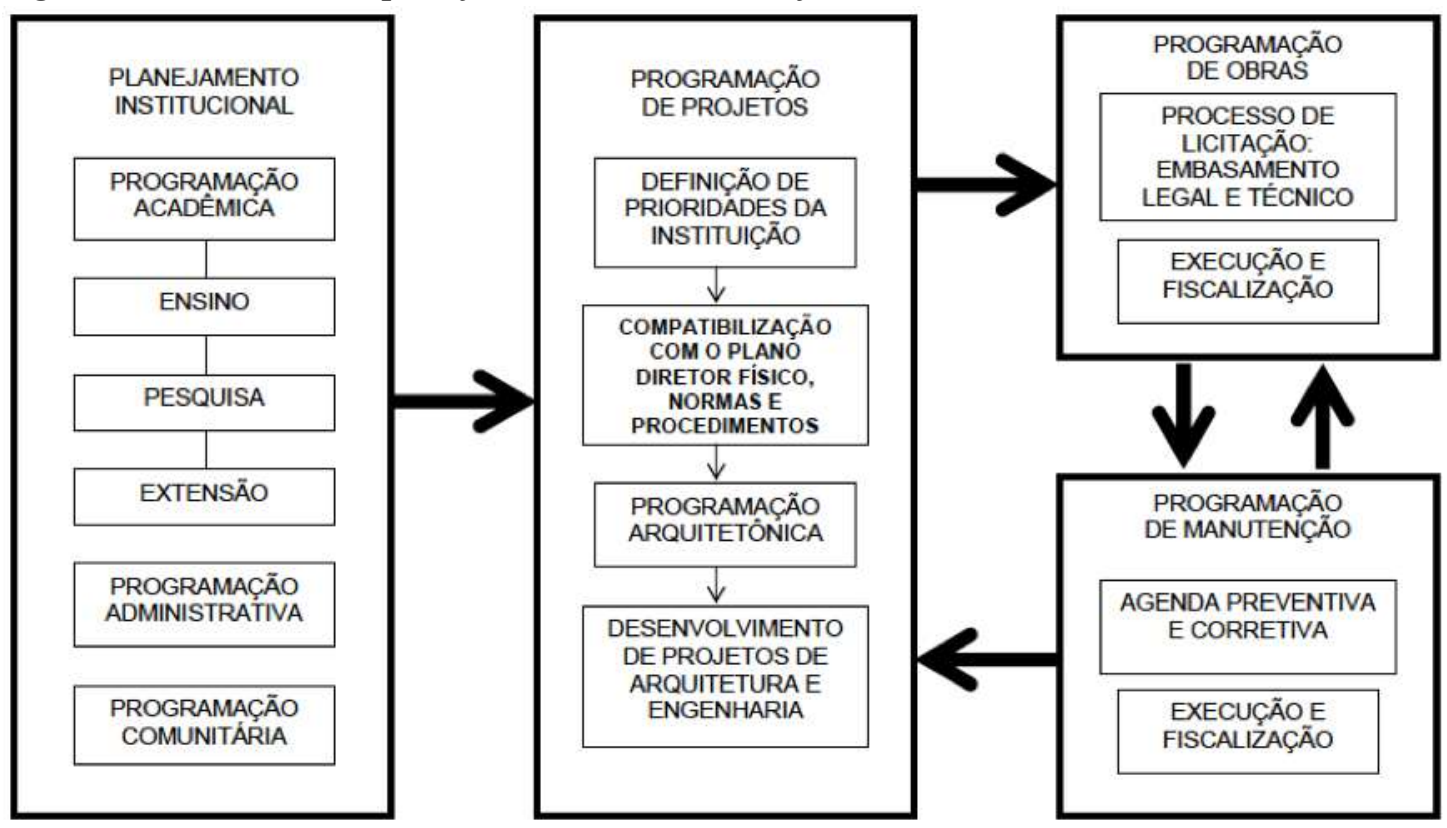

Retirado de: (UNB, 1998, p. 80)

Por fim, o instrumento do Material Flow Analysis (MFA) embora seja proposto para escalas regionais e de município, como exercício foi feito um esboço de como seria a aplicação deste instrumento no contexto do Campus São Paulo.

Os instrumentos de planejamento utilizados nos planos diretores de referencia, o da Universidade Federal do Rio de Janeiro, Universidade Federal de Minas Gerais, Universidade de Brasília, Universidade Federal de São Paulo, New York University, Johsn Hopkins University e University College London foram compilados para melhor visualização (ver Quadro 17). 
Quadro 17 - Instrumentos de planejamento utilizados no plano diretor das universidades

\begin{tabular}{|l|l|l|l|l|l|}
\hline Universidade & P.P. & P.M. & M.E. & D.G.R.S & MFA \\
\hline UFRJ & $\mathrm{X}$ & $\mathrm{X}$ & $\mathrm{X}$ & & \\
\hline UFMG & & & & & \\
\hline UNB & $\mathrm{X}$ & $\mathrm{X}$ & & $\mathrm{X}$ & \\
\hline Unifesp & $\mathrm{X}$ & $\mathrm{X}$ & $\mathrm{X}$ & & \\
\hline NYU & $\mathrm{X}$ & $\mathrm{X}$ & $\mathrm{X}$ & & \\
\hline $\begin{array}{l}\text { Johns } \\
\text { Hopkins }\end{array}$ & & & $\mathrm{X}$ & & \\
\hline UCL & $\mathrm{X}$ & $\mathrm{X}$ & & \\
\hline
\end{tabular}

Fonte: (UFRJ, 2009); (UFMG, 2009); (UNB, 1998); (NYU, 2008); (JOHNS HOPKINS

UNIVERSITY, 2009); (UCL, 2011);

Nota1: Plano diretor (PD) da Unifesp em desenvolvimento - material proveniente do processo de fiscalização.

Nota2: Processo Participativo (P.P.), conforme o texto do plano, se houveram consultas à comunidade acadêmica, oficinas, reuniões e outras metodologias de processo participativo.

Nota3: Diretrizes e parâmetros do plano diretor universitário alinhados ao Planejamento do Município $(P M)$, conforme informado no texto do PD

Nota4: Mapeamentos do entorno (ME) utilizados para formular propostas para o plano diretor

Nota5: Diagnóstico de Gerenciamento de Resíduos Sólidos (DGRS), incorporado ao plano diretor.

Nota5: Material Flow Analysis (MFA) feito para o CSP como exercício, não foi utilizado no PD.

\subsection{METABOLISMO URBANO E O PLANEJAMENTO INSTITUCIONAL}

Ao estabelecer metodologias para análise de fluxo de material e energia, o metabolismo urbano pode ser uma ferramenta para construir um diagnóstico que servirá de base para o desenho institucional que se deseje sustentável.

Esta afirmação se deve pelo fato de em outras referências, temas afins com estas análises são abordados, mesmo sem mencionar o conceito de metabolismo urbano, objetivando melhor uso de recursos, diminuição de impacto ambiental ou reintroduzir subprodutos em outros ciclos produtivos.

Sem mencionar metabolismo urbano, o PDInfra do Campus Baixadas Santista (UNIFESP, 2015), para ilustrar a importância do planejamento no contexto ambiental, adaptou um diagrama dos principais fluxos de um campus universitário (ver Figura 41), demonstrando fluxos de material e energia lineares (ZHANG, 2013) (KARVOUNIS, 2015). 
Figura 41 - Diagrama de "principais fluxos de um campus universitário"

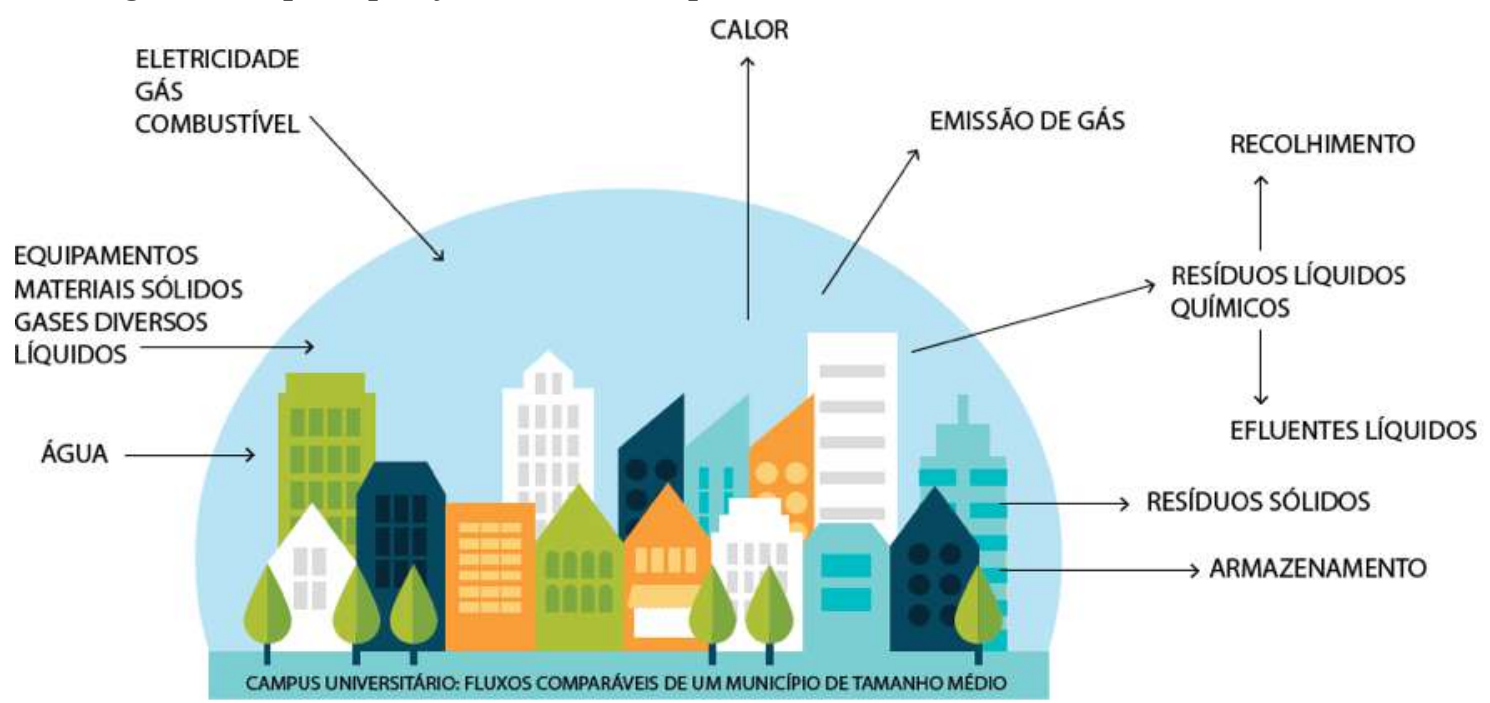

Fonte: (UNIFESP, 2015) - Diagrama adaptado de Careto \& Vendeirinho (2003) desenho: Idom

Argumenta-se que os fluxos de um campus universitário são comparáveis a um município de tamanho médio. De maneira análoga a cidades, as universidades também podem usar ferramentas comumente associadas ao planejamento municipal, como é o caso de planos diretores.

A visualização dos fluxos de materiais e energia pode fornecer um diagnóstico da situação, capaz de subsidiar decisões de projeto mais efetivas. E qual substancia, material ou energia que será analisada também indica qual o objetivo da cidade em reduzir consumo, melhorar gestão ou aprimorar processos do uso desses materiais ou substâncias.

$\mathrm{Na}$ escala de bairro ou de cidade, é possível utilizar os estudos de metabolismo urbano para orientar projetos urbanos, arquitetônicos e de sistemas (KENNEDY, PINCETL e BUNJE, 2011). Um dos primeiros estudos se refere à cidade de Bruxelas, onde se analisou o balanço de energia natural, conforme diagrama feito por Duvigneaud e Denayeyer-De Smet, em 1977.

Em ambos os casos, foram utilizados estes diagramas para demonstrar a predominância de fluxos lineares de materiais e energia. No caso do diagrama de Bruxelas (ver Figura 42), inclusive por poder visualizar a dimensão dos fluxos, pode-se rapidamente verificar quais são os maiores e mais impactantes fluxos em um sistema. 
Figura 42 - Estudo de metabolismo urbano de Bruxelas (1977) ECOSYSTEME BRUXELLES ( $16.178 \mathrm{ha}$ )

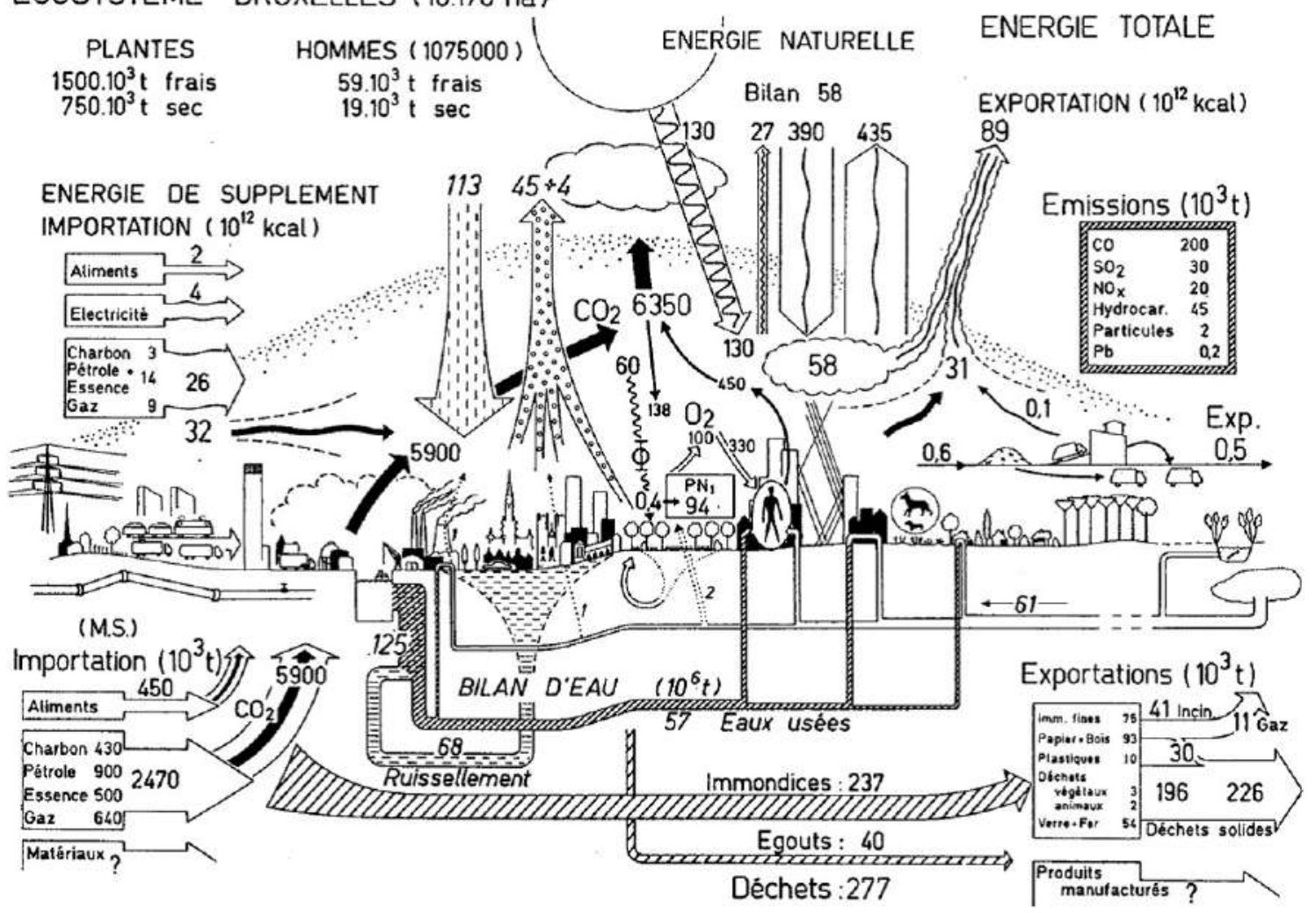

Fonte: Duvigneaud e Denayeyer-De Smet, 1977 apud (KENNEDY, PINCETL e BUNJE, 2011)

Embora existam várias metodologias de análise do metabolismo urbano, nesta pesquisa foi utilizado o Material Flow Analysis (MFA).

Os materiais estudados têm a ver com as atividades urbanas que serão consideradas no projeto. Para Baccini e Brunner (1991) para as principais atividades urbanas, são necessárias análises de ao menos quatro componentes: água, comida, material de construção e energia ${ }^{93}$ :

Com essas premissas em mente, um grupo de estudantes da Universidade de Toronto propôs um desenho sustentável em escala de bairro (ver Figura 43), usando

\footnotetext{
93 "The four major urban activities: to nourish and recover; to clean; to reside and work; and to transport and communicate, as identified by Baccini and Brunner (1991) are assessed in terms of four major components of urban metabolism: water, food (biomass), construction materials, and energy. Several examples partially demonstrate the integration of morphological and physiological perspectives.“(KENNEDY, PINCETL e BUNJE, 2011)

"As quatro principais atividades urbanas: fomentar e recuperar; limpar; morar e trabalhar e transportar e comunicar, como identificado por Baccini e Brunner (1991) são analisadas em termos de quatro grandes componentes de metabolismo urbano: água, comida (biomassa), material de construção e energia. Muitos exemplos demonstram parcialmente a integração das perspectivas morfológicas e fisiológicas." (tradução nossa).
} 
projetos arquitetônicos verdes e sistemas de transporte e energia alternativa. Pela análise dos fluxos de água, energia, nutrientes e materiais dentro de um sistema urbano, pode-se desenhar fluxos circulares, reduzindo entrada de recursos e saída de resíduos (KENNEDY, PINCETL e BUNJE, 2011).

\section{Figura 43 - Representação de um metabolismo sustentável para a Toronto Port Lands}

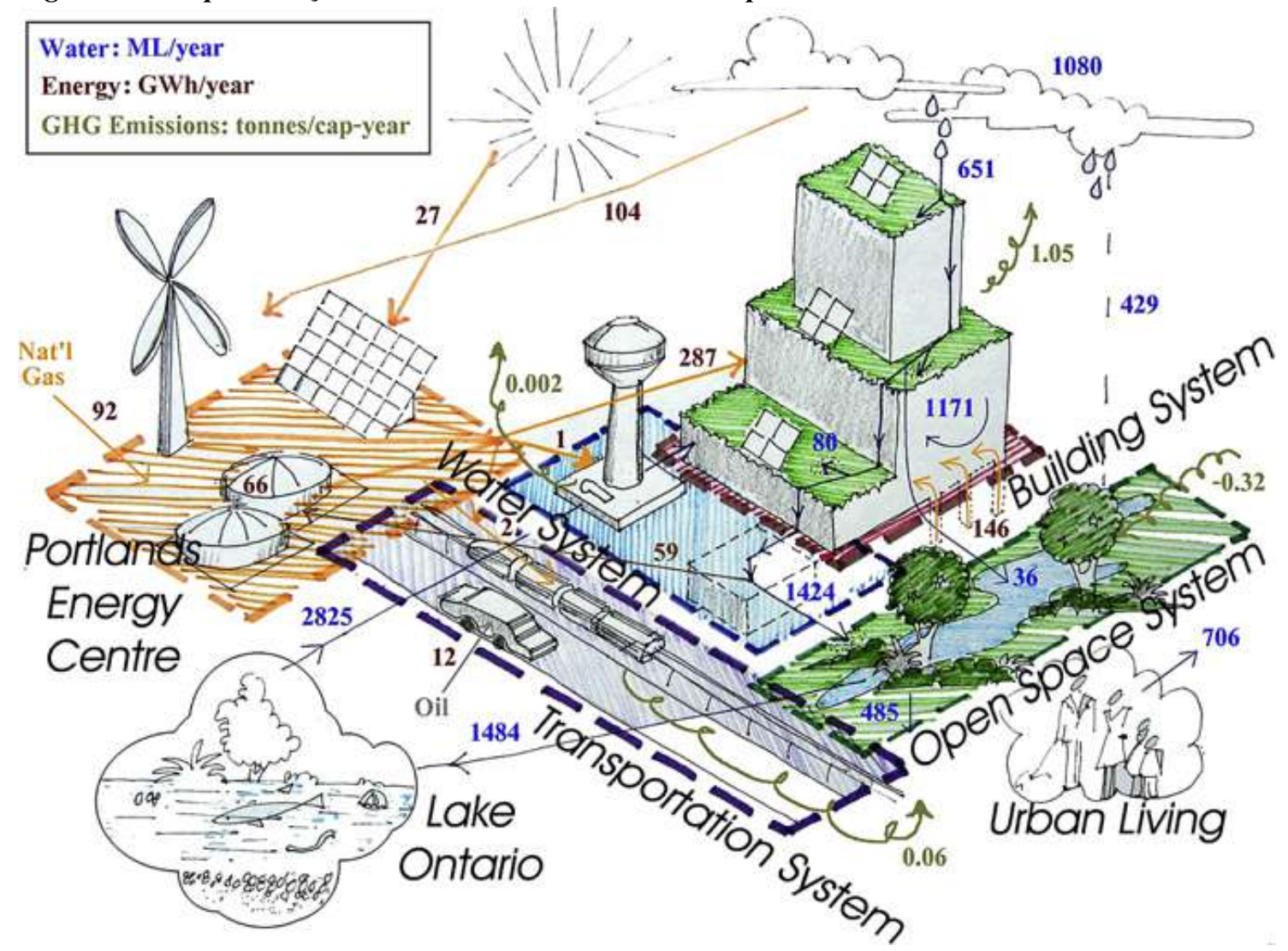

Fonte: (KENNEDY, PINCETL e BUNJE, 2011)

Na proposta de desenho sustentável, sistemas de reutilização de água cinza em sanitários e limpeza externa, o lodo usado em compostagem para produção de alimentos, energia vinda de fontes alternativas e de queima de resíduos (valorização energética), cujas cinzas seriam recicladas em materiais de construção e a energia excedente seria utilizada em sistema de transporte de veículo leve sobre trilhos.

Em exercícios de projeto como o apresentado, os fluxos de matéria e energia são os ideais, não os existentes. Em condições reais, existem menos possibilidades de estruturar um sistema a partir do zero. Como referência, porém, são válidas as propostas, mesmo que inviáveis no cenário atual.

Em situações em que há levantamentos e diagnósticos referentes a estoque de materiais, produção de resíduos, consumo de energia elétrica, consumo de água ou outros componentes que possam ser de interesse da instituição, dependendo do nível de 
detalhamento desses levantamentos, é possível ao menos realizar um "balanço grosseiro" dos fluxos de entrada e de saída.

Por "balanço grosseiro", entende-se uma visão geral de um sistema com o equilíbrio entre os fluxos de entradas, saídas e estoque. (VILLENEUVE, MICHEL, et al., 2004). Neste sistema estudado, que pode ser de um bairro a uma cidade, há diversos processos nos quais há fluxos de materiais e de energia,

Portanto, o desenho institucional, desde seus processos, suas instalações físicas, implantação e projetos arquitetônicos podem ser orientados a um desenho urbano mais sustentável por estudos de metabolismo urbano. 


\section{CAPÍTULO 4 - UNIVERSIDADE, CIDADE E SAÚDE}

Campi universitários são equipamentos urbanos que têm potenciais de transformação do entorno pelo desenho urbano, pelas suas atividades de ensino, pesquisa e extensão, como polo de atração de pessoas e serviços entre outros.

Entre as transformações possíveis estão mudanças relacionadas à transição ou implantação de medidas voltadas ao desenvolvimento sustentável. Esse conceito de sustentabilidade, em desenvolvimento desde o relatório Bruntland (ONU, 1987), busca equilíbrio entre os aspectos econômicos, sociais e ambientais nas ações da humanidade.

Neste capítulo apresenta-se os argumentos que relacionam a cidade e a universidade em prol do desenvolvimento sustentável, através das premissas dos Objetivos do Desenvolvimento Sustentável (ODS), em vigor desde 2015 e que tem como um dos países signatários o Brasil.

Acordos internacionais como a ODS, podem corroborar com políticas, regulamentos e normas nacionais que são até mesmo anteriores à ODS, como é o caso da Política Nacional de Resíduos Sólidos (PNRS) (BRASIL, 2010). E mesmo sendo anterior, muitas das metas estabelecidas nesta politica ainda não foram concretizadas ${ }^{94}$. Fato este que demonstra o desafio de se efetivar políticas que dependem de múltiplos atores, de governos e empresas a cidadãos, no Brasil.

No estudo de caso do planejamento do Campus São Paulo da Unifesp há diretrizes de projeto que buscam resolver de maneira integrada, o desenho urbano e arquitetônico a programas de necessidade ampliados, considerando não só demandas de usuários, mas também questões relacionadas ao gerenciamento de resíduos.

Como estabelecimento de saúde o campus tem uma grande produção de resíduos devido às suas atividades de ensino, pesquisa, extensão e assistência. Deste fato derivam duas constatações, a primeira que essas atividades são necessárias para a manutenção e aprimoramento da atenção à saúde do cidadão e por outro, que uma má gestão destes resíduos pode ser um risco à saúde ambiental e público.

Como produto do Plano Diretor de Infraestrutura, foi solicitado em edital de contratação, que houvesse um plano de gerenciamento de resíduos, sendo que para sua realização foram produzidos diagnósticos dos resíduos sólidos, em especial, dos resíduos sólidos de saúde (RSS).

94 Conforme relatório da Controladoria Geral da União (CGU) localizado em: http://www.cgu.gov.br/noticias/2018/01/cgu-avalia-execucao-da-politica-nacional-de-residuos-solidos 
Para complementar esse diagnóstico, ou melhor, buscando outra forma de visualiza-lo, foi elaborado uma análise de fluxo de material (MFA) (VILLENEUVE, MICHEL, et al., 2004) (BRUNNER e RECHBERGER, 2005) a partir das informações levantadas para o PDInfra, considerando o sistema o Campus São Paulo e o fluxo de saída como o volume de resíduos produzidos.

A visualização desse sistema permitie verificar, sob a ótica dos "pontos de alavancagem" (MEADOWS, 1999), quais seriam os pontos cuja mudança seria mais efetiva em direção à sustentabilidade.

Por fim, são elencadas possíveis contribuições de projetos urbanos, como o de campus universitário, para o desenvolvimento sustentável.

\subsection{A CIDADE, A UNIVERSIDADE E O DESENVOLVIMENTO SUSTENTÁVEL}

As cidades hoje comportam metade da população mundial, com projeções de aumento dessa proporção nas próximas décadas, dessa forma, as cidades, aglomerados urbanos e megalópoles terão cada vez mais impacto na demanda de recursos naturais e na pressão sobre outros biomas e na mudança climática.

Não à toa uma das metas se refere especificamente às cidades: a ODS 11 Construir cidades e assentamentos humanos inclusivos, seguros, resilientes e sustentáveis. Cada objetivo tem metas, que estão associadas à indicadores para acompanhar suas evoluções. Para se concretizar, objetivos como este precisam da interação e do comprometimento de vários segmentos da sociedade e uma delas, as universidades.

A contribuição de universidades não precisa se limitar a questão do ensino e formação de profissionais com disciplinas voltadas à sustentabilidade, pois um campus universitário tem potencial de ser referência nos quesitos construtivos, procedimentais, sistemáticos e urbanísticos para o desenvolvimento sustentável.

Nos projetos urbanos de campus universitário referenciados, foi possível identificar propostas institucionais que contribuem com metas do ODS $11^{95}$ referentes a aumento de planejamento e gestões participativas, atenção a resíduos sólidos e propiciar acesso a espaços públicos seguros, inclusivos, acessíveis e verdes ${ }^{96}$.

\footnotetext{
${ }^{95}$ Fonte: https://nacoesunidas.org/pos2015/ods11/

${ }^{96} 11.3$ Até 2030, aumentar a urbanização inclusiva e sustentável, e as capacidades para o planejamento e gestão de assentamentos humanos participativos, integrados e sustentáveis, em todos os países
} 
Com a primeira ressalva que o conceito de desenvolvimento sustentável não se restringe aos Objetivos do Desenvolvimento Sustentável, uma vez que, como política global, precisou-se de um mínimo de consenso entre os atores internacionais. Dessa forma, há, nos objetivos, metas que podem parecer contraditórias, ou mesmo protetoras do status quo, como por exemplo, as metas $8.1,8.10$ e $9.2^{97}$ dizem respeito a modelos econômicos que foram anteriormente adotados pelos ditos países desenvolvidos, porém que trouxeram graves problemas ambientais e sociais, como crescimento econômico sem preocupação com meio ambiente e bem-estar social.

Mesmo com o exposto acima, é evidente que políticas de escala mundial como esta são importantes para incentivar grupos locais a formular ações para atender estas metas e a metodologia da ODS permite acompanhar o avanço ou retrocesso das cidades através de indicadores.

A meta 11.3 preconiza a participação democrática em planejamento e gestão de assentamentos humanos em todos os países até 2030. No Brasil, ao menos, nas cidades que se enquadram na obrigatoriedade de formulação de planos diretores, por exemplo, com mais de vinte mil habitantes, eles devem ser feitos através de processos participativos (BRASIL, 2002). No caso das universidades públicas federais, a depender de seu regimento interno, há conselhos centrais deliberativos e consultivos com representações discentes, docentes e de técnicos para debater assuntos referentes a planos institucionais.

Reforçando essa premissa, no Plano de Desenvolvimento Institucional (PDI) da Unifesp coloca como uma de suas metas institucionais a gestão participativa:

Assegurar a gestão participativa dos recursos humanos e materiais para que os niveis de qualidade e relevância social se aproximem das metas

11.6 Até 2030, reduzir o impacto ambiental negativo per capita das cidades, inclusive prestando especial atenção à qualidade do ar, gestão de resíduos municipais e outros

11.7 Até 2030, proporcionar o acesso universal a espaços públicos seguros, inclusivos, acessíveis e verdes, particularmente para as mulheres e crianças, pessoas idosas e pessoas com deficiência (ONU, 2015)

97 8.1. Sustentar o crescimento econômico per capita de acordo com as circunstâncias nacionais e, em particular, um crescimento anual de pelo menos $7 \%$ do produto interno bruto [PIB] nos países menos desenvolvidos

8.10. Fortalecer a capacidade das instituições financeiras nacionais para incentivar a expansão do acesso aos serviços bancários, de seguros e financeiros para todos

9.2. Promover a industrialização inclusiva e sustentável e, até 2030 , aumentar significativamente a participação da indústria no setor de emprego e no PIB, de acordo com as circunstâncias nacionais, e dobrar sua participação nos países menos desenvolvidos. (ONU, 2015) 
almejadas, debatidas e expressas de modo consensual nas políticas e ações institucionais da Unifesp; (UNIFESP, 2016, p. 47)

Na meta 11.3 há dois indicadores ${ }^{98}$ para acompanhamento das ações, que se referem ao uso de terra por taxa de aumento de população e a proporção de cidades com estruturas de participação no planejamento urbano:

No quesito de participação direta, como verificado no capítulo do processo participativo, tanto na cidade quanto na universidade ainda há muito o que se trabalhar nessa área, porém é salutar que processos participativos sejam desenvolvidos e aprimorados.

Sobre o indicador de uso de terra por crescimento populacional, algumas universidades disponibilizam residência estudantil, que podem ser uma referência no uso racional de terra urbana.

A meta 11.6 pede especial atenção à qualidade do ar e a gestão de resíduos. Sobre esta última, o país já consta com um Plano Nacional de Resíduos Sólidos (BRASIL, 2010) que orientou politicas institucionais de universidades federais, como o PLS, por exemplo.

A Lei $n^{\circ}$. 12.305, de 2 de agosto de 2010, Política Nacional de Resíduos Sólidos (PNRS), estabeleceu a necessidade das instituições prestadoras de serviços elou produtoras, a exemplo da UnB, elaborarem um Plano de Gerenciamento de Resíduos Sólidos (PGRS) (BRASIL, 2010a).

O PGRS consiste em um instrumento de suma importância ao abarcar aspectos referentes à geração, segregação, acondicionamento, coleta, armazenamento, transporte, destinação e disposição final ambientalmente adequada dos resíduos, bem como a saúde pública, estabelecendo programas, metas e ações (BRASIL, 2010a). (UNB, 2018)

Tanto a PNRS, quanto políticas institucionais de universidades estão alinhadas também a algumas metas da ODS 12 - Assegurar padrões de produção e de consumo sustentáveis. Como verificado na meta 12.4 e 12.5. A meta 12.5, inclusive, condiz com os objetivos da PNRS conforme artigo $7^{\circ}$, parágrafo II:

\footnotetext{
${ }^{98}$ 11.3.1 Ratio of land consumption rate to population growth rate 11.3.2 Proportion of cities with a direct participation structure of civil society in urban planning and management that operate regularly and democratically (INTER-AGENCY AND EXPERT GROUP ON SDG INDICATORS (IAEG-SDGS), 2017)

11.3.1 Relação entre consume de terras e taxa de crescimento populacional

11.3.2 Proporção de cidades com estrutura de participação direta da sociedade civil no planejamento e gestão urbana que opera regularmente e democraticamente (tradução nossa).
} 
12.4 Até 2020, alcançar o manejo ambientalmente saudável dos produtos químicos e todos os resíduos, ao longo de todo o ciclo de vida destes, de acordo com os marcos internacionais acordados, e reduzir significativamente a liberação destes para o ar, água e solo, para minimizar seus impactos negativos sobre a saúde humana e o meio ambiente

12.5 Até 2030, reduzir substancialmente a geração de resíduos por meio da prevenção, redução, reciclagem e reuso (ONU, 2015)

II - Não geração, redução, reutilização, reciclagem e tratamento dos resíduos sólidos, bem como disposição final ambientalmente adequada dos rejeitos; (BRASIL, 2010)

A contribuição de uma universidade nesses indicadores estará diretamente ligada ao município em que ela se encontra. No caso do indicador que se refere a coleta regular de resíduos sólidos, ${ }^{99}$ pode-se dizer que um gerenciamento correto dos resíduos sólidos evite que um resíduo que poderia ser reciclável, seja descartado como um resíduo infectante, que tem custos e impactos ambientais maiores.

Ao considerar planos de transporte público ou de transporte ativo, como bicicletas, as universidades incentivam a redução de poluentes como os mencionados no indicador sobre matéria fina particulada, o que pode melhorar de alguma forma os indicadores da cidade.

A meta 11.7 diz respeito a prover espaços verdes e de acesso público. As universidades públicas sempre tiveram espaços abertos por princípio, embora não sejam necessariamente convidativos. A ampliação de espaços abertos à população em geral através de um desenho urbano mais generoso pode melhor a qualidade de vida tanto da comunidade acadêmica quanto dos demais habitantes da cidade.

Promoção do sentido de campus e da experiência da vida universitária, por meio de um ambiente convidativo, acessivel e seguro, que facilite a interação social e cultural, lazer e esporte. Convém destacar que o desenho dos espaços de relação entre os diferentes usos do campus é tão

\footnotetext{
${ }^{99}$ 11.6.1 Proportion of urban solid waste regularly collected and with adequate final discharge out of total urban solid waste generated, by cities

11.6.2 Annual mean levels of fine particulate matter (e.g. PM2.5 and PM10) in cities (population weighted). (INTER-AGENCY AND EXPERT GROUP ON SDG INDICATORS (IAEG-SDGS), 2017)

11.6.1 Proporção dos resíduos sólidos regularmente coletados e com destinação correta do total de resíduo sólido urbano gerado, por cidades.

11.6.2 níveis anuais de matéria fina particulada (p.e. PM2.5 e PM10) nas cidades (ponderado pela população). (tradução nossa)
} 
importante quanto o desenho dos edificios em si. (UNIFESP, 2016, p. 137)

No caso do indicador de áreas abertas ao público ${ }^{100}$ a relação é direta, pois se uma universidade propõe abertura de espaços de acesso público, a área construída deste tipo de espaço aumenta a média da cidade.

Não há relações diretas entre ações de universidades ao indicador de assédio físico ou sexual, embora questões de segurança pública possam ser melhoradas com espaços mais convidativos, com maior circulação de pessoas.

Espaços convidativos e que promovam o bem-estar estão alinhado ao ODS 3 Assegurar uma vida saudável e promover o bem-estar para todas e todos ${ }^{101}$, em todas as idades, há metas e indicadores que podem ter relação direta com ações institucionais:

3.6 Até 2020, reduzir pela metade as mortes e os ferimentos globais por acidentes em estradas

3.8 atingir a cobertura universal de saúde, incluindo a proteção do risco financeiro, o acesso a serviços de saúde essenciais de qualidade e o acesso a medicamentos e vacinas essenciais seguros, eficazes, de qualidade e a preços acessiveis para todos

3.9 Até 2030, reduzir substancialmente o número de mortes e doenças por produtos químicos perigosos, contaminação e poluição do ar e água do solo (ONU, 2015)

No que se refere à relação de universidade e cidade, estas metas e indicadores trazem medições objetivas para as ações que instituições podem contribuir para o desenvolvimento sustentável, outras metas podem ter relação indireta, como por exemplo, a universidade pode contribuir com a meta 8.1 de aumentar o PIB per capta ou até mesmo a meta 3.8 de alcançar a cobertura universal de saúde.

\footnotetext{
100 11.7.1 Average share of the built-up area of cities that is open space for public use for all, by sex, age and persons with disabilities

11.7.2 Proportion of persons victim of physical or sexual harassment, by sex, age, disability status and place of occurrence, in the previous 12 months (INTER-AGENCY AND EXPERT GROUP ON SDG INDICATORS (IAEG-SDGS), 2017)

11.7.1 Média de área construída de cidades que tem espaços abertos públicos de uso para todos, por gênero, idade e pessoas com deficiências.

11.7.2 Proporção de pessoas vítimas de assédio físico ou sexual, por gênero, idade, deficiência e local de ocorrência, nos 12 meses anteriores. (tradução nossa)

${ }^{101}$ Fonte: https://nacoesunidas.org/pos2015/ods3/
} 
Nos projetos urbanos em que se consideram proposições para melhoria da segurança do pedestre e ciclistas, como calçadas ampliadas e com todos recursos de acessibilidade, ciclovias e sinalização adequadas, entre outros, reduziriam as mortes e acidentes de trânsito, como preconiza a meta 3.6.

No Brasil, são 40 Hospitais Universitários, ou Institutos ligados às universidades, segundo o $\mathrm{MEC}^{102}$. Além de ensino, pesquisa e extensão, os hospitais ou institutos são importantes locais de assistência à população, como preconiza a meta 3.8.

Por serem geradores de resíduos químicos em pequena escala, universidades que tenham gerenciamento adequado, em conjunto com treinamento e formação de pessoal, podem contribuir diretamente com a meta 3.9.

Em suma, o papel das universidades na promoção do desenvolvimento sustentável é reconhecido ou mesmo incentivado, mesmo antes do acordo que determinou os Objetivos do Desenvolvimento Sustentável:

The United Nations Educational, Scientific and Cultural Organization states that the mission of the higher education sector is 'to promote higher education (...) as a key factor for cultural, economic and social development( ...) and as a promoter of human rights, sustainable development, democracy, peace and justice' (ORNE e DOORIS, 2010)

A Organização Educacional, Cientifica e Cultural das Nações Unidas, estabelece que a missão do setor de educação superior é de "promover a educação superior (...) como um fator essencial para o desenvolvimento cultural, econômico e social (...) e como um promotor de direitos humanos, desenvolvimento sustentável, democracia, paz e justiça" (tradução nossa)

No mundo, diversas universidades criam redes de sustentabilidade através de declarações ${ }^{103}$, a exemplo da Declaração de Talloires (1990), Halifax (1991), Kyoto (1993), Swamsea (1993), Barcelona (2004), Graz (2005), Abuja (2009) e Turim (2009).

A primeira desta, tem como signatárias 52 universidades brasileiras. Ressalva-se que a Universidade Federal de São Paulo não é signatária destas declarações, porém, verificou-se que há comprometimento com valores semelhantes em outros documentos institucionais.

\footnotetext{
102 http://portal.mec.gov.br/hospitais-universitarios?id=13808

${ }^{103}$ Fonte: http://ufscsustentavel.ufsc.br/universidades-sustentaveis/
} 
Portanto, as universidades podem contribuir com o desenvolvimento sustentável, e mais especificamente para os Objetivos do Desenvolvimento Sustentável, com ações que podem contribuir diretamente com indicadores de metas da ODS, se somando a outras políticas governamentais, de outras organizações e de indivíduos.

\subsection{UNIVERSIDADE E RESÍDUOS DE SERVIÇO DE SAÚDE.}

As universidades que tenham ensino, pesquisa ou serviços relacionados à saúde são considerados estabelecimentos de saúde (ANVISA, 2018). Estes estabelecimentos devem produzir planos de gerenciamento destes resíduos visando a proteção da saúde pública e da qualidade ambiental (BRASIL, 2010).

Antes dessas regulamentações ambientais, a atenção era mais voltada aos problemas decorrentes das atividades industriais (ARAÚJO, 2002) ${ }^{104}$, cujos danos ambientais eram de grande escala, e, portanto, maior evidencia.

Mesmo em coletores comuns de resíduos domiciliares, existe a possibilidade da presença de resíduos Classe I - perigosos, como por exemplo, pilhas, baterias, seringas usadas e remédios, dependendo, portanto de uma correta separação correta para a destinação final adequada.

Da mesma forma, em instituições de ensino há geração de resíduos perigosos e resíduos de saúde, que segregados corretamente, podem ter o melhor gerenciamento, apenas a partir da década de 80 estas começaram a se preocupar com esse assunto:

No Brasil, a preocupação mais efetiva com a gestão de resíduos em instituições acadêmicas começou no fim da década de 80 e início da década de 90, a partir das experiências com a coleta seletiva, seguida pelo gerenciamento dos resíduos químicos, dos resíduos de serviços de saúde e resíduos radioativos.

[...]

Atualmente, pode-se considerar que as abordagens de gerenciamento de resíduos químicos e perigosos nas universidades públicas brasileiras são associação das práticas de diluição, contenção, tratamento e disposição final em aterro e incineração.

(ARAÚJO, 2002, p. 25)

\footnotetext{
${ }^{104}$ Enquanto isso, as pequenas fontes geradoras adotavam, como prática de disposição final de seus resíduos a "diluição e dispersão", simplesmente despejando-os na pia e, por conseguinte aos corpos d'água, ou dispondo-os no solo, ou ainda lançando-os nos coletores comuns de resíduos domiciliares (SANDERS1 apud THOMPSON \& BAKAL (1995) e HASAN (1995)). (ARAÚJO, 2002)
} 
Como verificado no capítulo a respeito do Plano de Logística Sustentável (PLS) das universidades federais, ainda há uma lacuna com relação ao gerenciamento de resíduos, e até mesmo os resíduos de serviço de saúde, que englobam atividades de pesquisa. Por esse motivo, a gestão destes resíduos depende de um diagnóstico que seja feito da melhor maneira possível com os recursos financeiros e humanos disponíveis.

\subsection{DIAGNÓSTICO DO GERENCIAMENTO DE RESÍDUOS SÓLIDOS NO CAMPUS SÃO PAULO}

Foi estabelecido no Plano Diretor de Infraestrutura (PDInfra) que deveria ser produzido um Plano de Gerenciamento de Resíduos Sólidos (PGRS), atendendo assim, a determinação contida no art. 20, seção V da Lei No 12.305 (BRASIL, 2010).

Um PGRS, ainda conforme a lei citada, tem como conteúdo mínimo:

Art. 21. O plano de gerenciamento de resíduos sólidos tem o seguinte conteúdo mínimo:

I - descrição do empreendimento ou atividade;

II - diagnóstico dos resíduos sólidos gerados ou administrados, contendo a origem, o volume e a caracterização dos resíduos, incluindo os passivos ambientais a eles relacionados;

III - observadas as normas estabelecidas pelos órgãos do Sisnama, do SNVS e do Suasa e, se houver, o plano municipal de gestão integrada de resíduos sólidos:

a) explicitação dos responsáveis por cada etapa do gerenciamento de resíduos sólidos;

b) definição dos procedimentos operacionais relativos às etapas do gerenciamento de resíduos sólidos sob responsabilidade do gerador;

IV - identificação das soluções consorciadas ou compartilhadas com outros geradores;

$V$ - ações preventivas e corretivas a serem executadas em situações de gerenciamento incorreto ou acidentes;

$V I$ - metas e procedimentos relacionados à minimização da geração de resíduos sólidos e, observadas as normas estabelecidas pelos órgãos do Sisnama, do SNVS e do Suasa, à

reutilização e reciclagem;

VII - se couber, ações relativas à responsabilidade compartilhada pelo ciclo de vida dos produtos, na forma do art. 31;

VIII - medidas saneadoras dos passivos ambientais relacionados aos resíduos sólidos;

IX - periodicidade de sua revisão, observado, se couber, o prazo de vigência da respectiva licença de operação a cargo dos órgãos do Sisnama. (BRASIL, 2010) 
O diagnóstico do gerenciamento dos resíduos sólidos é uma importante fonte de dados a respeito da instituição, suas especificidades e subsídio para tomadores de decisão. Para o processo participativo, foram utilizados os dados preliminares para estimular o debate a respeito de questões administrativas e ambientais do campus. Para os técnicos responsáveis pelo planejamento e operação, as informações são essenciais para o dimensionamento e organização das atividades relacionadas ao manejo, armazenamento, coleta e disposição final. Para pessoas interessadas, as informações podem dizer respeito a pesquisas, fiscalização das ações institucionais e transparência. E para o gestor melhor embasamento para decisões.

O levantamento que embasa o diagnóstico foi iniciado no final de 2016 e o material que gerou a primeira versão do relatório do Plano Temático 5 - Campus Sustentável, foi entregue em meados de dezembro de 2017.

No período, a empresa realizou levantamentos em todos os imóveis em uso do campus. A equipe técnica de fiscalização, para atestar o material entregue, realizava o acompanhamento do serviço por amostragem ou por solicitação dos ocupantes do local

Para o "produto final" com as propostas que serão postas para deliberação nas instancias finais de decisão, o Plano de Gerenciamento de Resíduos de Serviço de Saúde (PGRSS), que faz parte do Plano Diretor de Infraestrutura (PDInfra) teve a contribuição de grupos internos, que detinham o conhecimento institucional das suas respectivas áreas, conforme extrato da versão 1 do Plano Temático 5:

O processo de desenvolvimento do PGRSS contou, quando possível, com o envolvimento das comissões da Divisão de Infraestrutura do Campus, a Divisão de Gestão Ambiental, o Comissão Técnica de Biossegurança CTBIO, Núcleo de Proteção Radiológica NPR, Comissão de Controle de Infecção Hospitalar CCIH, Comissão Interna de Prevenção de Acidentes CIPA, Serviço de Engenharia de Segurança e Medicina do Trabalho SESMET. O desenvolvimento do Plano contou ainda com o processo participativo através de reuniões e diversos debates com a comunidade - relatados no Volume do PDInfra intitulado "Estudos: visão de futuro e cenários estratégicos" - onde foi possivel obter sugestões, contribuições e validação das metas, diretrizes e ações propostas.

No início, o edital exigia um Plano de Gerenciamento de Resíduos Sólidos (PGRS), no entanto, no decorrer do desenvolvimento dos demais Planos Temáticos e do entendimento do Campus como um estabelecimento de saúde, foi-se estabelecendo que o produto seria um Plano de Gerenciamento de Resíduos de Serviço de Saúde, regulamentado pelas resoluções CONAMA no 283/01, CONAMA n ${ }^{\circ}$ 358/05 e ANVISA RDC 306/04 e mais recentemente, a RDC 222/18: 
$X L I$. plano de gerenciamento dos resíduos de serviços de saúde (PGRSS): documento que aponta e descreve todas as ações relativas ao gerenciamento dos resíduos de serviços de saúde, observadas suas características e riscos, contemplando os aspectos referentes à geração, identificação, segregação, acondicionamento, coleta, armazenamento, transporte, destinação e disposição final ambientalmente adequada, bem como as ações de proteção à saúde pública, do trabalhador e do meio ambiente; (ANVISA, 2018)

Em ambos planos há preocupação com a proteção da saúde pública, do trabalhador e do meio ambiente, a diferença se apresenta nas especificidades das regulamentações que os resíduos de serviço de saúde (RSS) têm, como por exemplo, como deve ser o coletor utilizado para transporte interno (art. 26 da RDC 222), lista de incompatibilidade química entre as principais substancias utilizadas pelos grandes geradores de resíduos de serviço de saúde (Anexo IV da RDC 222), entre outros.

A formulação do PGRSS dentro do Plano Diretor está alinhada ao conceito de integração entre as demais disciplinas do planejamento, considerando também o espaço físico, estoques, treinamento de pessoal ou estabelecimento de Procedimento Operacional Padrão (POP):

Art. $4^{\circ} \mathrm{O}$ gerenciamento dos RSS deve abranger todas as etapas de planejamento dos recursos físicos, dos recursos materiais e da capacitação dos recursos humanos envolvidos. (ANVISA, 2018)

Considerando, ainda, que um Plano Diretor é um projeto urbano existe uma atenção espacial à distribuição dos geradores ao longo do bairro da Vila Clementino. $\mathrm{O}$ Campus São Paulo, no quesito de grandes geradores de resíduo comum (Grupo D), de resíduo químico (grupo B), resíduo potencialmente infectante (Grupo A) e resíduos perfurocortantes ou escarificantes (Grupe E) tem dificuldades logísticas, pela forma com que a expansão do campus ocorreu.

O levantamento ocorreu na forma de senso, em que as equipes realizavam visitas técnicas em todos os recintos para verificar ou confirmar no cadastro existente, as atividades relacionadas a cada área, população, consumo de água e energia e tipos de resíduos produzidos. 
Figura 44 - exemplo de relatório de vistoria
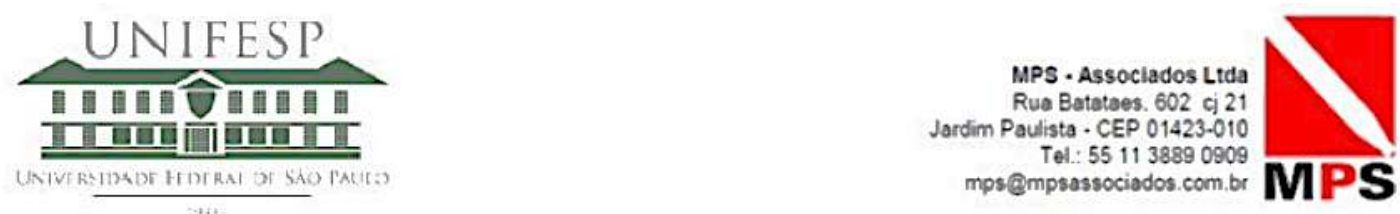

RELATÓRIO DE VISTORIA - SUMÁRIO EDIFÍCIO

\begin{tabular}{|c|c|c|c|c|c|}
\hline \multicolumn{6}{|l|}{ DADOS DO IMÓVEL } \\
\hline \multirow{2}{*}{\begin{tabular}{|l|} 
EDIFÍ́cIO \\
ENDEREÇO \\
\end{tabular}} & \multicolumn{5}{|c|}{ BIOTÉRIO FISIOLOGIA (PRIMATAS) } \\
\hline & \multicolumn{3}{|c|}{ RUA LOEFGREEN, 1990} & \multirow{2}{*}{\begin{tabular}{|l|} 
SETOR \\
QUADRA \\
\end{tabular}} & \multirow{2}{*}{0} \\
\hline CóD. EDIFício & $0201 \_032$ & próprio & \begin{tabular}{|l|l} 
TERRENO $\left(\mathrm{m}^{2}\right)$ & 158,75 \\
\end{tabular} & & \\
\hline ÁREA UNIFESP $\left(\mathrm{m}^{2}\right)$ & 224,06 & & ÁREA LEVANTADA $\left(\mathrm{m}^{2}\right) 200,89$ & LOTE & 0 \\
\hline
\end{tabular}

\begin{tabular}{|c|c|c|c|c|c|c|c|c|}
\hline \multicolumn{6}{|c|}{ População } & \multicolumn{3}{|c|}{ Áreas } \\
\hline \multicolumn{5}{|c|}{ Fixa } & \multirow{2}{*}{ Flutuante } & código & uso & total \\
\hline Docentes & Discentes & TAE & Outros & Total & & 01 & Iaboratório & 118,52 \\
\hline 0 & 0 & 1 & 0 & 1 & 5 & 02 & sala de aula & 0,00 \\
\hline \multicolumn{2}{|c|}{ TIPO } & COLETA & VOLUME & EMBALAGEM & ABRIGO & 03 & biblioteca & 0,00 \\
\hline \multicolumn{2}{|c|}{ BIOLÓGICOS } & 0 & 0 & 0 & 0 & 04 & restaurante & 0,00 \\
\hline \multicolumn{2}{|c|}{ PERFUROCORTANTE } & 0 & 0 & 0 & 0 & 05 & moradia & 0,00 \\
\hline \multicolumn{2}{|c|}{ QUÍMIcos } & 0 & 0 & 0 & 0 & 06 & espaços administrativos & 0,00 \\
\hline \multicolumn{2}{|c|}{ ORGÂNICOS } & diária & 1 s $30 \mathrm{~L} / \mathrm{dia}$ & saco preto & área externa & 07 & áreas multifuncionais & 0,00 \\
\hline \multicolumn{2}{|c|}{ RECICLÁVEIS } & diária & $1 \mathrm{~s} 15 \mathrm{~L} / \mathrm{dia}$ & saco azul & área externa & 08 & uso assistencial & 0,00 \\
\hline \multicolumn{2}{|c|}{ RADIOATIVOS } & 0 & 0 & 0 & 0 & 09 & áreas esportivas & 0,00 \\
\hline
\end{tabular}

Fonte: MPS Arquitetos Associados

Os dados foram posteriormente compilados em relatórios de vistoria (ver Figura 44), primeiro por edifício, para então se ter a imagem da situação do campus como um todo, podendo relacionar dados referentes ao tipo de atividade (auto declarada pelo usuário), população e tipos de resíduo.

Uma das exigências do edital era que as informações devessem ser transmitidas de formas didáticas, como mapas, diagramas ou outras, tanto para o processo participativo, quanto para os relatórios finais. Uma das maneiras encontradas, que atende a pelo menos dois itens do edital, o georreferenciamento das informações e visualização de dados, era demonstrar, através de mapas, duas questões importantes para o planejamento do campus: a dispersão dos edifícios e o volume produzido de resíduos.

A começar pelos resíduos comuns, a RDC 222 estabelece como resíduos do Grupo D:

Resíduos que não apresentam risco biológico, químico ou radiológico à saúde ou ao meio ambiente, podendo ser equiparados aos resíduos domiciliares. 
- Papel de uso sanitário e fralda, absorventes higiênicos, peças descartáveis de vestuário, gorros e máscaras descartáveis, resto alimentar de paciente, material utilizado em antissepsia e hemostasia de venóclises, luvas de procedimentos que não entraram em contato com sangue ou líquidos corpóreos, equipo de soro, abaixadores de língua e outros similares não classificados como Al.

- Sobras de alimentos e do preparo de alimentos.

- Resto alimentar de refeitório.

- Resíduos provenientes das áreas administrativas.

- Residuos de varrição, flores, podas e jardins.

- Resíduos de gesso provenientes de assistência à saúde.

- Forrações de animais de biotérios sem risco biológico associado.

- Resíduos recicláveis sem contaminação biológica, química e radiológica associada.

- Pelos de animais. (ANVISA, 2018, p. 25)

No Grupo D, os resíduos são dispostos em sacos pretos, assim como os resíduos domiciliares ou podem ser acondicionados em sacos azuis caso sejam recicláveis. Em 2017, os grandes geradores (mais de 200 litros/dia) produziram, no CSP 23.279,88 litros/dia de resíduos.

Os pequenos geradores de até 200 litros por dia são atendidos pela coleta pública domiciliar, enquanto os grandes geradores devem contratar empresas que prestam serviços de limpeza urbana com autorização municipal.

Os maiores edifícios estão no mapa (ver Figura 45) também como grandes geradores de resíduo comum. Como na coleta considera-se o volume (em litros), foram estabelecidos 5 intervalos entre 204,75 litros a 2030,00 litros. No mapa estão apresentados os locais onde há compactador de lixo, abrigos e um ponto de coleta, onde são separados alguns resíduos recicláveis. 
Figura 45 - Mapa dos grandes geradores de resíduo comum - ano: 2017

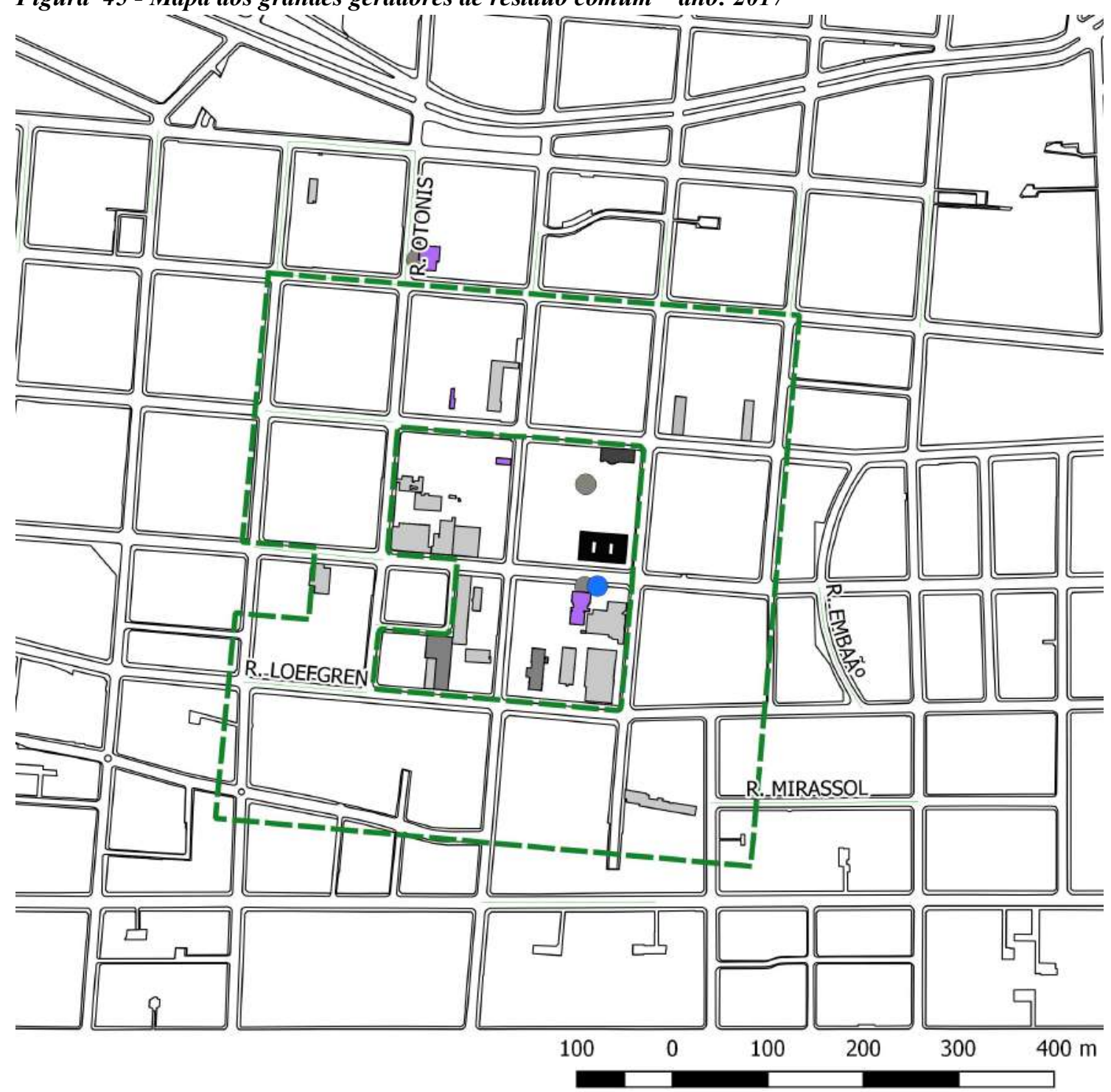

LEGENDA

residuos

- PONTO_COLETA_SECOS_S2000

$\square$ COLETA_COMPACTADOR_S2000

- ABRIGOS_COMUNS_S2000

TECIDO URBANO

- NOME_RUAS_PRINCIPAIS

- $=$ POLO_SAUDE_ENSINO_PESQUISA_SIRGAS200
EDIFICACOES CSP_ATRIBUTOS_GDE GERADOR COMUM

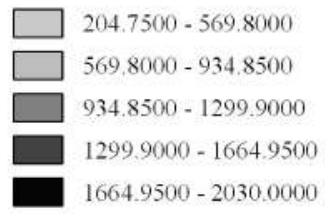

Base georreferenciada formulada por MPS Arquitetos Associados, 2017

No caso dos resíduos químicos (Grupo B), segundo a RDC 222:

Resíduos contendo produtos químicos que apresentam periculosidade à saúde pública ou ao meio ambiente, dependendo de suas características 
de inflamabilidade, corrosividade, reatividade, toxicidade, carcinogenicidade, teratogenicidade, mutagenicidade e quantidade.

- Produtos farmacêuticos

- Resíduos de saneantes, desinfetantes, desinfestantes; resíduos contendo metais pesados; reagentes para laboratório, inclusive os recipientes contaminados por estes.

- Efluentes de processadores de imagem (reveladores e fixadores).

- Efluentes dos equipamentos automatizados utilizados em análises clinicas.

- Demais produtos considerados perigosos: tóxicos, corrosivos, inflamáveis e reativos. (ANVISA, 2018)

Como os locais em que se identificou a geração de resíduos do Grupo B eram, em sua maioria, locais destinados à pesquisa, pode-se levantar a hipótese de que estes dados estejam subdimensionados, uma vez que diversos imóveis que realizam atividades assistenciais não constam nessa categoria.

Outro fato relacionado à atividade de pesquisa, segundo relatos de alguns pesquisadores presentes durante as visitas técnicas é que, diferentemente das atividades assistenciais, não há um padrão de consumo de produtos que posteriormente serão considerados resíduos químicos, pois dependem do fomento de pesquisas, de projetos de pesquisa e outras variáveis. Não foi identificado uma série histórica, mas em 2017, contabilizou-se como produção de resíduos químicos no Campus São Paulo o total de 28,1 quilos por dia.

Atualmente o campus conta com um ponto de coleta e nenhum abrigo adequado, como se nota em outras universidades brasileiras, sendo que os espaços destinados a esse uso não estão em conformidade com normas e oferecem riscos de contaminação do meio ambiente, riscos à saúde do trabalhador, risco de explosão, incêndio, entre outros (ver Figura 46). Embora exista necessidade de adequação o dimensionamento do abrigo é dificultoso pela inconstância de pedidos de coleta, quando um usuário aciona a Gestão Ambiental e depois deve-se aguardar a autorizatária por até 13 dias, conforme relato no Plano Temático 5:

Segundo o responsável da Gestão Ambiental, outra questão que é apontada como dificuldade é o fato da coleta por parte da Ecourbis não apresentar dias específicos ou previamente agendados. Após ser informada da necessidade de coleta, a mesma tem 13 dias para coletar tais resíduos. 
Figura 46 - abrigo de resíduos químicos inadequado localizado em edifício do Campus São Paulo

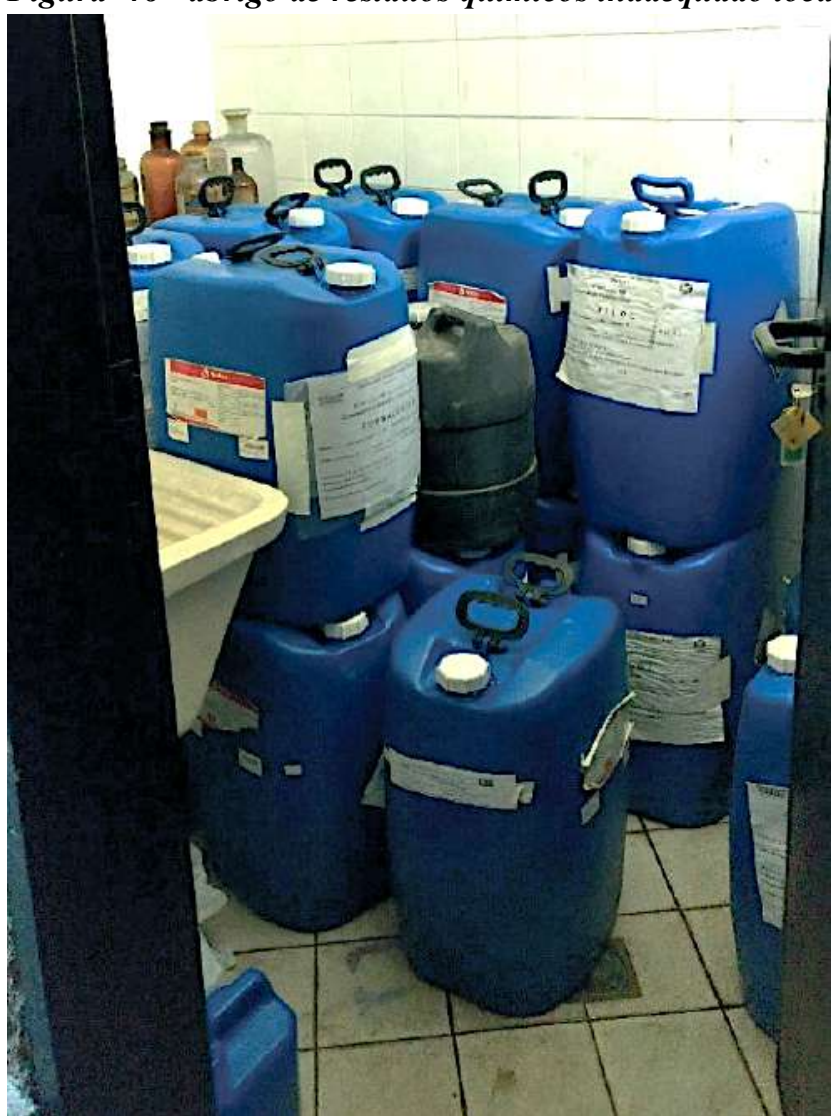

Fonte: MPS Arquitetos Associados, 2017

O mapa de geração de resíduos químicos (ver Figura 47) mostra que há poucos edifícios geradores, cuja geração também é relativamente baixa. Os edifícios geradores também estão próximos, o que viabilizaria um esforço conjunto entre estas áreas de pesquisa de ter espaços comuns de reagentários e melhorar o procedimento de segregação e acondicionamento destes.

No momento, o Campus dispõe de apenas um ponto de coleta de resíduos químicos, que fica em um local central a todos os geradores, porém ainda assim, muito resíduo químico teria que atravessar locais com possível contato com transeuntes até chegar ao ponto de coleta, o que é um risco. 
Figura 47 - Mapa de geração de resíduo químico CSP - ano: 2017

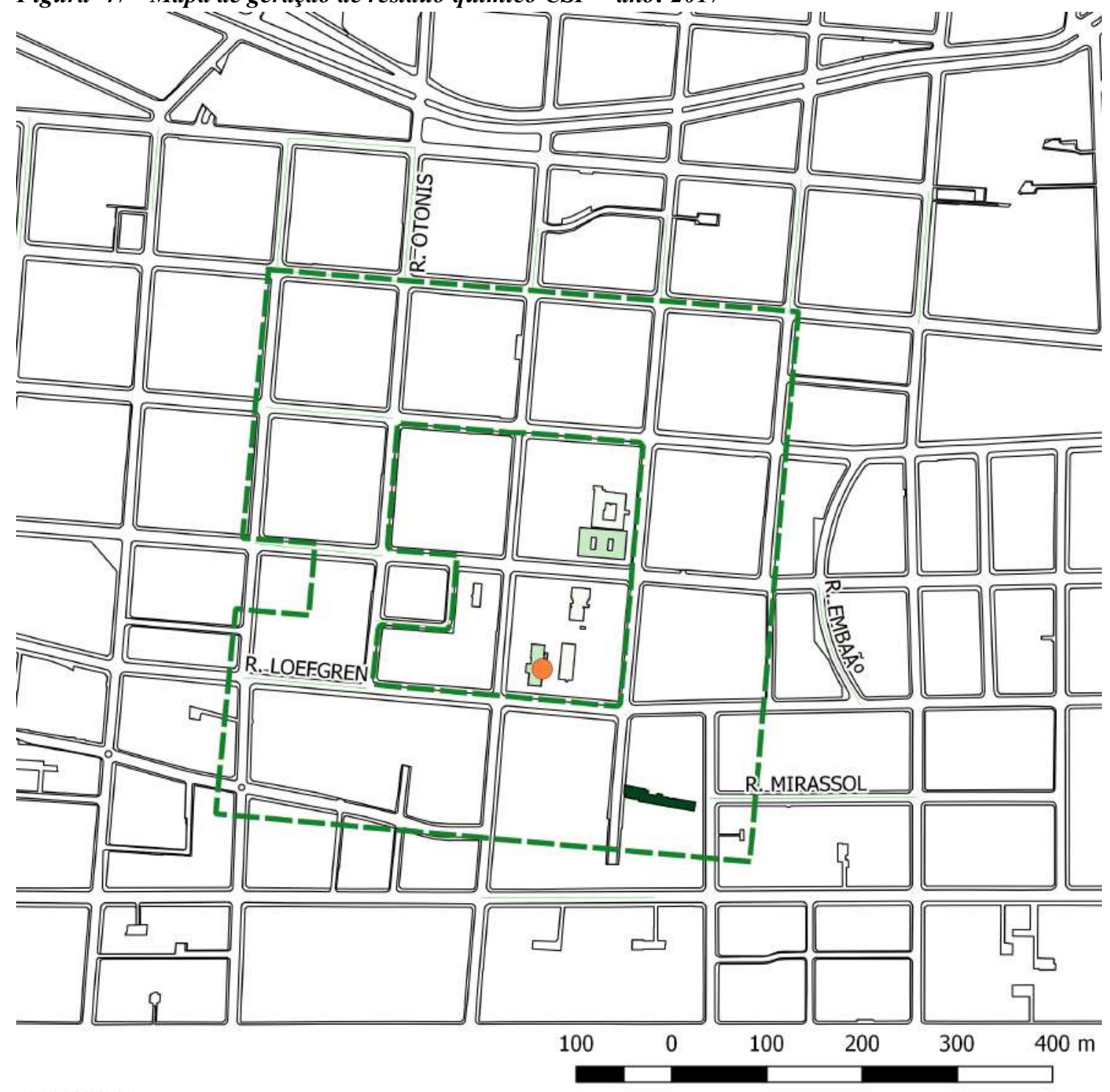

\section{LEGENDA}

residuos

EDIFICACOES_CSP_ATRIBUTOS_QUIMICOS

PONTO_COLETA_QUIMICOS_S2000

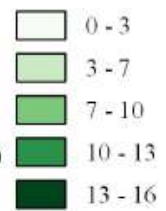

TECIDO URBANO

NOME_RUAS_PRINCIPAIS

- $=$ POLO_SAUDE_ENSINO_PESQUISA_SIRGAS200

Fonte: Base georreferenciada formulada por MPS Arquitetos Associados, 2017

No caso dos grupos A e E, estes foram agrupados por poderem ser armazenados no mesmo espaço e estarem relacionados às mesmas atividades, embora a classificação seja diferente. Percebe-se também que alguns problemas de gerenciamento são comuns aos dois grupos, principalmente no que se refere à segregação incorreta de resíduos para serem destinados como potencialmente infectantes e ao acondicionamento inadequado. 
Para o Grupo A, a RDC 222 define:

Resíduos com a possivel presença de agentes biológicos que, por suas características, podem apresentar risco de infecção. (ANVISA, 2018)

E para o Grupo E:

Materiais perfurocortantes ou escarificantes, tais como: lâminas de barbear, agulhas, escalpes, ampolas de vidro, brocas, limas endodônticas, pontas diamantadas, lâminas de bisturi, lancetas; tubos capilares; ponteiras de micropipetas; lâminas e lamínulas; espátulas; $e$ todos os utensílios de vidro quebrados no laboratório (pipetas, tubos de coleta sanguínea e placas de Petri) e outros similares. (ANVISA, 2018)

Para verificar as interfaces entre o planejamento urbano, saúde e gerenciamento de resíduos sólidos, foram destacadas as três principais classes levantadas para o diagnóstico: infectante, comum e químico. Na classificação conforme a RDC 222, estamos falando do Grupo A (resíduos potencialmente infectantes), Grupo B (resíduos químicos), Grupo D (resíduo comum) e Grupo E (Resíduos perfurocortantes ou escarificantes). Como os resíduos do Grupo E podem ter a coleta compartilhada com os resíduos do Grupo A, no diagnóstico estes foram contabilizados na categoria infectante.

Parágrafo único. Nas edificações não hospitalares nas quais houver serviços individualizados, os respectivos RSS dos Grupos A e E podem ter o armazenamento externo de forma compartilhada. (ANVISA, 2018)

O levantamento indica que, em 2017, foram gerados 2.380,01 quilos por dia de resíduos potencialmente infectantes, dos grupos A e E (ver Figura 49). Porém, constatouse que há descarte identificado e segregado incorretamente como RSS, o que certamente implica que este valor atualmente é superdimensionado, embora seja um valor de referencia para desenvolvimento de politicas institucionais.

Em um estudo desenvolvido no Departamento de Oftalmologia da Unifesp (MENEGON, 2016), acompanhando o gerenciamento dos RSS realizado no local por três meses, foi verificado uma série de inconsistências principalmente nas etapas de identificação, segregação (ver Figura 48) e acondicionamento:

Após a pesquisa, constatou-se que parte do resíduo comum e reciclável são descartados como resíduos de serviço de saúde, resultando em aumento do volume de resíduo infectante com impacto ambiental $e$ financeiro para a Instituição pelos riscos e alto custo, a ser pago, quando poderia ser evitado. (MENEGON, 2016) 
Figura 48 - Recipiente de resíduo perfurocortante indicando segregação incorreta

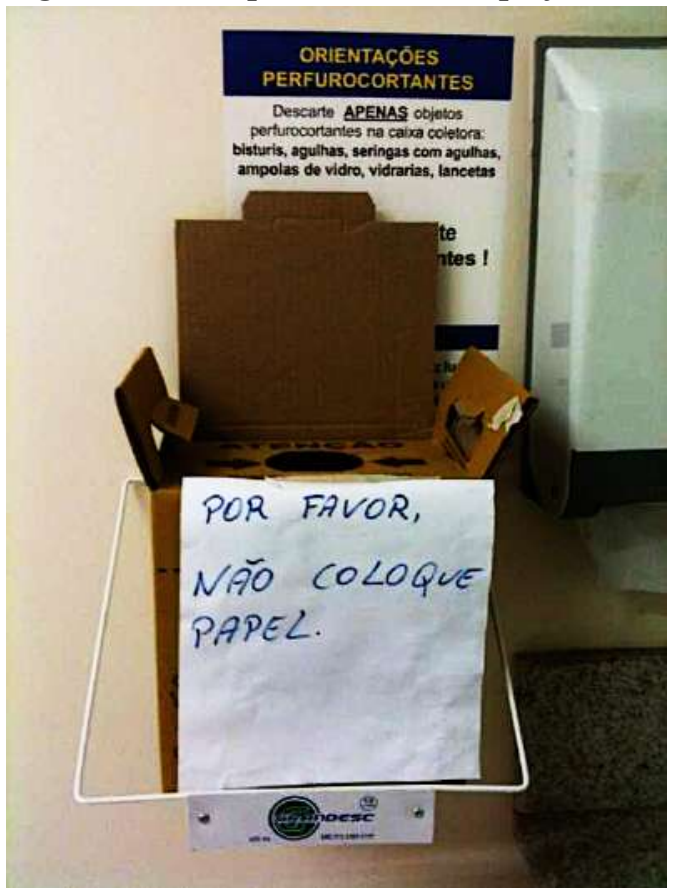

Fonte: (MENEGON, 2016, p. 64)

Em contraste com o método desenvolvido pela empresa, em que se realizaram visitas a todos os imóveis, porém sem o aprofundamento de visitas consecutivas, nos dois períodos e com acompanhamento das atividades, percebe-se que as metodologias refletem os objetivos, recursos humanos e financeiros disponíveis para cada estudo.

Por outro lado, reconhecendo que o diagnóstico do PDInfra tem valores de geração de resíduos aproximados, é declaradamente um ponto de partida para uma política institucional como um todo. Embora a visão corrente ainda seja de implementação departamental:

A urgência de implementação de uma política e plano de gestão de RSS na Instituição e a possibilidade de implementação de iniciativas nos serviços, particularmente no Departamento de Oftalmologia da UNIFESP, que pode servir de referência para outras unidades dessa universidade. Nesse sentido, enquanto não se tem uma politica maior da Instituição, a solução implica implementar ações para a mudança nos procedimentos e na cultura de descarte dos resíduos [...] (MENEGON, 2016) 
Figura 49 - Mapa geração de infectantes CSP - ano 2017

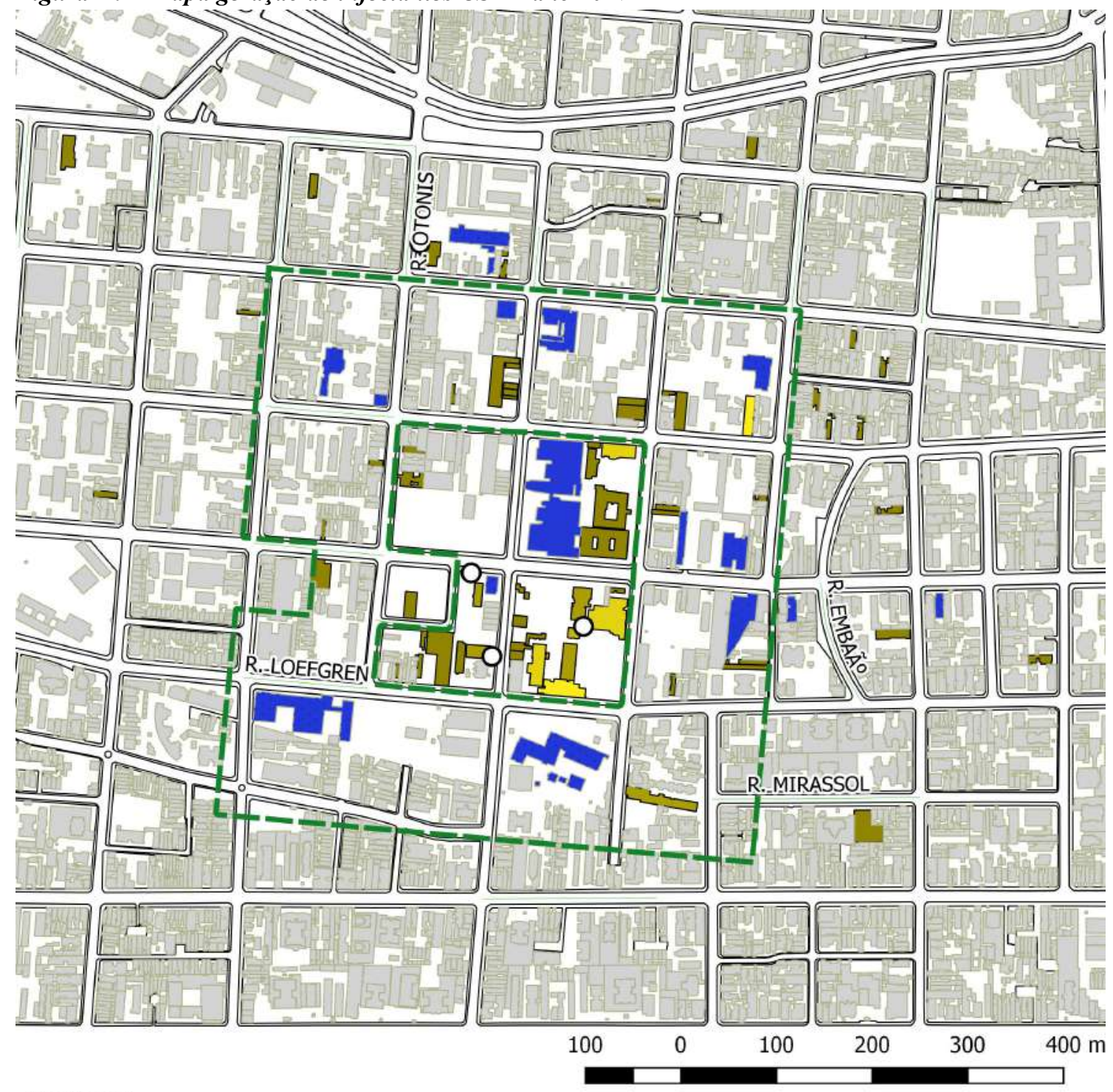

LEGENDA

residuos

EDIFICACOES_CSP_ATRIBUTOS_INFECTANTE

\begin{tabular}{|c|c|}
\hline O ABRIGOS_INFECTANTES_S2000 & $0.36-45.29$ \\
\hline TECIDO URBANO & $45.29-90.22$ \\
\hline NOME_RUAS_PRINCIPAIS & $90.22-135.14$ \\
\hline$==$ POLO_SAUDE_ENSINO_PESQUISA_SIRGAS 200 & $135.14-180.07$ \\
\hline ROS SERVICุOS DE SAÚDE & $180.07-225.00$ \\
\hline
\end{tabular}

Fonte: Base georreferenciada formulada por MPS Arquitetos Associados, 2017 
Figura 50 - Mapa de vínculos dos edifícios (2017)

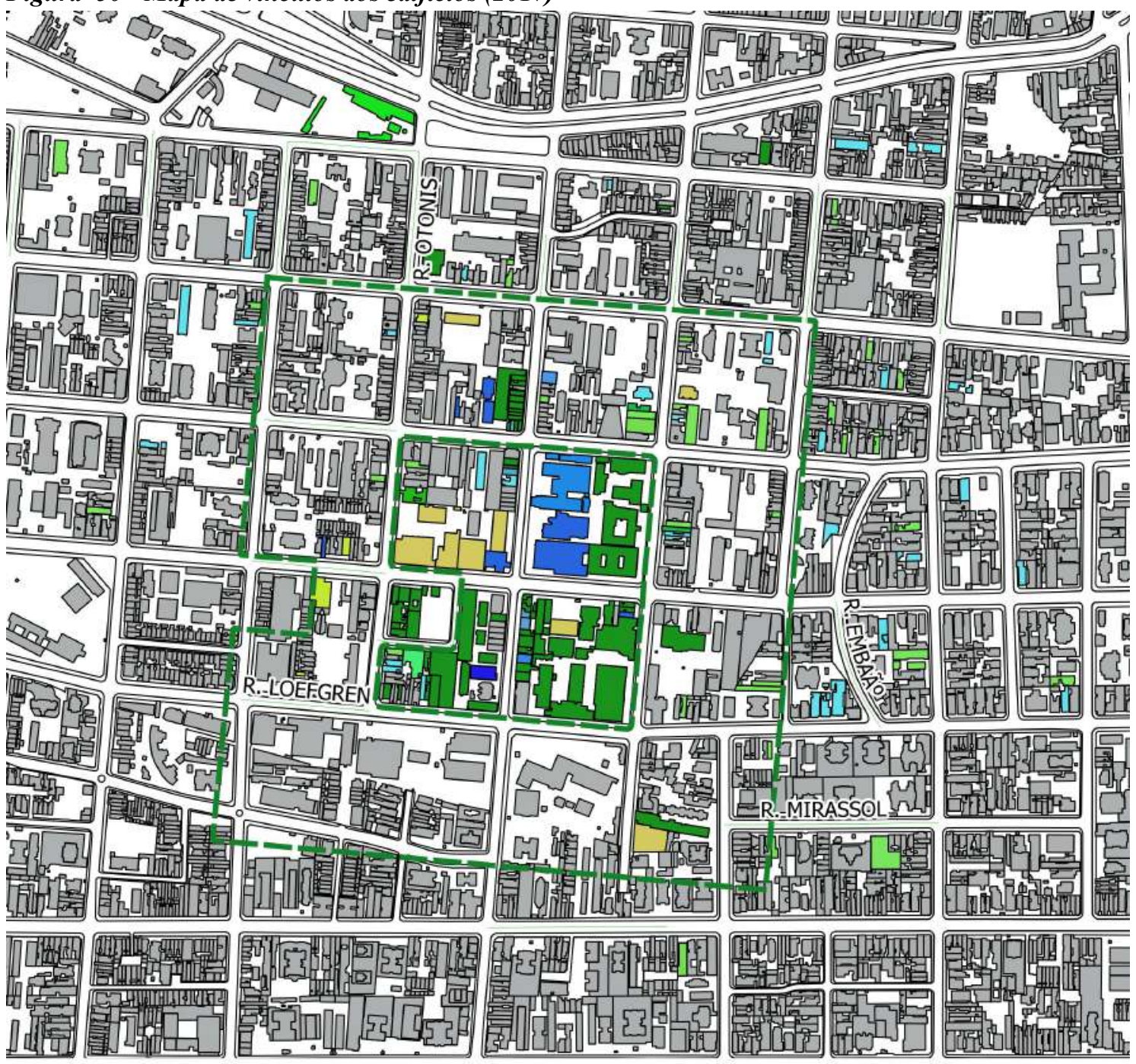

LEGENDA

TECIDO URBANO

- NOME_RUAS_PRINCIPAIS

- - POLO_SAUDE_ENSINO_PESQUTSA_SIRGAS200

EDIFICACOES_CSP_ATRIBUTOS_S2000 VINCULO

$\square$ CSP ALUGADO

$\square$ CSP ALUGADO E HSP-SPDM/HU ALUGADO

$\square$ CSP PROPRIO

CSP PROPRIO E HSP-SPDM/HU ALUGADO

$\square$ CSP PROPRIO E HSP-SPDM/HU PROPRIO

$\square$ Em Comodato do CEPEP para o CSP

$\square$ Em Termo de Cessão da Prefeitura para o CSP

$\square$ HSP-SPDM/HU ALUGADO

HSP-SPDM/HU ALUGADO E REITORIA ALUGADO

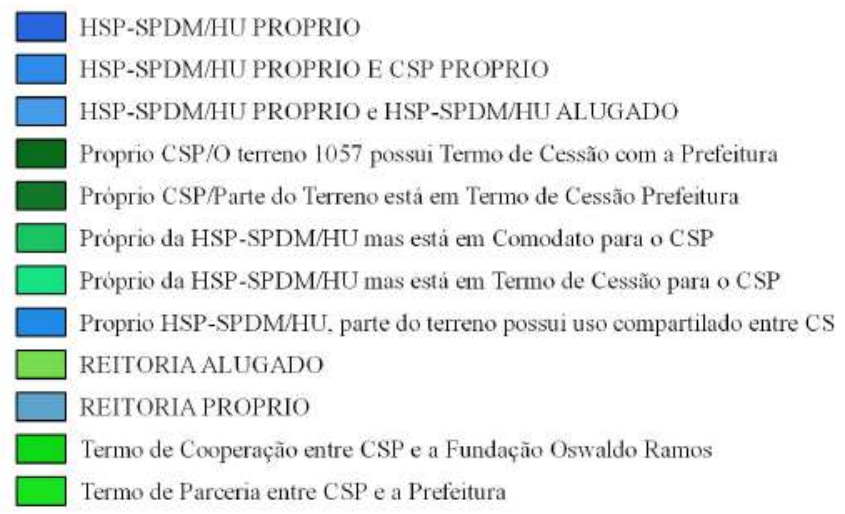

100

100

200 $400 \mathrm{~m}$

Fonte: Base georreferenciada formulada por MPS Arquitetos Associados, 2017 
Do ponto de vista administrativo, a gestão de resíduos que estão sob responsabilidade direta da instituição, é o mínimo exigido, porém, ao sobrepor as informações sobre os grandes geradores de resíduos comuns, dos geradores de resíduos químicos e de resíduos potencialmente infectantes, percebe-se que no campus há uma série de edifícios que não estão com informações relacionadas à geração de resíduos.

O primeiro motivo é que, como vimos nos antecedentes de planejamento do campus, o complexo do Hospital São Paulo e vários imóveis relacionados estão sob gestão de outra instituição, a SPDM. Outro motivo é que, houve levantamento dos pequenos geradores, porém os custos de coleta já são menores, pois não é necessário realizar novos contratos, uma vez que é realizada a coleta domiciliar. Ao analisar o mapa de gestão (ou vínculos) percebe-se a grande diversidade de titularidades no campus (ver Figura 50)

Outra análise que se faz é que dentre os edifícios do campus que estão fora do polo de centralidade, predominam locais com geração de resíduos infectantes de menor geração de volume $(0,36$ a $45,29 \mathrm{~kg} /$ dia $)$.

Ao utilizar estrategicamente estes incentivos urbanísticos do polo de centralidade para direcionar a concentração de atividades e verticalização dentro do polo, pode-se encaminhar quatro problemas, um referente ao diagnóstico dos resíduos sólidos, dois, relacionado ao atendimento à população, três, a respeito da diminuição do impacto ambiental e quatro, a respeito da racionalização do procedimento de coleta e consequentemente redução de custos.

Sobre o diagnóstico de resíduos sólidos, é importante que o monitoramento, revisão e aprimoramento do PGRSS sejam realizados pela equipe técnica interna da instituição, uma vez terminado o contrato com a empresa de formulação de Plano Diretor. E a dispersão física dificulta o acompanhamento, das já reduzidas equipes internas.

O atendimento à população na área assistencial tende a melhorias uma vez que as atividades que se complementam estejam em um mesmo edifício ou em edifícios próximos ao complexo hospitalar. Na situação diagnosticada em 2017, pode-se ter uma distância de até 1 quilometro entre ambulatórios de diferentes especialidades.

O impacto ambiental do campus diminuiu quando há menos necessidade de deslocamentos de ambulância, de transporte de materiais e outros, quando as atividades estão mais próximas. Redundâncias de equipamentos e infraestruturas diminuem em espaços compartilhados.

Por fim, a racionalização dos procedimentos de coleta através da reorganização espacial pode melhorar a proteção à saúde do trabalhador, com abrigos melhor 
dimensionados e projetados, menor necessidade de repetir operações, uma vez que diminuem o número de estabelecimentos que terão coleta especial e com isso, haverá também redução dos custos cobrados pelas concessionárias à instituição.

Ao analisar o caminho percorrido pela empresa autorizatária, em comparação com a classificação EGRS e demais estabelecimentos de serviços de saúde, percebe-se que os trajetos não são os mais eficientes e econômicos possíveis.

Considerando o contexto urbano, percebe-se que no entorno há outros estabelecimentos de saúde que certamente também tem contrato de coleta e uma TRSS relacionada a sua classificação EGRS (ver Figura 51).

Estas informações permitem que, partindo da municipalidade ou das instituições, um plano de gerenciamento mais integrado com outros geradores, que permita redução de custos para todos e melhor uso do contrato da autorizatária. Resistências a estas propostas, no entanto, devem vir da concessionária ou mesmo da Secretaria de Finanças, uma vez que na região reduziria a arrecadação de taxas.

Lembrando que um PGRS, segundo a lei que o regulamenta, deve constar a identificação de soluções consorciadas com outros geradores (BRASIL, 2010), o que somente é possível se o planejamento for contextualizado com informações do seu entorno.

Esta proposta de analisar os demais estabelecimentos de saúde para soluções consorciadas não foi considerada no PDInfra, embora possa ser incorporada posteriormente contribuições desta pesquisa em revisões futuras ou alinhar a ações já encaminhadas e pactuadas do plano.

Uma segunda possibilidade de ações conjuntas seriam compartilhamento de abrigos, e talvez até mesmo de procedimentos operacionais. Alguns edifícios são vizinhos de lote, pela lateral ou pelos fundos. Portanto, os resíduos potencialmente infectantes teriam o transporte interno, sem percorrer espaços públicos de maneira irregular.

Embora não tenham sido encontradas referências de ações consorciadas de geradores diferentes, entende-se que a lei do PNRS dá a possibilidade de se realizar esta ação. E no contexto de São Paulo, em que a TRSS é cobrada por faixa de geração é ainda mais vantajoso economicamente para as instituições. 
Figura 51 - Fluxo de coleta de infectante no campus e outros estabelecimentos de saúde

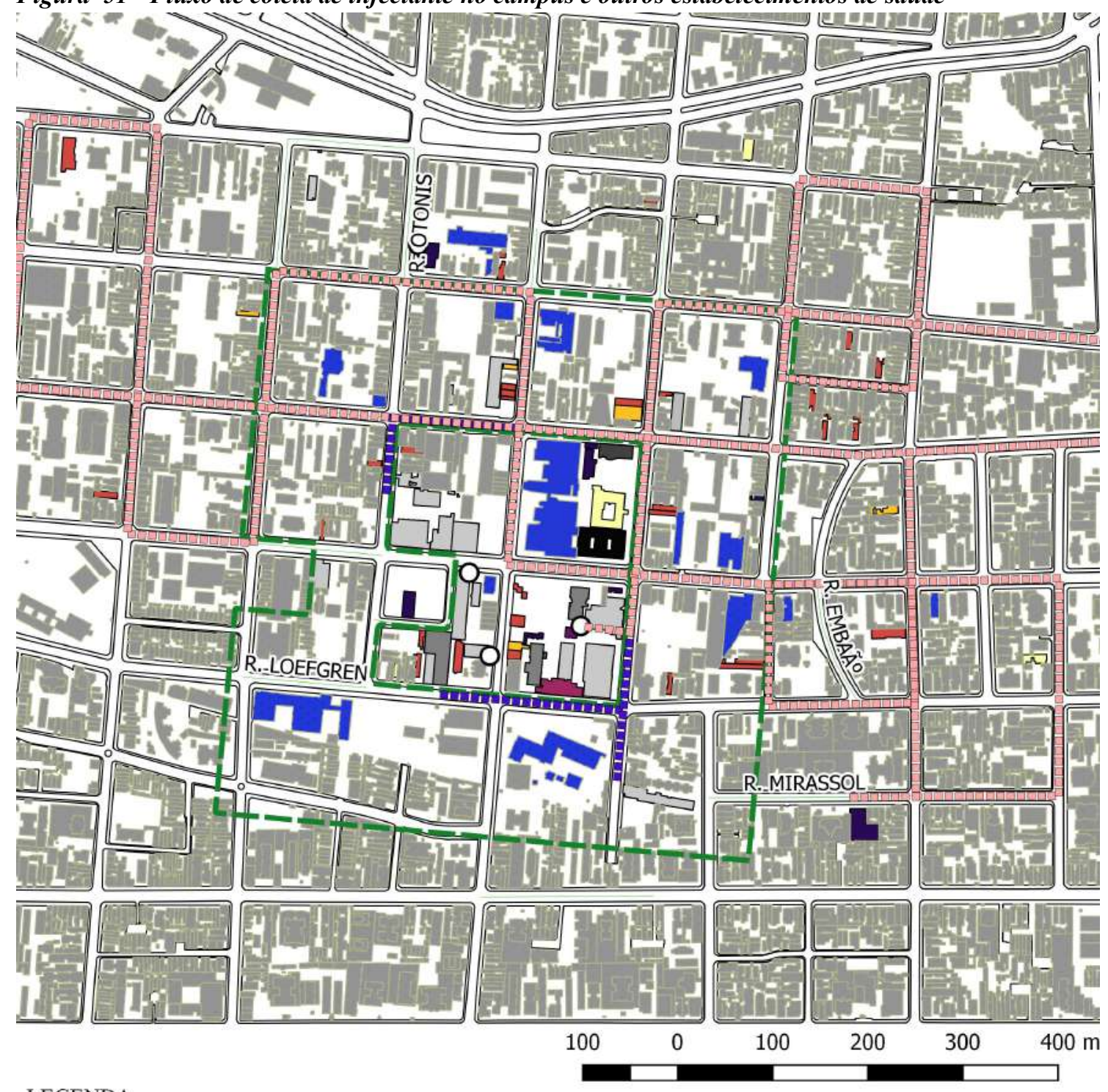

LEGENDA

residuos

EDIFICACOES_CSP_ATRIBUTOS_CLASSIFICAÇÃO

ח FLUXO_COLETA_PEQUENOS_GERADORES_S2000

m." FLUXO_COLETA_GRANDES_GERADORES_S2000

O ABRIGOS_INFECTANTES_S2000

TECIDO URBANO

NOME_RUAS_PRINCIPAIS

- - POLO_SAUDE_ENSINO_PESQUISA_SIRGAS200

OUTROS SERVIÇOS DE SAÚDE

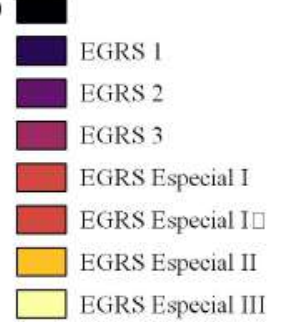

Fonte: Base georreferenciada formulada por MPS Arquitetos Associados, 2017

Para formular a análise do fluxo de material, temos como dados disponíveis a quantidade de resíduos sólidos gerados no campus no levantamento realizado pela empresa MPS Arquitetos Associados. Os dados foram compilados por atividade que era predominante no recinto no momento do levantamento (ver Tabela 4). 
Tabela 4 - Quantidade de resíduos diários e respectivas taxas por atividade

\begin{tabular}{l|c|c|c|c}
\multicolumn{1}{l}{$\begin{array}{l}\text { Atividade } \\
\text { Desconhecido }\end{array}$} & $\begin{array}{c}\Sigma \text { res_quim } \\
\text { (Kg/dia) }\end{array}$ & $\begin{array}{c}\Sigma \text { res_infectante } \\
(\mathbf{K g} / \text { dia) }\end{array}$ & $\begin{array}{c}\Sigma \text { res_comum } \\
\text { (L/dia) }\end{array}$ & $\Sigma$ taxa (R\$/ano) \\
\hline Acadêmico & & 45 & 481.12 & 6504.66 \\
\hline Administrativo & 4.48 & 120.17 & 3419.29 & 13009.32 \\
\hline Assistencial & & & 1350.19 & \\
\hline Biotério & 0.75 & 1101.99 & 8495.64 & 101224.6 \\
\hline Infraestrutura & & 383 & 178.5 & 33224.73 \\
\hline Laboratorial & 22.87 & 32.5 & 330.75 & 3321.42 \\
\hline Outros & & 687.51 & 6425.34 & 77388.62 \\
\hline \hline
\end{tabular}

Os valores da Tabela 4 se referem à soma dos resíduos sólidos por grupo segundo a classificação da RDC 222, no caso, os resíduos químicos (grupo B), resíduos infectantes (grupo A e E) e resíduos comuns (grupo D). Ressalta-se que existe geração de resíduos radioativos (grupo C) no campus, mas não foi possível obter informações a respeito dessa categoria neste levantamento. O tipo de resíduo e sua quantidade também impacta a instituição economicamente nos valores a serem pagos como taxas, contratos ou impostos.

Nos dados brutos, o resíduo comum foi contabilizado em volume, não em massa, por uma estimativa relacionando o número de sacos pretos a um volume em litros. Para colocar todas os grupos de resíduos no mesmo diagrama, foi feita uma conversão de litros para quilos.

A conversão foi feita pelos valores obtidos por um estudo de resíduos sólidos gerados na Universidade Federal do Pampa (RUBERG, NEUFELD, et al., 2009). Por 29 dias corridos, todos os sacos contendo resíduos sólidos coletados na Sede foram pesados e seus dados anotados em uma ficha de controle contendo: data, local de origem do resíduo (quando especificado provir da biblioteca), quantidade de sacos, capacidade do saco (50 ou 100 litros), características dos sacos (cheio, quase cheio, semi-vazio), peso individual por saco, peso total do dia, peso total da semana.

Como resultado, obteve-se a valor de $27,40 \mathrm{~kg} / \mathrm{L}$ e considerando, ainda que a Sede tem atividades predominantemente administrativas, pode-se considerar atribuir a ela a classificação de resíduo comum. Ao estabelecer essa relação, estima-se, portanto, que foram produzidos 849,46 quilos de resíduo comum no CSP. Estes valores serão utilizados para a análise de fluxo de material, que preferivelmente, utiliza as mesmas unidades de medida. 
Para formular indicadores, foram utilizados os dados de população e área ocupada por atividade (ver Tabela 5). A contagem da população considerou duas variáveis, a população fixa e flutuante e a contagem das áreas considerou o número de recintos e a área em metros quadrados.

A divergência do número de população acadêmica fornecida pelo PDI de 16.409 considera o número de docentes, discentes e técnicos, enquanto que pela metodologia do levantamento, eram questionados aos ocupantes a quantidade da população fixa (se eram docentes, discentes, técnicos ou outros) e flutuante. A depender do entrevistado, quem não tinha posto de trabalho, era considerado flutuante.

Apesar da discrepância de 16.409 para 29.192 pessoas, acredita-se que o valor maior esteja mais adequado ao estudo metabólico, uma vez que pacientes, alunos de curso de curta duração e outros visitantes também são responsáveis pela necessidade de movimentação de materiais e energia dentro da universidade.

Como esforço para simplificar as informações para melhor análise, tanto o uso quanto a população foram associados a atividades predominantes, mesmo sendo uma prerrogativa problemática, uma vez que as atividades são muitas vezes multidimensionais, por exemplo, o atendimento ambulatorial em alguns locais são tão assistenciais quanto acadêmicos.

Tabela 5 - Dados de área física e população do Campus São Paulo por atividade

\begin{tabular}{l|c|c|c|c|c}
\multicolumn{1}{c}{ Atividade } & $\begin{array}{c}\text { Recintos } \\
\text { (un.) }\end{array}$ & $\begin{array}{c}\text { Área ocupada } \\
\left(\mathbf{m}^{\mathbf{2}}\right.\end{array}$ & $\begin{array}{c}\text { População } \\
\text { fixa }\end{array}$ & $\begin{array}{c}\text { População } \\
\text { flutuante }\end{array}$ & $\begin{array}{c}\text { População } \\
\text { total }\end{array}$ \\
\hline Desconhecido & 67 & $1.475,79$ & 9 & 12 & 21 \\
\hline Acadêmico & 788 & $13.677,01$ & 689 & 2444 & 3133 \\
\hline Administrativo & 660 & $9.654,23$ & 263 & 587 & 850 \\
\hline Assistencial & 708 & $8.425,65$ & 1900 & 16560 & 18460 \\
\hline Biotério & 107 & $1.339,06$ & 45 & 30 & 75 \\
\hline Infraestrutura & 1664 & $17.538,22$ & 112 & 167 & 279 \\
\hline Laboratorial & 840 & $14.127,62$ & 1569 & 3230 & 4799 \\
\hline Outros & 1019 & $37.036,06$ & 1039 & 536 & 1575 \\
\hline \hline Grand Total & $\mathbf{5 . 8 5 3}$ & $\mathbf{1 0 3 . 2 7 3 , 6 4}$ & $\mathbf{5 . 6 2 6}$ & $\mathbf{2 3 . 5 6 6}$ & $\mathbf{2 9 . 1 9 2}$
\end{tabular}

Fonte: Baseado no levantamento de MPS Arquitetos Associados 
São propostos dois indicadores para resíduos sólidos (ver Tabela 6 e Figura 52), que podem ser comparados posteriormente com outras instituições, ou estabelecimentos de saúde. A quantidade gerada por pessoa por atividade e por categoria de resíduos e a quantidade gerada por área por atividade e por categoria de resíduo.

Tabela 6 - Indicadores de geração de resíduo per capita por atividade e tipo de resíduo no Campus São Paulo (2017)

\begin{tabular}{l|c|c|c} 
Atividade & Quimico (kg/pessoa) & Infectante (kg/pessoa) & Comum (kg/pessoa) \\
\hline Acadêmico & 0,00 & 0,04 & 1,09 \\
\hline Administrativo & - & - & 1,59 \\
\hline Assistencial & 0,00 & 0,06 & 0,46 \\
\hline Biotério & - & 5,11 & 2,38 \\
\hline Infraestrutura & - & 0,12 & 1,19 \\
\hline Laboratorial & 0,00 & 0,14 & 1,34 \\
\hline Total & $\mathbf{0 , 0 0}$ & $\mathbf{0 , 0 8}$ & $\mathbf{0 , 8 0}$
\end{tabular}

Fonte: Adaptado de MPS Arquitetos Associados e dados do Departamento de Infraestrutura do Campus São Paulo.

No primeiro indicador, verifica-se que os resíduos químicos têm uma geração pouco expressiva per capita, sendo que só há valores a partir da terceira casa decimal. As atividades que tem maior geração per capita são a Acadêmico (aproximadamente 0,001 $\mathrm{kg} / \mathrm{pessoa} / \mathrm{dia}$ ) e a Laboratorial (aproximadamente $0,005 \mathrm{~kg} / \mathrm{pessoa} / \mathrm{dia}$ ). Estes indicadores podem ser úteis institucionalmente para acompanhar a evolução do consumo de produtos químicos e ao comparar com outras instituições de porte semelhante, se a geração de resíduos químicos está coerente com as atividades ou se existe uma subnotificação dos usuários para coleta desse tipo de resíduo.

Os resíduos potencialmente infectantes em todas as atividades que os geram estão com valores próximos, (de 0,04 a 0,14 kg/pessoa/dia), o que indica que muitas dessas atividades são de fato relacionadas. A grande diferença está na atividade de biotério, que gera $5,11 \mathrm{~kg} /$ dia/pessoa. A justificativa aqui é resíduos provenientes de biotérios de produção, no ano do levantamento (2017), eram considerados potencialmente infectantes. E como os animais não são contabilizados como pessoas, há uma discrepância nos valores na ordem de cerca de 35 vezes.

Nos resíduos comuns, a situação é semelhante ao cenário anterior, o indicador de resíduos comuns per capita na atividade de biotério é muito maior do que as demais atividades, que estão com valores próximos entre si. Outro ponto que se destaca é o da atividade assistencial, com uma menor geração de resíduo comum, menos da metade de outras atividades. Como verificado no diagnóstico, foram apontadas situações em que resíduos estavam sendo descartados erroneamente como infectantes este indicador corrobora com esta afirmação, porém não é possível com os dados disponíveis estimar quanto deste resíduo é descartado incorretamente. 
A título de comparação, em 2011, a geração per capita de resíduo sólido urbano no município de São Paulo foi de $377,75 \mathrm{~kg} / \mathrm{ano}^{105}$, dividindo pelo número de dias úteis, dá o valor aproximado de $1,34 \mathrm{~kg} /$ dia.

Figura 52 - Gráfico de indicadores de geração de resíduos per capita no Campus São Paulo

\section{Indicadores de geração de resíduos $\mathrm{kg} / \mathrm{pessoa} /$ dia}

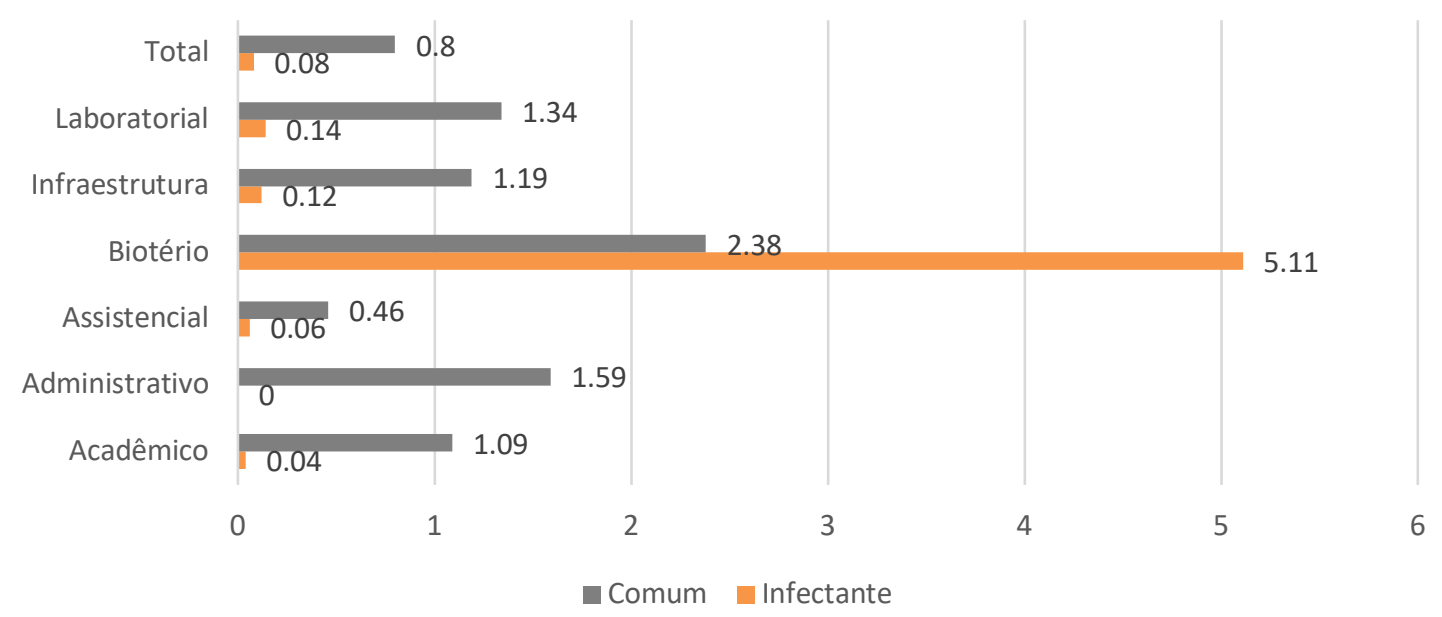

Fonte: Adaptado de MPS Arquitetos Associados e dados do Departamento de Infraestrutura do Campus São Paulo.

Ao analisar a relação entre geração de resíduos por áreas (ver Tabela 7 e Figura 53), os indicadores de produção de resíduos químicos são pouco expressivos, mesmo nas atividades de laboratório e assistencial.

Tabela 7 - Geração de resíduo por área por atividade no Campus São Paulo

\begin{tabular}{l|c|c|c} 
Atividade & Quimico $\left(\mathbf{k g} / \mathbf{m}^{\mathbf{2}}\right)$ & Infectante $\left.\mathbf{( k g} / \mathbf{m}^{\mathbf{2}}\right)$ & Comum $\left.\mathbf{( k g} / \mathbf{m}^{\mathbf{2}}\right)$ \\
\hline Acadêmico & 0,00 & 0,01 & 0,25 \\
\hline Administrativo & - & - & 0,14 \\
\hline Assistencial & 0,00 & 0,13 & 1,01 \\
\hline Biotério & - & 0,29 & 0,13 \\
\hline Infraestrutura & - & 0,00 & 0,02 \\
\hline Laboratorial & 0,00 & 0,05 & 0,45 \\
\hline \hline Total & $\mathbf{0 , 0 0}$ & $\mathbf{0 , 0 2}$ & $\mathbf{0 , 2 3}$
\end{tabular}

Fonte: Baseado no levantamento de MPS Arquitetos Associados e dados do Departamento de Infraestrutura do Campus São Paulo. Org. do autor.

No caso dos resíduos infectantes, a relação entre área e geração de resíduos sólidos aparenta seguir a lógica da relação entre a geração e pessoas, novamente com o a maior quantidade de resíduo por metro quadrado em biotério. A área ocupada por atividades

105 https://www.redesocialdecidades.org.br/br/SP/sao-paulo/quantidade-de-residuos-per-capita 
assistenciais, por ser uma das menores também contribui para que a quantidade de resíduo por metro quadrado seja maior que as de laboratório e acadêmico juntos.

O indicador de resíduos comuns por área tem padrões semelhantes ao do indicador de resíduos per capita, exceto pela área assistencial que tem o maior indicador, no caso de per capita, o maior indicador é o de biotério. Esta diferença aparenta ser pelo grande volume e uma área ocupada menor que outras atividades, a assistencial é a terceira menor área por atividade. Lembrando, no entanto, que o complexo do Hospital São Paulo é gerido por outra entidade e, portanto, não consta nesse levantamento da Unifesp

Figura 53 - Comparativo entre indicadores de geração de resíduo per capita e por $m^{2}$ no CSP

Indicadores de geração de resíduos $\mathrm{kg} / \mathrm{pessoa} / \mathrm{dia}$

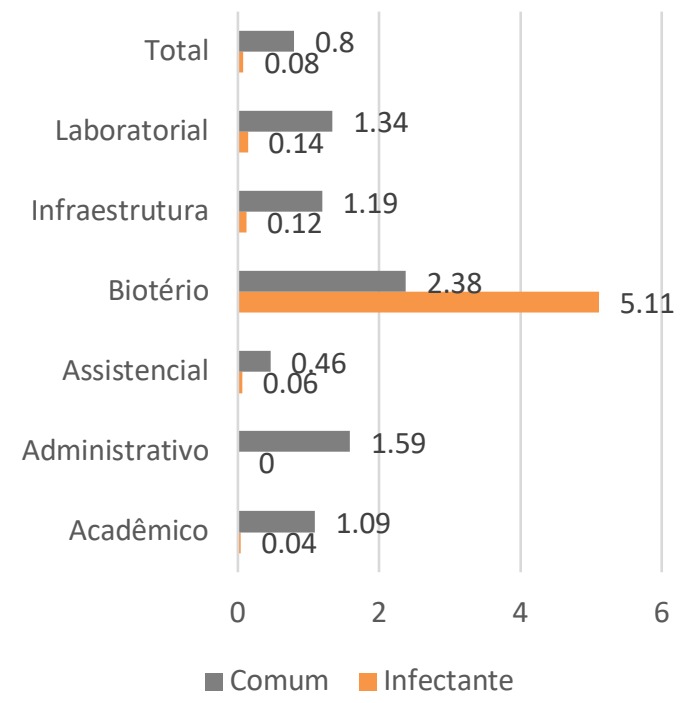

Indicadores de geração de resíduos $\mathrm{kg} / \mathrm{m}^{2} / \mathrm{dia}$

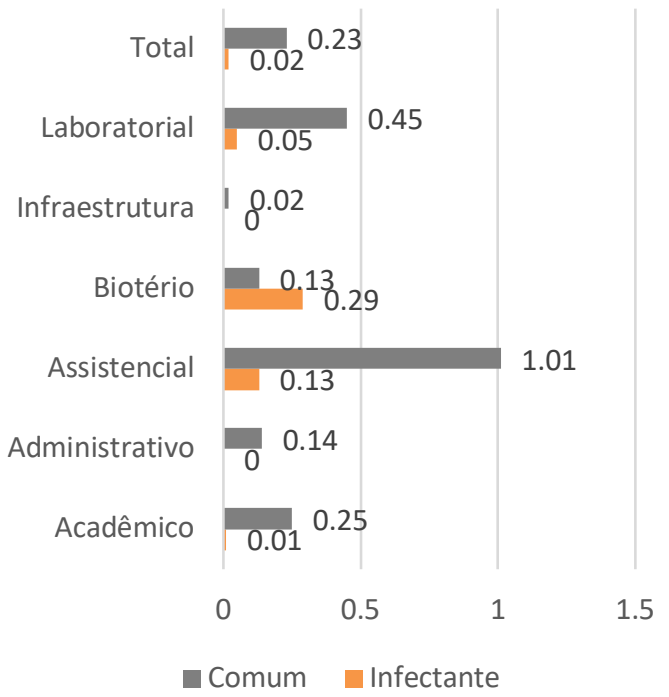

Fonte: Baseado no levantamento de MPS Arquitetos Associados e dados do Departamento de Infraestrutura do Campus São Paulo. Org. do autor.

Os indicadores, mapas, tabelas e diagramas provenientes do diagnóstico conferem melhor visualização e subsidiam os tomadores de decisão e apresentam meios de acompanhamento de ações institucionais, sem os quais não será possível aprimorar algumas das fases referentes à gestão de resíduos sólidos: geração, acondicionamento, armazenamento, coleta, transporte, triagem, tratamento, valorização e destinação final.

A seguir, explora-se um método utilizando os dados do diagnóstico para visualizar os fluxos de material, abordado no capítulo 1, o Material Flow Analisys (MFA) (VILLENEUVE, MICHEL, et al., 2004) (BRUNNER e RECHBERGER, 2005). 


\subsection{ANALISE DE FLUXO DE MATERIAL DO SISTEMA CAMPUS SÃO PAULO}

Com os dados do diagnóstico dos resíduos sólidos e utilizando os pressupostos metodológicos do MFA, é possível construir visualizações dos fluxos (ver Figura 54) que serão úteis na análise e proposição de ações por parte da instituição.

\section{Figura 54 - Diagrama do fluxo de resíduos conhecidos do CSP (2017)}

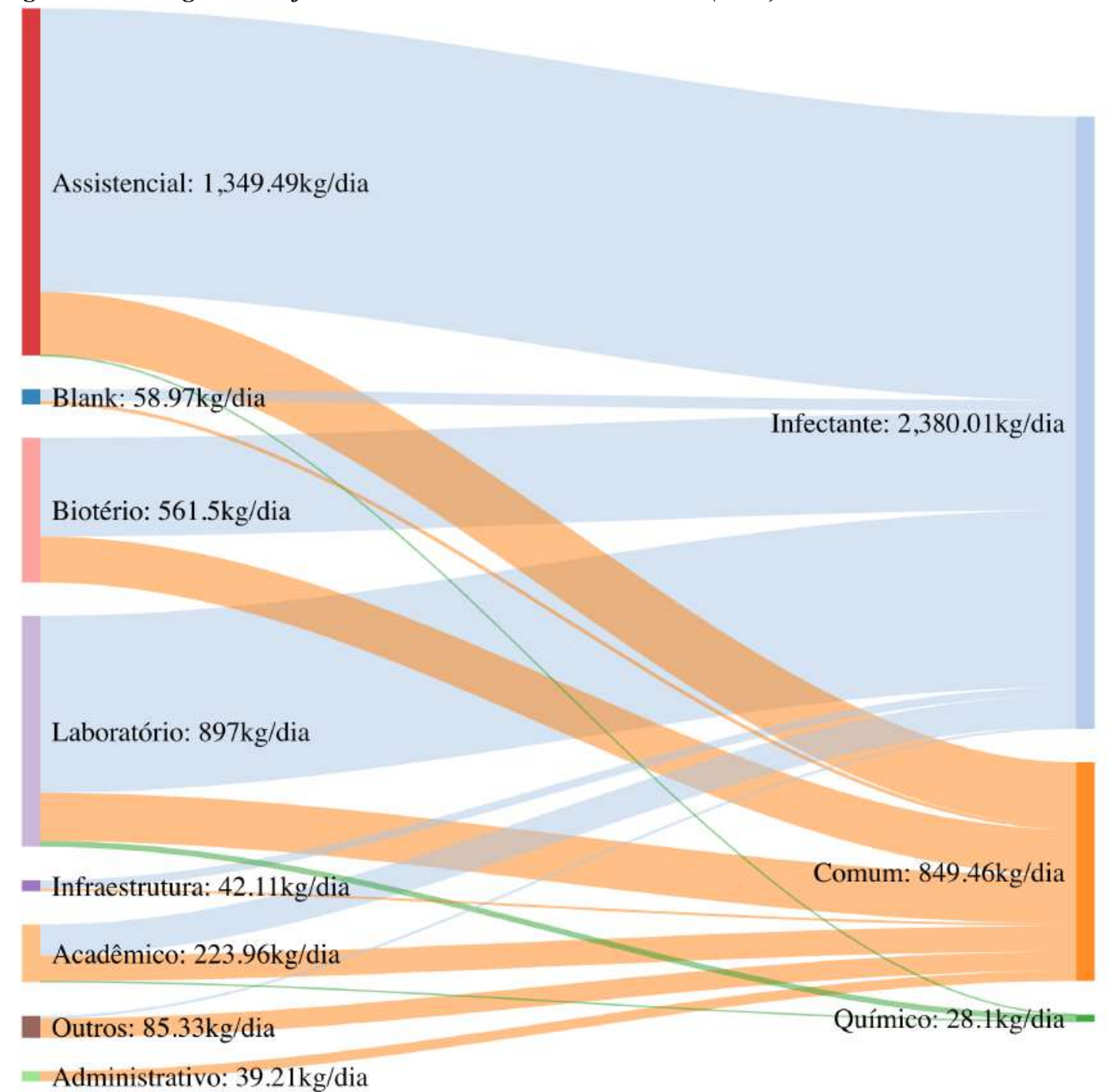

Fonte: Diagrama baseado no levantamento da empresa MPS Arquitetos Associados

Como atividade "Assistencial" foram consideradas os ambientes relacionados ao atendimento ao público, como ambulatórios, postos de coleta, consultórios e exames. Esta atividade gera $1.349,49 \mathrm{~kg}$ de resíduos por dia em 2017, sendo composto por resíduos infectantes (grupo A e E), comum (grupo D) e químico (grupo B). Este valor não considera o complexo Hospitalar do HSP, que não é gerido pela instituição. Dados 
encontrados de 2010, indicam que somente o hospital ${ }^{106}$ gerou $39.347,10 \mathrm{~kg}$ por mês, ou $1.311,57 \mathrm{~kg}$ por dia.

A atividade "Blank" não tiveram, durante o levantamento de campo, usos facilmente identificáveis, ou não foi possível obter informação com o ocupante no momento. Apesar disso, sabe-se que são coletados resíduos infectantes e comuns no local. O montante gerado não é expressivo, $58,97 \mathrm{~kg}$ por dia.

A atividade "Biotério", muitas vezes se confunde com a atividade Laboratório, uma vez que o biotério é um local onde se mantém vivos animais para futuros experimentos. Devido às normas vigentes em 2017, boa parte dos resíduos gerados eram considerados infectantes. 383 dos 561,5 quilos por dia são do grupo A, principalmente. Os demais resíduos são resíduos comuns.

A atividade "Laboratório" está relacionada aos espaços de pesquisa e ensino. Por se tratar de um campus voltado à saúde, há muitos experimentos que envolvem praticamente todos os subgrupos do Grupo A (ANVISA, 2018), em que há culturas e estoques de microrganismos, bolsas contendo sangue, entre outros (Subgrupo A1), peças anatômicas de animais ou carcaças (Subgrupo A2), peças anatômicas humanas (Subgrupo A3), recipientes, filtros, peças provenientes de procedimentos cirúrgicos entre outros (Subgrupo A4). São gerados 897 quilos de resíduos por dia de todos os grupos, nesta atividade.

A atividade "Infraestrutura" está relacionada às funções de manutenção, de engenharia clínica e de edificação, de estoque e de apoio a outras atividades. O montante é baixo, 42,11 quilos por dia e, apesar disso, boa parte dos resíduos são infectantes, 32,5 quilos.

A atividade "Acadêmico" está relacionada aos espaços de ensino, como salas de aula, laboratórios didáticos, anfiteatros, espaços de convivência, grêmios estudantis, espaços departamentais e administrativos de cursos e disciplinas. Esta atividade gera 233,96 quilos de resíduo por dia, de todos os grupos.

A atividade "Outros" está relacionada a outras atividades que não se adequavam a outras classificações, como creche, espaços alugados para terceiros e espaços multiusuários sem uma atividade definida. São gerados 85,33 quilos por dia, praticamente resíduo comum, com uma pequena parcela de resíduos infectantes.

\footnotetext{
$106 \mathrm{http}: / /$ portal.mec.gov.br/index.php?option=com_docman\&view=download\&alias=7304-hospital-saopaulo-unifesp\&category_slug=dezembro-2010-pdf\&Ittemid=30192
} 
A atividade Administrativo contempla basicamente os departamentos administrativos e as diretorias administrativas. Estas atividades são bem delimitadas, pois, mesmo sendo a atividade predominante,

Mesmo atribuído a uma atividade predominante apenas, os resíduos gerados são de classificações diversas.

Seguindo o princípio da conservação de massa, conforme preconiza o MFA, teríamos a mesma massa na entrada e na saída. Na forma de diagrama, de maneira didática, agrupamos os valores de massa de entrada e de saída e em que atividades estão sendo metabolizadas, para então, virar resíduo.

Neste exercício conceitual, não é possível medir as distorções provenientes do levantamento, a quantidade de material que não pôde ser contabilizada na coleta de resíduos, por exemplo, se algum resíduo foi descartado diretamente no esgoto, se um produto é volátil e se dissipou no estado gasoso e outras questões que impossibilitaram a medição exata dos fluxos de saída.

A visualização desses fluxos facilita a compreensão do sistema como um todo, ainda mais um sistema tão fragmentado como este. Ao analisar individualmente cada recinto, o pesquisador, usuário, técnico ou gestor pode considerar irrelevante o volume, no entanto, no contexto geral, o campus como um todo produz um volume considerável.

Em ambos diagramas, pode-se verificar a quantidade e fluxo conhecido, em outras palavras, a quantidade de resíduos que foram devidamente coletados. No entanto, sabese que há procedimentos de descarte irregular de "diluição e dispersão" (ARAÚJO, 2002) principalmente de resíduos químicos, que são diluídos e descartados como esgoto doméstico.

Ainda referente aos resíduos químicos, como provocado no processo participativo, sabe-se que o campus não dispõe de um controle central do estoque de seus reagentes e demais produtos químicos, de forma que é uma incógnita o estoque e se a coleta de resíduos químicos está subdimensionada.

Conforme verificado no Portal da Transparência, houveram 33 licitações concluídas de 2010 a 2018 que tiveram como objeto itens com algum destas palavras: químico, químicos, ácido, composto, orgânico, bombona, embalagem, frasco ou reagente (ver Apêndice D). Dos 33 itens, apenas 2 indicavam o volume dos produtos adquiridos para laboratórios. 
Figura 55 - gráfico número de compras $x$ ano no CSP

Compras Institucionais

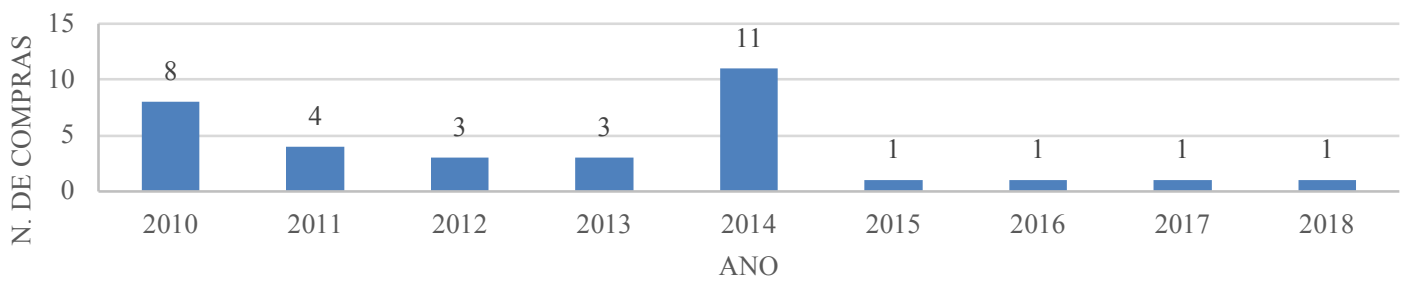

Fonte: Portal da Transparência da Unifesp.

Além disso, verifica-se também uma grande flutuação nas compras institucionais, com tendência de queda, conforme verificado na Figura 55, o número de licitações encerradas por ano, vem diminuindo. No entanto, não é possível tirar conclusões se houver variação de resíduos químicos na instituição, pois insumos adquiridos anteriormente podem ser descartados anos depois e novos insumos podem estar sendo incorporados por outras vias que não por meio de licitação.

Considerando ainda, o manual de aplicação de $M F A$ para gestão de resíduos urbanos (VILLENEUVE, MICHEL, et al., 2004) e do próprio conceito de MFA (BRUNNER e RECHBERGER, 2005), o sistema "Campus São Paulo" terá a análise de fluxo de material a partir das etapas propostas no manual da Resource Management Agency (RMA). (ver Quadro 18)

$\mathrm{Na}$ etapa 1, definimos o problema e o objetivo dessa análise. O problema de fluxo de materiais é que o campus é disperso e produz resíduos de serviço de saúde de classificações diversas. O objetivo dessa análise é simplificar as informações de modo a visualizar facilmente os pontos mais efetivos de intervenção.

Na etapa 2, é definido o sistema com base nos dados disponíveis. O sistema "Campus São Paulo" teve uma grande quantidade de informações levantadas e atualizadas em 2017 para embasar o PDInfra, de modo que é natural a delimitação do sistema com base nesses dados.

$\mathrm{Na}$ etapa 3, definimos os processos principais que comporão o sistema. Os principais são "estoque", "atividades" e "transporte", sendo possível visualiza-los de diversas maneiras, tanto em mapas, quanto em diagramas de fluxo de material. Outros processos foram elencados também, o "abrigo de resíduos" que é um dos componentes do "estoque", porém não há dimensionamento adequado no momento do levantamento. o processo "compostagem/horta" começou como um projeto de extensão em 2017, e embora o volume não seja expressivo, é um dos poucos exemplos de tentativa de fluxo circular dentro da universidade. O processo de "separação" ainda é inconstante no 
campus, pois depende de convênios com cooperativas de catadores e melhor segregação pelos usuários do campus.

Na etapa 4 há uma adaptação de "substancia", uma vez que os materiais ou insumos que entram no sistema não são classificados durante todo o processo metabólico, apenas na saída, em que, aí sim, são classificados conforme a RDC 222. Esta lacuna se justifica pela falta de informação a respeito dos fluxos de entrada e do estoque de materiais do campus.

$\mathrm{Na}$ etapa 5 verifica-se o "balanço grosseiro" do sistema. Pelo princípio de conservação de massa, teoricamente a massa de saída é a mesma da de entrada (ver Figura 56), daí o balanço grosseiro em que há perfeito equilíbrio no sistema.

Figura 56 - Diagrama do fluxo de resíduos conhecidos no CSP com estimativa de entradas (2017)

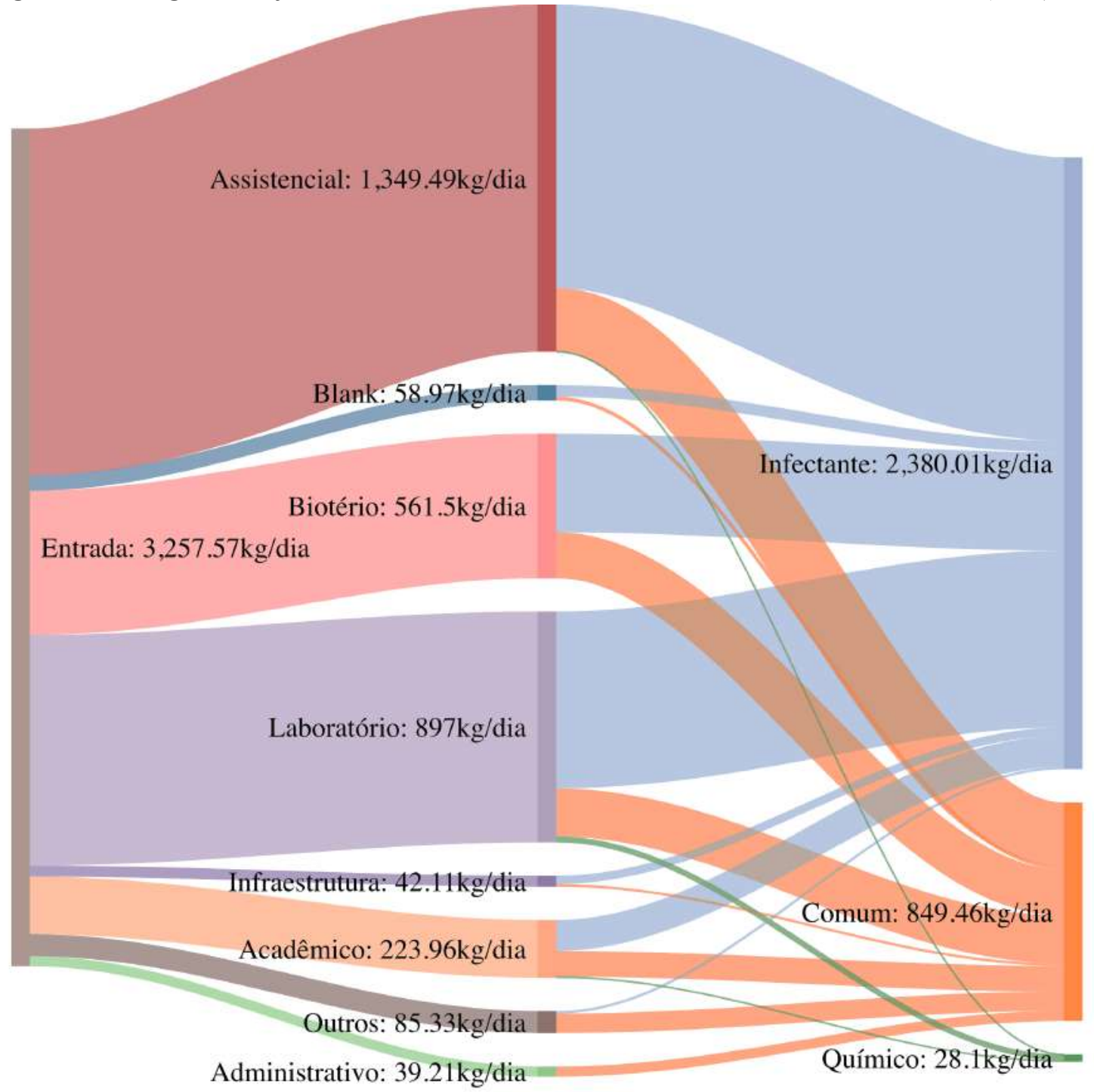

Fonte: Autor. Diagrama baseado no levantamento da empresa MPS Arquitetos Associados 
Dos resultados na forma dos diagramas apresentados nas figuras 54 e 56, é preciso fazer uma ressalva. Na figura 54 constam valores levantados, e na figura 56, como modelo conceitual, apresentou-se o que seria a entrada de material, considerando o pressuposto da metodologia (VILLENEUVE, MICHEL, et al., 2004) em que haveria entradas e saídas de mesmo valor.

$\mathrm{Na}$ etapa 6, verificam-se as variáveis do sistema simplificado, no caso as atividades, a classificação dos resíduos e a quantidade destes. Em cada variável, pode-se elencar ao menos dois parâmetros mais expressivos, em atividade, a assistencial e laboratório são as que geram maior quantidade de resíduos. Na classificação e quantidade, os principais são os resíduos infectantes (Grupo A e E) e os resíduos comuns (Grupo D).

A etapa 7 consiste em dar subsídios para futuras pesquisas, ou no caso do CSP, de continuação e aprimoramento das políticas de resíduos sólidos no campus. Para próximas ações é preciso melhorar o monitoramento de entrada de material e do seu estoque e afinar a classificação dos resíduos, trabalhando com melhor segregação pelo usuário na fonte e vistorias em períodos diferentes para que a sazonalidade se reflita também na quantidade de resíduos gerados, entre outras orientações.

A etapa 8 é calculado o fluxo de material do sistema. A princípio, o CSP gera 3.257,57 quilos de resíduos por dia, considerando resíduos potencialmente infectantes, químicos e comuns. Não foram contabilizados os resíduos radioativos. Para os autores do manual, um sistema com mais ou menos $20 \%$ de precisão entre o balanço de entrada, saída e estoque é tolerável (VILLENEUVE, MICHEL, et al., 2004). No entanto, não foi possível mensurar os fluxos de entrada, de modo que se considera o mesmo volume de entrada e de saída, apenas para fins ilustrativos.

Por não ser possível mensurar o equilíbrio, não há resultado para a etapa 9.

\begin{tabular}{|c|c|c|}
\hline Etapas & Fatores & Resultado \\
\hline 1. Definir problema e objetivo & Conceito & $\begin{array}{l}\text { Como analisar a produção de } \\
\text { RSS em um campus disperso? }\end{array}$ \\
\hline 2. Definir o sistema & Dados disponíveis & Sistema "Campus São Paulo" \\
\hline $\begin{array}{l}\text { 3. Selecionar e definir os } \\
\text { processos }\end{array}$ & Atividade & $\begin{array}{l}\text { Processos principais: "estoque", } \\
\text { "atividades", "transporte" }\end{array}$ \\
\hline 4. Selecionar substancias & Objetivo & $\begin{array}{l}\text { Substancias classificadas } \\
\text { conforme RDC } 222\end{array}$ \\
\hline 5. "balanço grosseiro" & Pontos principais & Diagrama \\
\hline 6. Analise de sensibilidade & Parâmetros & $\begin{array}{l}\text { Resíduos comuns (grupo D) e } \\
\text { Resíduos infectantes (A e E) }\end{array}$ \\
\hline 7. Planejamento da pesquisa & $\begin{array}{l}\text { Resultados da analise de } \\
\text { sensibilidade }\end{array}$ & $\begin{array}{l}\text { Afinar a classificação e } \\
\text { melhorar o monitoramento do } \\
\text { estoque }\end{array}$ \\
\hline
\end{tabular}


Continuação

\begin{tabular}{|l|l|l|}
\hline $\begin{array}{l}\text { 8. Calculo dos fluxos de } \\
\text { material }\end{array}$ & Dados & $\begin{array}{l}\text { São gerados 3.257,57 kg/dia de } \\
\text { resíduos }\end{array}$ \\
\hline $\begin{array}{l}\text { 9. Calculo da função de } \\
\text { transferência e coeficientes de } \\
\text { transferência }\end{array}$ & Fluxos & $\begin{array}{l}\text { Com os dados atuais, não é } \\
\text { possível calcular o equilíbrio } \\
\text { entre entrada, saída e estoque. }\end{array}$ \\
\hline $\begin{array}{l}\text { 10. Apresentação dos } \\
\text { resultados }\end{array}$ & Desenho do sistema & $\begin{array}{l}\text { Visualização do sistema } \\
\text { "Campus São Paulo" }\end{array}$ \\
\hline
\end{tabular}

Fonte: Adaptação do autor da metodologia de (VILLENEUVE, MICHEL, et al., 2004)

Por fim, apresenta-se um modelo simplificado do sistema "Campus São Paulo" de maneira semelhante a outros MFAs (ver Figura 57), porém com lacunas de informação, que demonstram a necessidade de estudos e levantamentos complementares. A visualização do sistema, mesmo com as incógnitas, permite analisar de maneira simplificada um sistema complexo, podendo assim, propor políticas e ações que sejam mais eficazes na solução de seus problemas.

De maneira sintética, o sistema compreende os fluxos de entrada (X), cujo quantitativo não foi possível de estimar, um estoque de materiais (Y) cujo dimensionamento não é conhecido e por uma saída $(Z)$, cujo quantitativo se refere à coleta de resíduos regular realizada no campus. Em destaque dois processos que contribuem para fluxos circulares no sistema, que seriam a compostagem e a separação para reciclagem.

Figura 57 - MFA do sistema "Campus São Paulo"

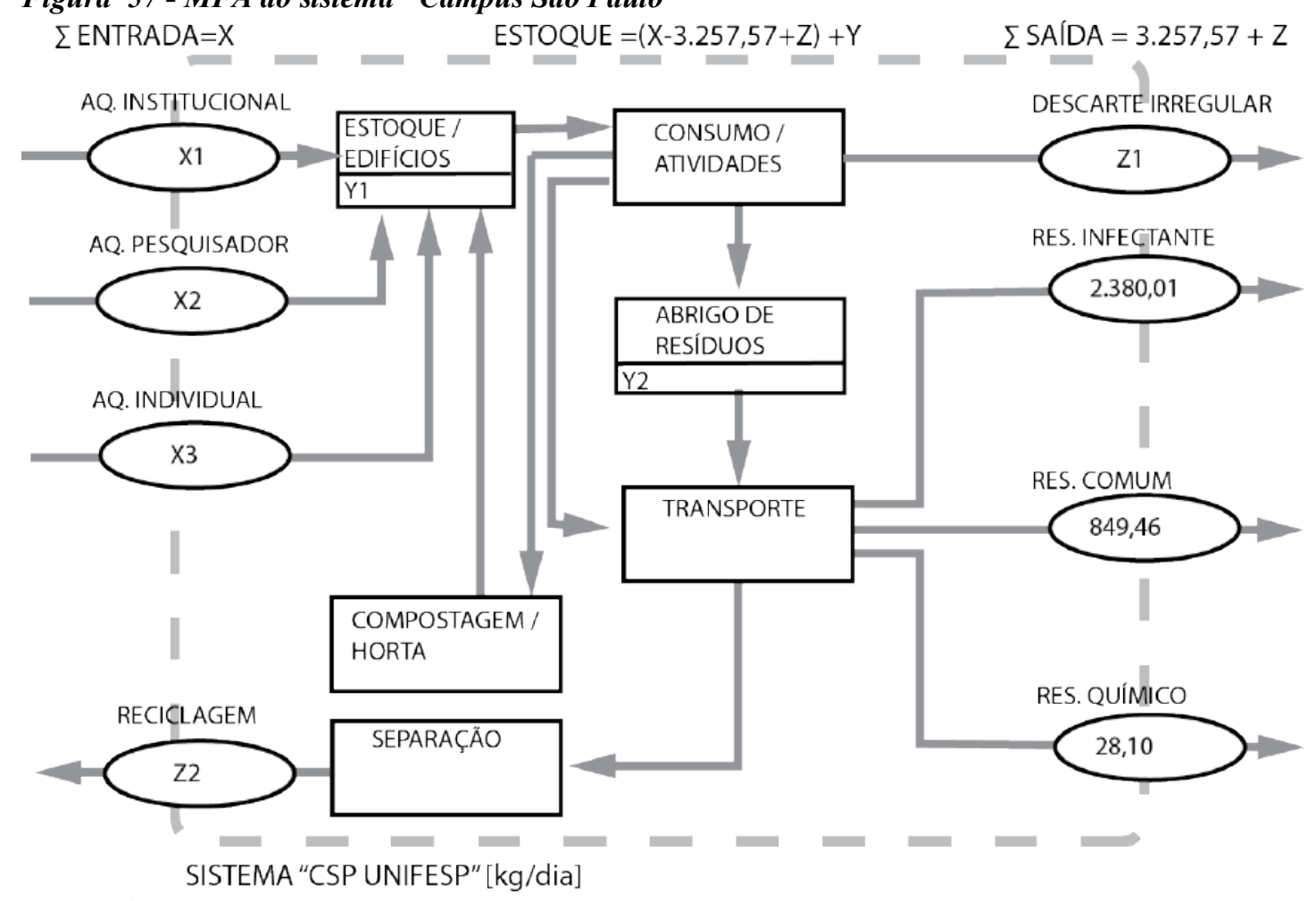

Fonte: Autor 
A compostagem (ver Figura 58), em conjunto com uma horta comunitária começou como um projeto de extensão ${ }^{107}$ e é um processo formalizado dentro do campus, com ações de sensibilização com a comunidade acadêmica e separação de material de preparo de alimentos pela própria equipe do Restaurante Universitário. A ação está associada a uma horta comunitária (ver Figura 59), em que se pretende ser também um espaço de convivência.

A separação de resíduos recicláveis, no entanto, é um processo ainda a ser regularizado, com convenio ou parceria com cooperativa de catadores e adequação do local de separação e de capacitação de pessoal para que não haja riscos à saúde do trabalhador. E complementando com a segregação correta na fonte geradora.

Figura 58 - Local de compostagem

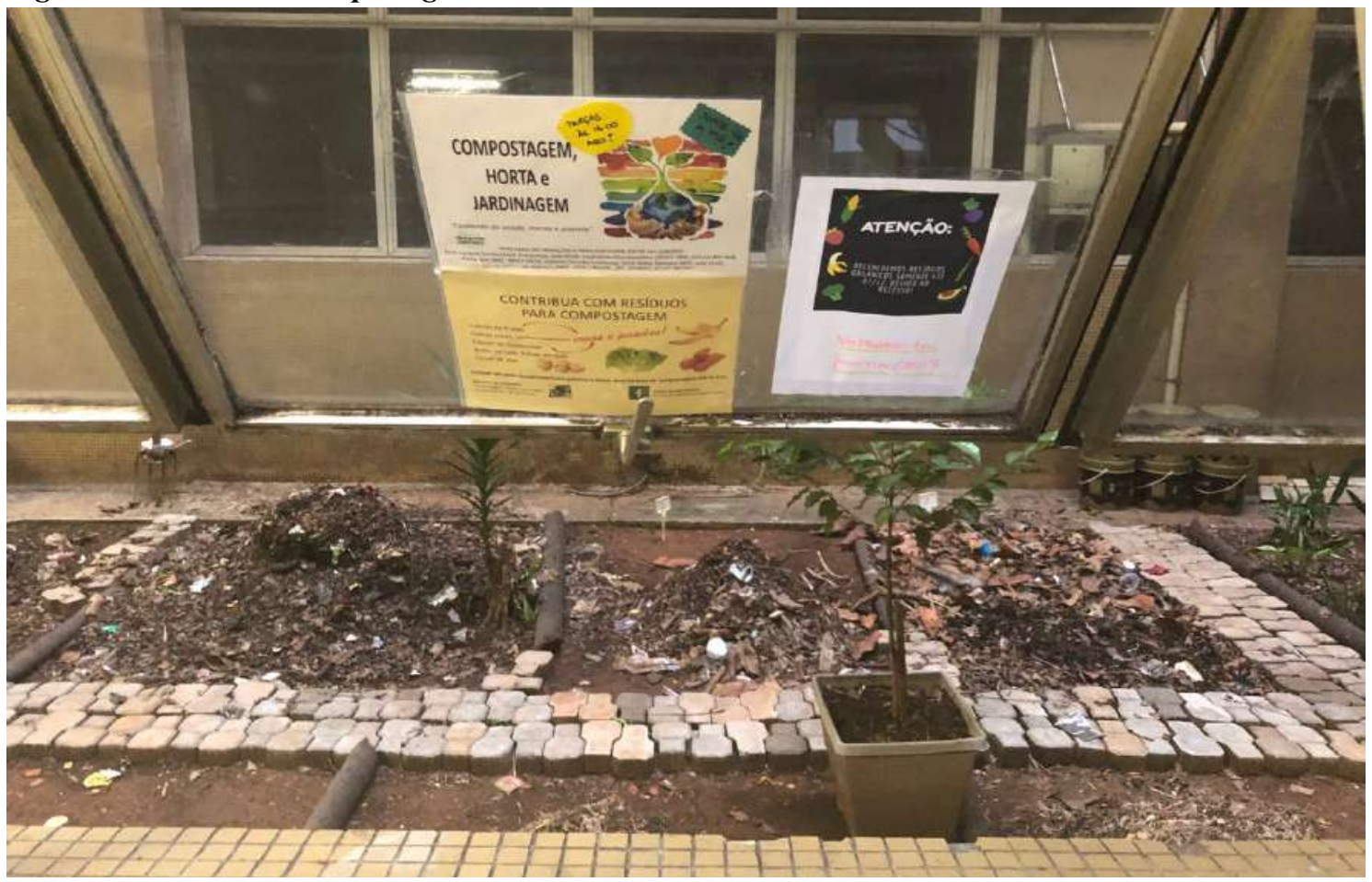

Foto do autor

$107 \mathrm{http} / / /$ www.unifesp.br/reitoria/dci/noticias-anteriores-dci/item/3405-terapia-de-horticultura-e-tema-deprojeto-de-extensao-e-pesquisa-na-unifesp 


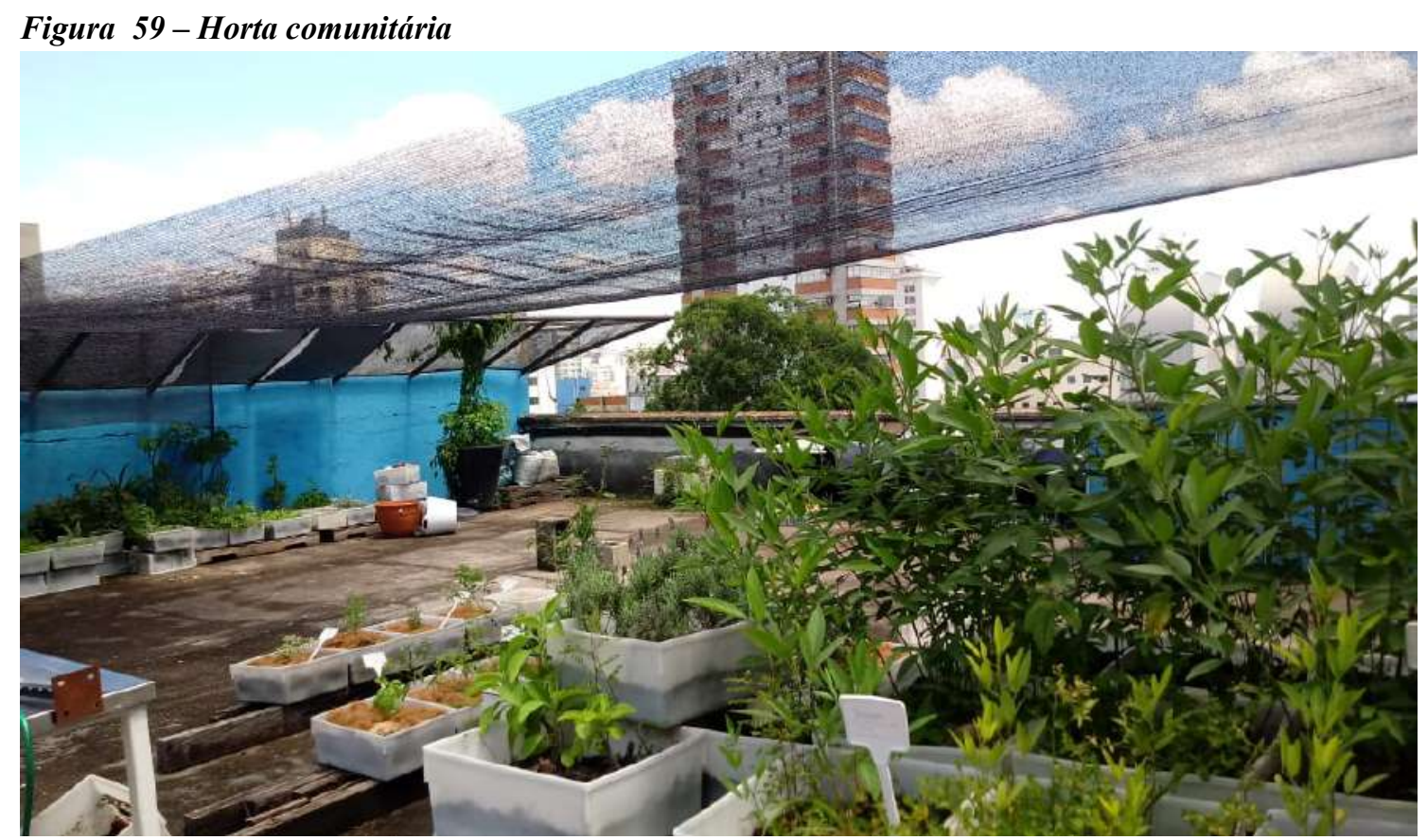

Foto do autor

Estes são, portanto, os principais fluxos e processos dentro do sistema CSP. Considerando que as atividades geram resíduos, o MFA é uma ferramenta muito interessante para subsidiar tomada de decisões, dimensionar ou repensar o volume de resíduos produzido e monitoramento da evolução do campus rumo à sustentabilidade.

\subsection{PONTOS DE INTERVENÇÃO EM UM SISTEMA OBJETIVANDO A SUSTENTABILIDADE - OS PONTOS DE ALAVANCAGEM}

De um ponto de vista sistêmico, essas ações, e dentre elas também os planos institucionais, estão dentro de certas categorias que foram chamadas de "leverage points", algo como "pontos de alavancagem" da autora Donella Meadows, em 1997. De acordo com a autora, em um sistema, há certos pontos que são mais efetivos em produzir mudanças. $\mathrm{Na}$ ordem crescente de eficácia ela descreve 12 pontos:

Locais para intervir em um Sistema (em ordem crescente de efetividade: 12. Constantes, parâmetros, números (como subsídios, impostos, padrões)

11. O tamanho de amortecedores e outros estoques de estabilização, relativo aos seus fluxos

10. a estrutura do estoque de materiais e fluxos (como rede de transportes, estruturas de envelhecimento da população)

9. A extensão dos atrasos, relativo a taxa de troca ou mudanças do sistema

8. A força feedbacks negativos, relativos aos impactos contrários ao que eles tentam corrigir 
7. o ganho em torno do manejo de ciclos de feedbacks positivos

6. a estrutura do fluxo de informações (quem tem e quem não tem acesso a que tipo de informação)

5. as regras do sistema (como os incentivos, punições e restrições).

4. $O$ poder de adicionar, mudar, evoluir, ou auto organizar uma estrutura do sistema

3. Os objetivos do sistema

2. A mentalidade ou paradigma nos quais o sistema, seus objetivos, estrutura, regras, atrasos, parâmetros - surgem

1. o poder de transcender paradigmas. (tradução nossa) ${ }^{108}$

Em relação aos assuntos estudados nesta dissertação, sob o viés dos pontos de alavancagem, podemos considerar em cada ponto as seguintes constatações:

A começar pelo ponto 12 - Constantes, parâmetros e números - podemos verificar que mudanças indicadas pela RDC 222 em relação à RDC 306, pode alterar parâmetros no que se refere à classificação de resíduos de serviço de saúde. No entanto, alterar esses parâmetros não influi no total gerado pela instituição, mas ressalta-se que a alteração pode resultar em economia na contratação de coleta de RSS, que é mais cara que a coleta de resíduos comuns.

No ponto 11 - O tamanho de amortecedores e outros estoques de estabilização, relativo aos seus fluxos - como a própria autora diz, são entidades em geral físicas e difíceis de mudar (MEADOWS, 1999). Como estoques da Universidade, podemos pensar em estoque de espaços ociosos, ou multiuso, que podem ser utilizados em casos de emergência ou para servirem de apoio durante a reforma ou remanejamento de atividades, o dimensionamento de estoques para cobrir as necessidades do campus também é importante, um estoque superdimensionado é mais caro de gerenciar e operacionalizar, além do risco de perda de validade de produtos. O estudo dos fluxos de materiais pode ajudar a dimensionar de forma mais racional esses estoques.

\footnotetext{
${ }^{108}$ Do original:

Places to Intervene in a System (in increasing order of effectiveness):

12. Constants, parameters, numbers (such as subsidies, taxes, standards)

11. The sizes of buffers and other stabilizing stocks, relative to their flows

10. The structure of material stocks and flows (such as transport networks, population age strucures)

9. The lengths of delays, relative to the rate of the system change

8. The strength of negative feedback loops, relative to the impacts they are trying to correct against

7. The gain around driving positive feedback loops

6. The structure of information flows (who does and does not have access to what kind of information).

5. The rules of the system (such as incentives, punishments, constraints)

4. The power to add, change, evolve, or self-organize system structure.

3. The goals of the system

2. The mindset or paradigm out of which the system - its goals, structure, rules, delays, parameters - arises

1. The power to transcend paradigms. (MEADOWS, 1999)
} 
Sobre o ponto 10 - a estrutura do estoque de materiais e fluxos - falamos de estruturas físicas, que são difíceis de mudar. Como verificamos nos mapas de resíduos sólidos do Campus São Paulo, há dezenas de edifícios com geração de resíduos químicos, potencialmente infectantes e comuns, espalhados pelo bairro, inclusive outros estabelecimentos de saúde. Não é intenção que estes fiquem concentrados em um único ponto, mas apontar para uma implantação mais racional que envolva menores deslocamentos e mais proximidade aos estoques exige grandes recursos econômicos.

No ponto 9 - A extensão dos atrasos - pode-se referir aos atrasos ou a demora de um sistema. Por exemplo, a extensão de tempo entre o nascer de uma criança e esta estar pronta para ter uma criança. No caso essa "demora", portanto, não é algo necessariamente ruim, mas é um ponto de alavancagem caso se consiga maneja-la. Por exemplo, plano diretor do CSP considera cenários de 5, 10 e 20 anos, portanto há uma grande distância temporal entre as ações de embasamento do plano e a sua efetivação. Inclusive o dimensionamento desses períodos é necessário para que as ações estejam de acordo com os tempos institucionais, sem sobrecarregar e sem deixa-la ociosa.

No ponto 8 - A força dos feedbacks negativos - um feedback negativo é um dispositivo de controle em um sistema para equilibra-lo ou mantê-lo em uma zona de segurança. Ao definir um limite, ou objetivo, este mecanismo age para corrigir um impacto contrário ao estabelecido. A autora dá como exemplo a Democracia, como um sistema de autocorreção entre a população e o seu governo, muito embora a força de um feedback negativo depende da combinação da precisão e velocidade do monitoramento (ou de informações), a rapidez e poder de resposta e dimensionamento dos fluxos corretivos.

No caso do sistema do campus universitário, os dispositivos de informação e monitoramento são essenciais para que ações corretivas sejam realizadas. O diagnóstico dos resíduos sólidos por exemplo, mantido e atualizado indicará a necessidade de ações de conscientização a advertências para manter os níveis de geração de resíduos condizentes com as atividades e com o número de usuários.

No ponto 7 - o ganho em torno do manejo de ciclos de feedbacks positivos - como a autora descreve, os feedbacks negativos são autocorretivos e os feedbacks positivos se auto reforçam. Um sistema que não checa seus feedbacks positivos, em última instancia pode autodestruir. Exemplos desse tipo de fluxo são: gripe, quanto mais gente pega, mais possibilidade de infectar outros; juros, quanto mais dinheiro no banco, mais dinheiro se ganha com aplicações;

Este ponto tem mais alavancagem que fortalecer os feedbacks negativos, pois manejar, ou diminuir os ciclos positivos dará mais tempo para respostas corretivas. Exemplo disso na universidade é que quanto mais imóveis alugados, mais disperso fica o 
campus e menos dinheiro tem para investir em espaços próprios. Considerando os reajustes de aluguéis, uma vez que se gasta dinheiro em aluguel, mais dinheiro será gasto em aluguel no próximo ano, e assim por diante. Diminuir esses ciclos tem maior efetividade que acionar dispositivos de controle dos preços ou alocar atividades de modo emergencial.

O ponto 6 - a estrutura do fluxo de informações - como mencionado no ponto 8, manter um monitoramento de resíduos sólidos é um feedback negativo do ciclo de geração de resíduos evitando que o volume gerado se torne insustentável para a instituição. $\mathrm{O}$ ponto 6 , complementando, tem um poder de alavancagem maior, pois a estrutura do fluxo de informações, cria um ciclo de entrega de informações onde antes não havia, portanto, pode fazer com que as pessoas se comportem de maneira diferente.

A exemplo do campus, no processo participativo os participantes tomaram conhecimento do volume e classificação dos resíduos gerados no campus para embasar a inclusão de propostas e sugestões para o planejamento institucional. Essa informação em geral estava dispersa em relatórios ou banco de dados.

O ponto 5 - as regras do sistema - a autora diz que se quiser entender o mal funcionamento de um sistema, preste atenção às regras, e quem tem poder sobre elas. Neste sentido, já estamos saindo da alçada dos planos, pois eles pretendem seguir as regras vigentes durante a sua formulação e consideram que estas regras ainda estarão em vigor quando o prazo estipulado for atingido.

Os planos de universidades como o PDInfra, por mais que haja autonomia universitária, existem regras (normas, leis, decretos...) que não podem ser ignorados, como por exemplo o zoneamento do Plano Diretor Estratégico do Município de São Paulo, leis orçamentárias, entre outras.

Dentro da estrutura acadêmica, no entanto, a instituição tem poder de criar regras, ou regimentos internos, para normatizar procedimentos, regrar o uso de espaço, entre outras. Estas atribuições são essencialmente políticas, pois são definidas e debatidas em comissões antes de serem apreciadas pelos Conselhos Centrais de deliberação ou mesmo pela Reitoria.

O ponto 4 - O poder de adicionar, mudar, evoluir, ou auto organizar uma estrutura do sistema - esta categoria compreende o poder de modificar qualquer aspecto dos pontos anteriores. Como a autora sublinha, se um sistema biológico, cultural, social ou econômico se torna rígido o suficiente para não evoluir, a longo prazo não estará apto a sobreviver neste planeta (MEADOWS, 1999). 
No contexto das universidades, cada uma tem uma estrutura organizacional mais ou menos rígida, no entanto, a auto-organização de uma instituição não ocorre de maneira tão orgânica quanto o nome sugere, sendo necessário trabalhar com consensos mínimos ao menos nas instancias de decisão. O que mostra que este poder é um poderoso ponto de alavancagem, mas é necessário antes de tudo, o querer mudar.

O que leva ao ponto 3 - Os objetivos do sistema - a autora verifica que em um sistema, mudar elementos da base gera pouca mudança. Quem tem o poder de mudar os objetivos do sistema, muda toda uma cadeia que inclui todos os pontos anteriores.

As universidades, e as cidades em que estão situadas, são sistemas com qual ou quais objetivos? Em termos gerais, se o objetivo fosse cumprir os Objetivos do Desenvolvimento Sustentável, o que inclui metas relacionadas à educação, à saúde, justiça social, entre outras, o planejamento e a estrutura organizacional seriam diferentes?

A autora menciona no ponto 2, A mentalidade ou paradigma nos quais o sistema, seus objetivos, estrutura, regras, atrasos, parâmetros surgem - como um importante ponto de alavancagem, pois independente das regras e estruturas da organização, sempre é possível ter meios de burla-los. Os paradigmas geram os sistemas, cujos objetivos, fluxos de informações, estoques e todos outros pontos são considerados como "naturais" ou "reais" pelos acordos sociais compartilhados.

Paradigmas como crescimento econômico é positivo e que a natureza está disponível para a extração humana são algumas das presunções com as quais se construiu o sistema social no qual vivemos. E mesmo as ODS são frutos destes mesmos paradigmas, embora busquem um cenário mais equilibrado que o atual. Basta ver que há metas que incluem crescimento econômico, fortalecer instituições financeiras e ampliar a industrialização.

No que se refere às universidades e sua relação com as cidades, a formação e o espaço de debate de ideias podem ter alguma influência na mentalidade predominante, embora se questione o alcance destas discussões frente à dispositivos de comunicação de massa e discursos oficiais.

Por fim, no ponto 1 , o poder de transcender paradigmas - se refere à consciência de que nenhum paradigma é a "verdade", ou seja, de alguma forma alcançar objetivos através do paradigma escolhido, não de um em que se está inserido.

As instituições de uma maneira geral, não tem esse poder, pois são fruto de paradigmas. A capacidade de transcender paradigmas de indivíduos ou de coletivos dentro da universidade podem trazer alguma mudança ao próprio sistema universitário, embora, hipoteticamente, não seja possível realizar nada sem mínimos consensos. 
Concluindo, a referência dos "pontos de alavancagem" são importantes complementações aos estudos de metabolismo urbano, planejamento e sustentabilidade, pois verifica-se que há diferentes potencialidades nas ações institucionais visando a sustentabilidade.

Muitas ações elencadas em Planos Diretores, Planos de Desenvolvimento Institucional e Planos de Logística Sustentável, se referem à pontos com pouca alavancagem, principalmente do 12 ao 9. No entanto, nos planos com processos participativos, publicação ou outras formas de comunicação, há um ponto de alavancagem poderoso, que é o 6 , sobre a estrutura de fluxos de informação. Portanto, se justificam processos de planejamento, principalmente com produção e divulgação de informações, pois estes são até mais efetivos que o dimensionamento de estoques e de fluxos.

\subsection{POSSÍVEIS CONTRIBUIÇÕES DE PROJETOS URBANOS VISANDO A SUSTENTABILIDADE}

Como verificado anteriormente, no item 4.1, ações de universidades podem contribuir com a cidade e com o desenvolvimento sustentável, mais especificamente nos indicadores e metas das ODS.

Dentre as ações mais efetivas, destaca-se a contextualização do planejamento institucional com os fatores urbanos do seu entorno. E pelas referências estudadas e o próprio estudo de caso, a modalidade de plano diretor parece ser a mais assertiva dos tipos de planejamento. Porém, é importante fazer uma pequena distinção entre plano diretor e projeto urbano, que no decorrer do texto, possa ter parecido serem sinônimos.

O plano diretor, como plano produzido a partir de um diagnóstico científico para apresentar propostas de desenvolvimento socioeconômico e futura organização espacial (VILLAÇA, 1999) não necessariamente contempla um projeto urbano, ou seja, um esquema organizativo que oferece orientações necessárias para a sua execução (SABOYA, 2018).

Entre as referências, pode-se tomar como exemplo a diferença entre o plano diretor da UFMG e o plano diretor da Unifesp. Enquanto o primeiro contém a setorização das atividades, o que orienta a organização espacial, mas não define outras questões de transporte, de paisagismo ou de volumetria do ambiente construído. O estudo de caso, além da setorização de atividades, propõe novas dinâmicas com a cidade, abertura de espaços de acesso público, desenho de calçada, mobiliário urbano entre outras. 
Ou seja, projetos urbanos estão mais próximos da concretização que um plano diretor, embora estes possam ser componentes ou decorrência de um plano diretor. Além disso, a fase do diagnóstico que embasa as diretrizes do plano, é importante para propostas de projeto mais adequadas nos quesitos social, econômico e ambiental.

Um exemplo de como o diagnóstico é importante para o projeto urbano, é a constatação de que existem possibilidades de soluções consorciadas com outros geradores de resíduo sólido conforme preconiza a PNRS (BRASIL, 2010), em especial os resíduos de serviço de saúde (RSS) dos demais estabelecimentos de saúde presentes no bairro (em azul) com edifícios geridos pela Unifesp e que compartilham o fundo ou lateral de lotes (ver Figura 60).

Figura 60 - Destaque para locais propícios a soluções consorciadas

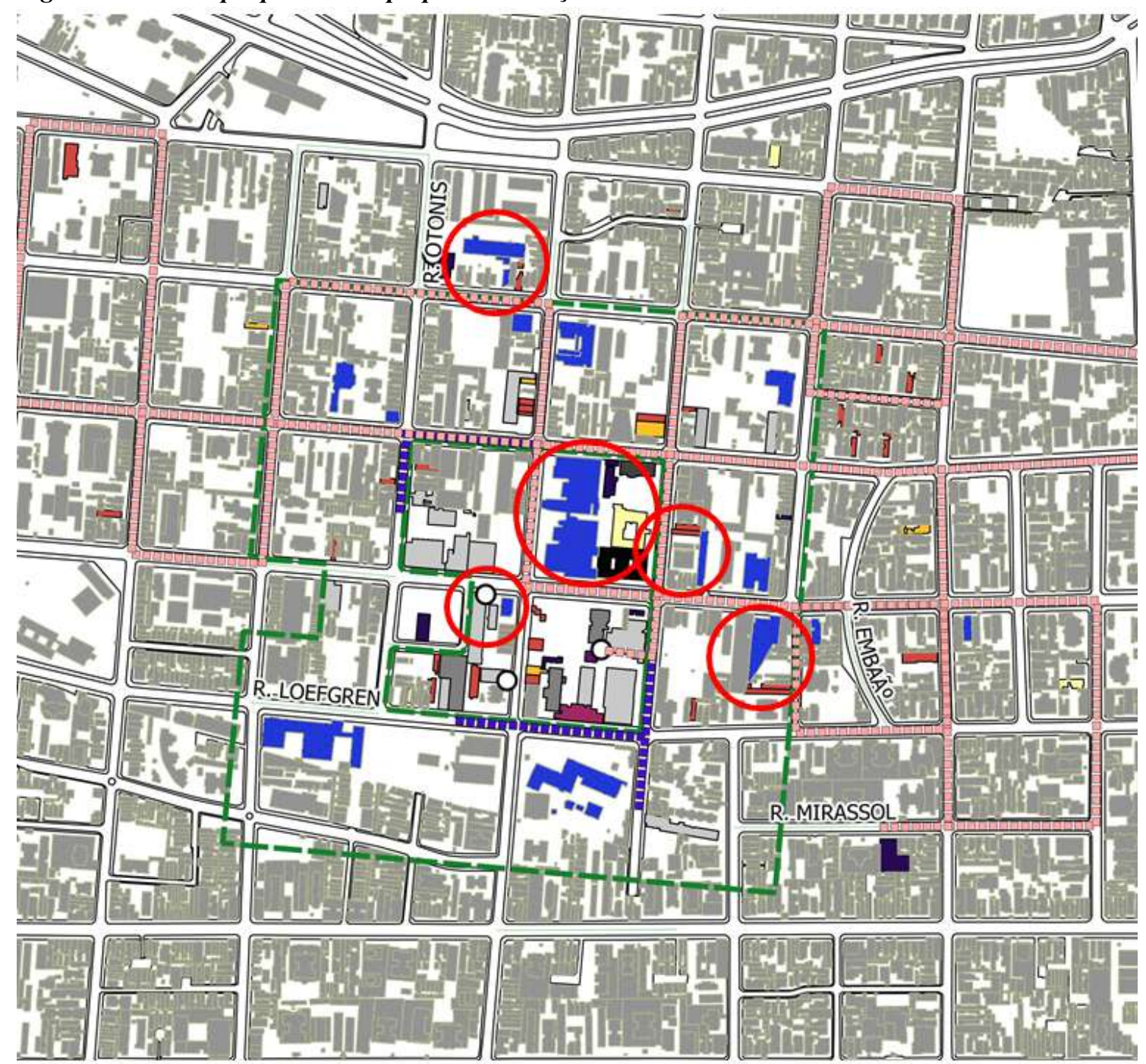




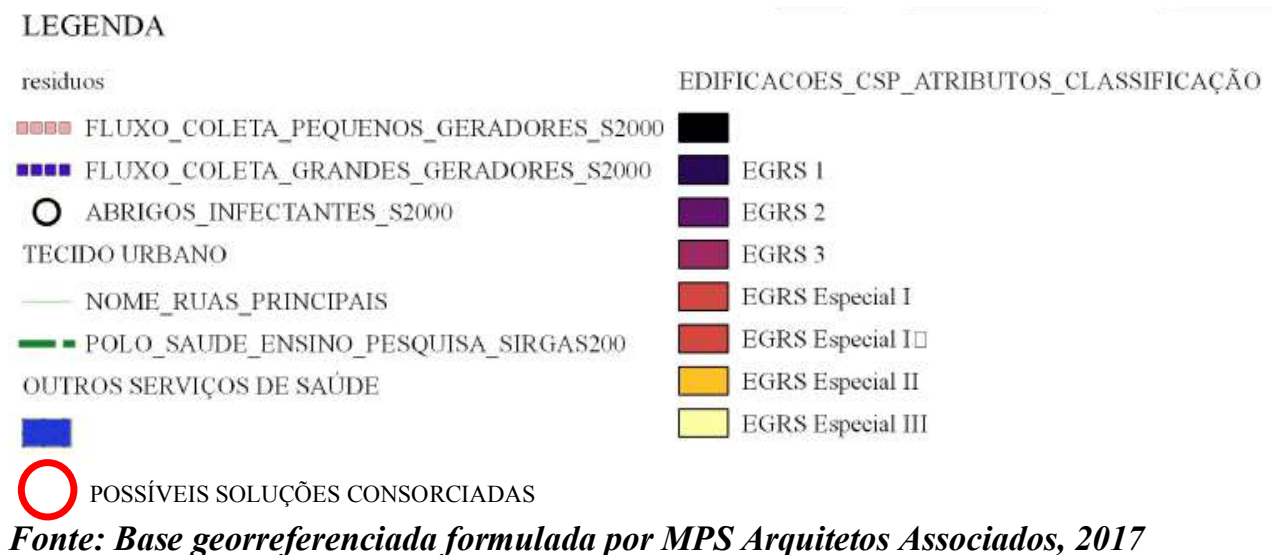

Passados os trâmites burocráticos (a pesquisa não encontrou referências de outras soluções consorciadas), é possível que soluções consorciadas de gestão de resíduos sólidos traga economia para todos os agentes, reduzindo custos de operação e de taxas de coleta e racionalize os procedimentos de coleta, de modo a reduzir o consumo de combustível nos trajetos de coleta e redução da exposição do trabalhador aos resíduos perigosos.

A contribuição de projetos urbanos com a sustentabilidade pode se dar também nas proposições para a cidade existente. Muitos exercícios projetuais consideram situações ideais em que se pode construir do zero estruturas que já serão adequadas e mais econômicas, porém não é o caso na maioria das vezes.

Instituições como as universidades, que já se encontram em áreas urbanizadas, podem contribuir com proposições que podem vir a ser referência para seus entornos, seja no quesito de urbanidade, de qualidade dos espaços, procedimentos e posturas que estejam mais alinhadas à sustentabilidade.

Os quesitos podem ser os já abordados pelas metas e indicadores dos ODS, mas nas próprias políticas locais podem ter metas associadas à sustentabilidade cuja contribuição das universidades é possível. No Município de São Paulo, desde 2008, o Poder Executivo é obrigado a publicar o Programa de Metas da cidade. E constatou-se que nas metas vigentes (2017-2020) há itens relacionados também aos ODS ${ }^{109}$.

Portanto, o plano diretor e seus projetos urbanos contextualizados com o entorno, podem revelar potencialidades de consórcio, parceria ou interações que sejam interessantes para a instituição e para a sociedade. Materializar essas intenções na forma de projetos para dialogar com outros entes públicos e privados é uma forma de integração do território universitário com o entorno e com outros setores da comunidade, podendo promover preceitos da sustentabilidade.

${ }^{109} \mathrm{http} / /$ planejasampa.prefeitura.sp.gov.br/assets/Programa-de-Metas_2017-2020_Final.pdf 


\section{CONSIDERAÇÕES FINAIS}

Constatou-se que as propostas do Plano Diretor de Infraestrutura do Campus São Paulo da Universidade Federal de São Paulo contribuem com aspectos do desenvolvimento sustentável, que podem ser verificados nas metas e indicadores dos Objetivos do Desenvolvimento Sustentável (ODS) 03, 11 e 12, referentes a saúde e bemestar, cidades sustentáveis e consumo e produção responsáveis, respectivamente.

Esta constatação se dá pela análise de referencias de outros planos e de seus instrumentos de planejamento. Não é incomum que universidades incorporem, quando fazem planos diretores, o contexto urbano do entorno para problematizar e propor novas relações com seus bairros e cidade, seja como um espaço de experimentações urbanas, como espaço de referência ou como indutor de revitalização ou transformações urbanas.

Apesar de não ser um instrumento de planejamento restrito à arquitetura e urbanismo, o plano diretor como encontrado nas referencias selecionadas segue as premissas e linguagem arquitetônica. E se mostrou o instrumento, entre os três selecionados, mais adequado à proposição de soluções efetivas voltadas à sustentabilidade, por ser baseado em diagnósticos científicos e poder incorporar diversas bases de informação atreladas à um espaço urbano que é finito.

A incorporação do diagnóstico de resíduos sólidos no plano diretor do Campus São Paulo da Unifesp se mostrou um instrumento inédito dentro da amostra de planos analisados. E verifica-se que resíduos sólidos podem ser elementos integradores de qualquer plano, pois atividades humanas de qualquer natureza geram resíduos.

Especialmente no caso do Campus São Paulo, que é um campus ligado ao ensino, pesquisa e extensão em saúde, utilizar nas bases de planejamento os dados de gerenciamento de resíduos de serviço de saúde revela o caráter multidimensional deste instrumento. Resíduos de serviço de saúde são produtos de um importante serviço à população, porém o gerenciamento incorreto destes resíduos oferece riscos à saúde do trabalhador, contaminação ambiental e infecção.

O diagnóstico também pode embasar decisões de planejamento, ao orientar a reorganização do espaço construído juntando atividades que produzem resíduos do mesmo grupo de classificação, cujo resultado é o aprimoramento dos processos de segregação, acondicionamento, coleta, armazenamento e transporte, destinação e disposição final, que fazem parte do gerenciamento de resíduos sólido. Este aprimoramento reduz custos para a instituição com pagamento de taxas por faixa de 
geração e também reduz o impacto ambiental e risco à saúde por contato com estes resíduos perigosos.

Outra forma de se visualizar as transformações ocorridas na instituição (ou cidade) que produzem os resíduos, em outras palavras, do metabolismo urbano, é a análise de fluxo de materiais. Apesar de não ser uma ferramenta utilizada nos planos diretores referenciados, ao produzir uma versão preliminar de MFA constatou-se que este pode ser um instrumento válido para planejamento institucional, não apenas de cidades.

A visualização do sistema por meio de diferentes tipos de diagramas e mapas, permite rápidos diagnósticos e facilmente identificar lacunas de informação, atividades ou processos que devem ser priorizados nas ações institucionais e outras decisões de gestão. A organização destas atividades e processos influencia na sua localização e viceversa. Portanto, a visualização de fluxos de materiais pode interagir com o planejamento do patrimônio construído.

Um instrumento de planejamento que permite que reorganização de atividades e espaços sejam propostos e incorporados à estrutura organizacional da instituição com mínimos consensos, é o processo participativo. Constatou-se que o processo participativo informa as especificidades e desafios da instituição enquanto coleta demandas e constrói propostas. É um instrumento essencial para a comunicação com a comunidade e adesão desta aos objetivos e valores institucionais.

E é a estrutura de fluxo de informações o ponto mais efetivo em se aplicar esforços no contexto do PDInfra, conforme metodologia dos "pontos de alavancagem", em razão da informação ter o potencial de mudar comportamentos e consequentemente, toda a cadeia de ações decorrentes será impactada positivamente.

A efetividade de um planejamento da universidade é um fator que contribui para a sua sustentabilidade. Por este motivo, recomenda-se que as universidades realizem planos que considerem também sua geração de resíduos e que a comunidade acadêmica e a sociedade como um todo se envolvam neste assunto. De modo que esse dialogo resulte na compreensão mais ampla deste componente dos determinantes sociais da saúde, ao tratar destes aspectos ambientais, comportamentais e sociais, se está melhorando também o bem-estar e saúde de todos.

O estudo de caso do Plano Diretor de Infraestrutura do Campus São Paulo da Unifesp feito nesta Dissertação, pode contribuir em três aspectos para futuras pesquisas ou processos. O primeiro é a respeito de morfologia, uso e ocupação de solo de instituições universitárias, sejam elas públicas ou privadas. A segunda é referente ao levantamento e adaptação de metodologias específicas para gerenciamento de resíduos de serviço de saúde. E a terceira envolve ferramentas de gerenciamento, que podem 
embasar o planejamento e aprimorar os procedimentos operacionais dentro das organizações.

Considerando as contribuições desta pesquisa e outros pontos expostos, abrem-se novas frentes de investigação a partir desta dissertação, incluindo outros componentes que podem ser elementos integradores de planejamento, como consumo de água, energia e outros fluxos de materiais dentro do metabolismo urbano. De modo que estudos futuros construam novos conhecimentos de maneira interdisciplinar acerca da universidade, cidade e saúde. 


\section{REFERENNCIAS}

ABNT. NB 1350 - Normas para elaboração de plano diretor. Rio de Janeiro. 1991.

ABNT. NBR 10.004. Rio de Janeiro. 2004.

ANVISA. Resolução da Diretoria Colegiada - RDC n 222. Brasilia. 2018.

ARAÚJO, V. S. D. Gestão de Resíduos especiais em universidades: Estudo de caso da Universidade Federal de São Carlos, Campus São Carlos. São Carlos: Universidade Federal de São Carlos, 2002.

ATCON, R. P. Manual sobre planejamento integral do campus universitário. In:

Administração integral universitária: uma teoria unificada da estruturação $\mathrm{e}$ administração universitárias. Brasilia: MEC, 1974. p. 155-249.

BORSI, K.; SCHULTE, C. Universities and the City: from islands of knowledge to districts of innovation. The Journal of Architecture, p. 1143-1180, 2018.

BRAMATTI, D. Veja mapa dos estrangeirismo nos edifícios de São Paulo. Blog do Estadão Dados, São Paulo, nov 2016. Disponivel em: $<$ http://blog.estadaodados.com/veja-o-mapa-dos-estrangeirismos-nos-edificios-de-saopaulo/ > . Acesso em: jan 2019.

BRASIL. LEI No 10.257, DE 10 DE JULHO DE 2001. Estatuto da Cidade, 10 jul 2001.

BRASIL. Estatuto da Cidade: guia para implementação pelos municípios e cidadadãos. Brasília. 2002.

BRASIL. Decreto Nº 5.773 DE 9 DE MAIO DE 2006, Brasília, 2006.

BRASIL. Lei N ${ }^{\circ}$ 12.305, DE 2 DE AGOSTO DE 2010. Política Nacional de Resíduos Sólidos, 10 ago 2010.

BRASIL. LEI N ${ }^{o}$ 12.527, DE 18 DE NOVEMBRO DE 2011. Lei de Acesso à Informação, Brasília, nov 2011.

BRASIL. DECRETO Nº 7.746 DE 5 DE JUNHO DE 2012, Brasilia, 2012.

BRUNNER, P. H.; RECHBERGER, H. Practical Handbook of Material Flow Analysis. [S.1.]: Taylor \& Francis e-Library, 2005.

CAPPON, D. Indicators for a Healthy City. Environmental Management and Health, 1, n. 1, 1990. 9-18.

CARVALHO, A. I. D. Determinantes sociais, econômicos e ambientais da saúde. In: 
FIOCRUZ, et al. A saúde no Brasil em 2030 - prospecção estratégica do sistema de saude brasileiro: população e perfil sanitário. Brasília: Scielo Books, 2013. p. 19-38.

COLOSSO, P. A crítica de Henri Lefebvre ao urbanismo moderno. XIV Seminário de História da cidade e do urbanismo. [S.1.]: [s.n.]. 2016.

CUNHA, L. A. Campus universitário: opção ou destino? In: MORHY, L. Universidade em Questão. Brasilia: Editora UnB, 2003.

DINARÈS, M. Urban Metabolism: A review of recent literature on the subject. Documents d'Anàlisi Geogràfica, 2014.

EPM. Plano Geral de Desenvolvimento Físico. Escola Paulista de Medicina. [S.1.]. 1982.

GÜNTHER, W. M. R. Resíduos Sólidos no Contexto da Saúde Ambiental. São Paulo: Faculdade de Saúde Pública, 2008.

GIL, A. C. Como elaborar projetos de pesquisa. 4 ed. ed. São Paulo: Atlas, 2008.

GONTIJO, C. E. D. O. Os Planos Diretores sob a óptica do Desenvolvimento sustentável e cidade saudável: o estudo nos Municípios de Ituiutaba e Uberlândia - MG. Ituiutaba, MG: Universidade Federal de Uberlândia, 2017.

GTBU. Bairro Universitário - Projeto Urbanístico Preliminar, São Paulo, 2010. Disponivel em: $<$ https://www.prefeitura.sp.gov.br/cidade/secretarias/upload/infraestrutura/cec/arquivos/ 2011_mai_bairro-universitario.pdf $>$. Acesso em: Julho 2017.

HARTE, N.; NORTH, J.; BREWIS, G. The World of UCL. Londres: UCL Press, 2018.

IBGE, 2017. Disponivel em: <https://www.ibge.gov.br/estatisticasnovoportal/sociais/populacao/9103-estimativas-de-

populacao.html?edicao $=9112 \& \mathrm{t}=$ resultados $>$. Acesso em: Junho 2017.

INTER-AGENCY AND EXPERT GROUP ON SDG INDICATORS (IAEG-SDGS). Global indicator framework for the Sustainable Development Goals and targets of the 2030 Agenda for Sustainable Development. Nova Iorque. 2017.

IPEA/SNI. Objetivos de Desenvolvimento do Milênio: Relatório Nacional de Acompanhamento. Brasília. 2014.

JOHNS HOPKINS UNIVERSITY. 2008 Homewood Campus Plan Update. Baltimore. 2009.

KARVOUNIS, A. Urban metabolism. In: CHRYSOULAKIS, N.; CASTRO, A. D.; MOORS, E. J. Understanding Urban Metabolism - A tool for urban planning. Nova York: Routledge, 2015. 
KENNEDY, C.; PINCETL, S.; BUNJE, P. The study of urban metabolism and its applications to urban planning and design. Environmental Pollution, p. 1965-1973, 2011.

MEADOWS, D. Leverage Points: Places to Intervene in a System. Hartland. 1999.

MENEGON, L. N. D. O lixo hospitalar oftalmológico poderá ser reutilizado? São Paulo: Universidade Federal de São Paulo, 2016.

MIKHAILOVA, I. Sustentabilidade: Evolução dos conceitos teóricos e os problemas de mensuração prática. Revista Economia e Desenvolvimento, Santa Maria, n. 16, 2004.

NAREDO, J. M. La economía en evolición: invento y configuración de la economía en los siglos XVIII y XIX y sus consecuencias actuales. Manuscrits 22, p. 83-117, 2004.

NYU. A University as Great as Its City: NYU's Strategy for Future Growth. New York. 2008.

NYU. A Brief History of New York University. New York University, 2018. Disponivel em: $\quad<$ https://www.nyu.edu/faculty/governance-policies-and-procedures/facultyhandbook/the-university/history-and-traditions-of-new-york-university/a-brief-historyof-new-york-university.html>. Acesso em: 28 nov. 2018.

OLIVEROS, J. C. Venny. An interactive tool for comparing lists with Venn's diagrams., 2007-2015. Disponivel em: <http://bioinfogp.cnb.csic.es/tools/venny/index.html $>$. Acesso em: 2018.

ONU. Relatório Nosso Futuro Comum. [S.1.]. 1987.

ONU. Transformando Nosso Mundo: A Agenda 2030 para o Desenvolvimento Sustentável, 2015. Disponivel em: <https://nacoesunidas.org/wpcontent/uploads/2015/10/agenda2030-pt-br.pdf $>$.

ORNE, J.; DOORIS,. Integrating health and sustainability: the higher education as a timely catalyst. Health Education Research, v. 25, p. 425-437, 2010.

PREFEITURA DE SÃO PAULO. Gestão Urbana SP, 2016. Disponivel em: $<$ https://gestaourbana.prefeitura.sp.gov.br/marco-regulatorio/zoneamento/entenda-ozoneamento/>. Acesso em: set 2018.

PREFEITURA DE SÃO PAULO. Parcelamento, Uso e Ocupação do Solo: Lei $\mathbf{n}^{0}$ 16.402, de 22 de março de 2016. São Paulo. 2016.

RIBEIRO, H. Saúde Pública e Meio Ambiente: evolução do conhecimento e da prática, alguns aspectos éticos. Saúde e Sociedade, p. 70-80, 2004.

RUBERG, C. et al. RESÍDUOS SÓLIDOS GERADOS NA UNIVERSIDADE FEDERAL DO PAMPA - CAMPUS DE SÃO GABRIEL/RS: ESTIMANDO A 
GERAÇÃO PER CAPITA. $25^{\circ}$ Congresso Brasileiro de Engenharia Sanitária e Ambiental. São Cristóvão: Universidade Federal de Sergipe. 2009.

SABOYA, R. T. D. Urbanidades, 02 jun. 2018. Disponivel em: $<$ http://urbanidades.arq.br/2008/06/o-que-e-plano-diretor/>.

SACHS, I. Caminhos para o Desenvolvimento Sustentável. Rio de Janeiro: Garamond, 2002.

SANTOS, N. M. D. Gerenciamento integrado de resíduos sólidos: Estudo de caso no Instituto Butantan. São Paulo: Universidade de São Paulo, 2015.

SEDGHI, A. London's rail system animated in 60 seconds. The Guardian, 2014. Disponivel em: <https:/www.theguardian.com/news/datablog/nginteractive $/ 2014 / \mathrm{mar} / 18 /$ londons-rail-system-animated-in-60-seconds $>$. Acesso em: jan 2019.

SILVA, J. A. Direito urbanístico brasileiro. São Paulo: Malheiros, 1995.

SILVEIRA, D. V. D. et al. O paradigma da segregação dos campi universitários no Brasil: Distanciamento físico e implicações sociais. Urbi centros \#3, Salvador, 2012. Disponivel em: <www.ppgau.ufba.br/urbicentros/2012/ST258.pdf>. Acesso em: Junho 2017.

SNIS. Diagnóstico do Manejo de Resíduos Sólidos Urbanos - 2016. Brasília. 2018.

TAUCHEN, J.; BRANDLI, L. L. a GESTÃO AMBIENTAL EM INSTITUIÇÕES DE ENSINO SUPERIOR: MODELO PARA IMPLANTAÇÃO EM CAMPUS UNIVERSITÁRIO. GESTÃo \& PRODUÇÃO, 13, n. 3, set-dez 2006. 503-515.

TAYLOR, L. A. et al. Leveraging the social determinants of Health: what works? Blue Cross Blue Shield of Massachusetts Foundation. Massachusetts. 2005.

UCL. UCL Bloomsbury Masterplan. Londres. 2011.

UFAL. Plano de Desenvolvimento Institucional, 2013. Disponivel em: $<$ https://ufal.br/transparencia/institucional/plano-de-desenvolvimento/2013-2017>. Acesso em: julho 2018.

UFAM. Plano de Desenvolvimento Institucional, 2016. Disponivel em: $<$ http://www.sic.ufam.edu.br/SIC/arquivos_sic/pdi_2016-2025.pdf $>$. Acesso em: julho 2018.

UFBA. Plano Diretor de Desenvolvimento Físico e Ambiental da Universidade Federal da Bahia 2009. Disponivel em: $<$ https://www.ufba.br/sites/portal.ufba.br/files/univers_nova.pdf $>$. Acesso em: julho 2018 . 
UFBA. Plano de Logistica Sustentável, 2016. Disponivel em: $<$ https://proplan.ufba.br/sites/proplan.ufba.br/files/pls_ufba_diagnostico_arquivo_junho _2016.pdf>. Acesso em: julho 2018.

UFBA. Plano de Desenvolvimento Institucional , 2018. Disponivel em: $<$ https://www.ufba.br/sites/portal.ufba.br/files/plano-desenvolvimento-institucionalufba_web_compressed.pdf >. Acesso em: julho 2018.

UFC. Plano de Logistica Sustentável, 2013. Disponivel em: $<$ http://www.ufc.br/images/_files/gestao_ambiental/plano_de_logistica_sustentavel_ufc. pdf $>$. Acesso em: julho 2018 .

UFC. Plano de Logística Sustentável da Universidade Federal do Ceará. Fortaleza. 2013.

UFC. Plano de Desenvolvimento Institucional, 2018. Disponivel em: $<$ http://www.proplad.ufc.br/wp-content/uploads/2017/12/resultados-consolidados-201712-15.pdf>. Acesso em: julho 2018.

UFG. Plano de Desenvolvimento Institucional, 2011. Disponivel em: $<$ https://www.prodirh.ufg.br/n/5163-publicacao-on-line-do-pdi-2011-2015-da-ufg >. Acesso em: julho 2018.

UFG. Plano de Logistica Sustentável, 2014. Disponivel em: $<$ https://sustentabilidade.prodirh.ufg.br/up/676/o/original_Site_PLS-UFG_20142015.pdf >. Acesso em: julho 2018.

UFMA. Plano de Logistica Sustentável, 2014. Disponivel em: $<$ http://www.ufma.br/portalUFMA/arquivo/DoGRffJ0NArQL0N.pdf >. Acesso em: julho 2018.

UFMA. Plano de Desenvolvimento Institucional, 2017. Disponivel em: $<$ http://www.ufma.br/portalUFMA/arquivo/puwEW8dc9aoshs4.pdf $>$. Acesso em: julho 2018.

UFMG. Resolução No 08/2009 - Institui o Regulamento de Uso e Ocupação do Campus da Pampulha da UFMG. Belo Horizonte. 2009.

UFMG. Plano de Desenvolvimento Institucional, 2013. Disponivel em: $<$ https://www.ufmg.br/dai/textos/PDI_UFMG\%202013_2017.pdf $>$. Acesso em: julho 2018.

UFMS, $2015 . \quad$ Disponivel em: $<$ http://novopdi.ufms.br/index.php?section=download\&page $=2>$. Acesso em: julho 2018 . 
UFMS. Plano de Logistica Sustentável, 2016. Disponivel em: $<$ https://proadi.ufms.br/files/2015/02/PLS_Relat\%C3\%B3rio_final_2016-1.pdf >. Acesso em: julho 2018.

UFPA. Plano de Logistica Sustentável, 2013. Disponivel em: $<$ https://ascom.ufpa.br/links/eventos/Minuta\%20Final\%20PLS.pdf $>$. Acesso em: julho 2018.

UFPA. Plano de Desenvolvimento Institucional, 2016. Disponivel em: $<$ https://portal.ufpa.br/images/docs/PDI_2016-2025.pdf > . Acesso em: julho 2018.

UFPE. Plano de Desenvolvimento Institucional, 2014. Disponivel em: <: https://www.ufpe.br/documents/38954/713399/pdi_14_18_of.pdf/28b6c0d5-ed53-44849936-1b8a9236e9ec>. Acesso em: julho 2018.

UFPE. Plano de Desenvolvimento Institucional 2014 - 2018. [S.1.]: [s.n.], 2015.

UFPR. Plano de Logistica Sustentável, 2016. Disponivel em: $<$ http://www.suinfra.ufpr.br/portal/dga/wp-content/uploads/sites/5/2017/01/Plano-deLog\%C3\%ADstica-Sustent\%C3\%A1vel-da-UFPR.pdf>. Acesso em: julho 2018.

UFPR. Plano de Logística Sustentável de UFPR. Curitiba. 2016.

UFPR. Plano de Desenvolvimento Institucional, 2017. Disponivel em: <: http://www.prograd.ufpr.br/portal/copeg/wp-content/uploads/sites/3/2013/08/PDI-20172021-Vers\%C3\%A3o-Parcial.pdf>. Acesso em: julho 2018.

UFRGS. Plano de Desenvolvimento Institucional, 2016. Disponivel em: $<$ http://www.ufrgs.br/pdi/pdi-2016-2026>. Acesso em: julho 2018.

UFRGS. Plano de Logistica Sustentável, 2016. Disponivel em: $<$ http://www.ufrgs.br/ufrgs/a-ufrgs/plano-de-logistica-sustentavel $>$. Acesso em: julho 2018.

UFRJ. Plano Diretor UFRJ 2020. Rio de Janeiro. 2009.

UFRJ. Plano de Desenvolvimento Institucional, 2018. Disponivel em: $<$ https://ufrj.br/docs/PDI.pdf $>$. Acesso em: julho 2018.

UFRN. Plano de Desenvolvimento Institucional, 2010. Disponivel em: $<$ https://www.ufrn.br/resources/documentos/pdi/PDI-2010-2019-final.pdf $>$. Acesso em: julho 2018.

UFRN. Plano de Logistica Sustentável, 2017. Disponivel em: $<$ https://www.ufrn.br/resources/documentos/planos/plano_de_Gestao_de_Logistica_Sus tentavel-PLS.pdf $>$. Acesso em: julho 2018.

UFSC. Plano Diretor do Campus da UFSC. Florianópolis. 2005. 
UFSC. Universidades sustentáveis, 2015. Disponivel em: $<$ http://ufscsustentavel.ufsc.br/universidades-sustentaveis/>. Acesso em: julho 2018.

UNB. PLANO DIRETOR FÍSICO DO CAMPUS UNIVERSITÁRIO DARCY RIBEIRO. Brasilia. 1998.

UNB. Plano de Desenvolvimento Institucional 2018-2022. Brasilia: [s.n.], 2017.

UNB. Plano de Desenvolvimento Institucional, 2018. Disponivel em: $<$ http://www.deg.unb.br/images/dtg/cil/legislacoes/Plano_de_Desenvolvimento_Instituc ional_2018-2022.pdf>. Acesso em: julho 2018.

UNB. Plano de Logistica Sustentável. Brasilia. 2018.

UNB. Plano de Logistica Sustentável, 2018. Disponivel em: $<$ https://www.noticias.unb.br/images/20180606PLSVersaoFinal.pdf $>$. Acesso em: juho 2018.

UNIFESP. Plano Diretor de Infraestrutura do Campus Diadema. São Paulo: Universidade Federal de São Paulo, 2014.

UNIFESP. Plano Diretor de Infraestrutura do Campus Baixada Santista. São Paulo. 2015.

UNIFESP. Plano de Desenvolvimento Institucional 2016-2020. São Paulo: [s.n.], 2016.

UNIFESP. Plano de Logistica Sustentável, 2017. Disponivel em: $<$ http://www.unifesp.br/reitoria/dga/images/PLS/Documentos/PLS-

UNIFESP\%202017.pdf > . Acesso em: julho 2018.

VILHENA, A. Lixo municipal: manual de gerenciamento integrado. São Paulo: CEMPRE, 2018.

VILLAÇA, F. O município no século XXI: cenário e perspectivas. CEPAM, São Paulo, 1999. 237-247.

VILLENEUVE, J. et al. MFA-Manual: Guidelines for the Use of Material Flow Analysis (MFA) for Municipal Solid Waste (MSW) Management. Resource Management Agency (RMA), 2004. Disponivel em: <rma.at/en/node/938>.

WHO REGIONAL OFFICE FOR EUROPE. City health planning: the framework. Copenhagen: [s.n.], 1996.

ZHANG, Y. Urban metabolism: A review of research methodologies. Environmental Pollution, 2013. 


\section{PRODUTO PROFISSIONAL}

A proposta deste Mestrado Profissional é de apresentar, além da dissertação, um produto de aplicação profissional afim com o tema pesquisado. O produto desenvolvido é um mapa interativo do Campus São Paulo com informações do diagnóstico de resíduos sólidos.

O mapa está disponível no link provisório:

https://unifesp-infra.carto.com/builder/96c04979-3a96-431c-a8cf-d37730cca4af/embed 


\section{LISTA DE ILUSTRAÇÕES}

Figura 1 - Mapa interativo mostrando a evolução do sistema de trens de Londres..... 217

Figura 2 - Mapa interativo de São Paulo - nomes estrangeiros nos edifícios.............. 217

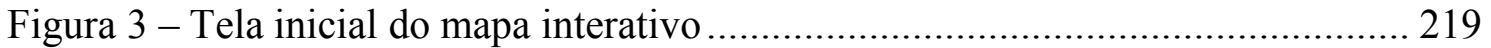

Figura 4 - Elementos da plataforma................................................................... 219

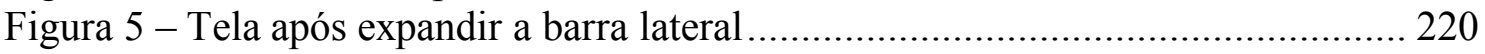

Figura 6 - Tela com o máximo de zoom disponível .......................................... 220

Figura 7 - Tela com a camada de resíduos infectantes habilitada. ........................... 221

Figura 8 - Tela com a camada de resíduos químicos habilitada............................. 222

Figura 9 - Tela com a camada de resíduos comuns habilitada.............................. 222

Figura 10 - Tela com o campus inteiro - widget completo ................................... 223

Figura 11 - Tela com trecho do campus - widget interage com as informações......... 224

Figura 12 - Tela do funcionamento da ferramenta "Auto Style"...............................2225

Figura 13 - Tela do funcionamento da ferramenta "Zoom" .................................... 225

Figura 14 - Tela do zoom ativado - novo gráfico aparece ....................................... 226

Figura 15 - Tela do zoom ativado - seleção de um valor específico ......................... 227

Figura 16 - Telas da versão mobile do mapa......................................................... 227

\section{SUMÁRIO}

PRODUTO PROFISSIONAL ..................ERROR! BOOKMARK NOT DEFINED. LISTA DE ILUSTRAÇÕES ................... ERROR! BOOKMARK NOT DEFINED. SUMÁRIO .........................................ERROR! BOOKMARK NOT DEFINED. INTRODUÇÃO .......................................ERROR! BOOKMARK NOT DEFINED. PRODUTO .......................................ERROR! BOOKMARK NOT DEFINED. REFERÊNCIAS ..................................ERROR! BOOKMARK NOT DEFINED. 


\section{5}




\section{INTRODUÇÃO}

Um mapa como representação gráfica de uma área do espaço, podem ter atribuídos valores a áreas, segmentos e pontos. Podemos dizer também que o mapa é uma forma de comunicação, sendo uma ferramenta capaz de sintetizar uma grande quantidade de informações de forma visual.

Utilizando a base georreferenciada desenvolvida para o PDInfra pela empresa MPS Arquitetos Associados, foram selecionadas algumas informações de interesse público referentes ao diagnóstico de resíduos sólidos, apresentados no capítulo 4 desta dissertação. As informações também constarão nas publicações do PDInfra após a aprovação do plano pelas instâncias de decisão da Universidade.

A inovação na forma de apresentar o mapa está na possibilidade selecionar a informação que deseja destacar. Assim, as informações poderão ser acessadas de maneira mais intuitiva e facilitada do que na navegação tradicional buscando em relatórios.

Esta proposta está em conformidade com a Lei de Acesso à Informação (LAI) LEI N ${ }^{\circ}$ 12.527, DE 18 DE NOVEMBRO DE 2011. Como pode ser verificado no destaque das diretrizes da lei abaixo:

I - observância da publicidade como preceito geral e do sigilo como exceção;

II - divulgação de informações de interesse público, independentemente de solicitações;

III - utilização de meios de comunicação viabilizados pela tecnologia da informação; (BRASIL, 2011)

Mapas interativos tem sido utilizados de diversas formas por meios de comunicação, universidades e empresas. Para o jornal The Guardian foi produzido um mapa interativo com a linha do tempo da evolução do sistema de trens em Londres (ver Figura 1).

Neste mapa é possível visualizar a evolução como uma animação, selecionar o ano, escolher o enquadramento do mapa entre outros aspectos de interesse do usuário. 
Figura 1-Mapa interativo mostrando a evolução do sistema de trens de Londres.

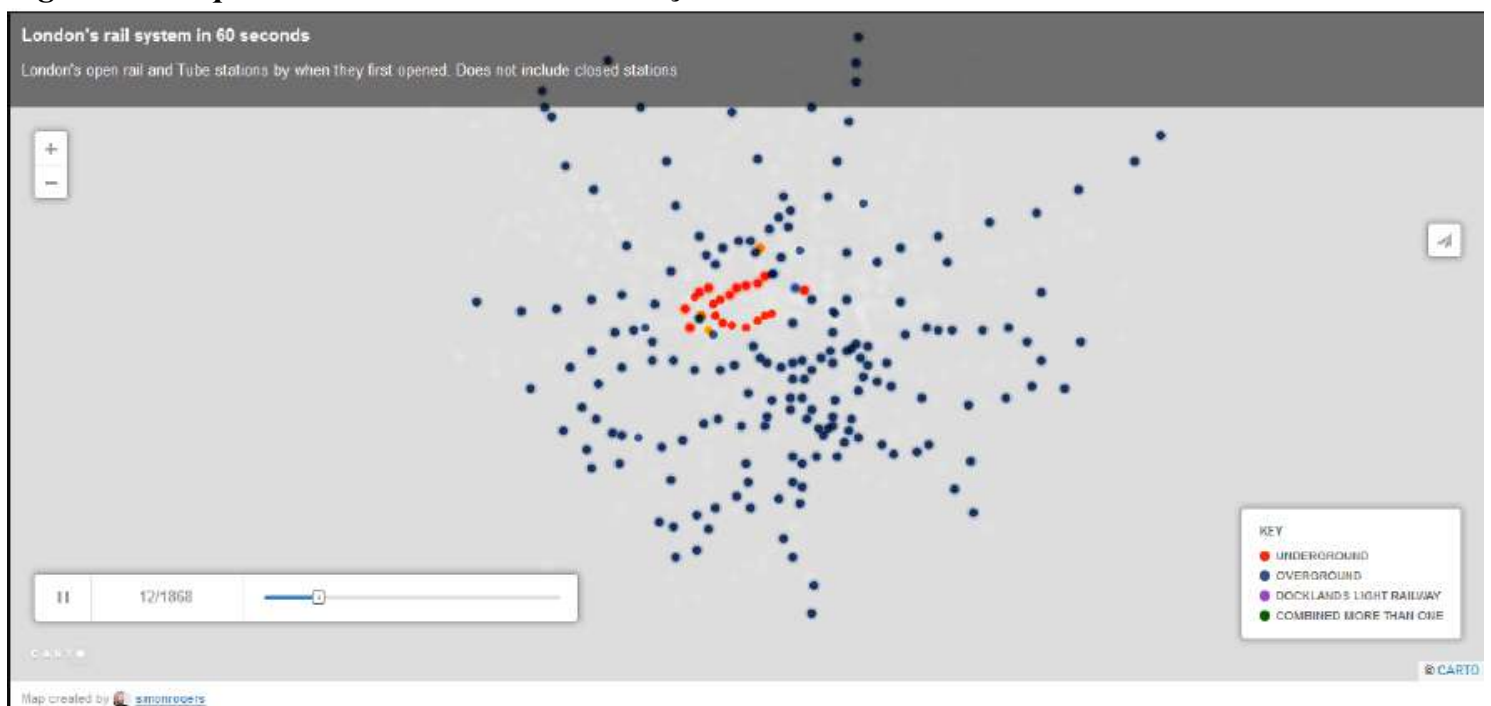

Fonte: https://www.theguardian.com/news/datablog/ng-interactive/2014/mar/18/londons-rail-systemanimated-in-60-seconds

Os mapas são "navegáveis", ou seja, não são estáticos, e informações e escalas podem ser selecionadas e apresentadas como "рор up", como na referencia de mapa de nomes estrangeiros nos edifícios do município de São Paulo (ver Figura 2).

Figura 2-Mapa interativo de São Paulo - nomes estrangeiros nos edifícios

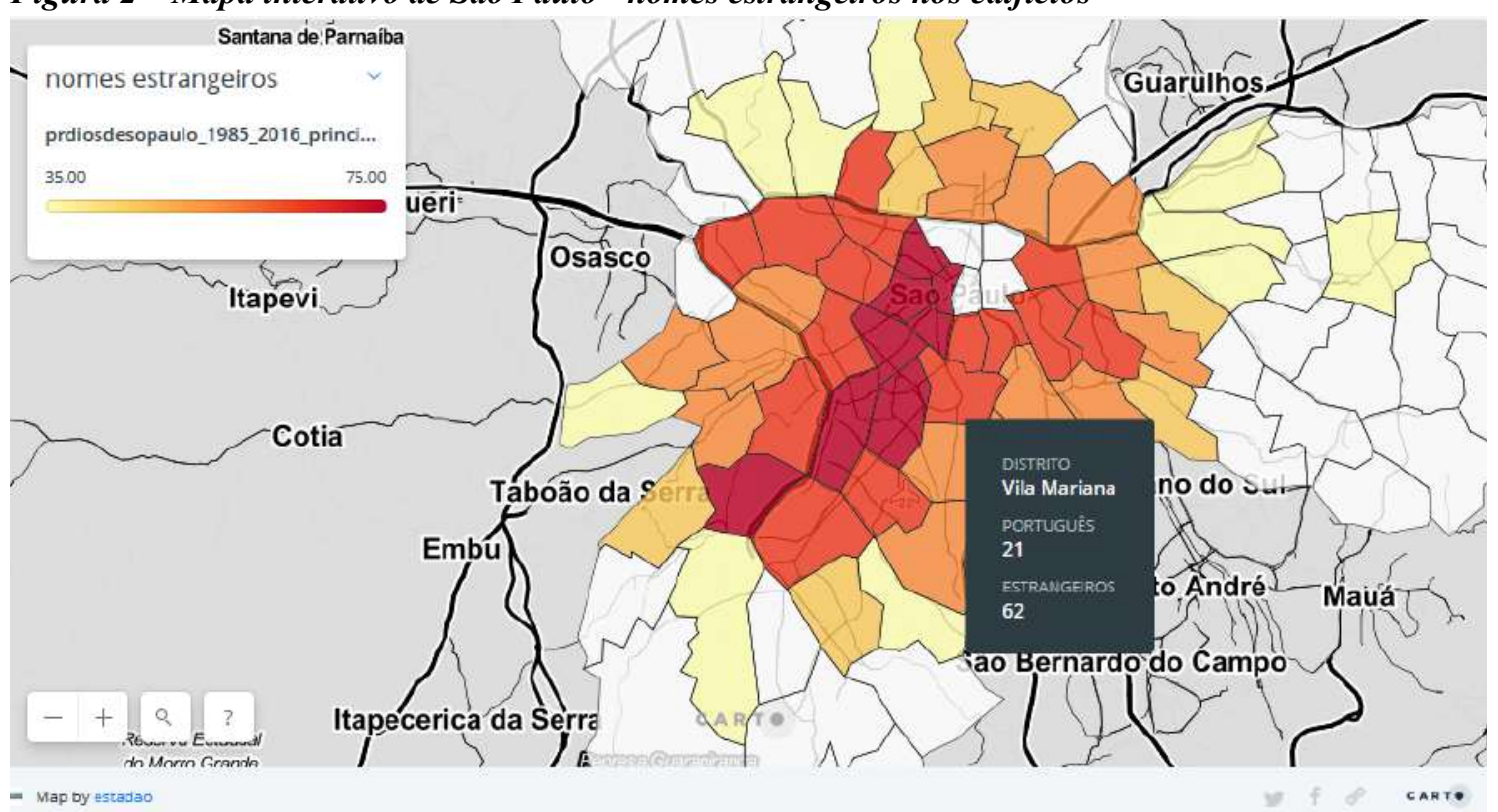

Fonte: http://blog.estadaodados.com/veja-o-mapa-dos-estrangeirismos-nos-edificios-de-sao-paulo/ 
Um mapa interativo, portanto, poderia ser utilizado por uma instituição ou empresa para divulgar publicamente e entre seus membros informações relevantes e de interesse geral. No exercício profissional, percebi que se questiona muito qual a área de um edifício, esta informação poderia ser disponibilizada facilmente em um mapa, por exemplo.

Como proposta profisssional de aplicação, portanto, buscou-se uma maneira criativa de utilizar essa ferramenta para apresentar dados que anteriormente estariam disponíveis apenas na forma estática e em relatórios.

\section{PRODUTO}

A base georreferenciada foi construída em um software livre chamado QGIS, porém para utiliza-lo é preciso ter o programa instalado, um conhecimento básico do seu funcionamento e todas as bases salvas no computador. Portanto, não atende ao proposto como mapa intuitivo e de fácil manuseio.

Para atender ao objetivo do produto proposto, o mapa deveria estar publicado em plataforma que não exija instalação de programa específico e que tenha uma interface simples e intuitiva, ou que possa ser adaptada para ser assim.

A plataforma CARTO é um serviço pago, porém oferece funcionalidades gratuitas limitadas pelo volume de dados ou de layers máximos por mapa. De qualquer forma, mesmo após adicionar diversas bases de dados, ainda foi possível trabalhar no site. O que pode futuramente ser um limitante é o número máximo de camadas possíveis na versão livre, que são 8. Para o mapa do produto foram utilizadas 6 camadas.

Para trabalhar na plataforma, antes de inserir as bases de dados, os arquivos de extensão .DBF .PRJ .QPJ .SHP E .SHX para leitura no programa QGIS, devem ser zipados para um arquivo único para conversão para extensão. .JSON que é reconhecida pela plataforma CARTO.

Foram colocadas na base de dados para formulação do mapa interativo uma camada "edificações Campus São Paulo" com informações referentes aos edifícios, entre eles os valores de geração de resíduos por categoria.

Todas as informações necessárias do diagnóstico já constavam nessa camada, porém, optou-se por criar mais três camadas com o mesmo conteúdo, mas com o nome de cada categoria de resíduo (infectante, químico e comum). Ao fazer isso, é possível criar um controle por camadas, podendo escolher qual resíduo que ficará em destaque. 
Ao acessar o link, a tela inicial já é o mapa do campus, enquadrado em uma escala que permita ver todo bairro (ver Figura 3).

\section{Figura 3 - Tela inicial do mapa interativo}

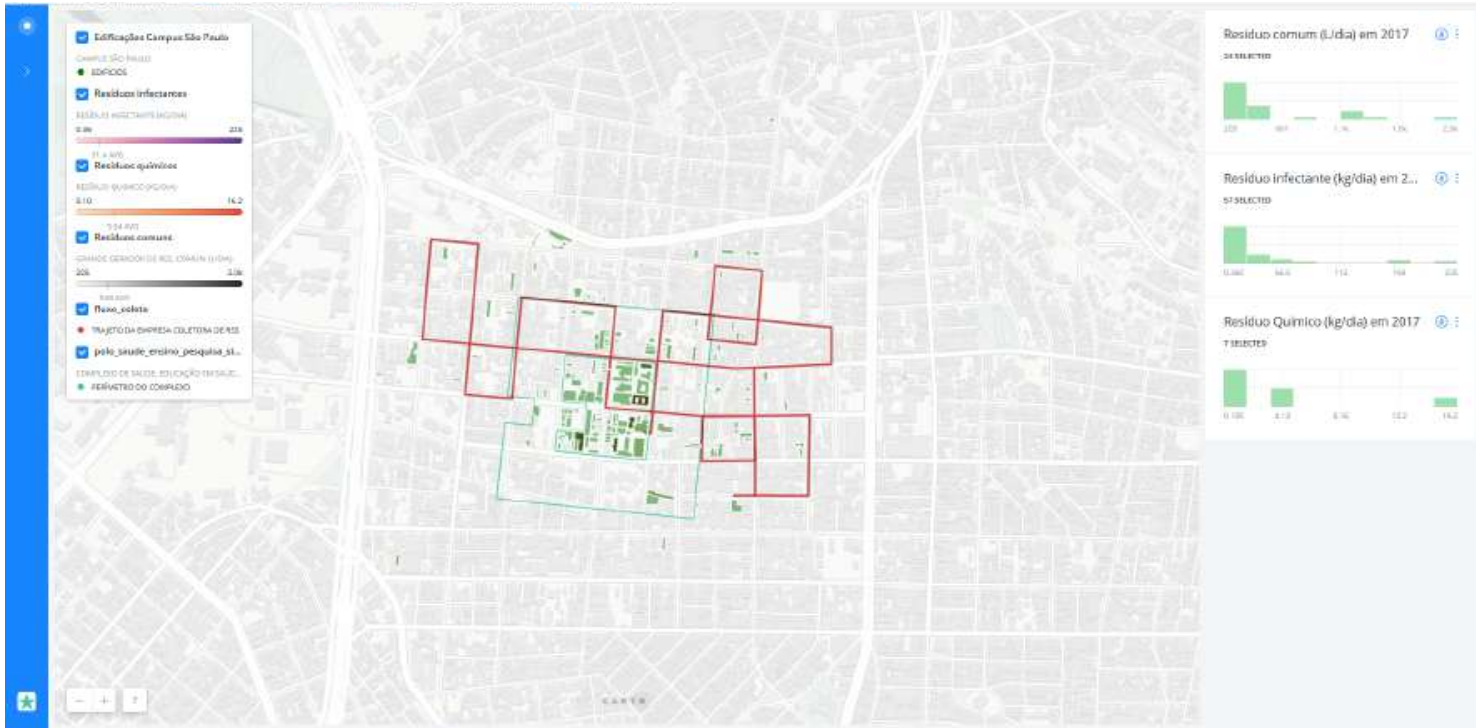

Fonte: autor

A página inicial tem 5 elementos principais: a barra lateral (1), o controle de zoom (2), o controle de camadas (3), o mapa (4) e os widgets (5) (ver figura 4).

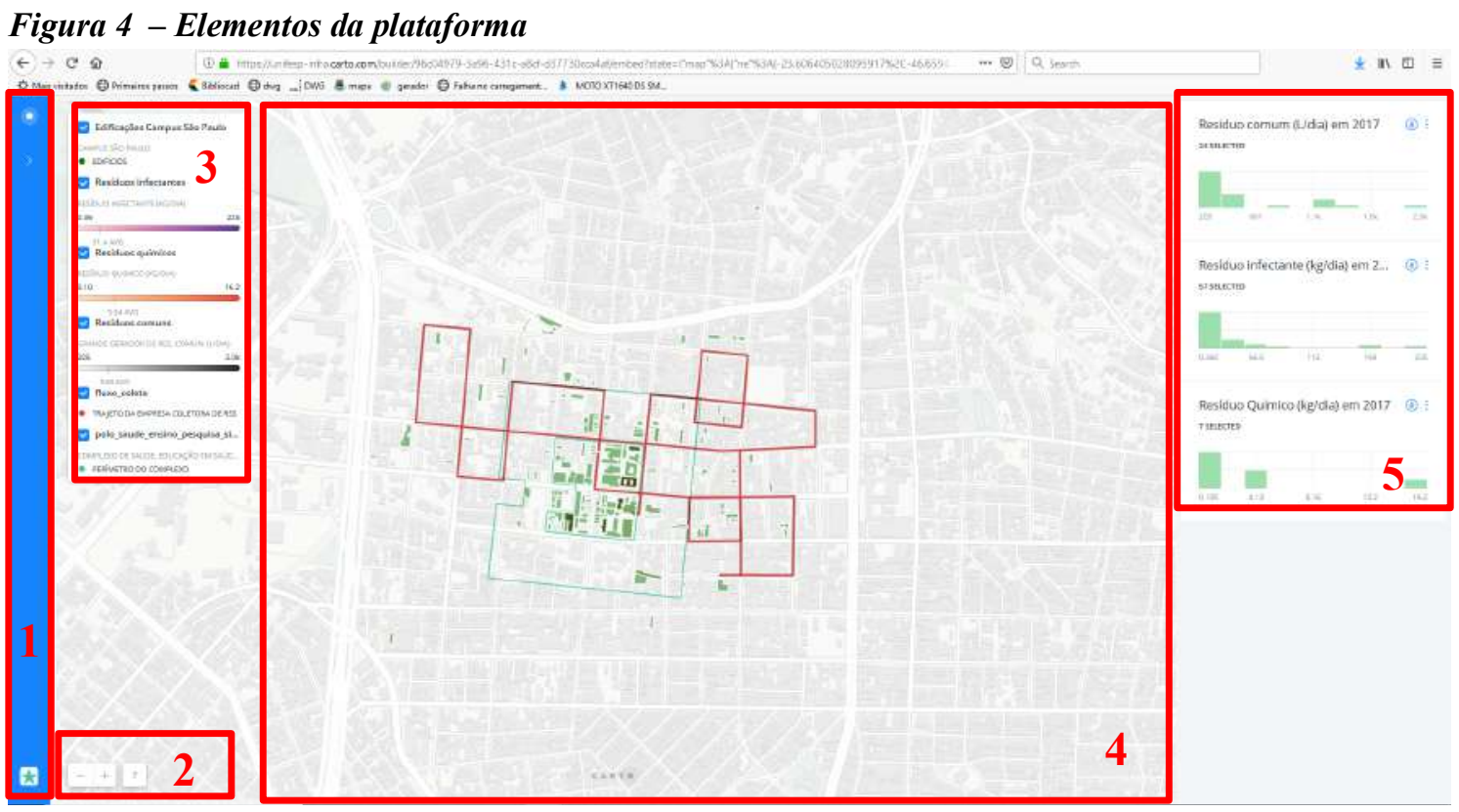

Fonte: autor

Legenda: 1 - barra lateral; 2 - controle de zoom; 3 -controle de camadas; 4 - mapa; 5 - “widgets” 
Figura 5 - Tela após expandir a barra lateral
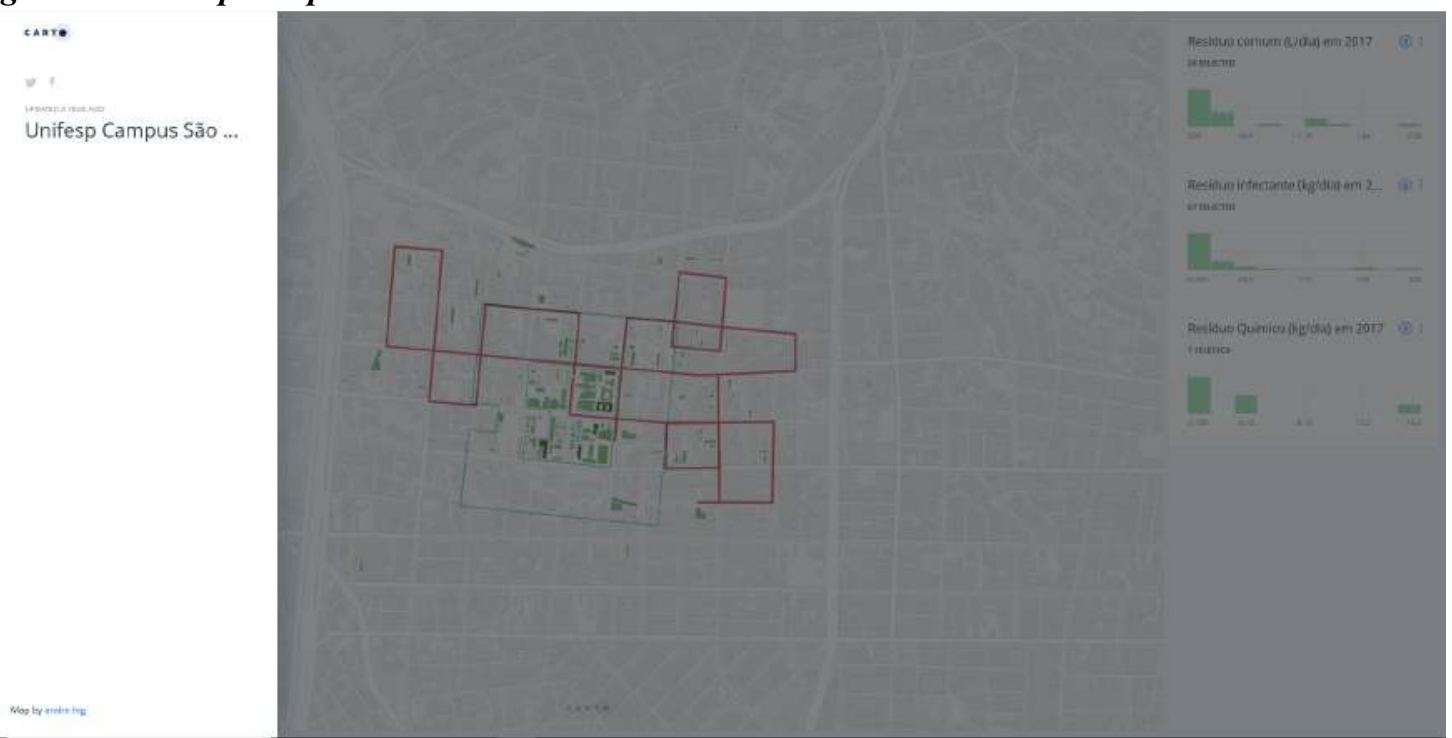

Fonte: autor

A barra lateral expande para apresentar o título do mapa (ver Figura 5), botões para compartilhar nas redes sociais do Twitter ou Facebook, período da última atualização e usuário que fez o mapa.

Figura 6-Tela com o máximo de zoom disponível

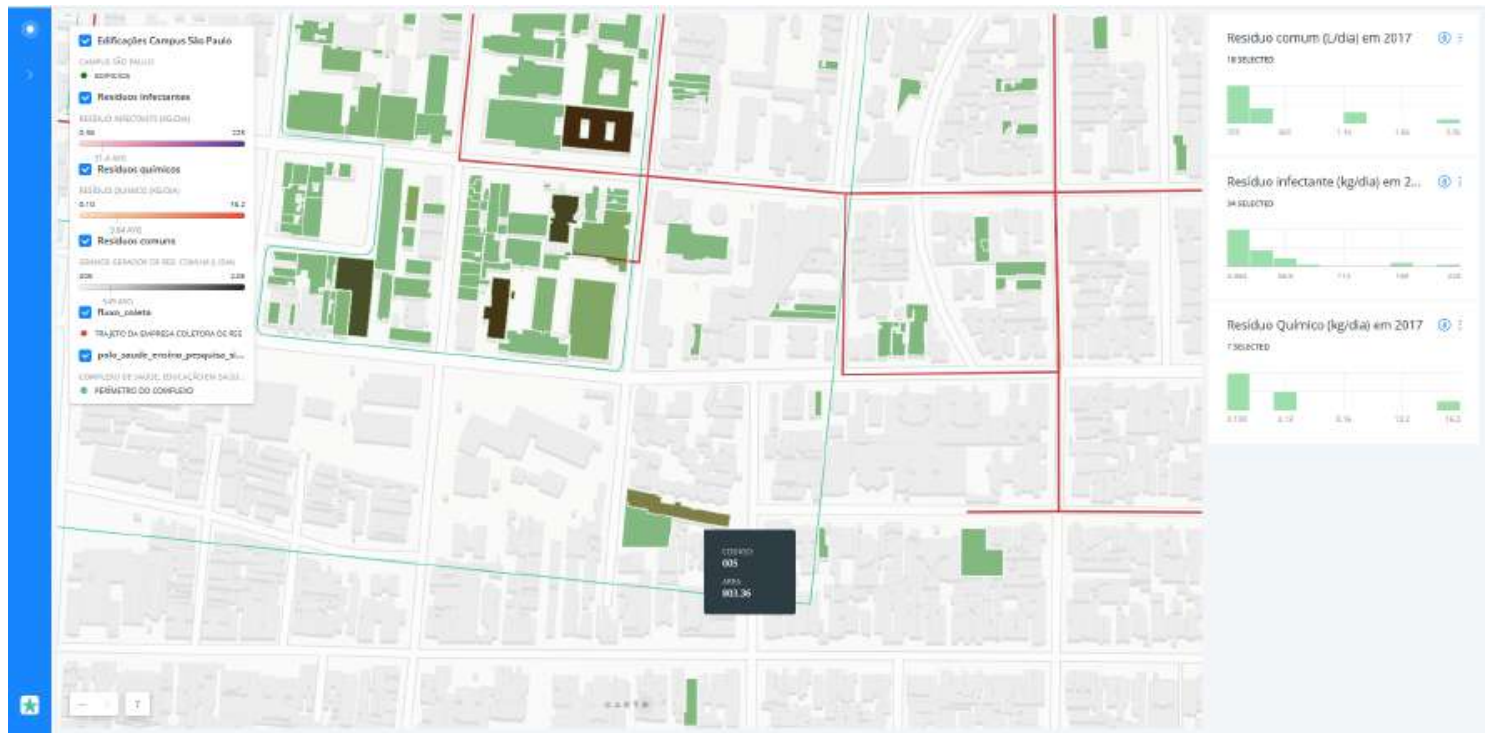

Fonte: autor

A escala do mapa (ver Figura 6) pode ser controlada nos botões $-\mathrm{e}+$ do controle de zoom ou usando o mouse, usando o scroll para aproximar ou afastar e segurar com o botão esquerdo para navegar pelo mapa. No botão “?” consta o crédito da base utilizada: (C) OpenStreetMap contributors, (c) CARTO. 
Ao passar o cursor em cima de um edifício, irá aparecer um pop up com o código do edifício e a área construída dele (ver Figura 6).

O controle de camadas, ou layers que dá ao usuário a escolha de qual informação quer ver. Por padrão, todas as camadas começam ligadas. E a ordem delas indica a sobreposição de uma sobre a seguinte no sentido de cima para baixo. No controle de layers foram inseridos a legenda referente a cada item também.

Para visualizar apenas os locais de produção dos resíduos infectantes, por exemplo, deve-se desligar as demais camadas e ligar apenas a "Resíduos infectantes" e "fluxo_coleta". Ligando outras camadas, as imagens irão se sobrepor (ver Figura 7).

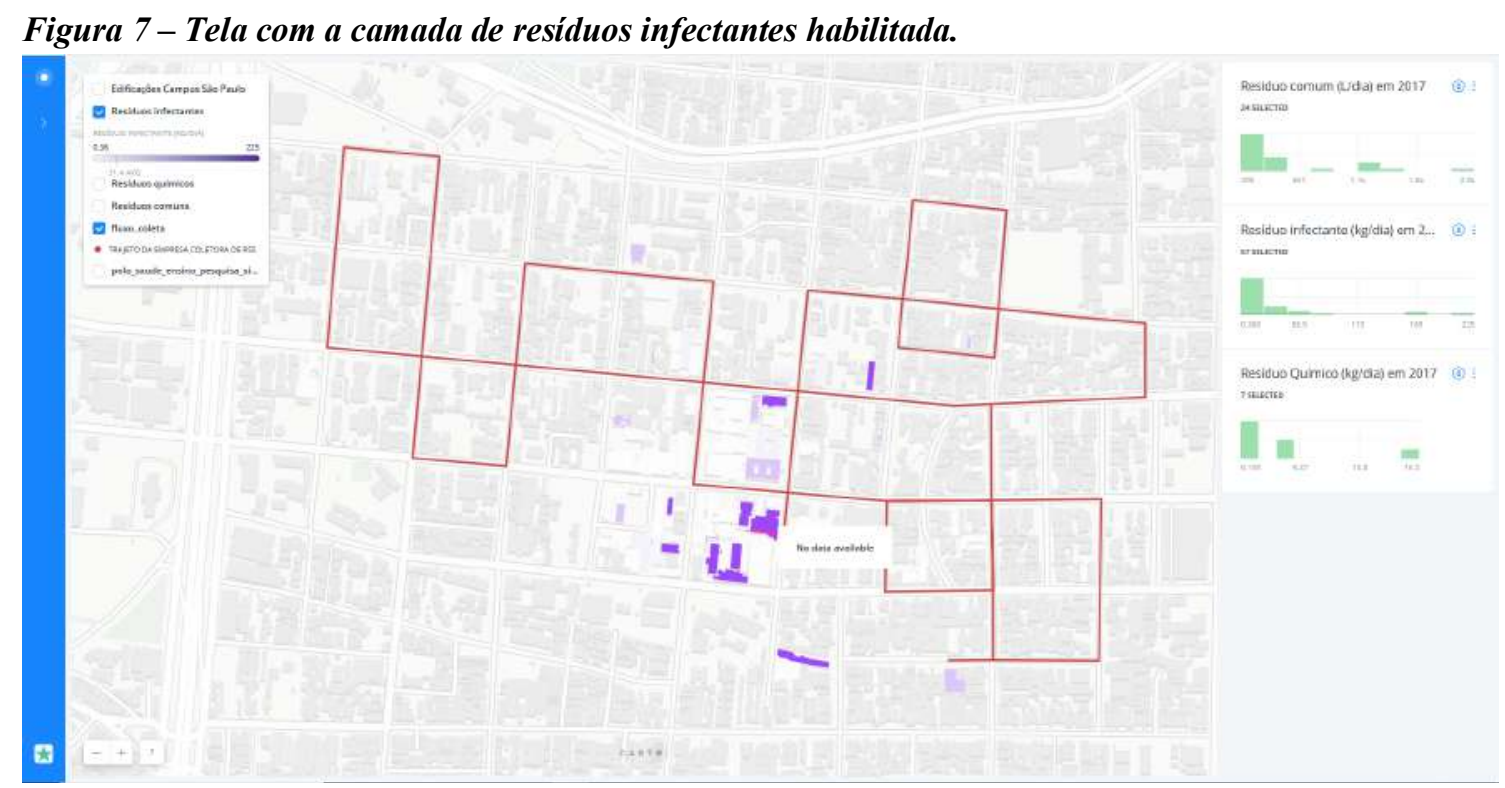

Fonte: autor

O problema desta versão, que precisará ser atualizada posteriormente, é que nesta camada, os dados não ficam aparecem disponíveis no pop up apenas a gradação de cores, referente ao volume de geração de resíduos infectantes (grupo A e E da RDC 222). A legenda indica que a geração vai de 0,36 a $225 \mathrm{~kg} /$ dia.

O mesmo ocorre nas demais camadas de resíduos químicos e comuns. No caso dos químicos (ver Figura 8), devido à baixa quantidade de resíduos detectada no diagnóstico, muitos edifícios que geram resíduos químicos, estão em tons claros, dificulta a visualização, mas por outro lado, não confunde com edifícios que não geram resíduos químicos. 
Figura 8-Tela com a camada de resíduos químicos habilitada.

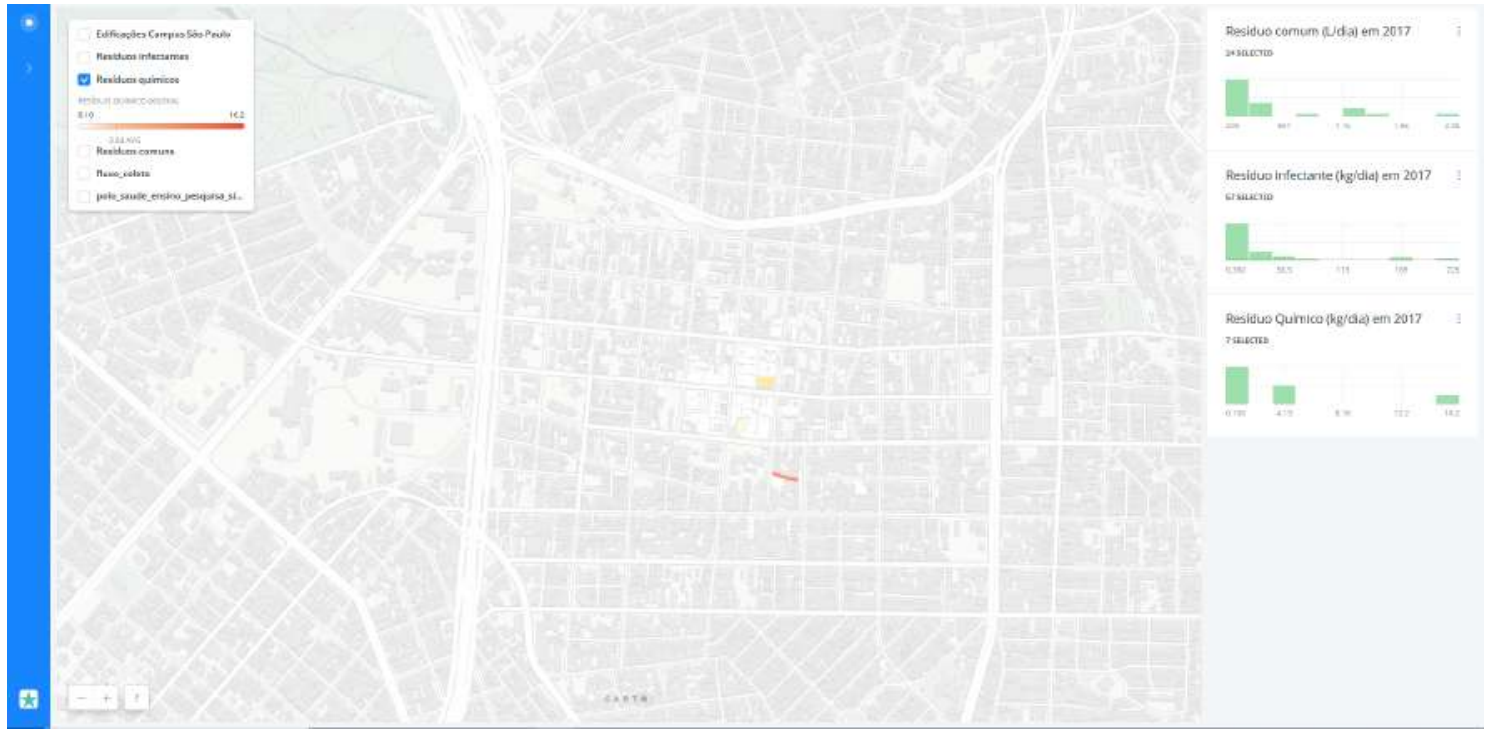

Fonte: autor

A tela com resíduos comuns (apenas os grandes geradores) aparece ao ligar a camada "Resíduos comuns", junto com a legenda e gradação de cores. No caso, optou-se por usar o valor em litros, sem a conversão para quilos. É possível saber o código do edifício ao clicar sobre o edifício em questão

Figura 9 - Tela com a camada de resíduos comuns habilitada.

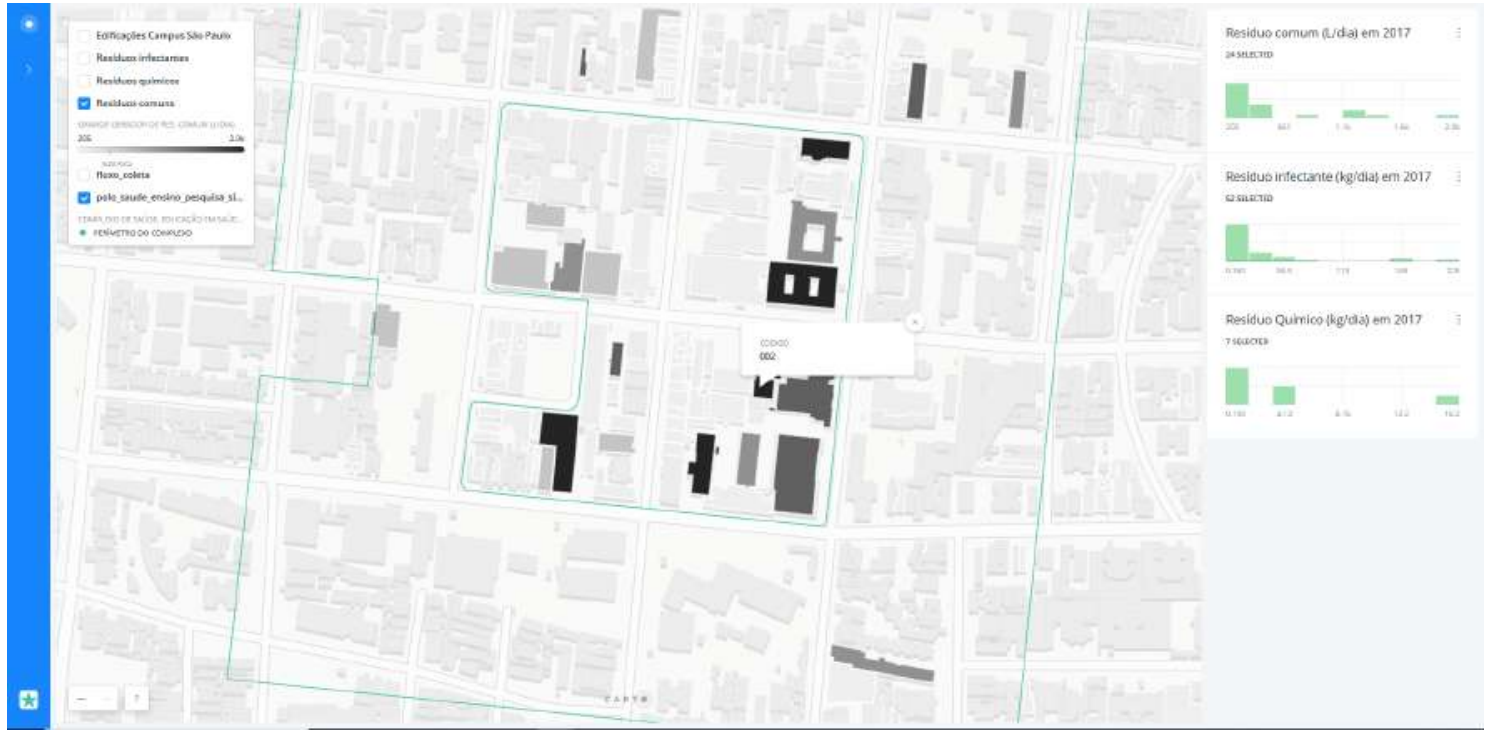

Fonte: autor

Por fim, os widgets na barra lateral direita têm uma função mais analítica (ver figura 9). Os gráficos são referentes ao número de edifícios por volume de resíduo e de qual categoria. A contagem se refere ao que está enquadrado no mapa. Ou seja, se o mapa estiver com enquadramento em uma área com menos edifícios geradores, o widget vai demonstrar isso. 


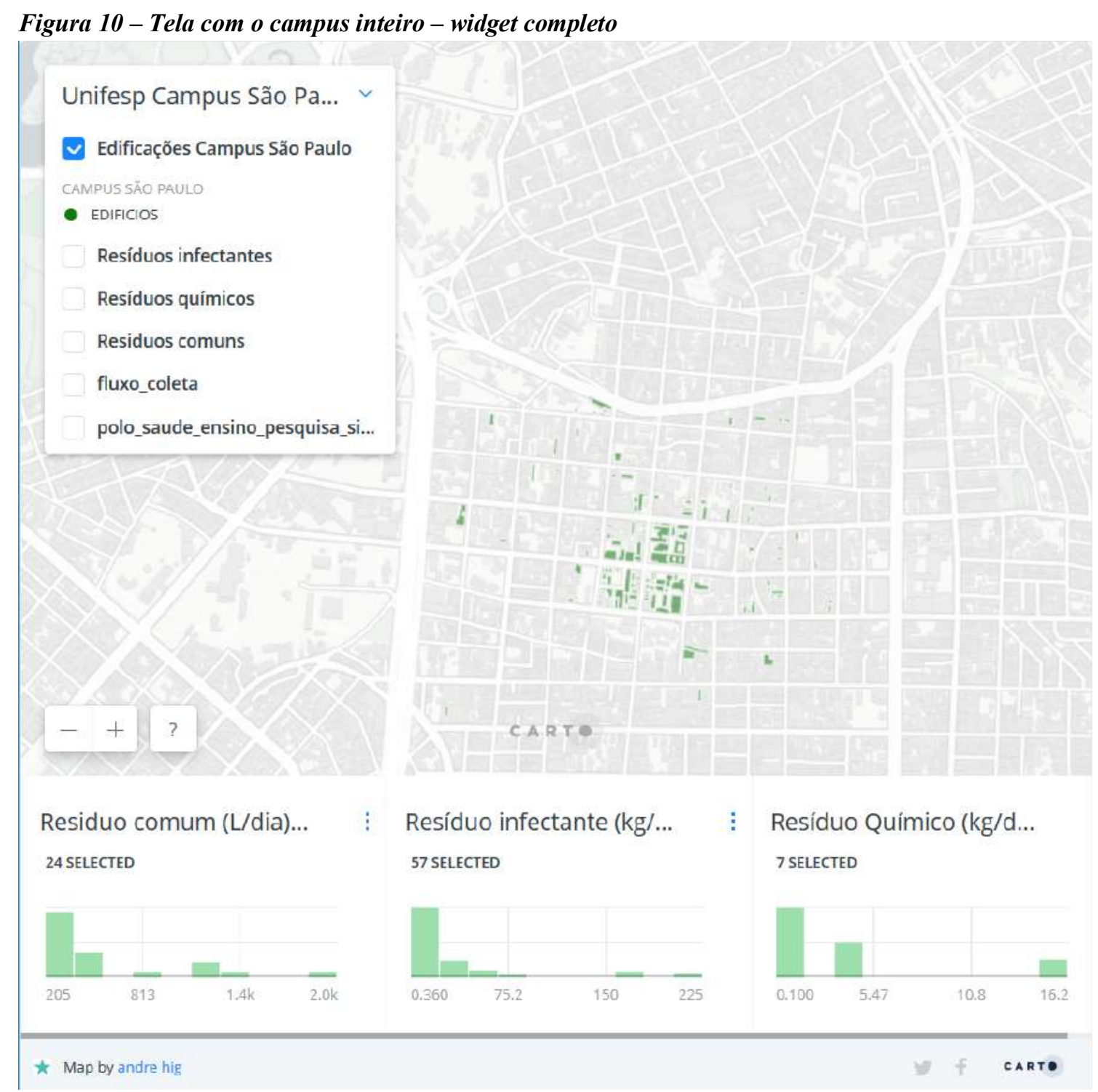

Fonte: autor

Verificamos que no campus, há 24 edifícios grande geradores de resíduo comum, 57 de resíduos infectantes e 7 de resíduos químicos. Atente que a camada de "Resíduos químicos", "Resíduos comuns" e "Resíduos infectantes" não precisa estar ligada, pois todas as informações já constavam na camada "Edificações Campus São Paulo" e como anunciado anteriormente as demais camadas foram feitas para facilitar a navegação do usuário (ver Figura 10).

Ao aproximar a tela de uma área fora do quadrante principal, podemos verificar que não há grandes geradores de resíduo comum e nem de resíduo químico (ver Figura 11). E verifica-se qual número de edifícios, ao clicar sobre a barra. 
Figura 11 - Tela com trecho do campus - widget interage com as informações

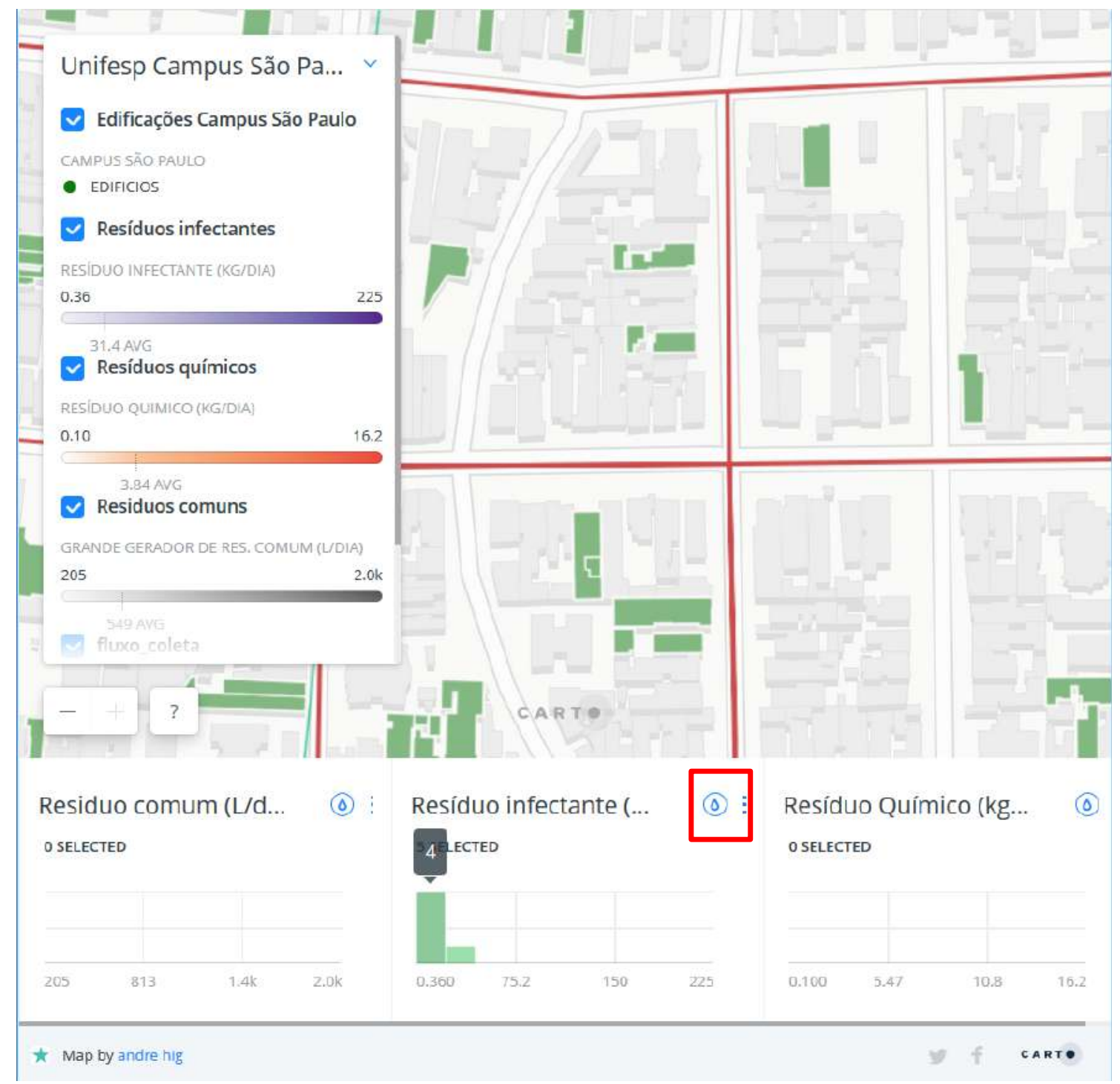

Fonte: autor

Outra função do widget, ao clicar no símbolo de azul de gota em uma categoria desejada, ele aplica um novo estilo e escala de cores pré-programada e interage com o mapa. Neste caso, é necessário que o layer correto esteja ligado para que a visualização acompanhe o widget.

Ao habilitar a função "Auto Style" (a gota azul), os edifícios ficam na escala de cor pré-definida e associada a valores da geração de determinada classificação de resíduo. Passando o mouse, sem clicar, em cima de uma coluna, o valor (número de edifícios) aparece (ver Figura 12). 
Figura 12 - Tela do funcionamento da ferramenta "Auto Style"

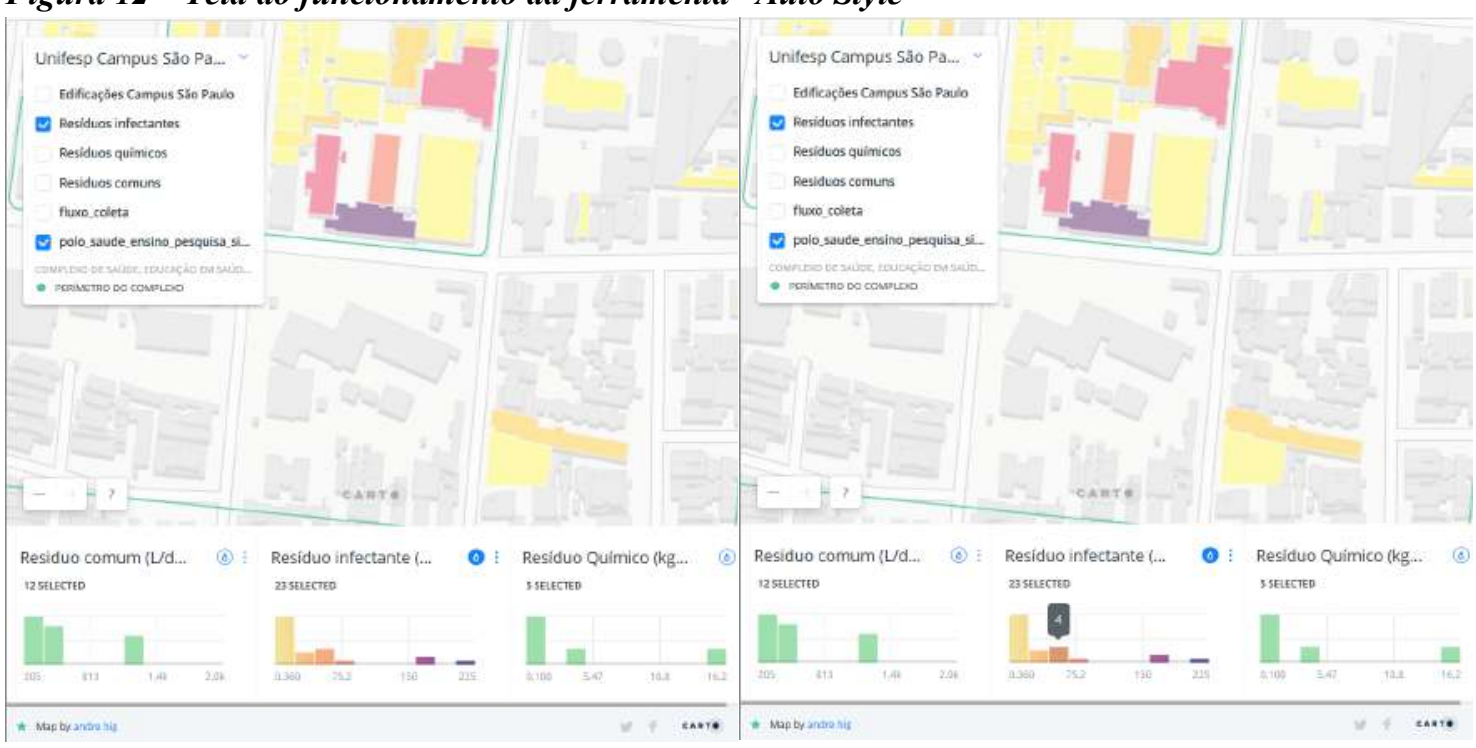

Fonte: autor

Ao clicar duas vezes em cima da coluna, aciona a ferramenta zoom, sendo possível definir inclusive qual trecho do gráfico se deseja ampliar. Basta arrastar o seletor que aparece para enquadrar o trecho desejado (ver Figura 13). Ao definir o trecho, o mapa vai se ajustando à seleção.

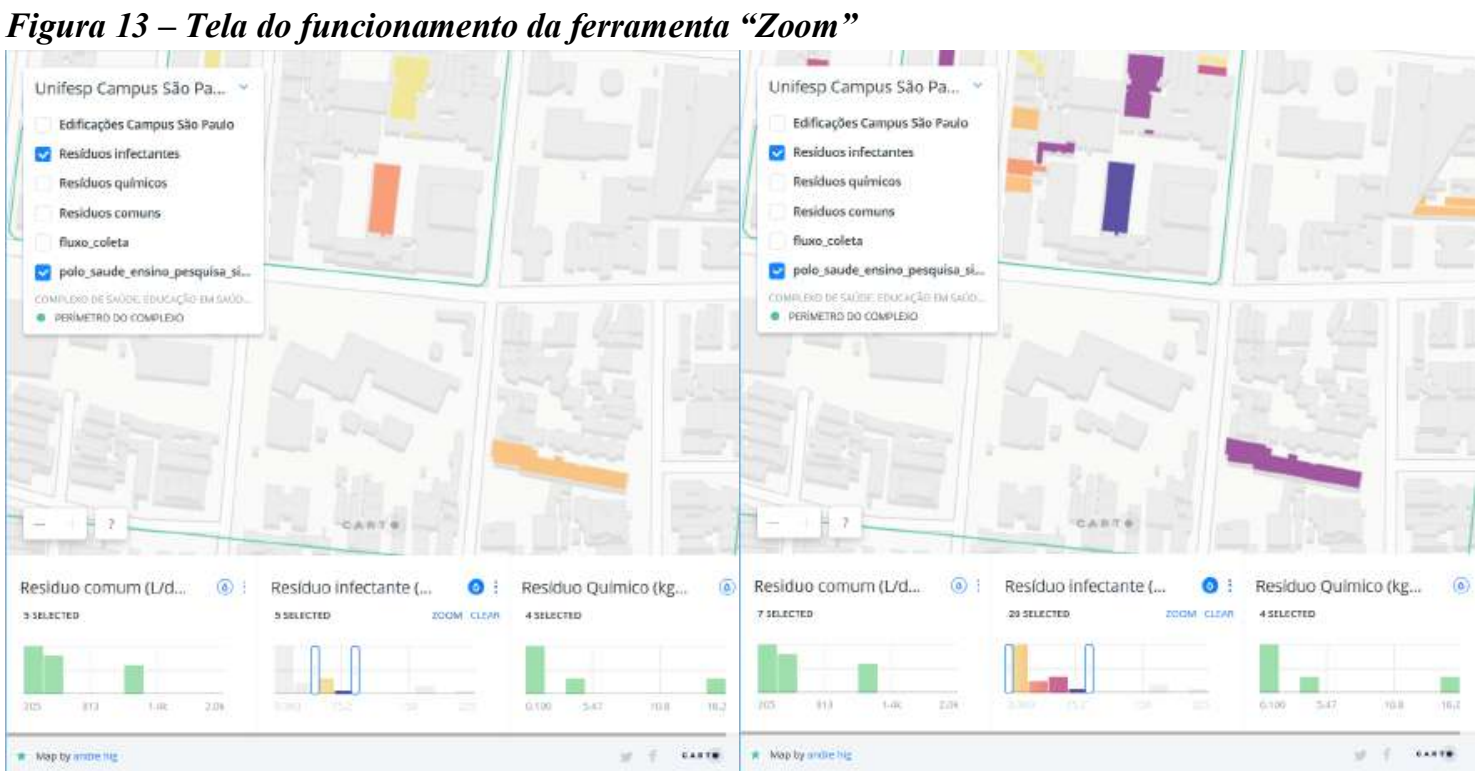

Fonte: autor

Quando o trecho desejado estiver selecionado, aperte "zoom" no canto superior direito do widget e o mapa ficará com a configuração de cores nova e um novo gráfico de colunas aparece logo abaixo, com valores dentro do trecho escolhido. Se desejar, clicando duas vezes em uma coluna com múltiplos valores, uma nova escala de cores surge e no mapa se destacam apenas esses edifícios (ver Figura 14). 


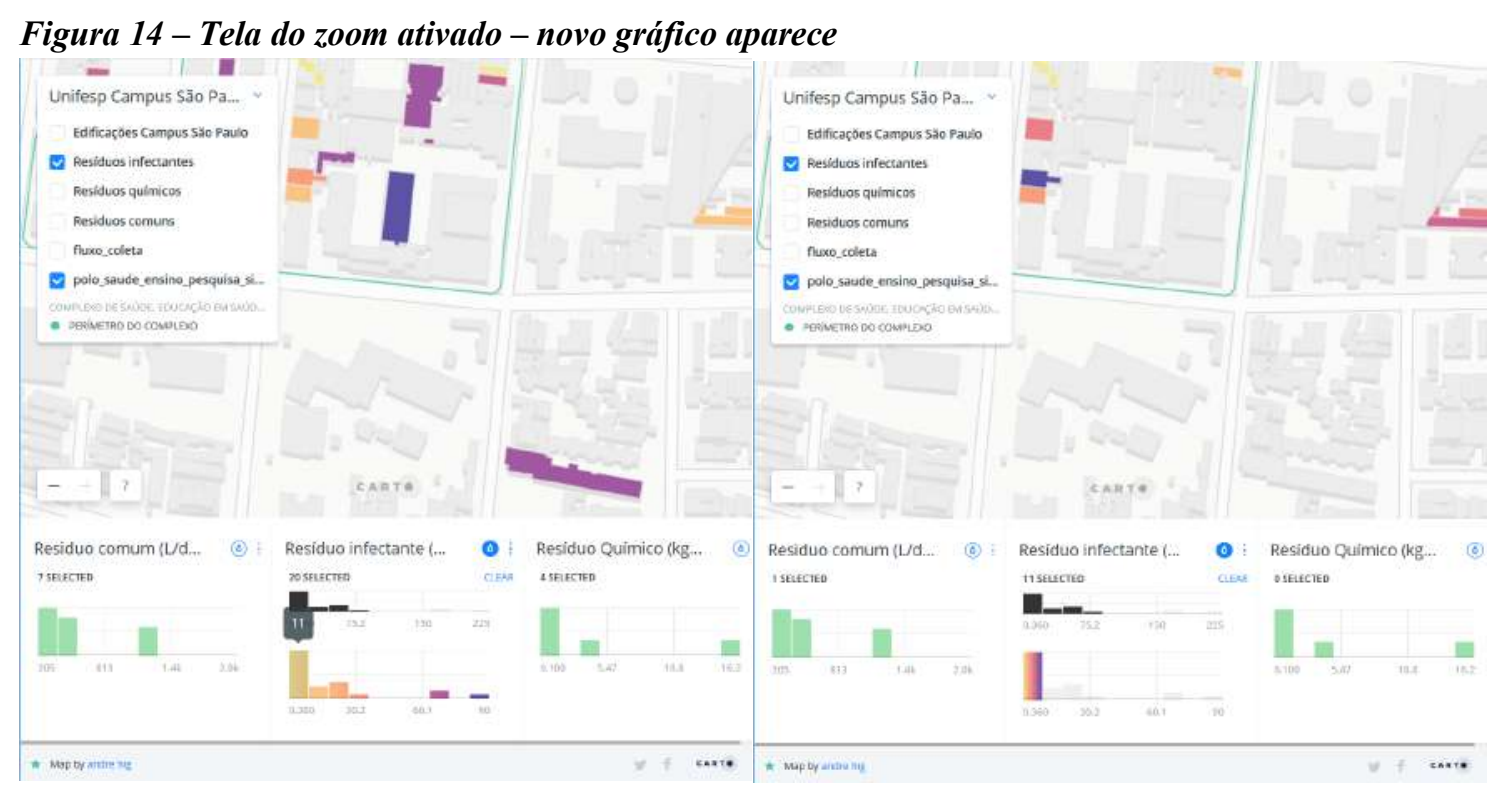

Fonte: autor

Quando a coluna indica que há apenas 1 edifício com determinado valor, ao clicar nele, será o único edifício no mapa. Passando o mouse em cima do edifício, o valor aparece em um pop up (ver Figura 15).

Para voltar à tela inicial, basta reiniciar o navegador. Se precisar sair da função zoom, clicar no botão "clear”, logo abaixo do ícone em formato de gota.

Só é possível aplicar o Auto style em uma categoria por vez. Ao usar recorrentemente, verificou-se que o ícone desta função por vezes não aparece, mas basta reiniciar o navegador que a função aparece.

Importante salientar que o mapa é disponível em versão web e mobile. Sendo possível acessar a versão interativa do mapa no computador e no celular. Na versão para smartphone (ver Figura 16), o controle de camadas e o mapa estão separados para melhor visualização. 
Figura 15 - Tela do zoom ativado - seleção de um valor específico

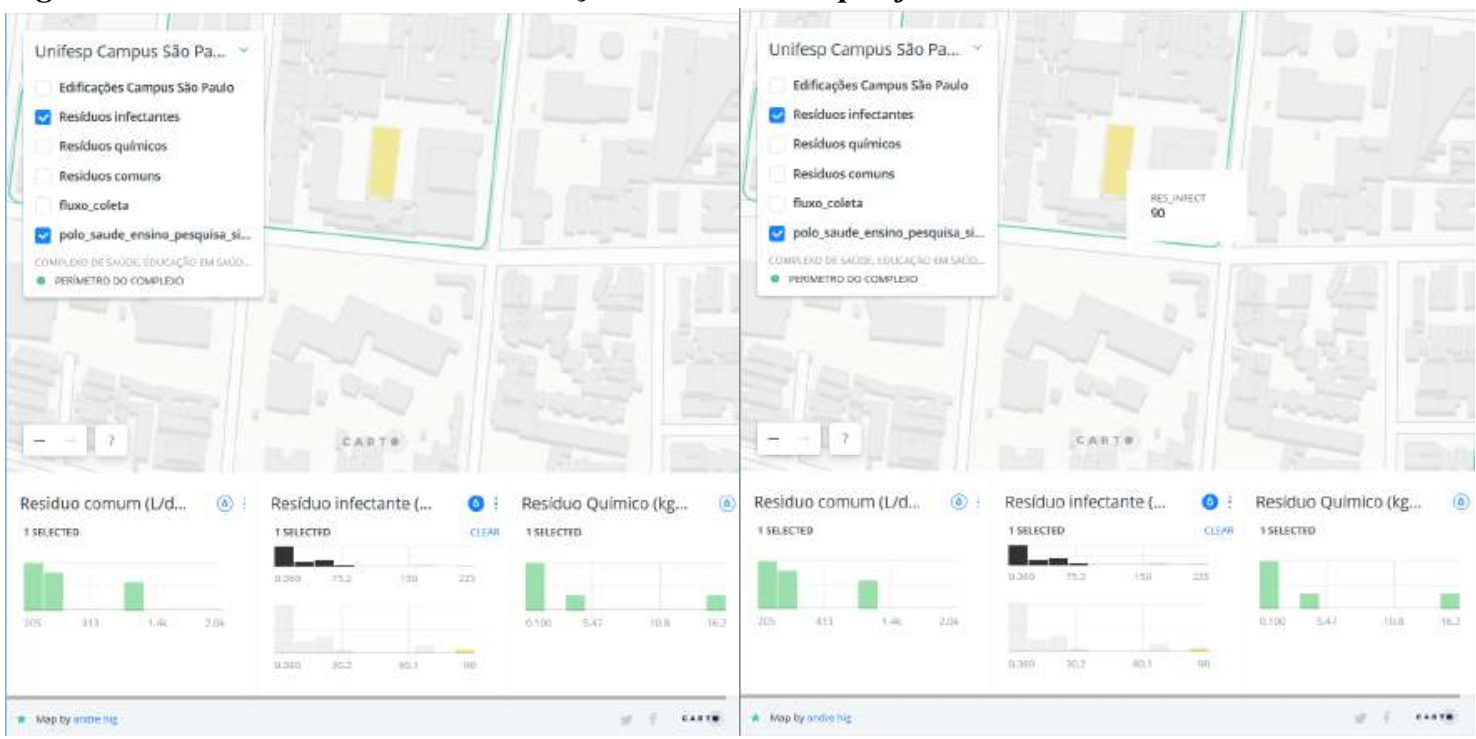

Fonte: autor

Figura 16 - Telas da versão mobile do mapa

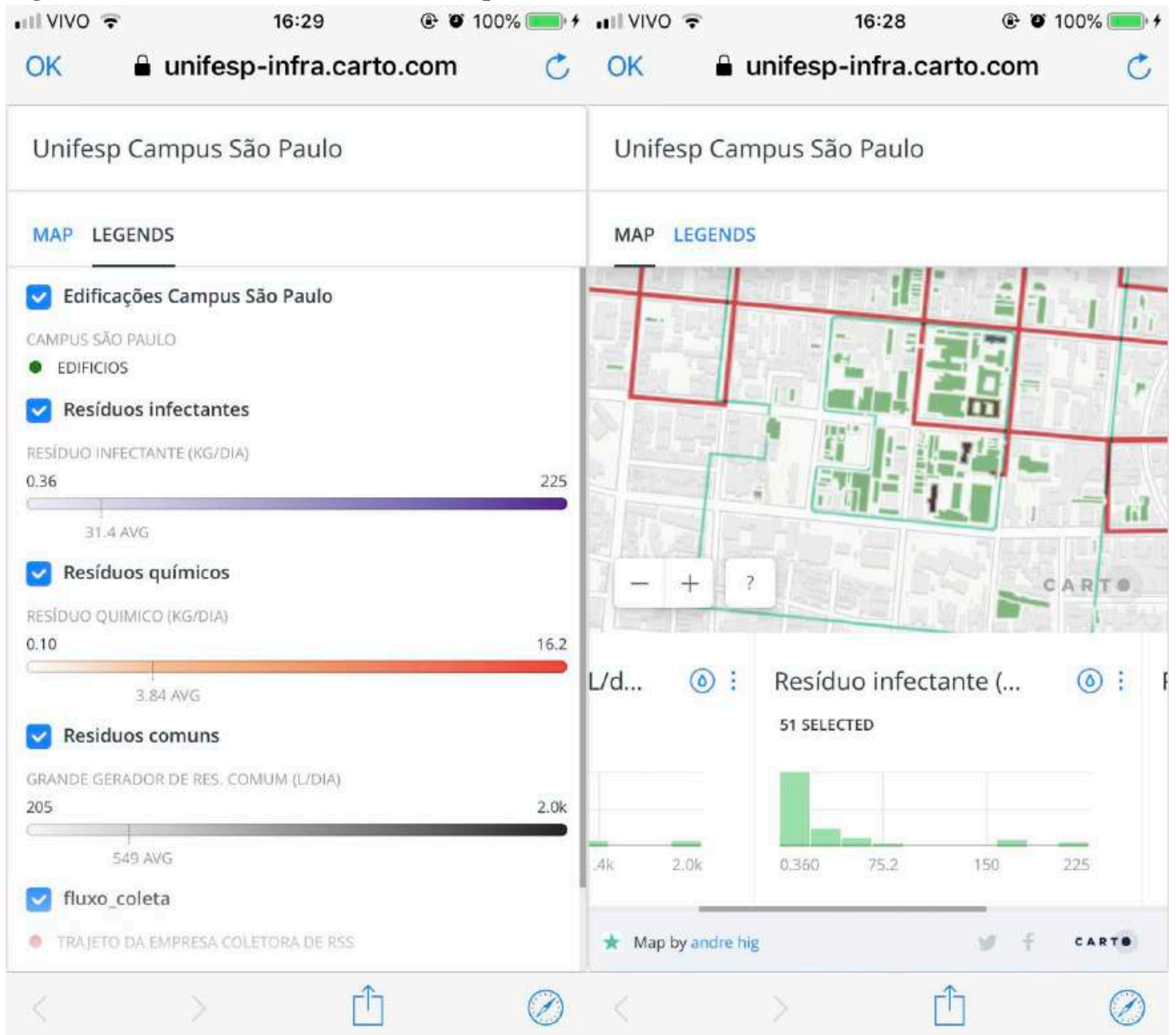

Fonte: autor 
Uma versão do mapa disponível e adaptada para a tela de celular é ideal para facilitar o acesso à informação. Sendo que as ferramentas são exatamente as mesmas, widget, zoom, controle de camadas e pop up com informação.

Espera-se que este produto profissional traga ao usuário do campus, à comunidade acadêmica, à pesquisadores e cidadãos em geral, acesso às informações de maneira intuitiva e facilitada. Além de ser uma base para futuros incrementos que podem vir a ser demandados pelas gestões da Universidade.

Ainda precisa ser aprimorada a relação das camadas com as informações que aparecem nos pop ups, mas verificou-se que esta falha não afeta a função de visualização do contexto geral do campus e o usuário não ficará sem informação, pois os valores máximos, mínimos e média aparecem na legenda.

Para futuros passos, é possível construir mapas com séries históricas, para analisar a evolução do Campus rumo à sustentabilidade, não somente em relação à resíduos sólidos, mas toda a gama de dimensões que compõe o desenvolvimento sustentável.

\section{REFERÊNCIAS}

BRAMATTI, D. Veja mapa dos estrangeirismo nos edifícios de São Paulo. Blog do Estadão Dados, São Paulo, nov 2016. Disponivel em: $<$ http://blog.estadaodados.com/veja-o-mapa-dos-estrangeirismos-nos-edificios-de-saopaulo/ >. Acesso em: jan 2019.

BRASIL. LEI N $\mathrm{N}^{\circ}$ 12.527, DE 18 DE NOVEMBRO DE 2011. Lei de Acesso à Informação, Brasília, nov 2011.

SEDGHI, A. London's rail system animated in 60 seconds. The Guardian, 2014. Disponivel em: $\quad<$ https://www.theguardian.com/news/datablog/nginteractive/2014/mar/18/londons-rail-system-animated-in-60-seconds $>$. Acesso em: jan 2019. 


\section{APÊNDICE A - MATRIZES DE REFERÊNCIA}

No Quadro 19 é possível visualizar os resultados de busca na base de dados, não sendo possível identificar "nós interdisciplinares" nas buscas referentes a "plano diretor" com "cidades saudáveis", "determinantes sociais da saúde", "gestão de resíduos" e "metabolismo urbano". Não houve nós interdisciplinares nas buscas de "metabolismo urbano". O maior nó interdisciplinar foi encontrado na busca relacionando "planejamento" e "sustentabilidade".

Quadro 19 - Matriz de referências - Scielo

\begin{tabular}{|l|c|c|c|c|c|c|c|c|c|c|c|c|c|c|}
\hline & P.D. & Plan. & M.P. & $\begin{array}{l}\text { Plan } \\
\text { n. }\end{array}$ & C.S. & H.C. & $\begin{array}{l}\text { D.S. } \\
\text { D.S. }\end{array}$ & $\begin{array}{l}\text { S.D. } \\
\text { O.H. }\end{array}$ & $\begin{array}{l}\text { G.R. } \\
\text { S. }\end{array}$ & W.M & M.U. & U.M. & Sust. & Sust. \\
\hline P.D. & 8 & {[]} & {[]} & {[]} & {[]} & {[]} & {[]} & {[]} & {[]} & {[]} & {[]} & {[]} & {[]} & {[]} \\
\hline Plan. & 6 & $\begin{array}{c}6.02 \\
4\end{array}$ & {[]} & {[]} & {[]} & {[]} & {[]} & {[]} & {[]} & {[]} & {[]} & {[]} & {[]} & {[]} \\
\hline M.P. & - & - & - & {[]} & {[]} & {[]} & {[]} & {[]} & {[]} & {[]} & {[]} & {[]} & {[]} & {[]} \\
\hline $\begin{array}{l}\text { Plan } \\
\text { n. }\end{array}$ & - & - & - & - & {[]} & {[]} & {[]} & {[]} & {[]} & {[]} & {[]} & {[]} & {[]} & {[]} \\
\hline C.S. & 0 & 4 & - & - & 13 & {[]} & {[]} & {[]} & {[]} & {[]} & {[]} & {[]} & {[]} & {[]} \\
\hline H.C. & - & - & - & - & - & - & {[]} & {[]} & {[]} & {[]} & {[]} & {[]} & {[]} & {[]} \\
\hline $\begin{array}{l}\text { D.S. } \\
\text { D.S. }\end{array}$ & 0 & 3 & - & - & 2 & - & 41 & {[]} & {[]} & {[]} & {[]} & {[]} & {[]} & {[]} \\
\hline $\begin{array}{l}\text { S.D. } \\
\text { O.H. }\end{array}$ & - & - & - & - & - & - & - & - & {[]} & {[]} & {[]} & {[]} & {[]} & {[]} \\
\hline $\begin{array}{l}\text { G.R. } \\
\text { S. }\end{array}$ & 0 & 3 & - & - & 0 & - & 0 & - & 8 & {[]} & {[]} & {[]} & {[]} & {[]} \\
\hline W.M & - & - & - & - & - & - & - & - & - & - & {[]} & {[]} & {[]} & {[]} \\
\hline M.U. & 0 & 0 & - & - & 0 & - & 0 & - & 0 & - & 0 & {[]} & {[]} & {[]} \\
\hline U.M. & - & - & - & - & - & - & - & - & - & - & - & - & {[]} & {[]} \\
\hline Sust. & 3 & 140 & - & - & 8 & - & 9 & - & 9 & - & 0 & - & $\begin{array}{c}2.25 \\
8\end{array}$ \\
\hline Sust. & - & - & - & - & - & - & - & - & - & - & - & - & - & - \\
\hline
\end{tabular}

Legenda ( ${ }^{\circ}$ de resultados):

$\begin{array}{llllll}0 & 1-100 & 101-500 & 501-1.000 & 1.001-5.000 & 5.001- \\ 10.000 & >10.001\end{array}$

Fonte: Scielo, 2018

Notas: P.D. : Plano Diretor - Plan.: Planejamento - M.P.: Master Plan - Plann.: Planning - C.S.:

Cidades Saudáveis - H.C.: Healthy Cities - D.S.D.S.: Determinantes Sociais da Saúde - S.D.O.H.:

Social Determinants of Health - G.R.S.: Gestão de Resíduos Sólidos - W.M.: Waste Management M.U.: Metabolismo Urbano - U.M.: Urban Metabolism - Sust.: Sustentabilidade/Sustainability

No Quadro 20 verifica-se que há nós interdisciplinares em todas as buscas. Sendo que as menos identificadas, novamente se referem ao metabolismo urbano ("urban metabolism") com plano diretor ("Master Plan") e determinantes sociais da saúde ("Social Determinants of Health"). Por outro lado, os maiores nós interdisciplinares se referem a planejamento ("planning") e plano diretor, e planejamento e sustentabilidade. 
Quadro 20 - Matriz de referências - Emerald Insight

\begin{tabular}{|c|c|c|c|c|c|c|c|c|c|c|c|c|c|c|}
\hline & P.D. & Plan. & M.P. & $\begin{array}{l}\text { Plan } \\
\text { n. }\end{array}$ & C.S. & H.C. & $\begin{array}{l}\text { D.S. } \\
\text { D.S. }\end{array}$ & $\begin{array}{l}\text { S.D. } \\
\text { O.H. }\end{array}$ & $\begin{array}{l}\text { G.R. } \\
\text { S. }\end{array}$ & $\begin{array}{l}\text { W.M } \\
\end{array}$ & M.U. & U.M. & Sust. & Sust. \\
\hline P.D. & - & [] & [] & [] & [] & [] & [] & [] & [] & [] & [] & [] & [] & [] \\
\hline Plan. & - & - & [] & [] & [] & [] & [] & [] & [] & [] & [] & [] & [] & [] \\
\hline M.P. & - & - & $\begin{array}{c}26.8 \\
76\end{array}$ & [] & [] & [] & [] & [] & [] & [] & [] & [] & [] & [] \\
\hline $\begin{array}{l}\text { Plan } \\
\text { n. }\end{array}$ & - & - & $\begin{array}{c}26.8 \\
76\end{array}$ & $\begin{array}{l}177 . \\
054\end{array}$ & [] & [] & [] & [] & [] & [] & [] & [] & [] & [] \\
\hline C.S. & - & - & - & - & - & [] & [] & [] & [] & [] & [] & [] & [] & [] \\
\hline H.C. & - & - & $\begin{array}{c}4.28 \\
2\end{array}$ & $\begin{array}{c}19.1 \\
85\end{array}$ & - & $\begin{array}{c}27.0 \\
57\end{array}$ & [] & [] & [] & [] & [] & [] & [] & [] \\
\hline $\begin{array}{l}\text { D.S. } \\
\text { D.S. }\end{array}$ & - & - & - & - & - & - & - & [] & [] & [] & [] & [] & [] & [] \\
\hline $\begin{array}{l}\text { S.D. } \\
\text { O.H. }\end{array}$ & - & - & 691 & $\begin{array}{c}3.94 \\
2 \\
\end{array}$ & - & $\begin{array}{c}1.93 \\
4\end{array}$ & - & $\begin{array}{c}6.22 \\
6\end{array}$ & [] & [] & [] & [] & [] & [] \\
\hline $\begin{array}{l}\text { G.R. } \\
\text { S. }\end{array}$ & - & - & - & - & - & - & - & - & - & [] & [] & [] & [] & [] \\
\hline W.M & - & - & 289 & $\begin{array}{c}1.99 \\
5 \\
\end{array}$ & - & 732 & - & 855 & - & $\begin{array}{c}31.6 \\
13\end{array}$ & [] & [] & [] & [] \\
\hline M.U. & - & - & - & - & - & - & - & - & - & - & - & [] & [] & [] \\
\hline U.M. & - & - & 67 & 264 & - & 241 & - & 33 & - & 165 & - & 379 & [] & [] \\
\hline Sust. & - & - & - & - & - & - & - & - & - & - & - & - & - & [] \\
\hline Sust. & - & - & $\begin{array}{c}10.5 \\
48\end{array}$ & $\begin{array}{c}57.0 \\
82\end{array}$ & - & $\begin{array}{c}11.9 \\
48\end{array}$ & - & $\begin{array}{c}2.94 \\
6\end{array}$ & - & $\begin{array}{c}14.3 \\
24\end{array}$ & - & 189 & - & $\begin{array}{c}85.0 \\
90\end{array}$ \\
\hline
\end{tabular}

Legenda $\left(\mathrm{n}^{\mathrm{o}}\right.$ de resultados):

0

$1-100$

$101-500$

$501-1.000$

$1.001-5.000$

$5.001-$

10.000

$>10.001$

Fonte: Emerald Insight, 2018

Notas: P.D. : Plano Diretor

Plan.: Planejamento

M.P.: Master Plan

Plann.: Planning

C.S.: Cidades Saudáveis

H.C.: Healthy Cities

D.S.D.S.: Determinantes Sociais da Saúde

S.D.O.H.: Social Determinants of Health

G.R.S.: Gestão de Resíduos Sólidos

W.M.: Waste Management

M.U.: Metabolismo Urbano

U.M.: Urban Metabolism

Sust.: Sustentabilidade/Sustainability

No Quadro 21 pode-se visualizar que não houve resultados na busca relacionando determinantes sociais da saúde e metabolismo urbano e apenas um resultado relacionando M.U. com cidades saudáveis. Há mais resultados nas buscas sobre planejamento e sustentabilidade, sendo que o nó interdisciplinar com mais referencias é com estas duas palavras chave, seguido por planejamento com "plano diretor". 
Quadro 21 - Matriz de referências - Teses USP

\begin{tabular}{|c|c|c|c|c|c|c|c|c|c|c|c|c|c|c|}
\hline & P.D. & Plan. & M.P. & $\begin{array}{l}\text { Plan } \\
\text { n. }\end{array}$ & C.S. & H.C. & $\begin{array}{l}\text { D.S. } \\
\text { D.S. }\end{array}$ & $\begin{array}{l}\text { S.D. } \\
\text { O.H. }\end{array}$ & $\begin{array}{l}\text { G.R. } \\
\text { S. }\end{array}$ & $\begin{array}{l}\text { W.M } \\
\end{array}$ & M.U. & U.M. & Sust. & Sust \\
\hline P.D. & $\begin{array}{c}3.04 \\
0\end{array}$ & [] & [] & [] & [] & [] & [] & [] & [] & [] & [] & [] & [] & [] \\
\hline Plan. & $\begin{array}{c}2.84 \\
0 \\
\end{array}$ & $\begin{array}{c}37.2 \\
00\end{array}$ & [] & [] & [] & [] & [] & [] & [] & [] & [] & [] & [] & [] \\
\hline M.P. & - & - & - & [] & [] & [] & [] & [] & [] & [] & [] & [] & [] & [] \\
\hline $\begin{array}{l}\text { Plan } \\
\text { n. }\end{array}$ & - & - & - & - & [] & [] & [] & [] & [] & [] & [] & [] & [] & [] \\
\hline C.S. & 69 & 176 & - & - & 164 & [] & [] & [] & [] & [] & [] & [] & [] & [] \\
\hline H.C. & - & - & - & - & - & - & [] & [] & [] & [] & [] & [] & [] & [] \\
\hline $\begin{array}{l}\text { D.S. } \\
\text { D.S. }\end{array}$ & 94 & 704 & - & - & 62 & - & 606 & [] & [] & [] & [] & [] & [] & [] \\
\hline $\begin{array}{l}\text { S.D. } \\
\text { O.H. }\end{array}$ & - & - & - & - & - & - & - & - & [] & [] & [] & [] & [] & [] \\
\hline $\begin{array}{l}\text { G.R. } \\
\text { S. }\end{array}$ & 463 & $\begin{array}{c}1.17 \\
0\end{array}$ & - & - & 6 & - & 6 & - & $\begin{array}{c}1.52 \\
0\end{array}$ & [] & [] & [] & [] & [] \\
\hline W.M & - & - & - & - & - & - & - & - & - & - & [] & [] & [] & [] \\
\hline M.U. & 20 & 40 & - & - & 1 & - & 0 & - & 39 & - & 20 & [] & [] & [] \\
\hline U.M. & - & - & - & - & - & - & - & - & - & - & - & - & [] & [] \\
\hline Sust. & $\begin{array}{c}1.48 \\
0 \\
\end{array}$ & $\begin{array}{c}7.34 \\
0\end{array}$ & - & - & 96 & - & 298 & - & $\begin{array}{c}1.12 \\
0 \\
\end{array}$ & - & 70 & - & $\begin{array}{c}10.5 \\
00\end{array}$ & [] \\
\hline Sust. & - & - & - & - & - & - & - & - & - & - & - & - & - & - \\
\hline
\end{tabular}

Legenda $\left(\mathrm{n}^{\mathrm{o}}\right.$ de resultados):

$\begin{array}{llllll}0 & 1-100 & 101-500 & 501-1.000 & 1.001-5.000 & 5.001- \\ 10.000 & >10.001\end{array}$

Fonte: Teses USP, 2018

Notas: P.D. : Plano Diretor

Plan.: Planejamento

M.P.: Master Plan

Plann.: Planning

C.S.: Cidades Saudáveis

H.C.: Healthy Cities

D.S.D.S.: Determinantes Sociais da Saúde

S.D.O.H.: Social Determinants of Health

G.R.S.: Gestão de Resíduos Sólidos

W.M.: Waste Management

M.U.: Metabolismo Urbano

U.M.: Urban Metabolism

Sust.: Sustentabilidade/Sustainability

No Quadro 22 não há presença de muitos nós interdisciplinares, não havendo resultados para estudos de "metabolismo urbano" e poucos resultados sobre "gestão de resíduos sólidos". "Plano diretor" e "Planejamento", assim como "planejamento" e "cidades saudáveis" tem interdisciplinariedade mais expressiva. 
Quadro 22 - Matriz de referências - LILACS

\begin{tabular}{|c|c|c|c|c|c|c|c|c|c|c|c|c|c|c|}
\hline & P.D. & Plan. & M.P. & $\begin{array}{l}\text { Plan } \\
\text { n. }\end{array}$ & C.S. & H.C. & $\begin{array}{l}\text { D.S. } \\
\text { D.S. }\end{array}$ & $\begin{array}{l}\text { S.D. } \\
\text { O.H. }\end{array}$ & $\begin{array}{l}\text { G.R. } \\
\text { S. }\end{array}$ & $\begin{array}{l}\text { W.M } \\
\end{array}$ & M.U. & U.M. & Sust. & Sust \\
\hline P.D. & $\begin{array}{c}3.81 \\
7\end{array}$ & [] & [] & [] & [] & [] & [] & [] & [] & [] & [] & [] & [] & [] \\
\hline Plan. & 274 & $\begin{array}{l}275 . \\
799\end{array}$ & [] & [] & [] & [] & [] & [] & [] & [] & [] & [] & [] & [] \\
\hline M.P. & - & - & - & [] & [] & [] & [] & [] & [] & [] & [] & [] & [] & [] \\
\hline $\begin{array}{l}\text { Plan } \\
\text { n. }\end{array}$ & - & - & - & - & [] & [] & [] & [] & [] & [] & [] & [] & [] & [] \\
\hline C.S. & 23 & 173 & - & - & $\begin{array}{c}1.23 \\
0\end{array}$ & [] & [] & [] & [] & [] & [] & [] & [] & [] \\
\hline H.C. & - & - & - & - & - & - & [] & [] & [] & [] & [] & [] & [] & [] \\
\hline $\begin{array}{l}\text { D.S. } \\
\text { D.S. }\end{array}$ & 2 & 110 & - & - & 8 & - & $\begin{array}{c}1.74 \\
2 \\
\end{array}$ & [] & [] & [] & [] & [] & [] & [] \\
\hline $\begin{array}{l}\text { S.D. } \\
\text { O.H. }\end{array}$ & - & - & - & - & - & - & - & - & [] & [] & [] & [] & [] & [] \\
\hline $\begin{array}{l}\text { G.R. } \\
\text { S. }\end{array}$ & 0 & 8 & - & - & 0 & - & 0 & - & 39 & [] & [] & [] & [] & [] \\
\hline $\begin{array}{l}\text { W.M } \\
\end{array}$ & - & - & - & - & - & - & - & - & - & - & [] & [] & [] & [] \\
\hline M.U. & 0 & 0 & - & - & 0 & - & 0 & - & 0 & - & 1 & [] & [] & [] \\
\hline U.M. & - & - & - & - & - & - & - & - & - & - & - & - & [] & [] \\
\hline Sust. & 8 & 143 & - & - & 17 & - & 3 & - & 8 & - & 0 & - & $\begin{array}{c}1.17 \\
0\end{array}$ & [] \\
\hline Sust. & - & - & - & - & - & - & - & - & - & - & - & - & - & - \\
\hline
\end{tabular}

Legenda ( ${ }^{o}$ de resultados):

$\begin{array}{llllll}0 & 1-100 & 101-500 & 501-1.000 & 1.001-5.000 & 5.001- \\ 10.000 & >10.001\end{array}$

Fonte: LILACS, 2018

Notas:

P.D. : Plano Diretor

Plan.: Planejamento

M.P.: Master Plan

Plann.: Planning

C.S.: Cidades Saudáveis

H.C.: Healthy Cities

D.S.D.S.: Determinantes Sociais da Saúde

S.D.O.H.: Social Determinants of Health

G.R.S.: Gestão de Resíduos Sólidos

W.M.: Waste Management

M.U.: Metabolismo Urbano

U.M.: Urban Metabolism

Sust.: Sustentabilidade/Sustainability

O Quadro 23 contém resultados para todas as pesquisas interdisciplinares, apesar de apenas três resultados para "determinantes sociais da saúde" e "metabolismo urbano". E muitos resultados para buscas em inglês de "sustentabilidade" e "planejamento". 
Quadro 23 - Matriz de referências - Google Acadêmico

\begin{tabular}{|c|c|c|c|c|c|c|c|c|c|c|c|c|c|c|}
\hline & P.D. & Plan. & M.P. & $\begin{array}{l}\text { Plan } \\
\text { n. }\end{array}$ & C.S. & H.C. & $\begin{array}{l}\text { D.S. } \\
\text { D.S. }\end{array}$ & $\begin{array}{l}\text { S.D. } \\
\text { O.H. }\end{array}$ & $\begin{array}{l}\text { G.R. } \\
\text { S. }\end{array}$ & $\begin{array}{l}\text { W.M } \\
\end{array}$ & M.U. & U.M. & Sust. & Sust. \\
\hline P.D. & $\begin{array}{c}62.4 \\
00\end{array}$ & [] & [] & [] & [] & [] & [] & [] & [] & [] & [] & [] & [] & [] \\
\hline Plan. & $\begin{array}{c}54.0 \\
00\end{array}$ & $\begin{array}{c}1.55 \\
0.00 \\
0\end{array}$ & [] & [] & [] & [] & [] & [] & [] & [] & [] & [] & [] & [] \\
\hline M.P. & - & - & $\begin{array}{l}244 . \\
000\end{array}$ & [] & [] & [] & [] & [] & [] & [] & [] & [] & [] & [] \\
\hline $\begin{array}{l}\text { Plan } \\
\text { n. }\end{array}$ & - & - & $\begin{array}{l}316 . \\
000\end{array}$ & $\begin{array}{c}4.60 \\
0.00 \\
0\end{array}$ & [] & [] & [] & [] & [] & [] & [] & [] & [] & [] \\
\hline C.S. & 331 & $\begin{array}{c}1.41 \\
0\end{array}$ & - & - & $\begin{array}{c}2.18 \\
0\end{array}$ & [] & [] & [] & [] & [] & [] & [] & [] & [] \\
\hline H.C. & - & - & 941 & $\begin{array}{c}12.0 \\
00\end{array}$ & - & $\begin{array}{c}33.4 \\
00\end{array}$ & [] & [] & [] & [] & [] & [] & [] & [] \\
\hline $\begin{array}{l}\text { D.S. } \\
\text { D.S. }\end{array}$ & 387 & $\begin{array}{c}3.56 \\
0\end{array}$ & - & - & $\begin{array}{c}2.18 \\
0\end{array}$ & - & $\begin{array}{c}5.69 \\
0\end{array}$ & [] & [] & [] & [] & [] & [] & [] \\
\hline $\begin{array}{l}\text { S.D. } \\
\text { O.H. }\end{array}$ & - & - & 572 & $\begin{array}{c}34.5 \\
00\end{array}$ & - & $\begin{array}{c}2.45 \\
0\end{array}$ & - & $\begin{array}{c}70.2 \\
00\end{array}$ & [] & [] & [] & [] & [] & [] \\
\hline $\begin{array}{l}\text { G.R. } \\
\text { S. }\end{array}$ & $\begin{array}{c}1.59 \\
0\end{array}$ & $\begin{array}{c}6.46 \\
0\end{array}$ & - & - & 33 & - & 25 & - & $\begin{array}{c}10.2 \\
00\end{array}$ & [] & [] & [] & [] & [] \\
\hline W.M & - & - & $\begin{array}{c}17.8 \\
00\end{array}$ & $\begin{array}{c}358 . \\
000\end{array}$ & - & $\begin{array}{c}1.74 \\
0\end{array}$ & - & $\begin{array}{c}1.47 \\
0\end{array}$ & - & $\begin{array}{c}1.39 \\
0.00 \\
0\end{array}$ & [] & [] & [] & [] \\
\hline M.U. & 179 & 428 & - & - & 20 & - & 3 & - & 54 & - & $\begin{array}{c}2.19 \\
0\end{array}$ & [] & [] & [] \\
\hline U.M. & - & - & 787 & $\begin{array}{c}7.64 \\
0\end{array}$ & - & 200 & - & 47 & - & $\begin{array}{c}2.17 \\
0\end{array}$ & - & $\begin{array}{c}9.34 \\
0\end{array}$ & [] & [] \\
\hline Sust. & $\begin{array}{c}25.1 \\
00\end{array}$ & $\begin{array}{l}206 . \\
000\end{array}$ & - & - & $\begin{array}{c}1.03 \\
0\end{array}$ & - & $\begin{array}{c}1.74 \\
0\end{array}$ & - & $\begin{array}{c}7.74 \\
0\end{array}$ & - & 476 & - & $\begin{array}{r}585 \\
000\end{array}$ & [] \\
\hline Sust. & - & - & $\begin{array}{l}114 . \\
000\end{array}$ & $\begin{array}{c}2.68 \\
0.00 \\
0\end{array}$ & - & $\begin{array}{c}11.1 \\
00\end{array}$ & - & $\begin{array}{c}25.6 \\
00\end{array}$ & - & $\begin{array}{c}402 . \\
000\end{array}$ & - & $\begin{array}{c}7.70 \\
0\end{array}$ & - & $\begin{array}{c}3.63 \\
0.00 \\
0\end{array}$ \\
\hline
\end{tabular}

Legenda ( ${ }^{o}$ de resultados):

$\begin{array}{llllll}0 & 1-100 & 101-500 & 501-1.000 & 1.001-5.000 & \begin{array}{l}5.001- \\ 10.000\end{array}\end{array}$

Fonte: Google, 2018

Notas:

P.D. : Plano Diretor

Plan.: Planejamento

M.P.: Master Plan

Plann.: Planning

C.S.: Cidades Saudáveis

H.C.: Healthy Cities

D.S.D.S.: Determinantes Sociais da Saúde

S.D.O.H.: Social Determinants of Health

G.R.S.: Gestão de Resíduos Sólidos

W.M.: Waste Management

M.U.: Metabolismo Urbano

U.M.: Urban Metabolism

Sust.: Sustentabilidade/Sustainability

Foram adotados padrões de cores para melhor visualização dos resultados e os resultados duplicados foram deletados, para que a matriz não tenha um aspecto de difícil leitura. 


\section{APÊNDICE B - MAPAS DO CONTEXTO URBANO DO CAMPUS SÃO PAULO}

Neste apêndice estão mapas do contexto urbano que complementam o texto do item 2.2. referentes ao Campus São Paulo e o bairro da Vila Clementino.

O mapa indicando o zoneamento vigente, desde 2014, no bairro em que se encontra o Campus São Paulo da Unifesp (ver Figura 61) é predominantemente Zona de Estruturação Urbana (ZEU).

Optou-se por indicar apenas a ZEU, pois todo os imóveis em uso do Campus estavam dentro deste zoneamento.

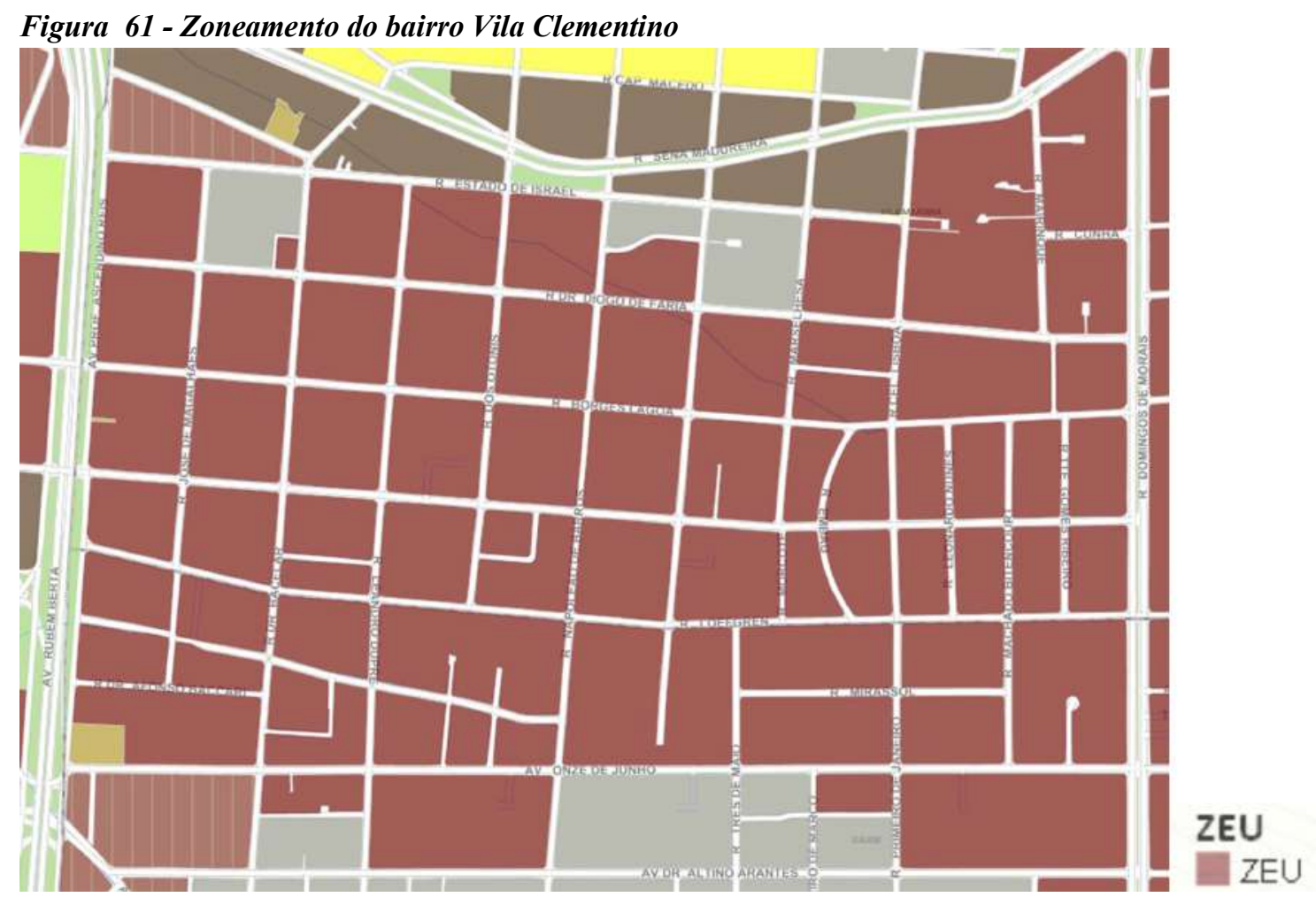

Fonte: plataforma Geosampa

O escopo do Plano Diretor de Infraestrutura (PDInfra) do CSP incluía análises referentes a mobilidade e acessibilidade do entorno para embasar propostas, que podem ser apresentadas às instancias responsáveis pelo tráfego, transporte público, manutenção e desenho de calçadas entre outros.

Neste contexto, verificou-se os dados georreferenciados disponíveis no momento de acidentes com vítima e atropelamento no entorno no CSP (ver Figura 62). 
Figura 62 - Locais de acidente na envoltória do CSP

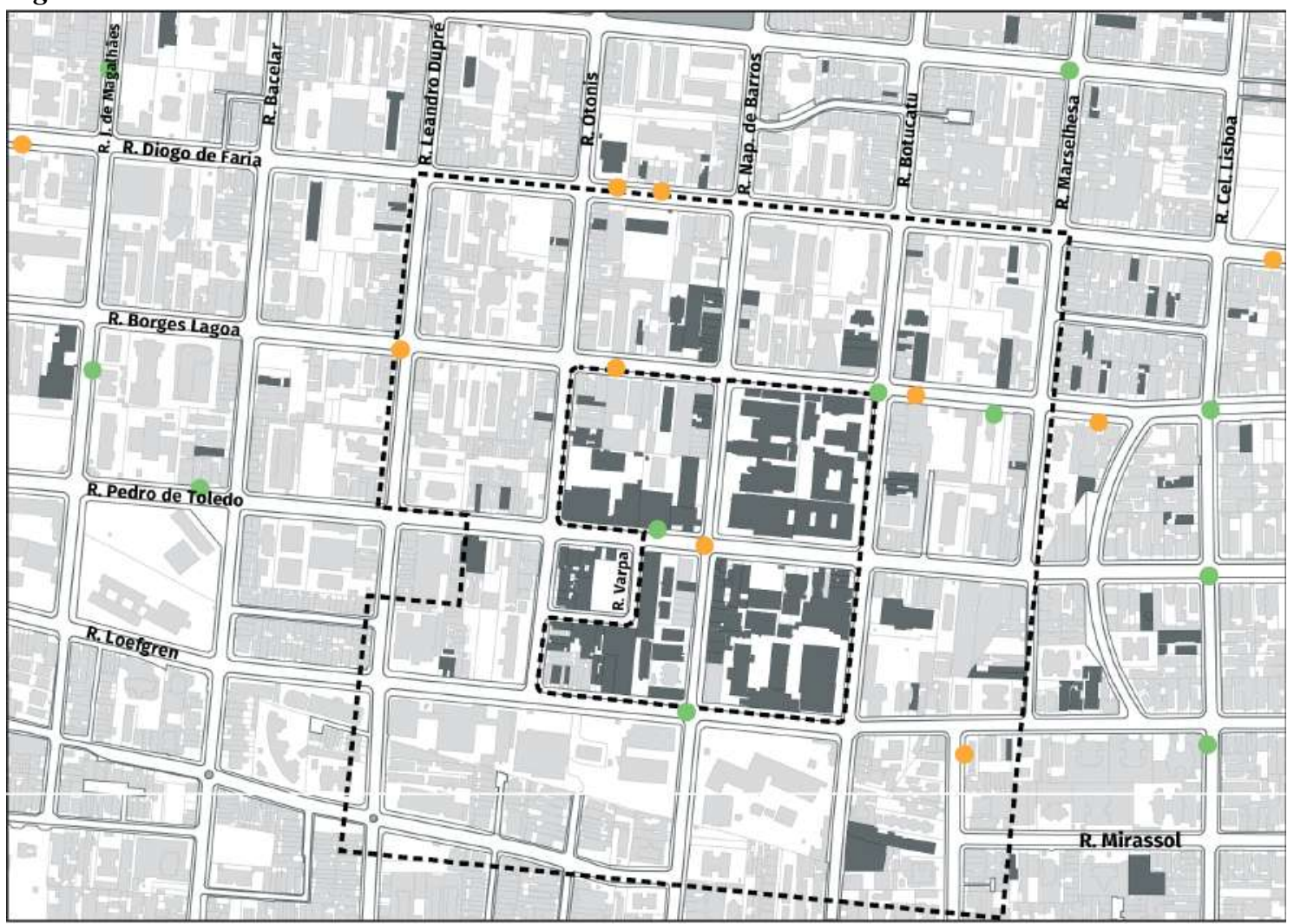

Locais de Acidente (CET, 2013)

Acidentes com vítima

Atropelamento

Fonte: MPS Arquitetos Associados (2017)

Outra análise que foi realizada e que pode ser de interesse de outras pesquisas futuras, é o mapa de uso predominante do entorno (ver Figura 63), em que se pode verificar que o bairro predominantemente é composto por edificações de uso residencial vertical de médio e alto padrão. 
Figura 63 - Mapa de uso predominante da área envoltória do Campus São Paulo - Unifesp

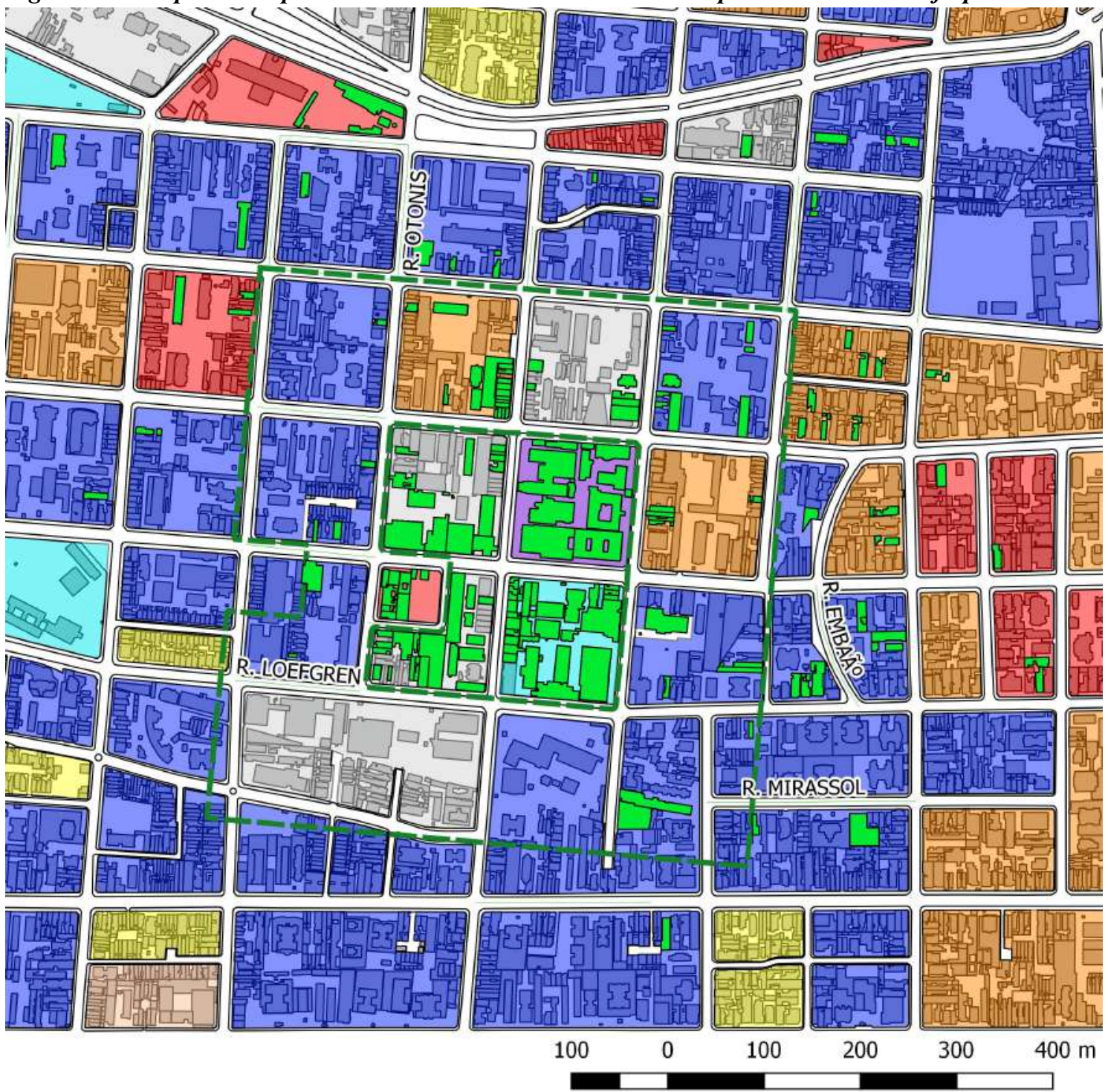

LEGENDA

TECIDO URBANO

NOME_RUAS_PRINCIPAIS

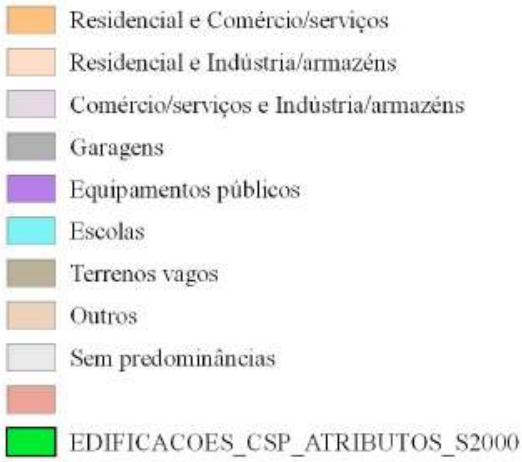

Fonte: Base georreferenciada formulada por MPS Arquitetos Associados, 2017 e dados de uso predominante: plataforma Geosampa 
E complementando o mapa anterior, é possível verificar no mapa de densidade populacional (ver Figura 64) a distribuição geográfica do adensamento populacional em relação aos edifícios do CSP.

Figura 64 - Mapa de densidade populacional da área envoltória do Campus São Paulo - Unifesp

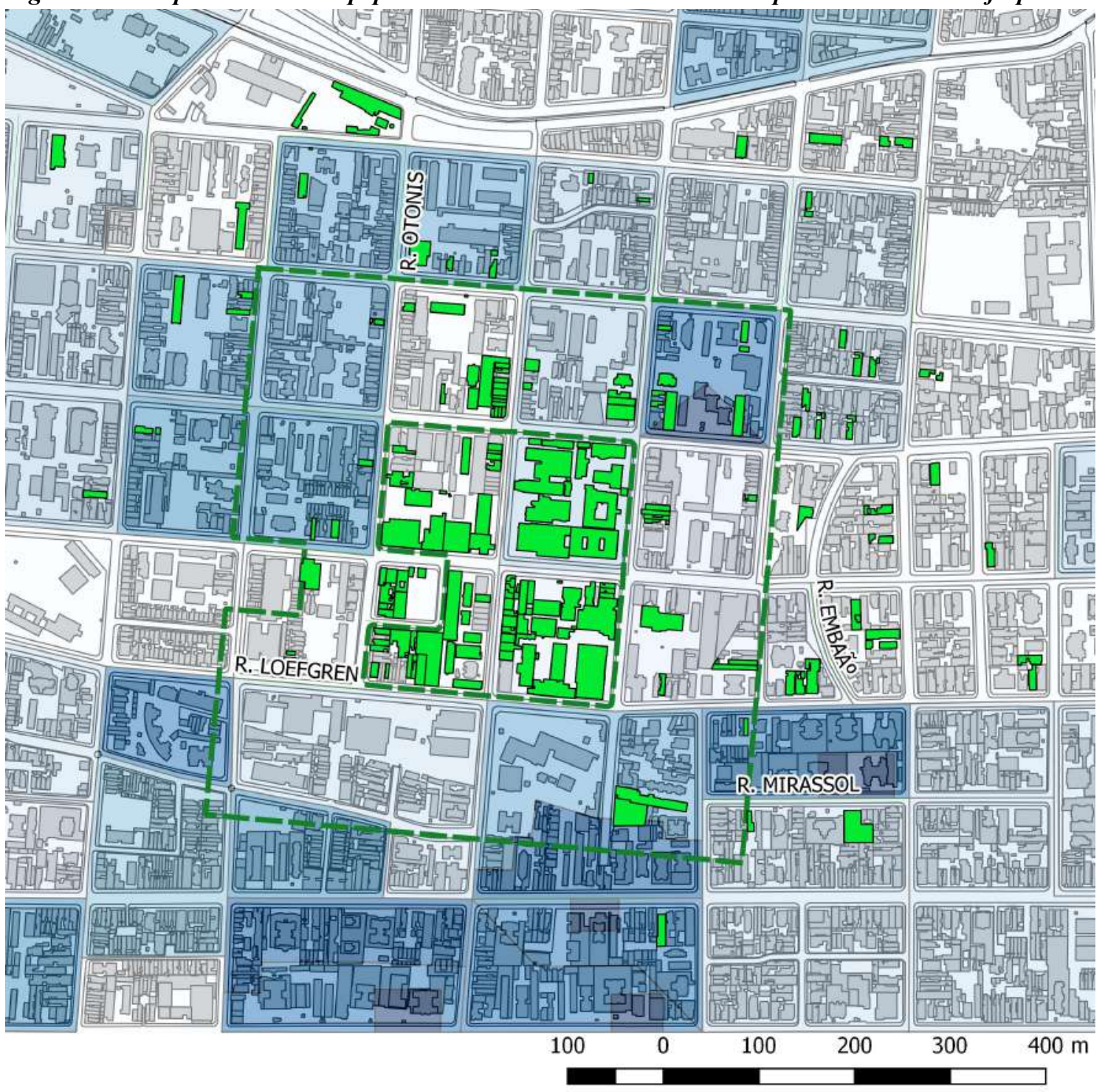

LEGENDA

\begin{tabular}{l|l}
$\square$ EDIFICACOES_CSP_ATRIBUTOS_S2000 & $113-137$ \\
TECIDO URBANO & $137-172$ \\
- NOME_RUAS_PRINCIPAIS & $172-221$ \\
$-=$ POLO_SAUDE_ENSINO_PESQUISA_SIRGAS200 & $221-294$ \\
\hline SIRGAS_SHP_densidade_demografica_2010 & $294-412$ \\
$\square$ & -63 \\
$\square$ & $412-797$ \\
\hline$\square-85$ & $797-6511$ \\
$85-113$ &
\end{tabular}

Fonte: Base georreferenciada formulada por MPS Arquitetos Associados, 2017 e dados de densidade populacional: plataforma Geosampa 
Por fim, para se ter um panorama da dispersão de resíduos em relação aos demais edifícios do campus e em relação ao bairro, foi feito um mapa em que todos os tipos de resíduos são apresentados (ver Figura 65). 
Figura 65 - Mapa com sobreposição dos tipos de resíduos, outros edifícios do campus e malha urbana

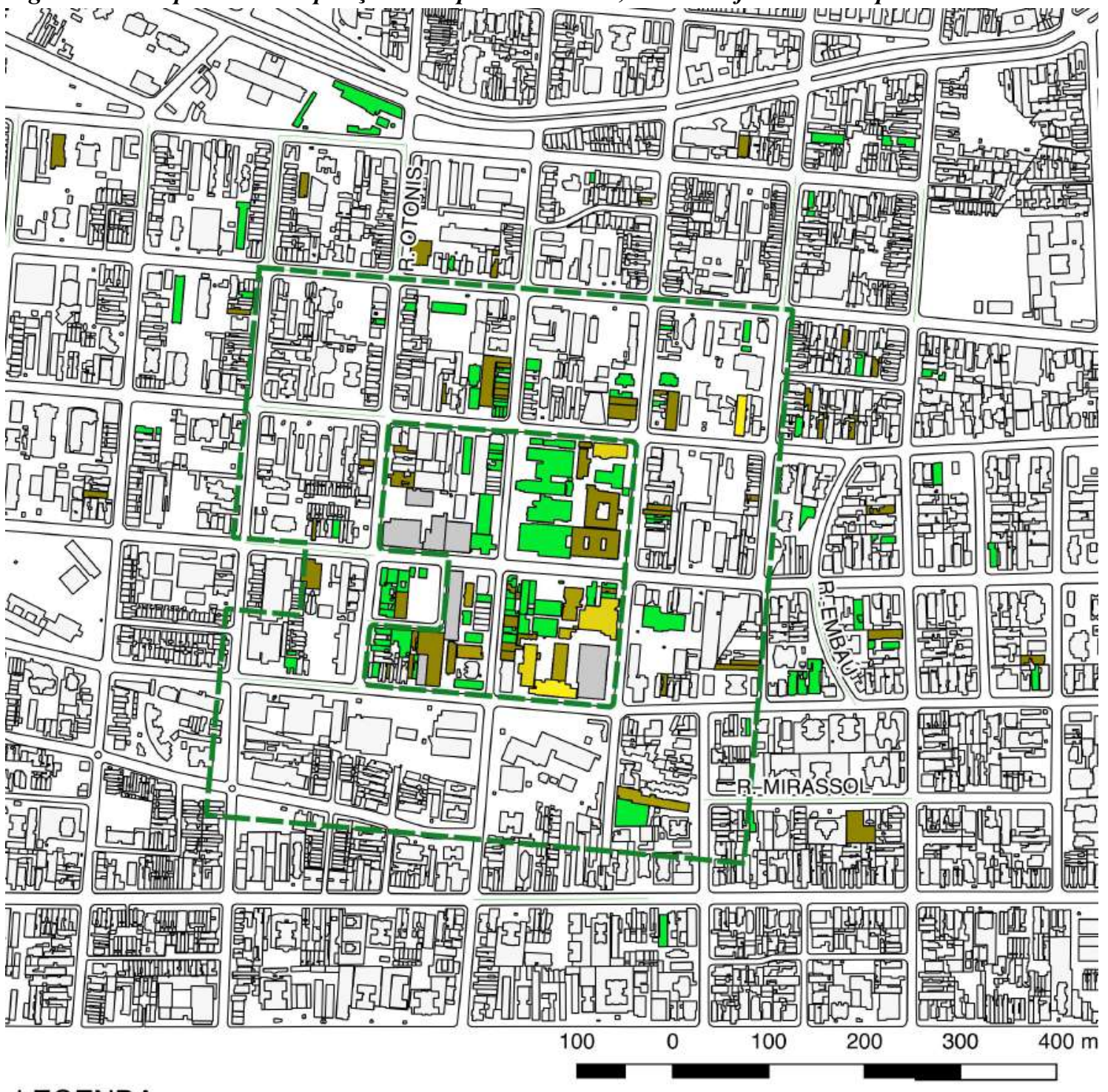

\section{LEGENDA}

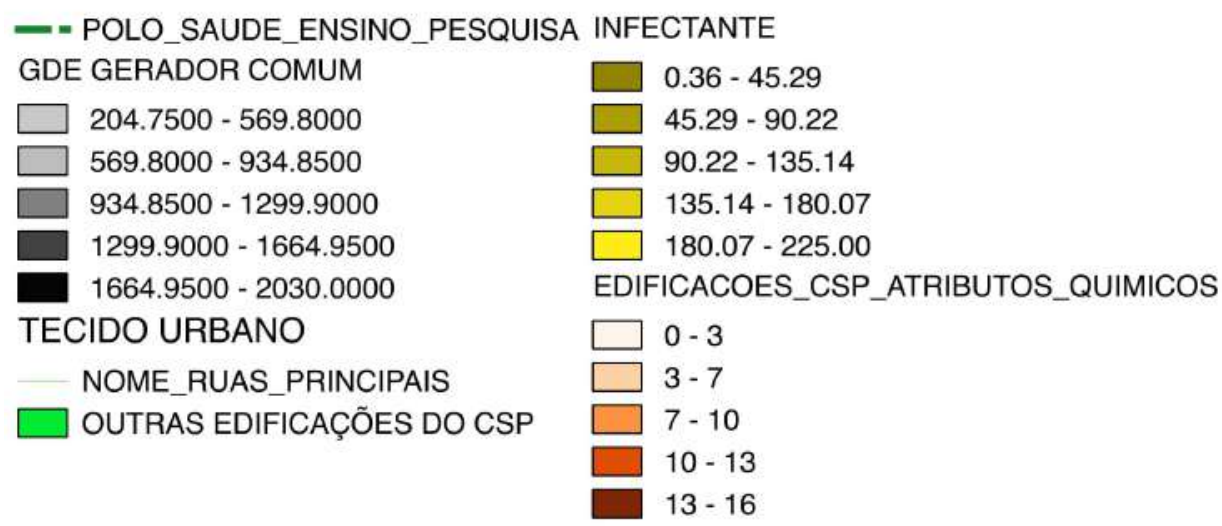

Fonte: Base georreferenciada formulada por MPS Arquitetos Associados, 2017 


\section{APÊNDICE C - PLANOS DIRETORES ANTERIORES DO CAMPUS SÃO PAULO (1982 E 2010)}

Neste apêndice são apresentados os dois planos diretores que antecederam o Plano Diretor de Infraestrutura (PDInfra), que foram publicados em 1982 e 2010.

Em 1982 foi colocado o primeiro planejamento institucional do Campus São Paulo no modelo de plano diretor encontrado. À época, não existia a figura de "Campus São Paulo", pois ainda era Escola Paulista de Medicina (EPM).

Assim como todos os planos posteriores, o plano de 1982 coloca o Hospital São Paulo (HSP) no escopo do planejamento, embora seja gerido por outra pessoa jurídica, a Associação Paulista para o Desenvolvimento da Medicina (SPDM) ${ }^{110}$, argumentando que:

A Escola Paulista de Medicina, fundada em 1933 e federalizada em 1956, é uma autarquia vinculada ao Ministério de Educação e Cultura (MEC). O Hospital São Paulo, que fazia parte integrante da antiga entidade particular, continuou como pessoa jurídica de direito provado após a citada federalização, nem por isso se dissolvendo, na prática, o conjunto Escola-Hospital que existia até então.

[‥]

A federalização não veio modificar esta situação, pois o complexo EPMHSP, que se formou em 1940, na prática não se dissociou até hoje, dadas as intimas ligações que existem entre ambas as entidades, não só no campo assistencial como também no aprimoramento da formação dos médicos "produzidos". (EPM, 1982, p. 9)

Esta situação pode ser verificada na planta contendo a informação de gestão de imóveis. Na época, o complexo consistia em cinco quadras principais em que a EPM e SPDM ocupavam ao menos $30 \%$ do total da quadra. As áreas remanescentes eram ocupadas por propriedades particulares caracterizadas como casa assobradadas e geminadas com área construída de $80 \mathrm{a} 100 \mathrm{~m}^{2}$ e com idades superiores a 20 anos à época.

O contexto urbano diagnosticado na época foi considerado como um dos pontos de partida do planejamento do espaço físico, conforme anunciado nas primeiras páginas do documento que gerou o plano diretor e também na formulação das bases:

Maior ênfase será dada ao planejamento físico em detrimento de um plano acadêmico, o que se acredita já em franco andamento e com metas

110 À época, Sociedade Paulista para o Desenvolvimento da Medicina. 
caracterizadas. Mesmo no plano físico, qualquer elucubração mais livre esbarra fatalmente em um fator concreto, qual seja, a situação geográfica da Escola, pois sua localização na malha urbana é inquestionável, ao menos por tempo previsível. (EPM, 1982, p. 2)

Por sua situação numa zona densamente construída e de ocupação não recente, o Complexo EPM-HSP goza de todos os serviços de infraestrutura urbana tais como transportes, eletricidade, água, esgoto, gás e telefone. Cumpre ressaltar que as redes de serviço ainda estão bem dimensionadas, sem saturação, uma vez que a região não sofreu alterações substanciais em sua ocupação original. (EPM, 1982, p. 18.)

As bases utilizadas no planejamento de gestão de imóveis (ver Figura 66), da situação da malha urbana e infraestrutura urbana apresentam o contexto em que a Escola estava inserida na época. No entanto, na base não constam os imóveis alugados que eram ocupados pela Residência Médica, Oftalmologia e outros departamentos em imóveis dispersos.

Outra constatação é que o bairro, já nesta época, estava consolidado (ver Figura 67) e com infraestruturas urbanas suficientes para as atividades de ensino, pesquisa, assistência e extensão (ver Figura 68). E, portanto, um local apto à expansão das atividades previstas. 
Figura 66 - Gestão dos imóveis do Campus São Paulo em 1982

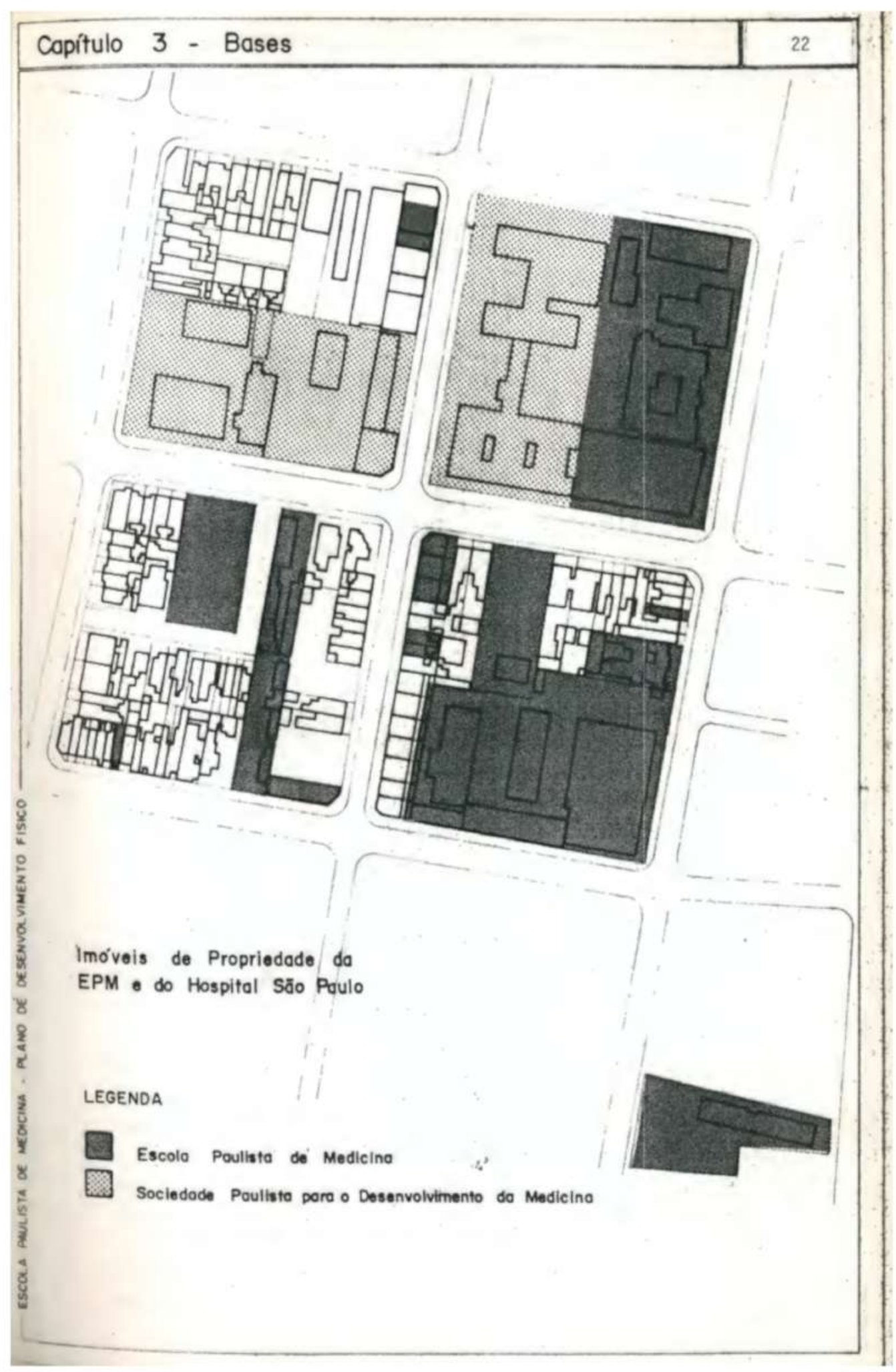

Fonte: (EPM, 1982, p. 22) 
Figura 67 - Malha urbana do entorno do Campus São Paulo em 1982

;apitulo 3 - Bases

SITUAÇĀO NA MALHA URBANA

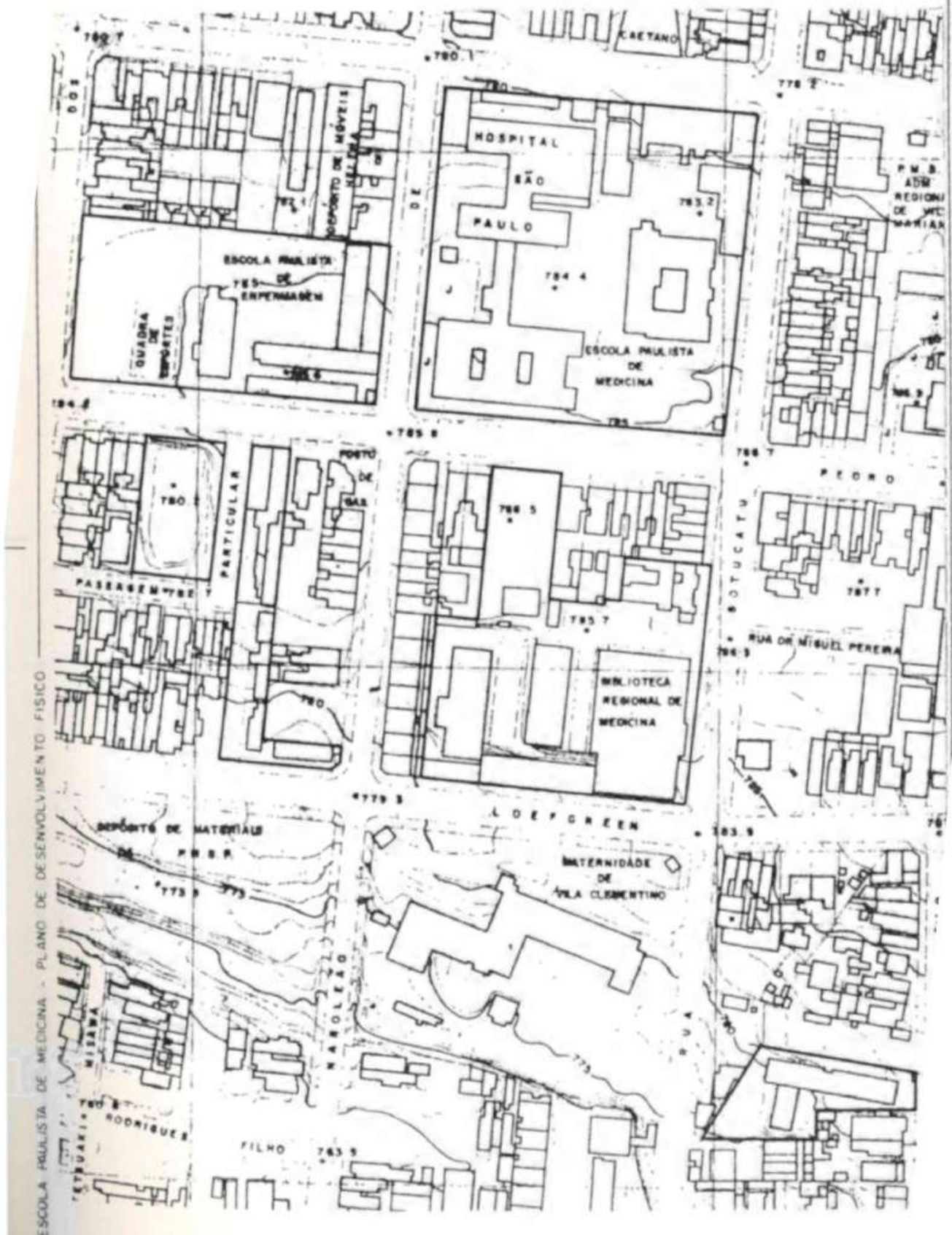

Retirado de (EPM, 1982, p. 19) 
Figura 68 - Infraestrutura urbana do entorno do Campus São Paulo em 1982

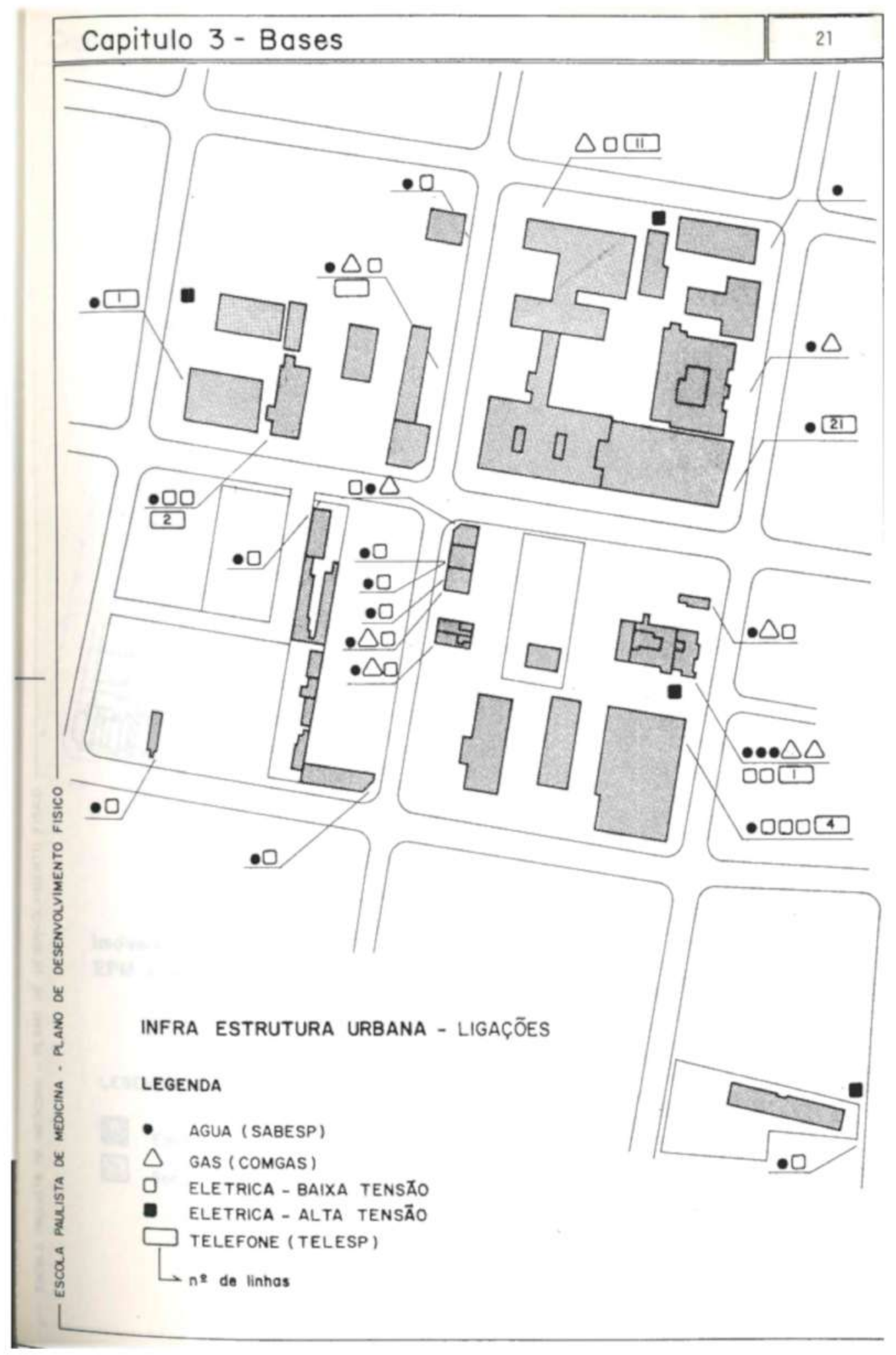

Retirado de (EPM, 1982, p. 21) 
Figura 69 - Ocupação dos espaços do Campus São Paulo em 1982

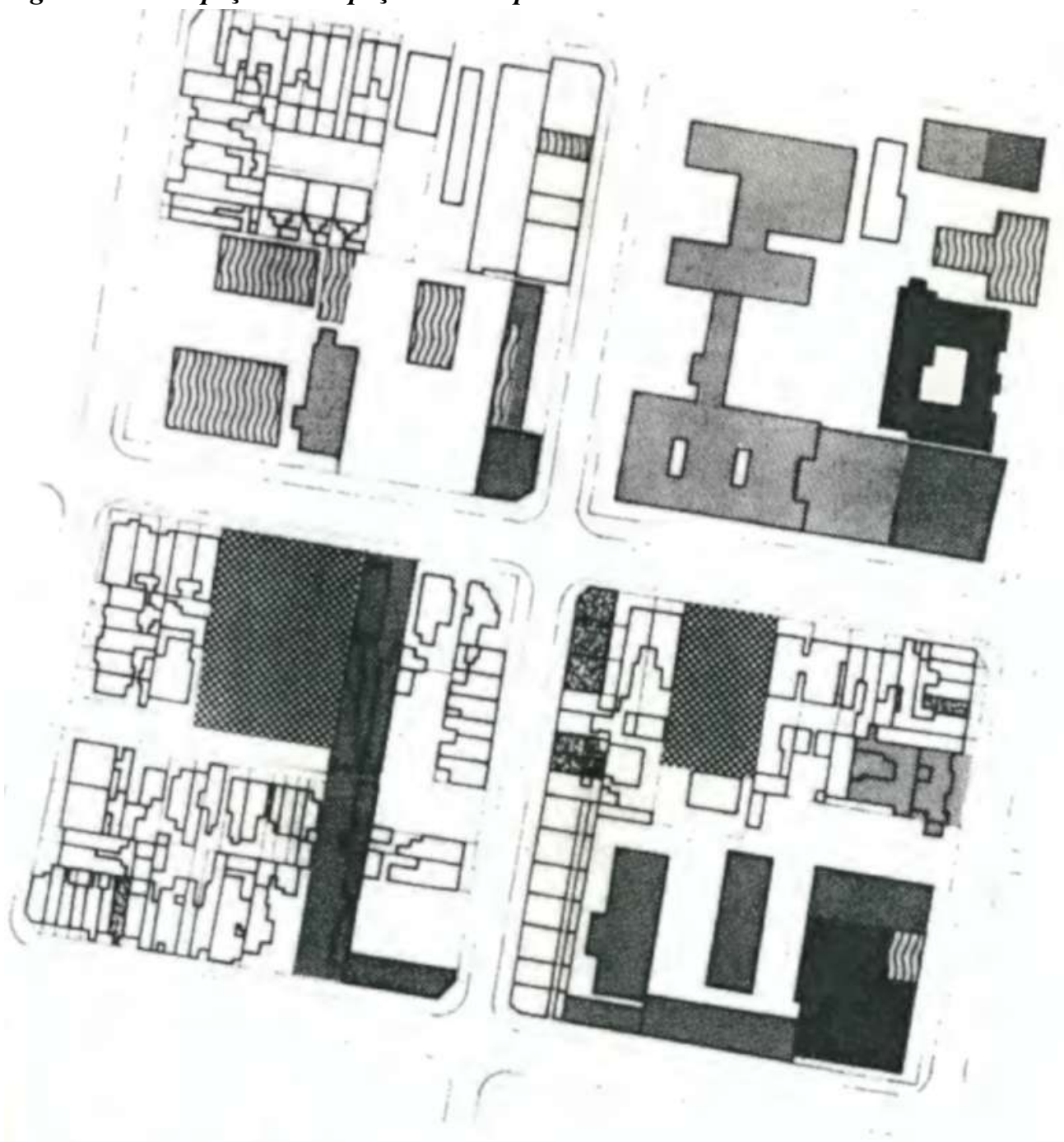

Distribuiçāo por Atividades

(Existente)

LEGENDA

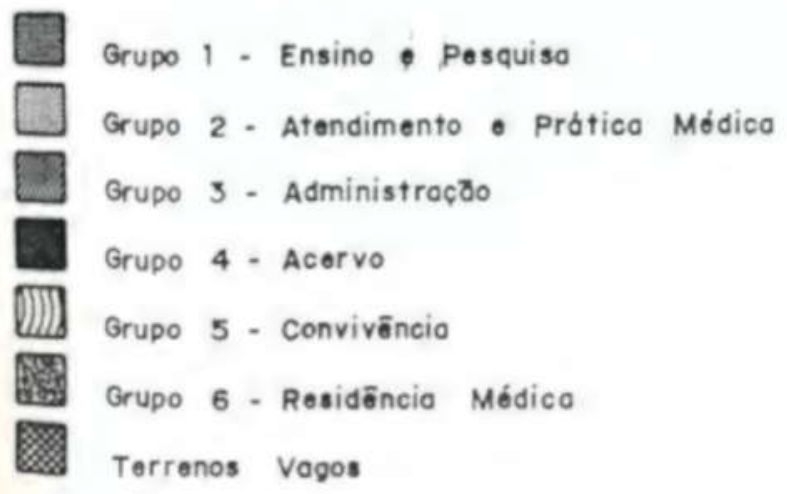

Retirado de (EPM, 1982, p. 45) 
Desde a federalização, o crescimento da EPM foi desenvolvido sem o devido planejamento, de "forma aparentemente caótica, caracterizando a expansão pouco ordenada da EPM" "11. Esta conclusão veio do fato de que, agrupando as atividades em 6 tipos, verificou-se que não houve racionalização na implantação destas (ver Figura 69).

As atividades consideradas foram :1- Pesquisa e Ensino; 2- Atendimento e Prática Médica; 3- Administração; 4- Acervo; 5- Centro de Convivência; 6- Residência Médica. Pelas exigências de cada atividade, muitos dos edifícios não atendem às necessidades, mesmo após reformas de adaptação em sobrados e mesmo em edifícios novos:

Pelo acima exposto, fica evidente que as constantes reformas e adaptações sem sanar os problemas completamente, oneram sobremaneira a EPM e o HSP, e tornam, pela inadequação do espaço, deficiente sua produtividade. (EPM, 1982, p. 44)

Como proposta para solução da situação diagnosticada, o plano sugere a "integração imobiliária" inclusive para um "hospital particular" que pudesse se auto sustentar, ou que fosse uma fonte alternativa de receita. Vale ressaltar que este plano foi desenvolvido antes da Constituição Cidadã de 1988 e antes mesmo do Sistema Único de Saúde (1988), não sendo, portanto, estranho uma instituição pública propor um hospital privado de maneira explícita.

A integração imobiliária, como principal vantagem, possibilitará o aumento real do espaço disponivel pela diminuição dos recuos necessários, áreas de circulação externa, racionalização dos fluxos internos, etc. Da mesma forma tornará possivel introduzir novos parâmetros para a organização racional quanto a utilização dos serviços oferecidos pela infra-estrutura urbana (água, luz, telefone, etc.). (EPM, 1982, p. 55)

[...] deve ser analisada a criação de um hospital particular vinculado ao Hospital São Paulo, ou mesmo a criação dentro dele de setores de atendimento particular sob controle total da Sociedade Paulista para o Desenvolvimento da Medicina, atual administradora do HSP.

A criação de serviços de atendimento nos moldes de um "hospital particular", com fins lucrativos (lucros suficientes para se auto sustentar), além das vantagens já enumeradas, aumentaria sensivelmente o tempo de permanência dos docentes possibilitando, nos horários de pico inferior, o atendimento de parte de suas clientelas particulares [...] (EPM, 1982, p. 57)

${ }^{111}$ Retirado de (EPM, 1982, p. 41) 
No entanto, a polêmica gerada por esta idéia, já várias vezes aventada, não permite, neste Plano, a sua adoção pura e simples. Qualquer espaço fisico necessário à sua concretização deverá ser procurado (eventualmente com a redução de outros) se e quando de sua implantação. (EPM, 1982, p. 58)

A integração imobiliária mencionada incluiria a junção de lotes e imóveis para construção ou ampliação de edifícios que atendessem às demandas e normas referentes às atividades. Para que a nova ocupação seja racionalizada, propõe-se um zoneamento (ver Figura 70) por atividade. Zona 1 - Ensino e Pesquisa, Zona 2 - Atendimento e Prática Médica, Zona 3 - Administração, Zona 4 - Acervo, Zona 5 - Convivência e Zona 6 Residência Médica. 
Figura 70 - Zoneamento proposto para o Campus São Paulo em 1982

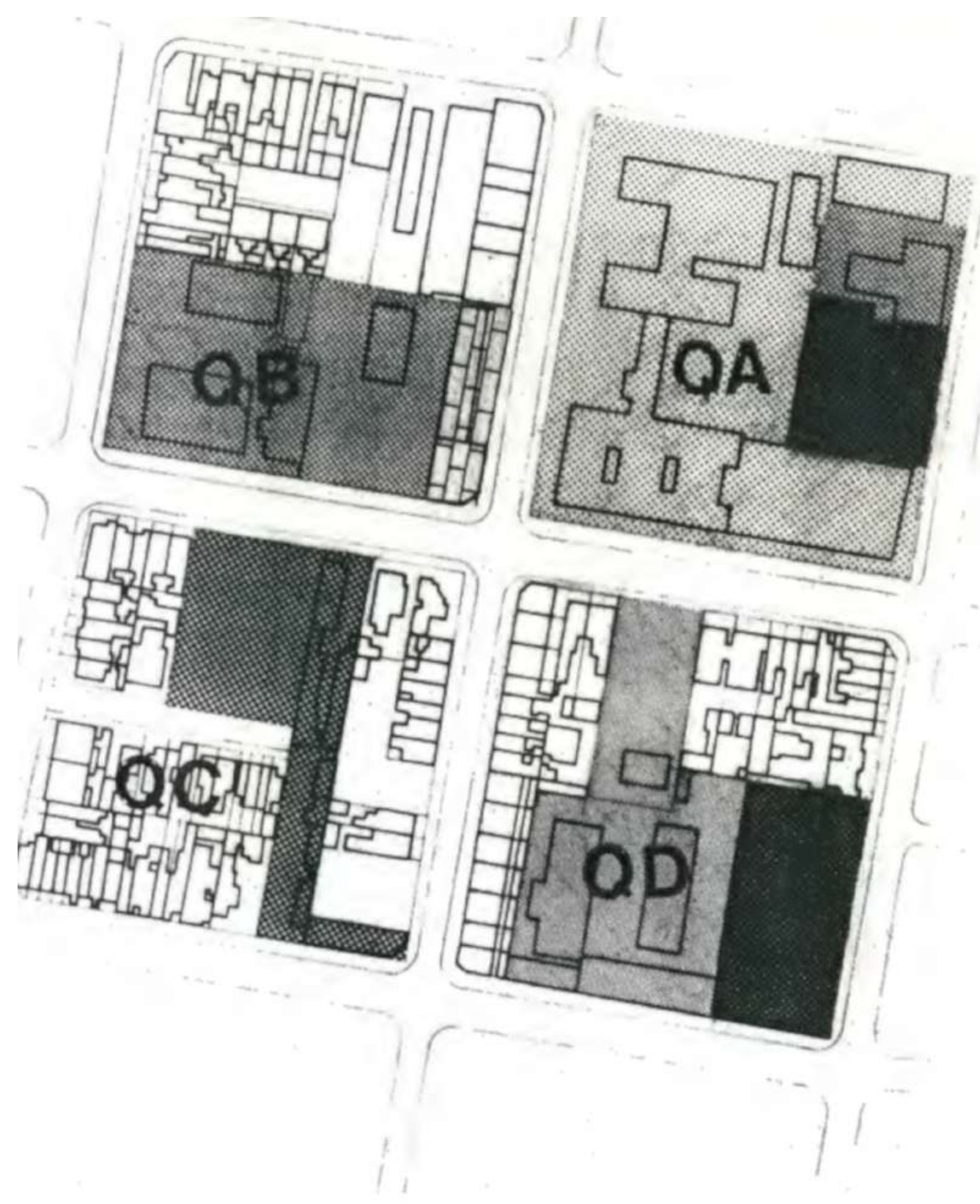

Zoneamento Proposto
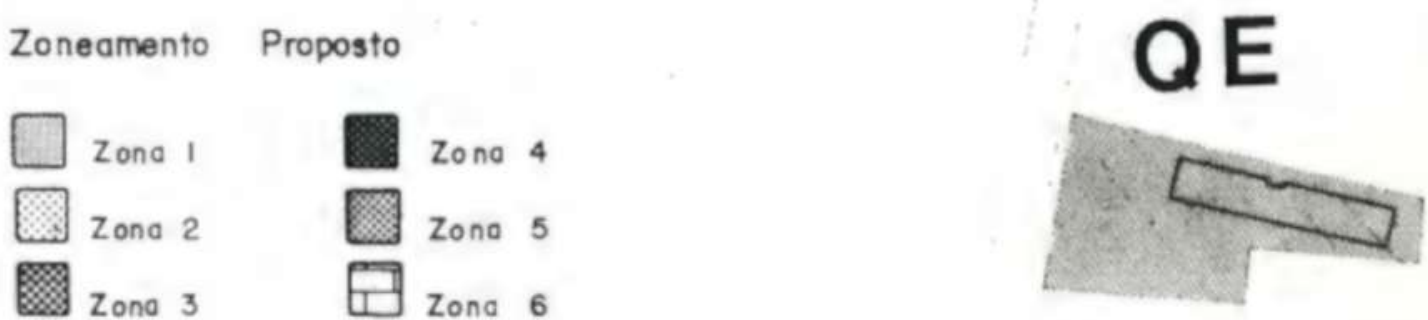

Retirado de (EPM, 1982, p. 68)

O plano indica onde poderiam ser novos edifícios e as premissas que deverão ser atendidas por eles, no entanto, sem estudos preliminares dessas construções. As premissas 
básicas deste plano seriam a verticalidade, uma vez que a Escola se encontra em região de alto custo de terrenos e a flexibilidade, pela ocupação do espaço ser dinâmica.

Muitas dessas premissas continuam presentes, como veremos a seguir, no projeto urbanístico iniciado em 2006, com a formação do Grupo de Trabalho do Bairro Universitário $(\mathrm{GTBU})^{112}$, realizado a partir de um convenio com a Prefeitura Municipal de São Paulo. Neste período, a instituição já estava formalizada como Universidade Federal de São Paulo.

A primeira diferença entre os planos diretores está na equipe técnica que produziu cada um deles. No primeiro, de 1982, a equipe era constituída por membros da Escola, enquanto que na segunda, foi realizada em colaboração com equipe externa à instituição. Não constam nos créditos nomes comuns aos dois projetos.

O plano de 1982 não foi completamente implementando, uma vez que a premissa de verticalização não foi atendida nos anos de expansão das atividades do campus, com mais cursos, profissionais e estudantes, porém sem atentar para a questão do planejamento de espaço físico:

O complexo reúne 5 cursos de nivel superior, 233 programas na esfera do saber médico-biológico, e cerca de 190 cursos de extensão, o que implica em mais de 11.500 estudantes e 3.300 profissionais, entre médicos e professores, no seu campus. Atende mensalmente a 43.800 pacientes em urgência, e 152.000 pacientes em consultas, no vasto sistema de saúde de que se constitui. A implementação dessa formidável atuação ocorreu mediante a construção de novos edificios de porte e da ocupação de edificações e residências das redondezas da unidade original na rua Botucatu, espraiando-se pelo bairro até ocupar mais de duas centenas de imóveis. (GTBU, 2010)

112 Portaria 3089 de 7 de agosto de 2006 - Prefeitura de São Paulo 


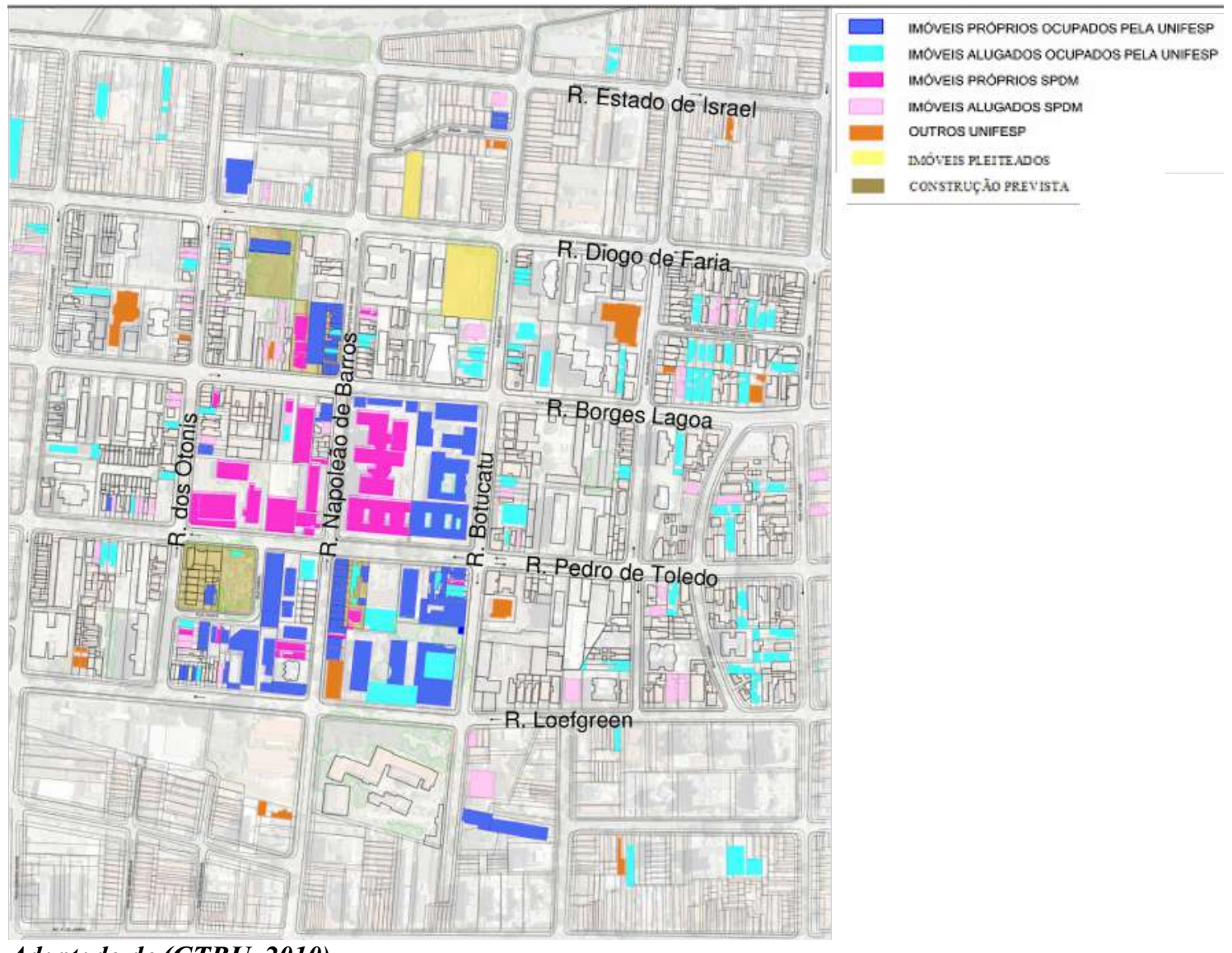

Adaptado de (GTBU, 2010)

A questão urbana, diagnosticada em 1982, se mantém neste contexto, porém agora com a informação do número de imóveis que são próprios e alugados (ver Figura 71). O espraiamento do campus para atender a crescente demanda das atividades de ensino, pesquisa, extensão e assistência causou desconfortos ao entorno, majoritariamente residencial, porém, a Prefeitura também enxerga potenciais do chamado "turismo de saúde" que podem ser potencializados:

Tal transformação não poderia ocorrer sem que se gerassem alguns conflitos e provocasse certo desconforto, tanto para os antigos moradores, quanto para os atuais usuários desses serviços, em que pese a elevada qualidade do atendimento prestado a ambos os grupos pelas instituições públicas que estão na origem e no centro dessas atividades. As demandas que resultam da intensa dinâmica esboçada acima, e que se manifestam em decorrência da atração de atividades para a região, constituem-se em excepcional desafio para a cidade e sua gestão, e apontam para considerável potencial a ser dinamizado.

\section{[‥]}

A intensa dinâmica que ali se localiza revela-se em oportunidade para se desenvolver na região bairro vocacionado para atividades 
relacionadas ao universo de atuação da UNIFESP e do Hospital São Paulo, ainda inexploradas.

A afluência de visitantes e de pacientes que acorrem para a região, vindos de outras regiões do país, e mesmo do exterior, pelo seu porte, constitui-se no fenômeno tratado como turismo de saúde, e para esse contingente a estrutura de serviços próximos é consideravelmente insuficiente. (GTBU, 2010)

Como primeiro diagnóstico do contexto urbano, o grupo entende como características da situação atual, que o bairro tem a vocação em serviços na área de Saúde, que as atividades da Unifesp estão dispersas, dificultando os fluxos próprios das atividades, ocupação de renque de casas e sobrados é inadequado, coincidindo com a baixa utilização de solo; conflito entre a distribuição de atividades e os serviços públicos como transporte e coleta de lixo (ver Figura 72), ocasionando condições ambientais impróprias; condições de locomoção e utilização do espaço público precárias e ausência de espaço e serviços próprios da Universidade.

Um ponto a ser ressaltado é que a preocupação do plano agora começa a incorporar não apenas questões programáticas de necessidade de espaço, mas de qualidades ambientais e urbanas, inclusive mencionando outras infraestruturas urbanas como coleta de resíduos, transporte público e espaço público.

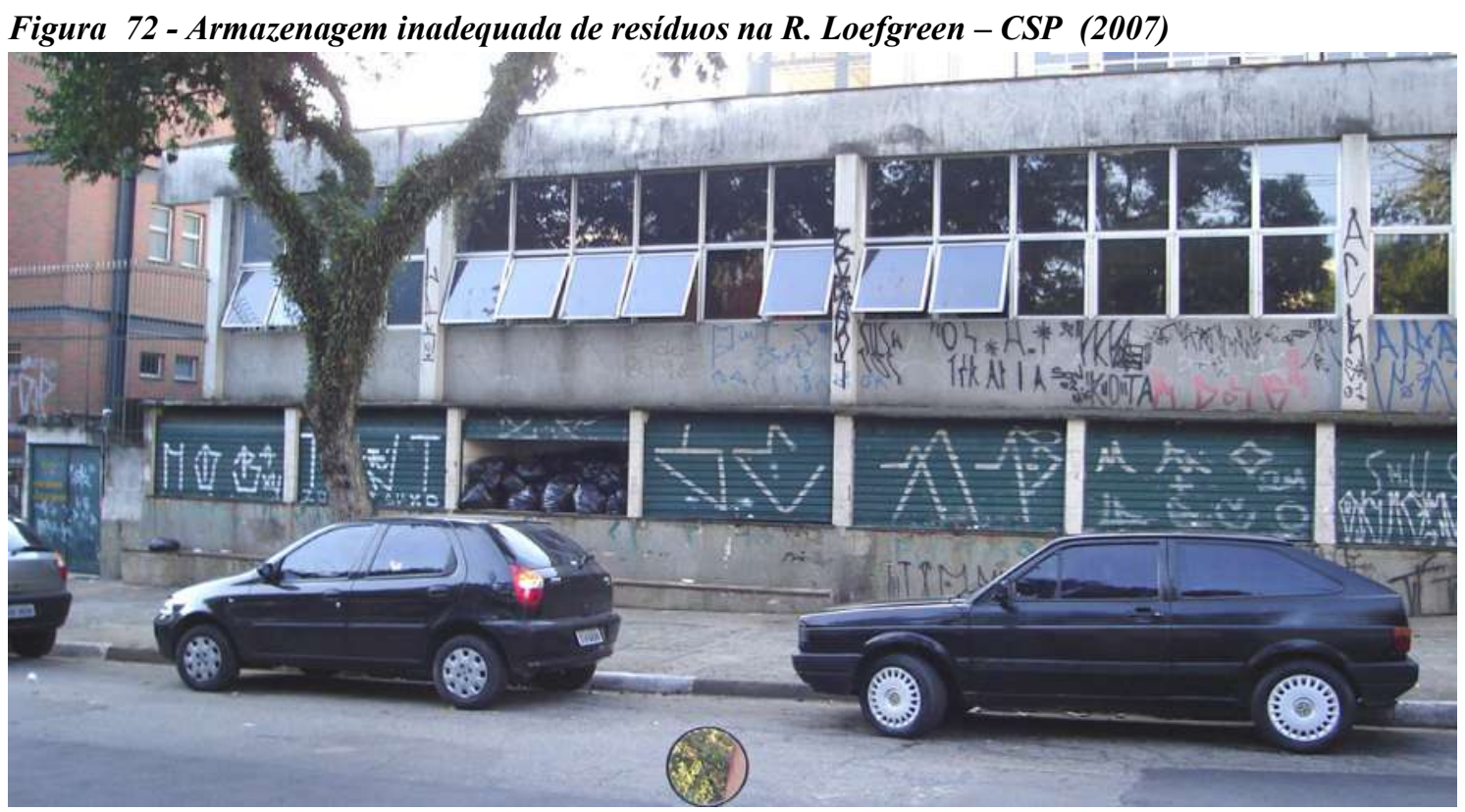

Fonte: $G T B U$

Considerando o exposto, o grupo propõe diretrizes de projeto que tem semelhanças com o primeiro plano, como o adensamento de atividades da Universidade. Incluindo duas novas diretrizes, a de melhorar as condições ambientais e de dirigir a 
expansão da Unifesp em concordância com o planejamento proposto do bairro (ver Figura 73) e da Subprefeitura, em cujo plano regional ${ }^{113}$ consta:

Subseção II - Da AIU-2 Área de Intervenção Urbana Pedro de Toledo: Art. 40 - Fica criada a Área de Intervenção Urbana Pedro de Toledo com a finalidade de readequação urbana do entorno do Complexo Hospitalar do Hospital São Paulo e da Escola de Medicina, compreendendo a estação projetada na rua Pedro de Toledo da futura linha 5 do Metrô.

I. O projeto urbanistico específico da AIU-2 Pedro de Toledo deverá considerar na sua elaboração as seguintes diretrizes:

a) reorganização do complexo hospitalar no que se refere aos espaços públicos, acessos estacionamentos, passagens de pedestres;

b) implantação de pequena praça ligada ao complexo hospitalar; c) implantação de mobiliário urbano de qualidade e alta durabilidade, incluindo bancos, pontos de ônibus, lixeiras, caixas de correio;

d) implantação de dispositivos de iluminação no nível dos pedestres especialmente nas vias próximas ao complexo hospitalar;

e) implantação de dispositivos de acessibilidade em todas as quadras da AIU, não apenas nos cruzamentos e incluídos os dispositivos para deficientes visuais;

f) arborização geral;

g) homogeneização de anúncios e cartazes de propaganda;

h) desenho de qualidade na estação de Metrô;

i) estacionamentos, subterrâneos ou não, em alguns locais estratégicos e adequados a serem construidos e geridos pela iniciativa privada;

j) estudo de volumetria e de gabaritos a ser respeitado pelas novas edificações;

k) estudo das possibilidades de utilização de espaço aéreo e subterrâneo para ligações entre prédios e outras finalidades;

l) desenho urbano do conjunto que propicie limpeza e condições de segurança;

m) implantação de coleta seletiva de lixo;

n) trabalho junto aos moradores, comerciantes e prestadores de serviços para que o projeto venha a ser de interesse de todos, assim como futuramente sua manutenção.

$113 \mathrm{http} / / /$ documentacao.camara.sp.gov.br/iah/fulltext/anexos/PL0139-2004-12_VMARIANA.pdf 
Figura 73 - Mapa de desenvolvimento urbano do entorno do CSP (2004)

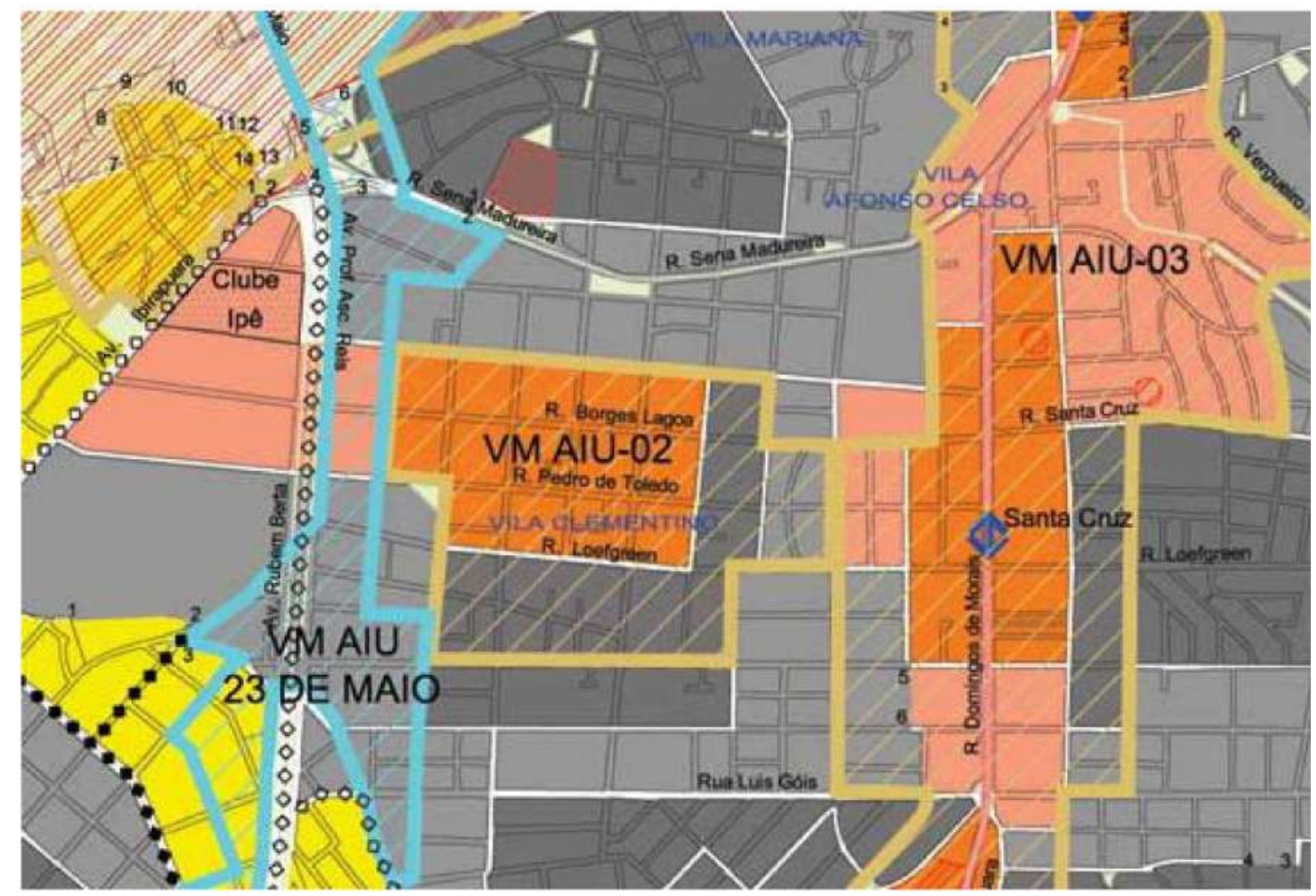

Fonte: $G T B U$

O projeto, então, adota como partido orientar a construção e ocupação de atividades relacionadas a percursos (ver Figura 74). Um percurso universitário (verde), com criação de áreas verdes e circulação dentro das quadras, as atividades desenvolvidas seriam as acadêmicas. Um percurso clínico (azul), com tratamento de calçadas e principais atividades envolvendo a assistência. E o corredor acadêmico e de serviços (laranja), com tratamento de calçadas, priorização de transporte coletivo nos eixos de corredor de ônibus e priorização de transporte individual nas paralelas.

O resultado proposto é de um conjunto adensado com a liberação do nível térreo para praças arborizadas e disposição das atividades segundo uma lógica de percursos caminháveis (ver Figura 75). 
Figura 74 - Proposta de percursos e implantação do Campus São Paulo em 2010
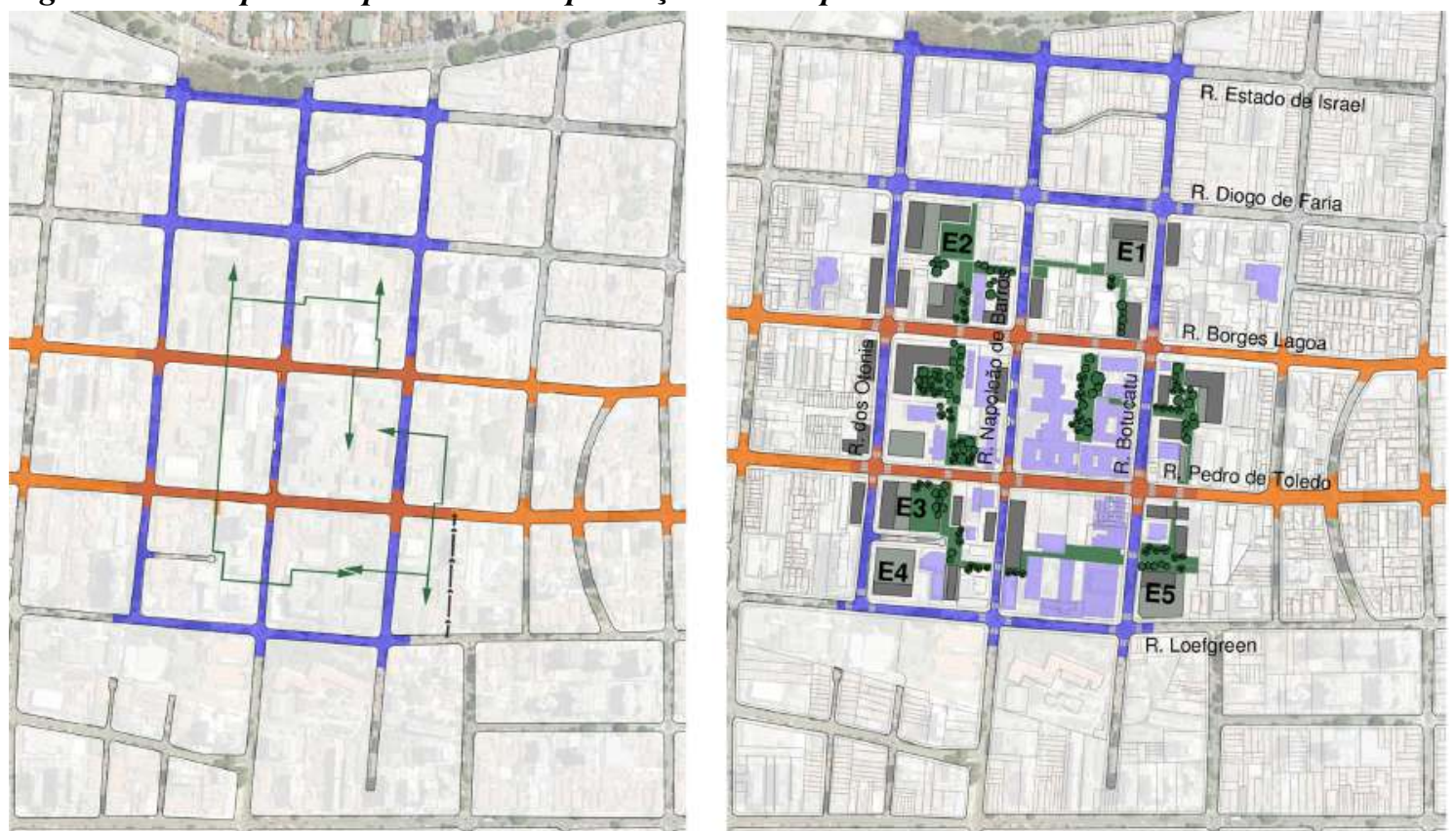

Adaptado de (GTBU, 2010)

Figura 75 - Volumetria existente (2010) e proposta do Campus São Paulo
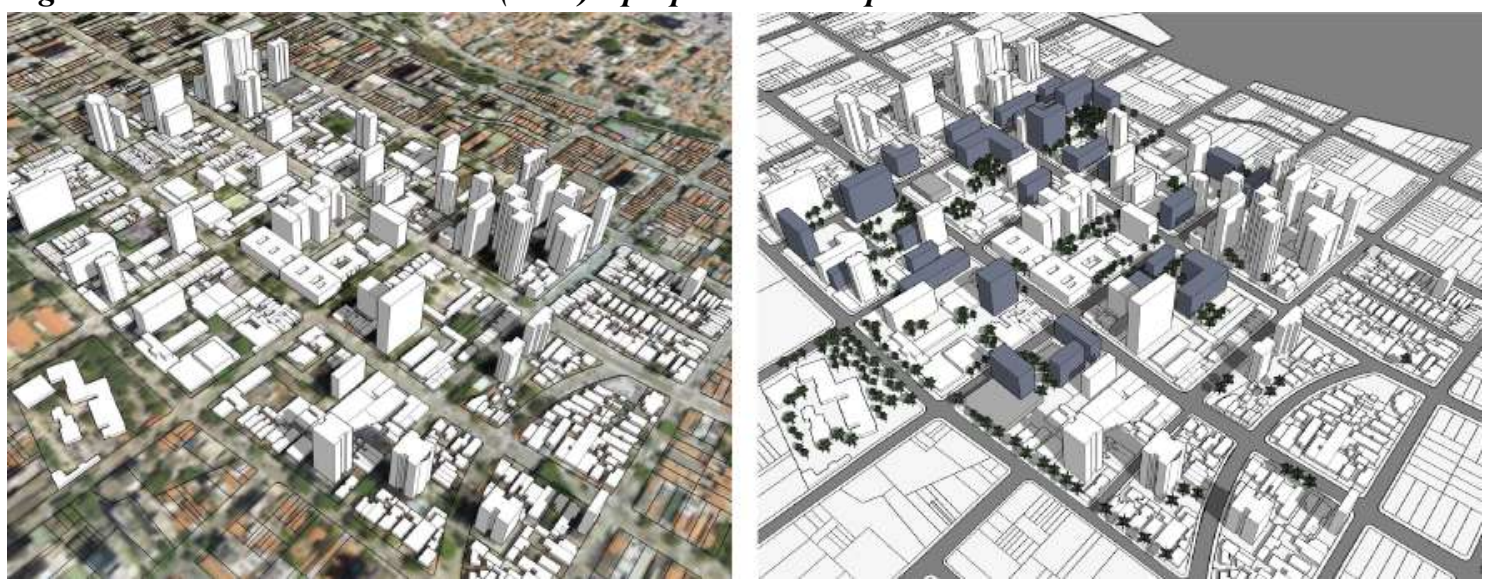

Adaptado de (GTBU, 2010)

Este primeiro retrospecto histórico tem como objetivo demonstrar a evolução da ocupação do campus, além de analisar, em cada contexto, quais eram os parâmetros e características dos diagnósticos realizados para embasar o planejamento. Há uma continuidade de diretrizes, embora os planos não tenham sido totalmente efetivados. Cabe uma pesquisa historiográfica mais detalhada sobre as razões pelas quais não foi possível concretizar os projetos.

O processo, e não os resultados dele, oferecem um panorama da evolução dos métodos de planejamento. Houve um incremento de informações e contextos utilizados para embasar as decisões de projeto e o escopo dele, ampliou-se o público para o qual se 
está projetando os espaços, inicialmente para demandas internas, depois acrescentando também os demais cidadãos que frequentam ou passam pelo local.

Figura 76 - Projeto urbanístico - bairro universitário - Campus São Paulo (2010)

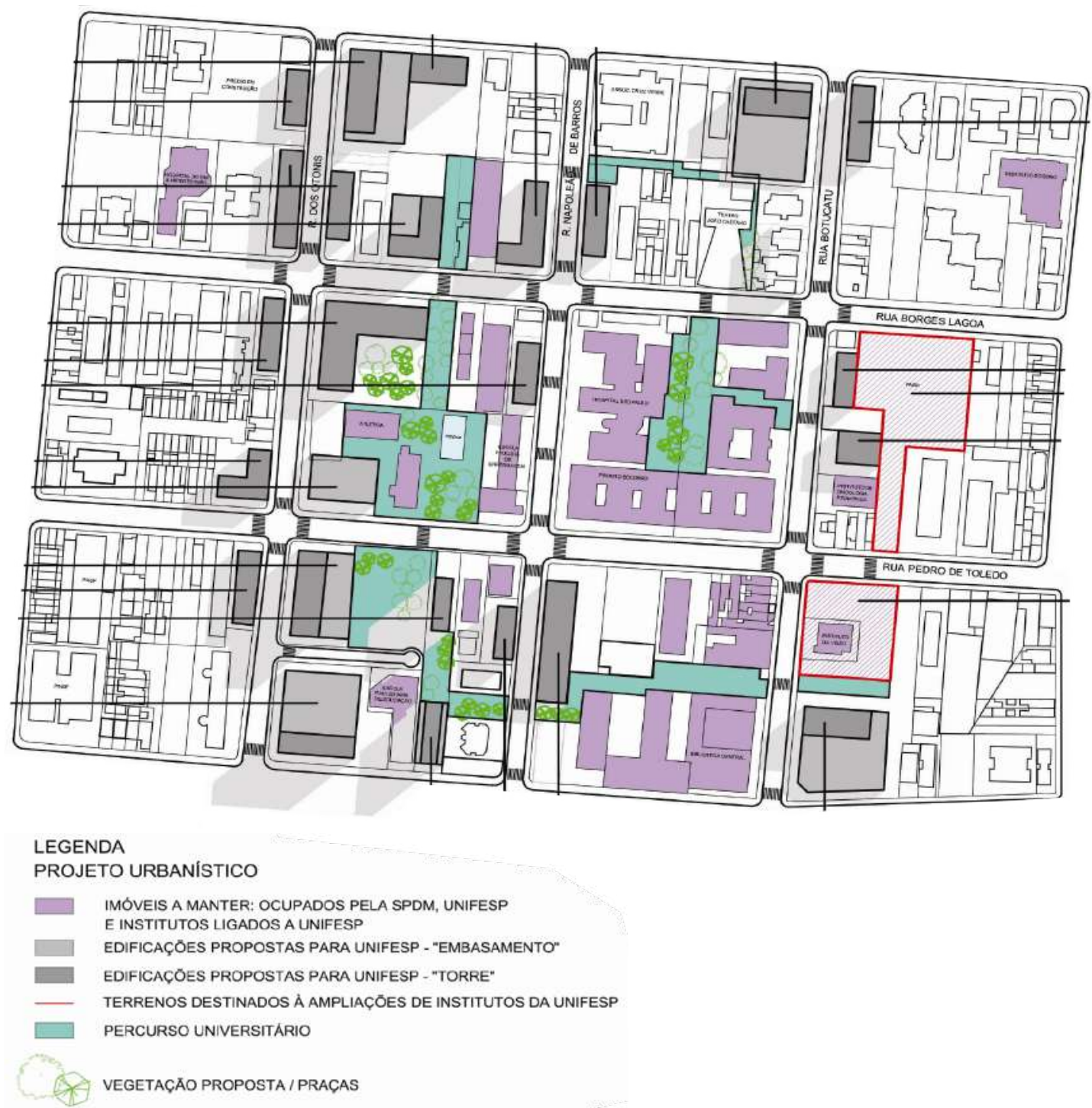

Fonte: Adaptado de (GTBU, 2010)

No plano "bairro universitário" (GTBU, 2010), houve um desenho urbano incorporando demandas institucionais com melhorias urbanas disponíveis para todos. Em detalhe, podemos verificar que os espaços livres no térreo após a verticalização das atividades tornam-se praças ou espaços abertos, havendo maior permeabilidade da quadra, para travessia ou como espaços de convívio e estar (ver Figura 76).

A proposta de "percurso universitário" desenhou um circuito conectados por praças e espaços abertos que ligam as atividades acadêmicas. Para dar continuidade a esses percursos, são posicionadas travessias de pedestre no meio da quadra, essa solução não é apenas formal, mas também traz segurança aos usuários, uma vez que a maior parte 
dos atropelamentos na região ocorrem em esquinas, conforme verificado em mapa de localização de acidentes em 2013.

O desenho urbano proposto em 2010 não foi concretizado, porém algumas premissas foram adotadas posteriormente, já que uma das diretrizes do PDI (UNIFESP, 2016) é que se tenha integração com o entorno. Esta diretriz se estende ao PDInfra, que terá o papel de traduzir essa orientação em projeto de desenho urbano.

\section{APÊNDICE D - EXTRATOS DE LICITAÇÕES PARA AQUISIÇÕES DE PRODUTOS QUÍMICOS PELA UNIFESP NO PERÍODO DE 2010 A 2018}

Neste apêndice estão os registros de aquisições de produtos químicos realizados pelo Departamento de Importação e Compras. Com as expressões buscadas: químico, químicos, acido, composto, orgânico, bombona, embalagem, frasco e reagente:

Extratos do portal da transparência da Universidade Federal de São Paulo: http://www.licitacoes.unifesp.br/imprressao.php?intOpcao=0\&intTipoE

Licitações encerradas de 2010 a 2018:

\section{Total 33 itens:}

Campus: SÃO PAULO - DEPARTAMENTO DE IMPORTAÇÃO E COMPRAS

Contato: FRANCISCO PEREIRA DOS SANTOS NETO - (11) 5576-4186

$\mathrm{N}^{\circ}$ Dispensa: 128/2013 - Modalidade: DISPENSAVEL

Objeto: AQUISIÇÃO DE CLORIDRATO DE CETAMINA 10 \% FRASCO COM 50ML,

CLORIDRATO DE XILASINA $2 \% 10$ ML E HALOTANO 250 ML. - DISPENSA COM BASE NO

INCISO XXI - ART. 24, LEI 8666/93 (PROJETO DE PESQUISA FINANCIADO PELA CAPES)

CNPJ/NOME: 44734671000151 / CRISTALIA PRODUTOS QUIMICOS FARMACEUTICOS LTDA

Valor: $\mathrm{R} \$ 4.038,25$

Campus: SÃO PAULO - DEPARTAMENTO DE IMPORTAÇ̃̃O E COMPRAS

Contato: CLAUDIA MARCOLINO DA SILVA - (11) 5576-4186

$\mathrm{N}^{\circ}$ Dispensa: 130/2013 - Modalidade: DISPENSAVEL

Objeto: AQUISÇÃO DE ISOFLURANO - ( C1)- ( GEN ) E ÁLCOOL ETÍLICO- INCISO XXI-AT.

24,LEI 8666/93

CNPJ/NOME: 44734671000151 / CRISTALIA PRODUTOS QUIMICOS FARMACEUTICOS LTDA

Valor: $\mathrm{R} \$ 4.230,00$

Campus: SÃO PAULO - DEPARTAMENTO DE IMPORTAÇÃO E COMPRAS

Contato: FRANCISCO PEREIRA DOS SANTOS NETO - (11) 5576-4186

Edital: 351/2016 - Modalidade: PREGÃO

Objeto: ÁCIDO CLORÍDRICO PARA ATENDER AS NECESSIDADES DO CAMPUS SÃO PAULO /

UNIFESP.

Período de retirada do edital: 17/11/2016 à 30/11/2016 08:59 hrs.

Endereço de retirada: www.comprasnet.gov.br $(\mathrm{UASG}=153031)$

Data início de acolhimento das propostas eletrônicas: 17/11/2016 
Data limite de acolhimento das propostas eletrônicas: 30/11/2016 08:59 hrs Data de abertura da seção pública: 30/11/2016 09:00 hrs.

Informações Complementares: Maiores Informações: fps.neto@unifesp.br

Campus: SÃO PAULO - DEPARTAMENTO DE IMPORTAÇÃO E COMPRAS

Contato: ALINE CHRISTIAN ANDRADE - (11) 5576-4186

$N^{o}$ Dispensa: 1/2015 - Modalidade: INEXIGIVEL

Objeto: Desinfetante de médio nível para superfícies, composto de: Monopersulfato de Potássio (princípio ativo registrado no Ministério da Saúde), ácido sulfâmico, ácido málico, hexametafosfato de sódio, sulfonato de sódio, sulfonato de sódio dodecil benzeno, cloreto de sódio,corante amaranto EEC No 123 e aromatizante. Apresentação em pó.

CNPJ/NOME: 31673254000102 / LABORATORIOS B. BRAUN S/A.

Valor: R\$6.930,00

Campus: SÃO PAULO - DEPARTAMENTO DE IMPORTAÇÃO E COMPRAS

Contato: LUCIANA DE CARVALHO CUNHA - (11) 5576-4186

No Dispensa: 74/2013 - Modalidade: DISPENSAVEL

Objeto: AQUISIÇÃO DE SISTEMA DE ELETROFORESE HORIZONTAL, GEL TRAY 7x8CM .

INCLUI EHP- 02, EHP - 04 E GE- 062 E EQUIPAMENTO PARA SEPARAÇÃO DE ACIDOS

NUCLÉICOS E PARA VISUALIZAÇÃO DE FRAGMENTAÇÃO DE DNA DE CÉDULAS

INDIVIDUAS- BEM DESTINADOS A PROJETO DE PESQUISA FINANCIADO PELA CAPES ART. 24, INCISO XXI- LEI 8666/93

CNPJ/NOME: 06307188000100 / WR RESEARCH PRODUTOS LABORATORIAIS LTDA

Valor: R\$ 2.310,00

Campus: SÃO PAULO - DEPARTAMENTO DE IMPORTAÇÃO E COMPRAS

Contato: SHEYLA DE SANTANA ARAUJO - (11) 5576-4186

Edital: 128/2010 - Modalidade: PREGÃO (Registro de preço )

Objeto: AQ. DE GLICERINA BRANCA BIDESTILADA PURA (BOMBONA 50L)

Período de retirada do edital: 20/05/2010 à 01/06/2010 10:30 hrs.

Endereço de retirada: www.comprasnet.gov.br $(\mathrm{UASG}=153031)$

Data início de acolhimento das propostas eletrônicas: 20/05/2010

Data limite de acolhimento das propostas eletrônicas: 01/06/2010 10:30 hrs.

Data de abertura da seção pública: 01/06/2010 10:31 hrs.

Informações Complementares:

Campus: SÃO PAULO - DEPARTAMENTO DE IMPORTAÇÃO E COMPRAS

Contato: LUCIANA DE CARVALHO CUNHA - (11) 5576-4186

$\mathrm{N}^{\circ}$ Dispensa: 111/2014 - Modalidade: DISPENSAVEL

Objeto: AQUISIÇÃO DE MATERIAIS E REAGENTES PARA LABORATÓRIO DESTINADOS A PESQUISA CAPES.

CNPJ/NOME: 53994497000177 / UNISCIENCE DO BRASIL LTDA Valor: R\$ 3.930,84

Data provável de realização:

Campus: SÃO PAULO - DEPARTAMENTO DE IMPORTAÇÃO E COMPRAS

Contato: LUCIANA DE CARVALHO CUNHA - (11) 5576-4186

$\mathrm{N}^{\circ}$ Dispensa: 138/2014 - Modalidade: DISPENSAVEL

Objeto: REAGENTE DE ALTA SENSIBILIDADE UTILIZADO PARA A QUANTIFICAÇÃO DE PROTEINAS HUMANAS

CNPJ/NOME: 19026341000164 / BIODOME LTDA-ME Valor: R\$ 7.000,00

Data provável de realização:

Campus: SÃO PAULO - DEPARTAMENTO DE IMPORTAÇÃO E COMPRAS

Contato: FRANCISCO PEREIRA DOS SANTOS NETO - (11) 5576-4186 
$\mathrm{N}^{\circ}$ Dispensa: 146/2014 - Modalidade: INEXIGIVEL

Objeto: REAGENTES PARA PURIFICAÇÃO DNA ILLUSTRA BLOOD - MARCA GE HEALTHCARE

CNPJ/NOME: 55487029000131 / GE HEALTHCARE LIFE SCIENCES DO BRASIL

LTDA Valor: R\$ 12.950,00

Data provável de realização:

Campus: SÃO PAULO - DEPARTAMENTO DE IMPORTAÇÃO E COMPRAS

Contato: VANIA SIMOES LOPES - (11) 5576-4186

Edital: 152/2014 - Modalidade: PREGÃO

Objeto: Aquisição de Reagentes de Laboratórios

Período de retirada do edital: 02/07/2014 à 06/08/2014 08:59 hrs.

Endereço de retirada: www.comprasnet.gov.br $(\mathbf{U A S G}=\mathbf{1 5 3 0 3 1})$

Data início de acolhimento das propostas eletrônicas: 02/07/2014

Data limite de acolhimento das propostas eletrônicas: 06/08/2014 08:59 hrs.

Data provável de realização:

Data de abertura da seção pública: 06/08/2014 09:00 hrs.

Informações Complementares: Em caso de dúvidas entrar em contato atrvés do email

claudia.esteves@unifesp.br

Campus: SÃO PAULO - DEPARTAMENTO DE IMPORTAÇÃO E COMPRAS

Contato: LUCIANA DE CARVALHO CUNHA - (11) 5576-4186

Edital: 154/2014 - Modalidade: PREGÃO

Objeto: $\mathrm{O}$ objeto da presente licitação é a escolha da proposta mais vantajosa para a aquisição de

REAGENTES PARA USO LABORATORIAL, conforme condições, quantidades e exigências

estabelecidas neste Edital e seus anexos.

Período de retirada do edital: 11/07/2014 à 25/07/2014 08:59 hrs.

Endereço de retirada: $w w w$. comprasnet.gov.br $(\mathbf{U A S G}=\mathbf{1 5 3 0 3 1})$

Data início de acolhimento das propostas eletrônicas: 11/07/2014

Data limite de acolhimento das propostas eletrônicas: 25/07/2014 08:59 hrs.

Data provável de realização:

Data de abertura da seção pública: 25/07/2014 09:00 hrs.

Informações Complementares: As solicitações de esclarecimentos de dúvidas deverão ser

encaminhadas excluisvamente para o e-mail: luciana.cunha@unifesp.br.

Campus: SÃO PAULO - DEPARTAMENTO DE IMPORTAÇÃO E COMPRAS

Contato: RODRIGO MARIANO DE SOUZA - (11) 5576-4186

Edital: 155/2018 - Modalidade: PREGÃO

Objeto: AQUISIÇÃO DE MATERIA DE CONSUMO: REAGENTES PARA ANÁLISE EM HPLC E OUTROS

Período de retirada do edital: 25/07/2018 à 06/08/2018 09:00 hrs.

Endereço de retirada: www.comprasnet.gov.br $($ UASG $=\mathbf{1 5 3 0 3 1})$

Data início de acolhimento das propostas eletrônicas: 25/07/2018

Data limite de acolhimento das propostas eletrônicas: 06/08/2018 09:00 hrs.

Data provável de realização: 08/2018

Data de abertura da seção pública: 06/08/2018 09:01 hrs.

Informações Complementares: 
Campus: SÃO PAULO - DEPARTAMENTO DE IMPORTAÇÃO E COMPRAS

Contato: GILSON ROBERTO PERUCIO - (11) 5576-4186

$\mathrm{N}^{\circ}$ Dispensa: 159/2014 - Modalidade: INEXIGIVEL

Objeto: REAGENTES DE PURIFICAÇÃO GFX PCR DNA GEL BAND ( 250 PURIF.) CÓD.

28903471N. C.M. 38220090 CÓD. 28-9034-71

CNPJ/NOME: 55487029000131 / GE HEALTHCARE LIFE SCIENCES DO BRASIL

LTDA Valor: R\$ 5.195,00

Data provável de realização:

Campus: SÃO PAULO - DEPARTAMENTO DE IMPORTAÇÃO E COMPRAS

Contato: CLAUDIA REGINA ESTEVES - (11) 5576-4186

$\mathrm{N}^{\circ}$ Dispensa: 179/2014 - Modalidade: DISPENSAVEL

Objeto: Materiais Reagentes para uso Laboratorial

CNPJ/NOME: 20330549000151 / SERGIO PICOLLI SALATA - ME Valor: R\$ 19.600,00

Data provável de realização:

Campus: SÃO PAULO - DEPARTAMENTO DE IMPORTAÇÃO E COMPRAS

Contato: VANIA SIMOES LOPES - (11) 5576-4186

Edital: 186/2014 - Modalidade: PREGÃO

Objeto: Aquisição de Reagentes para uso Laboratorial.

Período de retirada do edital: 08/07/2014 à 11/08/2014 08:59 hrs.

Endereço de retirada: www.comprasnet.gov.br $(\mathrm{UASG}=153031)$

Data início de acolhimento das propostas eletrônicas: 08/07/2014

Data limite de acolhimento das propostas eletrônicas: 11/08/2014 08:59 hrs.

Data provável de realização:

Data de abertura da seção pública: 11/08/2014 09:00 hrs.

Informações Complementares: Em caso de dúvida entrar em contato através do email

claudia.esteves@unifesp.b

Campus: SÃO PAULO - DEPARTAMENTO DE IMPORTAÇÃO E COMPRAS

Contato: VANIA SIMOES LOPES - (11) 5576-4186

Edital: 190/2014 - Modalidade: PREGÃO

Objeto: Reagentes para uso laboratorial.

Período de retirada do edital: 11/07/2014 à 23/07/2014 09:00 hrs.

Endereço de retirada: www.comprasnet.gov.br $(\mathbf{U A S G}=\mathbf{1 5 3 0 3 1})$

Data início de acolhimento das propostas eletrônicas: 11/07/2014

Data limite de acolhimento das propostas eletrônicas: 23/07/2014 09:00 hrs.

Data provável de realização:

Data de abertura da seção pública: 23/07/2014 09:01 hrs.

Informações Complementares: Em caso de dúvidas entrar em contato com Sidney Leal da Rocha atraves do email sidney.rocha@unifesp.br

Campus: SÃO PAULO - DEPARTAMENTO DE IMPORTAÇÃO E COMPRAS

Contato: VANIA SIMOES LOPES - (11) 5576-4186

No Dispensa: 201/2014 - Modalidade: DISPENSAVEL

Objeto: Aquisição de reagente da marca sigma

CNPJ/NOME: 68337658000127 / SIGMA ALDRICH BRASIL LTDA. Valor: R\$ 5.215,50

Data provável de realização: 
Campus: SÃO PAULO - DEPARTAMENTO DE IMPORTAÇÃO E COMPRAS

Contato: FRANCISCO PEREIRA DOS SANTOS NETO - (11) 5576-4186

Edital: 268/2014 - Modalidade: PREGÃO

Objeto: Aquisição de Reagentes para Laboratório - marca MERCK, conforme condições, quantidades e exigências estabelecidas no Edital.

Período de retirada do edital: 16/07/2014 à 28/07/2014 10:59 hrs.

Endereço de retirada: www.comprasnet.gov.br $(\mathbf{U A S G}=\mathbf{1 5 3 0 3 1})$

Data início de acolhimento das propostas eletrônicas: 16/07/2014

Data limite de acolhimento das propostas eletrônicas: 28/07/2014 10:59 hrs.

Data provável de realização:

Data de abertura da seção pública: 28/07/2014 11:00 hrs.

Informações Complementares: Maiores informações: fps.neto@unifesp.br

Campus: SÃO PAULO - DEPARTAMENTO DE IMPORTAÇÃO E COMPRAS

Contato: RODRIGO MARIANO DE SOUZA - (11) 5576-4186

Edital: 290/2017 - Modalidade: PREGÃO

Objeto: Aquisição de reagentes para laboratório da marca Roche

Período de retirada do edital: 05/10/2017 à 18/10/2017 09:00 hrs.

Endereço de retirada: www.comprasnet.gov.br $($ UASG $=\mathbf{1 5 3 0 3 1})$

Data início de acolhimento das propostas eletrônicas: 05/10/2017

Data limite de acolhimento das propostas eletrônicas: 18/10/2017 09:00 hrs.

Data provável de realização: 10/2017

Data de abertura da seção pública: 18/10/2017 09:01 hrs.

Informações Complementares:

Campus: SÃO PAULO - DEPARTAMENTO DE IMPORTAÇÃO E COMPRAS

Contato: FRANCISCO PEREIRA DOS SANTOS NETO - (11) 5576-4186

Edital: 292/2011 - Modalidade: PREGÃO

Objeto: AQUISIÇÃO DE REAGENTES E MATERIAIS PARA LABORATÓRIO

Período de retirada do edital: 19/10/2011 à 03/11/2011 09:00 hrs.

Endereço de retirada: www.comprasnet.gov.br $($ UASG $=153031)$

Data início de acolhimento das propostas eletrônicas: 19/10/2011

Data limite de acolhimento das propostas eletrônicas: 03/11/2011 09:00 hrs.

Data provável de realização:

Data de abertura da seção pública: 03/11/2011 09:01 hrs.

Informações Complementares: Maiores informações através do e-mail: fps.neto@unifesp.br

Campus: SÃO PAULO - DEPARTAMENTO DE IMPORTAÇÃO E COMPRAS

Contato: LUCIANA DE CARVALHO CUNHA - (11) 5576-4186

Edital: 304/2014 - Modalidade: PREGÃO

Objeto: O objeto da presente licitação é a escolha da proposta mais vantajosa para a aquisição de REAGENTES PARA USO LABORATORIAL, conforme condições, quantidades e exigências estabelecidas neste Edital e seus anexos.

Período de retirada do edital: 06/08/2014 à 19/08/2014 08:59 hrs.

Endereço de retirada: www.comprasnet.gov.br $($ UASG $=\mathbf{1 5 3 0 3 1})$

Data início de acolhimento das propostas eletrônicas: 06/08/2014 
Data limite de acolhimento das propostas eletrônicas: 19/08/2014 08:59 hrs.

Data provável de realização:

Data de abertura da seção pública: 19/08/2014 09:00 hrs.

Informações Complementares: Os esclarecimentos deverão ser solicitados excluisvamente pelo e-mail: luciana.cunha@unifesp.br,

Campus: SÃO PAULO - DEPARTAMENTO DE IMPORTAÇÃO E COMPRAS

Contato: FRANCISCO PEREIRA DOS SANTOS NETO - (11) 5576-4186

Edital: 322/2011 - Modalidade: PREGÃO

Objeto: AQUISIÇÃO DE REAGENTES E PRODUTOS PARA LABORATÓRIO

Período de retirada do edital: 25/10/2011 à 09/11/2011 09:00 hrs.

Endereço de retirada: www.comprasnet.gov.br $(\mathbf{U A S G}=\mathbf{1 5 3 0 3 1})$

Data início de acolhimento das propostas eletrônicas: 25/10/2011

Data limite de acolhimento das propostas eletrônicas: 09/11/2011 09:00 hrs.

Data provável de realização:

Data de abertura da seção pública: 09/11/2011 09:01 hrs.

Informações Complementares: Maiores informações através do e-mail: fps.neto@unifesp.br

Campus: SÃO PAULO - DEPARTAMENTO DE IMPORTAÇÃO E COMPRAS

Contato: VANIA SIMOES LOPES - (11) 5576-4186

Edital: 332/2010 - Modalidade: PREGÃO

Objeto: AQUISIÇÃO DE MEDICAMENTOS, REAGENTES PARA LABORATÓRIO E OUTROS

Período de retirada do edital: 05/10/2010 à 18/10/2010 09:00 hrs.

Endereço de retirada: www.comprasnet.gov.br $(\mathbf{U A S G}=\mathbf{1 5 3 0 3 1})$

Data início de acolhimento das propostas eletrônicas: 05/10/2010

Data limite de acolhimento das propostas eletrônicas: 18/10/2010 09:00 hrs.

Data provável de realização:

Data de abertura da seção pública: 18/10/2010 09:01 hrs.

Informações Complementares: Fone: (11) 5576-4883 E-mail: vaniacompra.dm@epm.br

Campus: SÃO PAULO - DEPARTAMENTO DE IMPORTAÇÃO E COMPRAS

Contato: ALINE CHRISTIAN ANDRADE - (11) 5576-4186

Edital: 339/2012 - Modalidade: PREGÃO

Objeto: Aquisição de reagentes para laboratório.

Período de retirada do edital: 25/09/2012 à 05/10/2012 09:00 hrs.

Endereço de retirada: www.comprasnet.gov.br $(\mathbf{U A S G}=\mathbf{1 5 3 0 3 1})$

Data início de acolhimento das propostas eletrônicas: 25/09/2012

Data limite de acolhimento das propostas eletrônicas: 05/10/2012 09:00 hrs.

Data provável de realização:

Data de abertura da seção pública: 05/10/2012 09:01 hrs.

Informações Complementares: Maiores informações: aline.christian@unifesp.br

Campus: SÃO PAULO - DEPARTAMENTO DE IMPORTAÇÃO E COMPRAS

Contato: SINARA APARECIDA FARAGO DE MELO - (11) 5576-4186

Edital: 340/2011 - Modalidade: PREGÃO

Objeto: Aquisição de Reagentes e Material para Laboratório. 
Período de retirada do edital: 07/11/2011 à 21/11/2011 10:00 hrs.

Endereço de retirada: $w w w$. comprasnet.gov.br $(\mathbf{U A S G}=\mathbf{1 5 3 0 3 1})$

Data início de acolhimento das propostas eletrônicas: 07/11/2011

Data limite de acolhimento das propostas eletrônicas: 21/11/2011 10:00 hrs.

Data provável de realização:

Data de abertura da seção pública: 21/11/2011 10:01 hrs.

Informações Complementares: Maiores Informações pelo portal: www.comprasnet.gov.br

Campus: SÃO PAULO - DEPARTAMENTO DE IMPORTAÇÃO E COMPRAS

Contato: VANIA SIMOES LOPES - (11) 5576-4186

Edital: 344/2010 - Modalidade: PREGÃO

Objeto: AQUISIÇÃO DE MEDICAMENTOS, REAGENTES E PRODUTOS PARA LABORATÓRIO

Período de retirada do edital: 28/10/2010 à 11/11/2010 09:00 hrs.

Endereço de retirada: www.comprasnet.gov.br $($ UASG $=153031)$

Data início de acolhimento das propostas eletrônicas: 28/10/2010

Data limite de acolhimento das propostas eletrônicas: 11/11/2010 09:00 hrs.

Data provável de realização:

Data de abertura da seção pública: 11/11/2010 09:01 hrs.

Informações Complementares:

Campus: SÃO PAULO - DEPARTAMENTO DE IMPORTAÇÃO E COMPRAS

Contato: VANIA SIMOES LOPES - (11) 5576-4186

Edital: 371/2010 - Modalidade: PREGÃO

Objeto: AQUISIÇÃO DE REAGENTES, MEDICAMENTOS E MATERIAIS PARA

LABORATÓRIO

Período de retirada do edital: 04/11/2010 à 17/11/2010 09:00 hrs.

Endereço de retirada: www.comprasnet.gov.br $($ UASG $=\mathbf{1 5 3 0 3 1})$

Data início de acolhimento das propostas eletrônicas: 04/11/2010

Data limite de acolhimento das propostas eletrônicas: 17/11/2010 09:00 hrs.

Data provável de realização:

Data de abertura da seção pública: 17/11/2010 09:01 hrs.

Informações Complementares: Fone: (11) 5576-4883 E-mail: vaniacompra.dm@epm.br

Campus: SÃO PAULO - DEPARTAMENTO DE IMPORTAÇÃO E COMPRAS

Contato: FRANCISCO PEREIRA DOS SANTOS NETO - (11) 5576-4186

Edital: 384/2010 - Modalidade: PREGÃO

Objeto: Aquisição de Reagentes e Materiais para Laboratórios.

Período de retirada do edital: 23/11/2010 à 03/12/2010 10:00 hrs.

Endereço de retirada: $w w w$. comprasnet.gov.br $($ UASG $=153031)$

Data início de acolhimento das propostas eletrônicas: 23/11/2010

Data limite de acolhimento das propostas eletrônicas: 03/12/2010 10:00 hrs.

Data provável de realização:

Data de abertura da seção pública: 03/12/2010 10:01 hrs.

Informações Complementares: Telefone para contato: (11) 5576-4881 / E-mail: fps.neto@unifesp.br

Campus: SÃO PAULO - DEPARTAMENTO DE IMPORTAÇÃO E COMPRAS 
Contato: FRANCISCO PEREIRA DOS SANTOS NETO - (11) 5576-4186

Edital: 402/2010 - Modalidade: PREGÃO

Objeto: Aquisição de Reagentes de Materiais para Laboratórios.

Período de retirada do edital: 24/11/2010 à 06/12/2010 10:00 hrs.

Endereço de retirada: www.comprasnet.gov.br $($ UASG $=153031)$

Data início de acolhimento das propostas eletrônicas: 24/11/2010

Data limite de acolhimento das propostas eletrônicas: 06/12/2010 10:00 hrs.

Data provável de realização:

Data de abertura da seção pública: 06/12/2010 10:01 hrs.

Informações Complementares: Telefone para contato: (11) 5576-4881 / E-mail: fps.neto@unifesp.br

Campus: SÃO PAULO - DEPARTAMENTO DE IMPORTAÇÃO E COMPRAS

Contato: VANIA SIMOES LOPES - (11) 5576-4186

Edital: 408/2010 - Modalidade: PREGÃO

Objeto: AQUISIÇÃO DE MEDICAMENTOS E REAGENTES PARA LABORATÓRIO

Período de retirada do edital: 03/11/2010 à 16/11/2010 09:00 hrs.

Endereço de retirada: www.comprasnet.gov.br $($ UASG $=\mathbf{1 5 3 0 3 1})$

Data início de acolhimento das propostas eletrônicas: 03/11/2010

Data limite de acolhimento das propostas eletrônicas: 16/11/2010 09:00 hrs.

Data provável de realização:

Data de abertura da seção pública: 16/11/2010 09:01 hrs.

Informações Complementares: E-mail: vaniacompra.dm@epm.br Fone: (11) 5576-4883

Campus: SÃO PAULO - DEPARTAMENTO DE IMPORTAÇÃO E COMPRAS

Contato: ALINE CHRISTIAN ANDRADE - (11) 5576-4186

Edital: 409/2010 - Modalidade: PREGÃO

Objeto: Aquisição de reagentes e materiais de laboratório.

Período de retirada do edital: 25/11/2010 à 07/12/2010 10:00 hrs.

Endereço de retirada: www.comprasnet.gov.br $($ UASG $=153031)$

Data início de acolhimento das propostas eletrônicas: 25/11/2010

Data limite de acolhimento das propostas eletrônicas: 07/12/2010 10:00 hrs.

Data provável de realização:

Data de abertura da seção pública: 07/12/2010 10:01 hrs.

Informações Complementares: Telefone para contato: (11) 5576-4884 e-mail:

aline.christian@unifesp.br

Campus: SÃO PAULO - DEPARTAMENTO DE IMPORTAÇÃO E COMPRAS

Contato: FRANCISCO PEREIRA DOS SANTOS NETO - (11) 5576-4186

Edital: 411/2012 - Modalidade: PREGÃO

Objeto: AQ. DE REAGENTE

Período de retirada do edital: 10/10/2012 à 23/10/2012 08:59 hrs.

Endereço de retirada: www.comprasnet.gov.br $($ UASG $=153031)$

Data início de acolhimento das propostas eletrônicas: 10/10/2012

Data limite de acolhimento das propostas eletrônicas: 23/10/2012 08:59 hrs.

Data provável de realização:

Data de abertura da seção pública: 23/10/2012 09:00 hrs. 
Informações Complementares: MAIORES INFORMAÇÕES: FPS.NETO@UNIFESP.BR

Campus: SÃO PAULO - DEPARTAMENTO DE IMPORTAÇÃO E COMPRAS

Contato: FRANCISCO PEREIRA DOS SANTOS NETO - (11) 5576-4186

Edital: 421/2011 - Modalidade: PREGÃO

Objeto: AQUISIÇÃO DE REAGENTES E MATERIAIS PARA LABORATÓRIO

Período de retirada do edital: 10/11/2011 à 24/11/2011 09:00 hrs.

Endereço de retirada: www.comprasnet.gov.br $($ UASG $=\mathbf{1 5 3 0 3 1})$

Data início de acolhimento das propostas eletrônicas: 10/11/2011

Data limite de acolhimento das propostas eletrônicas: 24/11/2011 09:00 hrs.

Data provável de realização:

Data de abertura da seção pública: 24/11/2011 09:01 hrs.

Informações Complementares: Maiores Informações: (11) 5576-4881 ou através do email: fps.neto@unifesp.br.

Campus: SÃO PAULO - DEPARTAMENTO DE IMPORTAÇÃO E COMPRAS

Contato: FRANCISCO PEREIRA DOS SANTOS NETO - (11) 5576-4186

Edital: 489/2012 - Modalidade: PREGÃO

Objeto: AQ. DE REAGENTES PARA LABORATÓRIO

Período de retirada do edital: 11/10/2012 à 24/10/2012 08:59 hrs.

Endereço de retirada: $w w w$. comprasnet.gov.br $($ UASG $=153031)$

Data início de acolhimento das propostas eletrônicas: 11/10/2012

Data limite de acolhimento das propostas eletrônicas: 24/10/2012 08:59 hrs.

Data provável de realização:

Data de abertura da seção pública: 24/10/2012 09:00 hrs.

Informações Complementares: MAIORES INFORMAÇÕES: FPS.NETO@UNIFESP.BR 